\title{
Hydraulic Research in the United States 1955
}

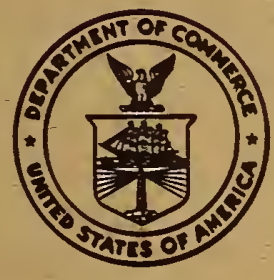

United States Department of Commerce

National Bureau of Standards Miscellaneous Publication 215 


\section{Capacities of Plumbing Stacks in Buildings}

A study of the maximum load that can be brought from a horizontal branch into a stack down which water is being discharged from fixtures on higher floors. This phase of a projected complete investigation, intended to make drainage design more economical, is concentrated on the drainage stack and the building drain. The report describes tests to determine terminal velocities and terminal lengths in stacks as well as tests on stacks and drains. It analyzes stack conditions in a multistory building and suggests applications of the study's results.

Order NBS Building Materials and Structures Report 132, Capacities of Plumbing Stacks in Buildings, 28 pages. Price: 25 cents.

\section{Self-Siphonage of Fixture Traps}

An explanation of the extent to which trap-seal losses are influenced by such considerations as the diameter of the trap and the depth of trap seal, the diameter and slope of the fixture drain, the type of vent fitting used, and the rate of discharge of the fixture. The report shows the importance of standardizing fixture traps and the hydraulic characteristics of plumbing fixtures, such as lavatories, sinks, and trays; and it makes recommendations for use by code-writing authorities.

Order NBS Building Materials and Structures Report 126, Self-Siphonage of Fixture Traps, 32 páges. Price: 20 cents.

\section{Wet Venting of Plumbing Fixtures}

An account of extensive research and laboratory tests to determine the feasibility of using vented one- and two-story plumbing drainage systems. The conclusions reached regarding satisfactory operation limits for wet-vented fixtures are given in a form suitable for inclusion in plumbing codes. The report describes test procedures and explains results. Diagrams, tables, and graphs are included showing the trap-seal losses that occur under various conditions of wet venting and indicating the maximum permissible unvented lengths of fixture drain.

Order NBS Building Materials and Structures Report 119, Wet Venting of Plumbing Fixtures, 27 pages. Price: 25 cents.

\section{Stack Venting of Plumbing Fixtures}

A report describing tests involving use of pipes, traps, connections, and vents made of transparent plastics which make all flow phenomena visible. Similar tests were made with regular metal fittings to obtain comparative data and to permit correlation of results. The report discusses and interprets results, 


\section{Hydraulic Research in the United States}

1955

Edited by Helen K. Middleton

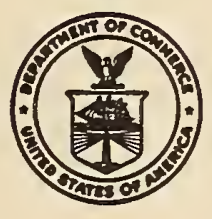

National Bureau of Standards Miscellaneous Publication 215 Issued July 1, 1955 
FOREWORD

The information contained in this publication was compiled from reports by the various hydraulic and hydrologic laboratories in the United States and Canada. The cooperation of these agencies is greatly appreciated.

Projects are numbered chronologically, and the number once assigned is repeated for identification purposes until a project is completed. Numbers commencing with 2049 refer to projects which are reported for the first time. All projects are in active state, unless otherwise noted under $(f)$.

It is emphasized that the National Bureau of standards does not have in its files reports or detailed information regarding the research projects reported by other organizations. Such information may be obtained from the correspondent listed under (c) or immediately following the title of the organization reporting the work. It is of course understood that any laboratory submitting reports on its work will be willing to supply information to properly qualified inquirers.

A similar bulletin, "Hydraulic Research", compiled and published by the International Association for Hydraulic Research, contains information on hydraulic research being conducted in foreign countries. This bulletin is edited by Prof. J. Th. Thijsse, Director of the Hydraulic Laboratory at the Technical University of Delft, Netherlends, and Secretary of the International Association for Hydraulic Research. Copies may be obtained from the Secretary at $\$ 6.00$ each (postage included).

A bulletin entitled "Directory of Hydromechanics Research Projects in the United states Related to Naval Architecture and Marine Engineering" is prepared by the Hydrodynamics Committee of the Society of $\mathrm{Nav}$ al Architects and Marine Engineers. Copies may be obtained by addressing the Secretary of the Society, Captain W. N. Landers, society of Naval Architects and Marine Engineers, 74 Trinity Place, New York 6, N. Y. 

(a) Number and title of project
(b) Project conducted for
(c) Correspondent
(d) Nature of project.

(e) Description
(f) Present status
(g) Results
(h) Publications 
BALDWIN-IIMA-HAMILTON CORPORATION, THE

Hydraulic Turbine Laboratory, Philadelphia $42, \mathrm{~Pa}$.

Mr. W. R. MacNamee, Manager, Hydraulic Turbine Department

Mr. C. H. Diehl, Supervisor of Laboratory

BEACH EROSION BOARD (see U. S. GOverment)

BONNEVIIIE HYDRAULIC LABORATORY (see U. S. GOvernment)

BROOKLYN, POLYTECHNIC INSTITUTE OF

99. Livingston Street, Brooklyn 2, N. Y.

Prof. Chilton A. Wright, Professor of Hydraulic and Sanitary Engineering

CALIFORNIA INSTITUTE OF TECHNOLOGY

Hydrodynamics Laboratory, Pasadena 4 , Calif.

CALIFORNIA, UNIVERSITY OF

College of Agriculture, Davis, Calif.

Prof. F. J. Veihmeyer, Directing Head, Department of Irrigation

CALIFORNIA, UNIVERSITY OF

College of Agriculture, Los Angeles 24, Calif.

Prof. M. R. Huberty, Chairman, Department of Irrigation and Soils

CALIFORNIA, UNIVERSTTY OF

College of Engineering, Berkeley 4, Calif.

Prof. J. W. Johnson, Fluid Mechanics Labor atory

CALIFORNIA, UNIVERSTTY OF SOUTHERN

Research Foundation for Cross-Connection Control, Los Angeles 7, Calif.

Dr. Robert E. Vivian, Director

CARNEGIE INSTITUTE OF TECHNOLOGY

Department of Civil Engineering, Pittsburgh 13, $\mathrm{Pa}$.

Prof. F. T. Mavis, Head

COLORADO A AND M COLLEGE

Department of Civil Engineering, Fort Collins, Colo.

Dr. Maurice I. Albertson, Head of Fluid Mechanics Research

COLORADO UNLIVERSITY

Department of Civil Engineering, Boulder, Colo.

Prof. Warren Raeder, Head

COLUMBIA UNIVERSTTY

Department of Civil Engineering, New York 27, N. Y.

Dr. Richard Skalak, Fluid Mechanics Labor atory

CONNECTICUT, UNIVERSTTY OF:

Hydraulic Rese arch Laboratory, Box U-37, Storrs, Conn.

Prof. Victor Scottron, Associate Professor of Civil Engineering

CONNECTICUT, UNIVERSTTY OF

Soils Mechanics Labor atory, Box U-37, Storrs, Conn.

Prof. Edward V. Gant, Associate Professor of Civil Engineering 
CORNELL UNI VERSITY

School of Civil Engineering, Ithaca, N. Y.

Dr. N. A. Christensen, Director

Prof. Andre L. Jorissen, Head, Dept. of Hydraulics and Hydraulic Engineering

DAVID TAYLOR MODEL BASTN (see U. S. Government)

GORGIA INSTITUTE OF TECHNOLOGY

School of Civil Engineering, Atlanta, Ga.

Prof. C. E. Kindsv ater

HARVARD UNIVERSTTI

Department of Mathematics, Div. of Applied Science, Cambridge 38, Mass.

IDAHO, UNTVERSITY OF

Engineering Experiment Station, Moscow, Idaho

Dean Allen S. Janssen, Director

ILLINOIS INSTITUTE OF TECHNOLOGY

Armour Research Foundation, Chicago 16, Illinois

Dr. Haldon A. Leedy, Vice President and Director

IILINOIS STATE WATER SURVEY DIVISION

Engineering Subdivision, Box 232, Urbana, IIl.

Mr. H. E. Hudson, Jr., Head

Engineering Research Subdivision, Box 117, Peoria, IIl。

Dr. Max suter, Heed

ILUINOIS STAIE VIATERTAYS DIVISION

Department of Public Works and Bulldings, 201 West Monroe St., Springfield, IIl.

Mr. Thomas B. Casey, Engineer

ILLINOIS, UNIVERSITY OF

Department of Theoretical and Applied Mechanics, 214 Talbot Laboratory, Urbana, Ill.

Prof. F. B. Seely, Head

ILIINOIS, UNIVERSITY OF

Hydraulic Engineering Lebor atory, Urbana, Ill.

Prof. J. J. Doland, Director of Hydraulic Engineering

IONA INSTTIUTE OF HYDRAULIC RESEARCH

State University of Iowa, Iowa City, Iowa

40

Dr. Hunter Rouse, Director

IOIA, STATE UNIVERSITY OF (see IOwa Institute of Hydraulic Reseerch)

JOHNS HOPKINS UNI VERSITY, THE

Applied Physics I. boratory, Silver Spring, Md.

Mr. R. E. Gibson, Director

JOHNS HOPKINS UNIVERSITY, THE

School of Engineering, Baltimore 18, Md.

Dr. John C. Geyer

LEHIGH UNIVERSITY

Fritz Engineering Laboratory, Bethlehem, Pa. Dr. W. J. Eney, Director 
LOUISI ANA STATE UNIVERSITY AND A AND M COLLEGE

School of Hydraulic Engineering, Baton Rouge 3, La.

Prof. T. M. Lowe, Director

MARYLAND UNIVERSTTY

Glenn L. Martin College of Engineering and Aeronautical Sciences,

College Park, Md.

Prof. John B. Cournyn, In charge Hydraulic Labor atory

MASSACHUSETTS INSTITUTE OF TECHNOLOGY

Department of Civil and Sanitary Engineering, Cambridge 39, Mass.

Dr. Arthur T. Ippen, Head, Hydrodynamics Labor atory

MASSACHUSETTS INSTITUTE OF TEECHNOLOGY

Department of Mechanical Engineering, Cambridge 39, Mass.

Prof. C. R. Soderberg, Head

MASSACHUSETTS INSTITUTE OF TECHNOLOGY

Department of Naval Architecture and Marine Engineering, Cambridge 39, Mass.

Prof. S. C. Powell, Director, Propeller Tunnel

MASSACHUSETTS, UNTVERSITY OF

Engineering Research Institute, Amherst, Mass.

Dean George A. Marston, Director

MIICHIGAN STATE COLLEGE

Department of Civil Engineering, East Lansing, Mich.

Prof. Harold R. Henry

MICHIGAN, UNIVERSTTY OF

Department of Civil Engineering, 320 West Engineering Bullding, Ann Arbor, Mich.

Prof. E. F. Brater

MIICHIGAN, UNIVERSITY OF

Experimental Naval Tank, 326 West Engineering Building, Ann Arbor, Mich.

Prof. Louis A. Baier, Director

MINNESOTA, UNIVERSITY OF (see St. Anthony Falls Hydraulic Laboratory)

MISSISSIPPI STATE COLIEGE

Engineering and Industrial Research Station, Box 1516, State College, Miss.

Dr. Harold Flinsch, Director

MISSOURI SCHOOL OF MINES AND METALLURGY

Department of Civil Engineering, Rolla, Mo.

Prof. Joe B. Butler, Chairman

MISSOURI, UNIVERSITY OF

Department of Civil Engineering, Columbia, Mo.

Prof. H. W. Wood

NEWPORT NEWS SHIPBUILDING AND DRY DOCK COMPANY

Hydraulic Labor atory, Newport News, Va.

Mr. C. H. Hencock, Director

NEW YORK UNIVERSTTY

Department of Chemical Engineering, Bronx 53, New York

Prof. John Happel, Chairman 
NEW YORK UNIVERSITY

Department of Engineering Mechanics, New York 53, N. Y.

Dr. Glen N. Cox, Chairman

NORTH CAROLINA STATE COLIEGE OF AGRICULTURE AND ENGINEERING

University of North Carolina, Dept. of Engineering Research, Raleigh, N.C.

Prof. N. W. Connor, Director

NORTHWE STERN UNIVERSITI

The Technological Institute, Evanston, IIl.

Dr. Donald H. Loughridge, Dean

NOTRE DAME, UNIVERSITY OF College of Engineering

Dr. Karl E. Schoenherr, Dean

PELTON WATER WHEEL COMPANY, THE 2929 - 19th Street, San Francisco 10, Calif.

Mr. I. M. White, Manager of Engincering

Mr. R. M. Bacchi, Development Engi neer

PENNSYLVANIA STATE ONIVERSITY

Hydraulics Labor atory, State College, $\mathrm{Pa}$.

Prof. Sam Shulits, Head

PENNSYLVANIA STATE UNIVERSTTY

Ordnance Research Laboratory, College of Engineering, P. O. Box 30,

State College, $\mathrm{Pa}$.

Dr. G. G. Quarles, Director

PEMNSYLVANIA WATER AND POWER COMPANY

405 Fulton National Bank Building, Lancaster, $\mathrm{Pa}$.

Dr. S. K. Waldorf, Engineer of Rese arch

RENSSELAER POLYTECHNIC INSTITUTE

Mechanical Engineering Department, Troy, N. I.

Prof. Grant K. Palsgrore, Director, Hydraulic Laboratory

RESEARCH FOUNDATION FOR CROSS-CONNECTION CONIROL (see University of Southern California)

ROCKY MOUNTAIN HYDRAULIC LABORATORY

Allenspark, Colo.

Prof. C. J. Posey, Director (winter address: State University of Iowa, Iowa City, Iowa)

RWTGERS UNIVERSTTY .

Department of Botany, New Brunswick, N. J.

Prof. M. F. Buell

ST. ANTHONY FALLS HYDRAULIC LABORATORY

University of Minnesota, Hennepin Island, Minneapolis 14, Minn.

Dr. Lorenz G. Straub, Director

SOCIETY OF NAVAL ARCHITECTS AND MARDNE ENGINEERS

74 Trinity Place, New York 6, N. Y.

Capt. W. N. Landers, Secretary

SOUTHERN METHODIST UNIVERSITY

School of Engineering, Hydraulics Laboratory, Dallas, Texas

Prof. I. W. Santry 
STANE ORD UNI VERSITY

Department of Civil Engineering, Stanford, Calif.

Prof. John K. Vennard, Director, Hydraulic Laboratory

SIEVENS INSTITUTE OF TECHNOLOGY

Experimental Towing Tank, 71 l Hudson Street, Hoboken, N. J.

Dr. Kenneth S. M. Davidson, Director

TAYLOR MODEL BASIN (see U. S. Goverment)

TENNESSEE, UNIVERSITY OF

Hydraulic Laboratory, Dept. of Civil Engineering, Knoxville 16, Tenn.

$\mathrm{Dr}$. Henry H. Ambrose

TEXAS, UNIVERSITY OF

Department of Civil Engineering, Austin 12, Texas

Dr. Walter L. Moore, Directing Head

UTAH STATE AGRICULTURAL COLLEGE

Engineering Experiment Station, Log an, Dtah

Dr. J.E. Christiansen, Dean, School of Engineering and Technology

WASHINGTON, STATE COLIEGE OF

Dept. of Civil Engineering and Division of Industrial Research, Pullman, Wash.

Prof. C. L. Barker, Hydraulic Engineer

WASHINGTON, UNIVERSITY OF

Department of Civil Engineering, Seattle 5, Wash.

Prof. R. B, van Horn, Acting Director

WATERWAYS EXPERIMENT STATION (see U. S. Goverment)

WISCONSIN, UNIVERSITY OF

Hydraulic and Sanitary Laboratory, Madison 6, Wis.

Prof. Arno T. Lenz

WORCESTER POLYTECHNIC INSTITUTE

Alden Hydraulic Laboratory, Worcester 2, Mass.

Prof. L. J. Hooper, Director

J. S. GOVERRMENT ACENCIES

\section{DEPARTMENT OF AGRICULTUEE}

AGRICULTURAL RESEARCH SERVICE

Soil and Water Conservation Research Branch, Beltsville, Md.

Dr. Robert M. Salter, Chlef

DEPARTMENT OF AGRTCULTURE

FOREST SERVICE

California Forest and Range Experiment Station

P. 0. Box 245, Berkeley 1, Calif.

Mr. George M. Jemison, Director

Intermountain Forest and Range Experiment Station 
Northeastern Forest Experiment Station

102 Motors Avenue, Upper Darby, $\mathrm{Pa}$.

Dr. Ralph W. Marquis, Director

Pacific Northwest Forest and Range Experiment Station

Post Office BOx 4059, Portland 8, Ore.

Mr. R. W. Cowlin, Director

Rocky Mountain Forest and Range Experiruent Station

221 Forestry Blag., Fort Collins, Colo.

Mr. Raymond Price, Director

Southeastern Forest Experiment Station

P. O. Box 2570, Asheville, N. C.

Mr. E. L. Denmon, Director

DEPARTMENT OF THE ARMY

CORPS OF ENGTNEERS

Beach Erosion Board

5201 Little Falls Road, N. W., Washington 16, D. C. colonel L. H. Hewitt, President

Bonneville Hydraulic Laboratory

628 Pittock Block, Portland 5, Ore.

The District Engineer

Los Angeles District

121

P. O. Box 17277 Foy Station, Los Angeles 17, Calif.

The District Engineer

St. Paul District

1217 U. S. Post Office and Custom House, St. Paul 1, Minn.

The District Engineer

Waterways Experiment Station

P. 0. BOx 63I, Vicksburg, Miss.

Director

DEPARTMENT OF COMMERCE

BUREAU OF PUBLIC ROADS

Hydraulics Branch, Washington 25, D. C.

Mr. Carl F. Izzard, Chief

NATIONAL BUREAU OF STANDARDS

National Hydraulic Labor atory

Washington 25, D. C.

WEATHER BUREAD

Hydrologic Services Division, Wiash. 25, D. C. Mr. Willi an E. Hiatt, Chief

DEPARTMENT OF THE INTERIOR

GEOLOGICAL SURVEY

Washington $25, \mathrm{D} . \mathrm{C}$.

Mr. R. W. Davenport, Acting Chief Hydraulic Engineer 
BUREAU OF RECLAMATION

Branch of Design and Construction

Denver Federal Center, Denver, Colo.

Mr. L. N. McClennan, Chief Engineer

DEPARTMENT OF THE NAVY

NAVAL BOIIER AND TURBINE LABORATORY

Philadel phia 12, Pennsylv ani a

The Commanding officer and Director

NAVAL ORDNANCE TEST STATION

Pas adena Annex, 3202 E. Foothill Blvd., Pasadena 8, Calif.

The Commander, Attn. Code P807

OFFICE OF NAVAL RESEARCH Washington 25, D. C.

DAVID TAYLOR MODEL BASTN

Washington 7, D. C.

The Commanding Officer and Director

TENNESSEE VALIEY AUTHORITY

HYDRAULIC DATA BRANCH Knoxville, Tenn.

Mr. Albert S. Fry, Chief

\section{CANADIAN LABORATORTES}

BRITISH COLUMBIA, UNIVERSITY OF Hydraulics Laboratory, British Columbia, Vancouver, Canada

Prof. H. C. Gunning, Dean, Faculty of Applied Science

McGILL UNIVERSITY

Department of Civil Engineering, Montreal 2, Que., Canada

Prof. R. E. Jamieson, Chairmen, Dept. of Civil Engineering and Applied Mechanics

MONTREAL, ÉCOLE POLYTECHNIQUE DE

Hydraulics Labor atory, 1430 Rue Saint-Denis, Montreal 18, Canada

Prof. Raymond Boucher, Head, Department of Hydraulic Engineering

NATIONAL RESEARCH COUNCIL

Division of Mechanical Engineering, Montreal Road, Ottawa, Canada

Mr. J. H. Parkin, Director

QUEEN'S UNIVERSITY

Faculty of Applied Science, Kingston, Ontario, Canada

Prof. D. S. Ellis, Dean, Faculty of Applitd Science

TORONTO, UNIVERSITY OF

Department of Mechanicel Engineering, Toronto 5, Canada

Prof. E. A. Allcut, Professor of Mechanical Engineering 
THE BALDWIN-LIMA-HAMILTON CORPORATION, Hydraulic Turbine Laboratory.

Inquiries concerning Projects Nos. 27, 1814, 2049, and 2050, should be addressed to Mr. C. H. Diehl, Hydraulic Turbine Laboratory, Baldwin-Lima-Hamilton Corporation, Philadelphia $42, \mathrm{~Pa}$.

(271) ADJUSTABLE AND FIXED BLADE PROPELLER-TYPE HYDRAULIC TURBINE MODELS.

(b) Laboratory project.

(d) Experimental; applied research for design.

(e) To improve performance of present designs, and to extend the range of application of this type turbine. Propeller munners of various designs in combination with modified turbine settings are being methodically tested in the 1l-inch cavitation flume. Efficiency, output, cavitation, runaway speed, hydraulic thrust, and hydraulic blade torque are measured.

(g) Results provide data for improvement of existing design and information for designs which extend the range of application.

(1814) PUMP MODELS.

(b) Laboratory project.

(d) Experimental; applied research.

(e) Model pumps of the centrifugal and axial flow types have been tested to determine characteristics of: efficiency, horse power, discharge, cavitation, thrust, runaway speeds, blade and wicket gate torques.

(2049) DRAFT TUBE INVESTIGATIONS.

(b) Laboratory project.

(d) Experimental; applied research.

(e) Draft tubes of various lengths, widths, heights and flare have been tested. The purpose was to determine the effect of dimensional changes on the performance of various propeller type turbines.

(g) The results will provide information that will extend the application of propeller type turbines.

(2050) PUMP TURBINE IABORATORY.

(b) Laboratory project.

(d) Experimental; applied research.

(e) A closed flume for the testing of pump-turbine model units is being installed in an extention of the present laboratory building. The performance characteristics of efficiency, horsepower, discharge, thrust, cavitation, runaway speeds, blade and wicket gate torques will be obtained on models of prototype units.

POLYTECHNIC INSTITUTE OF BROOKLYN.

Inquiries concerning Projects Nos. 1546 and 1547 should be addressed to Prof. M. W. Stewart, Polytechnic Institute of Brooklyn, 99 Livingston St., Brooklyn 1, N. Y.

(15L6) IESIGN AND CONSTRUCTION OF A FLUID POLARISCOPE.

(f) Completed.

(h) "Stucty of Fluid Flow by Means of Fluid Polariscope." Bachelor's Thesis, A. M. James. (Available on loan.) 
(1547) DESIGN AND CONSTRUCTION OF A 6-INCH WATER TUNNEL.

(b) Laboratory project.

(d) Applied research.

(e) Design and construction of a 6-inch water tunnel to be used for various laboratory exercises as well as for fluid flow studies.

(f) Design completed - construction suspended.

(h) "Design and Construction of 6-inch water Tunnel." Bachelor's Thesis, S. Moskowitz. (Available on loan.)

\section{CALIFORNIA TNSTITUTE OF TECHNOLOGY.}

Inquiries concerning projects should be addressed to the following, all at Hydrodynamics Laboratory, California Institute of Technology, Pasadena L, Calif.

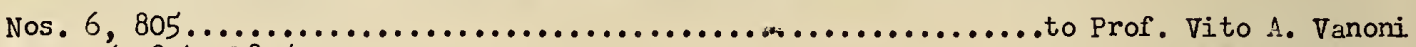

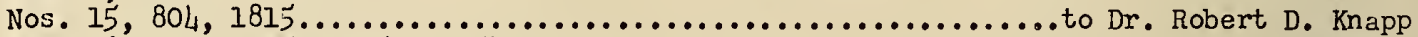

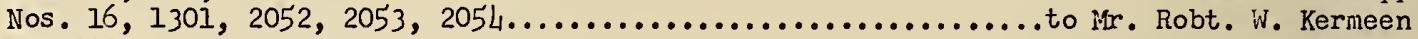

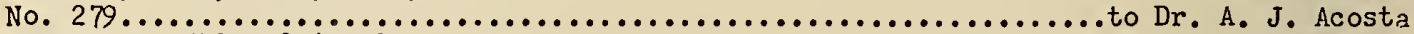

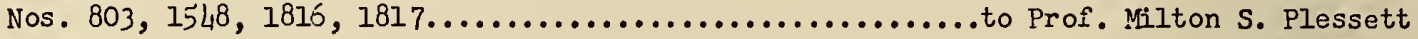

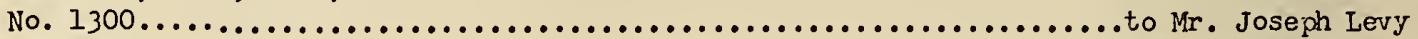
No. $1549 \ldots \ldots \ldots \ldots \ldots \ldots \ldots \ldots \ldots \ldots \ldots \ldots \ldots \ldots \ldots \ldots \ldots \ldots \ldots$. . . . M . John H. Carr

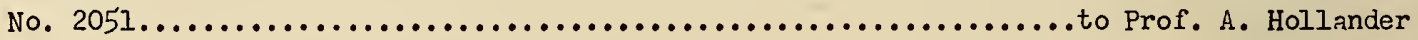

(6) MECHANICS OF SEDIMENT TRANSPORTATION.

(b) Cooperative with the U. S. Army, Corps of Engineers, Missouri River Division.

(d) Experimental and theoretical; basic research.

(e) To investigate the mechanies of transportation of sediment by flowing fluids inclading studies of the suspended load as well as the bed load phases of the problem.

(h) "Laboratory Studies of the Mechanics of Streams Flowing Over a Movable Bed of Fine Sand." Thesis by N. H. Brooks, Calif. Inst. of Technology, 1954.

(15) STUDIES OF CAVITATION PHENOMENA.

(b) Office of Naval Research, Department of the Navy.

(d) Experimental; basic research.

(e) Details of fixed void type cavitation have been studied experimentally in the water tunnel. Special emphasis has been given to characteristics of the interface, djnamics of entrainment at downstream end of cavity, and behavior of entrained voids.

(g) Two fundamental characteristics of fixed cavities have been delineated: (a) The cavity interface is packed with small traveling voids. (b) There is a stagnation zone at the downstream end of the cavity. The liquid upstream from this zone forins a re-entrant flow into the cavity. This results in a cyclic process: formation-filling-breakoff.

(h) "Present Status of Cavitation Research", Robert T. Knapp, Mechanical Engineering, Vol. 76 , No. 9, Sept. 1954, pp. 731-734.

"Recent Investigations of the Mechanics of Cavitation and Cavitation Damage", Robert T. Knapp. Paper No. 54--A-105. Presented at the Annual Meeting of the Amer. Society of Mech. Engineers, New York, N. Y., Nor. 28-Dec. 3, 1954.

(16) HYDRODYNAMIC FORCES ON SUBMERGED BODIES.

(b) Bureau of Ordnance and Office of Naval Research, Department of the Navy.

(d) Experimental; basic and appljed research.

(e) Hydrodynamic forces on bodies of different shapes and designs are measured in water tunnels and a vertical drop tank. The important steady state and damping force coefficients are obtained. These data are used to predict full scale behavior. 
(h) "Water Tunnel and Drop Tank Tests of a Streamlined Body of Revolution for the Naval Ordnance Test Station, Pasadena, Calif." R. W. Kermeen and R. L. Waid (in preparation). "Hydrodynamic Forces on Prolate Ellipsoidal Bodies", John A. Stallkamp, Calif. Inst. of Tech., 1954. (Hydrodynamics Laboratory report in preparation).

(279) FLOWI IN ROTATING CHANNELS.

(b) Office of Naval Research, Department of the Navy.

(d) Experimental and theoretical.

(e) Studies on the internal and over-all flow behavior and hydrodynamic performance of centrifugal pump impellers, volutes and axial flow pumps.

(h) "Potential Flow Through Radial Flow Turbomachine Rotors", A. J. Acosta, C.I.T. Hydrodynamics Laboratory Report No. E-19.4, Feb. 1954.

mote on the Effect of Meridian Curvature", A. J. Acosta, C.I.T. Hydrodynamics Laboratory Report No. E-19.5, April 1954.

"Experimental Study of Flow Between Centrifugal Pump Shrouds", H. N. Tyson, Jr., C.I.T. Hydrodynamics Laboratory Report No. E-19.6, July 1954.

(803) DYNAMICS OF CAVITATION AND CAVITATION DAMAGE.

(b) Office of Naval Research, Department of the Navy.

(d) Theoretical and experimental; basic research.

(e) Dynamic behavior of cavitation bubbles; theoretical and experimental studies of cavitation damage.

(h) "The Production of Accelerated Cavitation Damage by an Acoustic Field in a Cylindrical Cavi.ty", A. T. Ellis, C.I.T. Hydrodynamics Laboratory Report No. 2l-14 (in preparation). "On the Mechanism of Cavitation Damage", M. S. Plesset and A. T. Ellis, C.I.T. Hydrodynamics Laboratory Report No. 21-15, June 1954.

"An Intermediate Theory of Longitudinal Stress Waves in Bars", G. W. Sutton, C.I.T. Hydrodynamics Laboratory Report No. 21-18, Sept. 1954.

"The Grouth and Collapse of Vapor Bubbles", S. A. Zwick, C.I.T. Hydrodynamic Laboratory Report No. 21-19, Nor. 1954 .

"On the Stability of the Spherical Shape of a Vapor Cavity in a Liquid", M. S. Plesset and T.P. Mitche11, C.I.T. Hydrodynamics Laboratory Report No. 26-9, July 1954.

"Note on the Dynamics of Small Vapor Bubbles in Liquids", S. A. Zwick and M. S. Plesset, C.I.T. Hydrodynamics Laboratory Report No. 26-7, Feb. 1954.

(804) THE EFFECT OF PHYSICAL CHARACTERISTICS OF LIQUID ON THE INCEPTION OF CAVITATION.

(b) Office of Naval Research, Department of the Navy.

(d) Experimental; basic research.

(e) Scope of investigations has been extended to include the dynamic testing of treated samples under normal flow conditions. To date pressurized samples show significant apparent tensile strengths, but of somewhat lower magnitude than those determined by boiling point measurements. The results of these experiments, like all others in this particular research, appear to have inherent wide scatter. Thus, considerable additional work will be required before generalizations $c$ an be made.

(805) DIFFUSION IN TURBULENT FLOW.

(b) U. S. Air Force.

(d) Experimental.

(e) Diffusion and turbulence measurements have been made in a water tunnel with a 12-in. square working section for three similar turbulence-producing grids.

(f) Completed.

(h) Report in preparation. 
(b) Office of Naval Research, Department of the Navy.

(d) Experimental; basic research.

(e) An investigation of the phenomena accompanying the entry into water of solids traveling at moderate speeds. The intial study covers the formation of the cavity, and the measurement of pressure within the cavity formed behind spheres entering the water vertically.

(f) Suspended.

(1301) HYDRODYNAMICS OF FREE-BOUNDARY AND CAVITY FLOWS.

(b) Bureau of Ordnance and Office of Naval Research, Dept. of the Navy.

(d) Experimental and analytical; basic and applied research.

(e) Free-surface and closed-jet water tunnels are used in experimental and analytical studies of cavity and jet flows in two and three dimensions.

(g) Drag and cavity shape measurements on a variety of body shapes including cones, disks and spheres. The results have been compared wherever possible with theoretical results. Scale and tunnel blockage effects have also been studied.

(h) "Water Tunnel Measurements on Spheres in Cavity Flow", En-Yun Hsu and B. Perry, Calif. Inst. of Tech. Hydrodynamics Laboratory Report No. E-24.9, April 1954.

"An Experimental Study of the Hydrodynamic Forces Acting on a Family of Cavity-Producing Conical Bodies of Revolution Inclined to the Flow", T. Kiceniuk, Calif. Inst. of Tech. Hydrodynamics Laboratory Report No. E-12.17, June 1954 .

"Stagnation Cup Flow", B. Perry, Calif. Inst. of Tech. Hydrodynamics Laboratory Report (in preparation).

"An Experimental Study of Vapor Cavities in a Closed Jet Water Tunneln, R. W. Kermeen, Calif. Inst. of Tech. Hydrodynamics Laboratory Report (in preparation).

\section{(15L8) SPECIAL PROBLEMS IN HYDRODYNAMICS.}

(b) Office of Naval Research, Department of the Navy.

(d) Theoretical and experimental; basic research.

(e) Studies of cavitating and noncavitating flow.

(h) "Two-Dimensional Sink Flow of a Viscous, Heat-Conducting, Compressible Fluid; Cylindrical Shock Waves", Y. T. Wu, C.I.T. Hydrodynamics Laboratory Report No. 21-16, Aug. 1954 .

"Flow through a Heavily Loaded Actuator Disc", Y. T. Wu, C.I.T. Hydrodynamics Laboratory Report No. 21-17, (in preparation).

"On the Application of Free Streamiine Theory to Cavity Flows", M. S. Plesset and Byrne Perry, Jubile Scientifique de M.D.P. Riabouchinsky, Mémoires sur la Mécanique des Fluides, (Publications Scientifuques et Techniques du Ministere de 1'Air, 1954).

"On the Stability of Fluid Flows with Spherical Symmetry", M. S. Plesset, Jour. of Applied Physics, Vol. 25, No. 1, pp. 96-98, Jan. 1954.

(1549) WAVE FORCES AND PFESSURES.

(b) Bureau of Yards and Docks, Department of the Navy.

(d) Experimental and theoretical; applied research.

(e) Total force and moment acting on rigid bulkheads due to wave breaking being investigated.

(f) Completed.

(g) Correlation between impulse measurements and solitary waves momentum theory has been obtained for the case of waves breaking against a vertical bulkhead.

(h) "Wave Forces on Curved and Stepped Barriers", John H. Carr, Calif. Inst. of Tech. Hydrodynamics Laboratory Hydraulic Structures Division Report No. E-11.2, June 1954. "Breaking Wave Forces on Plane Barriers", John H. Carr, Calif. Inst. of Tech. Hydrodynamics Laboratory, Hydraulic structures Division Report No. E-11.3, Nov. 1954. 
(1815) THE CORRELATION OF THE MECHANICS OF CAVITATION WITH THAT OF PHYSICAL DAMAGE.

(b) Bureau of Ships, Department of the Navy.

(d) Experimental; basic research.

(e) Objective is on the basis of the present knowledge of the mechanics of the cavitation process to endeavor to clarify the mechanics of cavitation damage of solid surfaces. Two approaches are being used: (1) Study of damage on standard metal specimens subjected to cavitation in the water tunnel; (2) study of damage on samples of same material in the standard magnetostriction equipment.

(g) Pure annealed aluminum has been employed as standard damage specimen. Microscopic examination after very short runs shows the surface covered by pits produced by plastic deformation, with no material removed. Indications are that pitting rate per unit area furnishes rough measure of cavitation intensity. Variations of intensity with both cavity length and flow velocity have been studied.

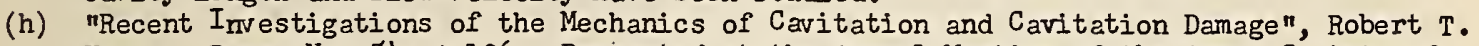
Knapp. Paper No. 54--A-106. Presented at the Anmual Meeting of the Amer. Society of Mech. Engineers, New York, Nov. 28-Dec. 3, 1954.

(1816) FORCE CHARACTERISTICS OF SUBMERGED HYDROFOIIS ONDER CAVITATING CONDITIONS.

(b) Bureau of Ships, Department of the Navy.

(d) Theoretical and Experimental; basic research.

(e) Studies of hydrofoils.

(h) "Calculation of Hydrofoil Sections from Prescribed Pressure Distribution", Blaine R. Parkin and Glenn H. Peebles, C.I.T. Hydrodynamics Laboratory Report No. 47-1, (in preparation).

"The High-Speed Water Tunnel Three-Component Force Balance", George M. Hotz, and J. T. McGraw, C.I.T. Hydrodynamics Laboratory Report No. 47-2, (in preparation). "Pressure Distribution on a Hydrofoil Running near the Water Surface", Blaine R. Parkin, B. Perry and Y. T. Wh, C.I.T. Hydrodynamics Laboratory Report No. 47-3, (in preparation). "Comparison of the Characteristics of a Hydrofoil under Noncavitating and Cavitating Operation", B. Perry and Y. T. Wu, C.I.T. Hydrodynamics Laboratory Report No. 47-4, (in preparation).

(1817) SCALE EFFECTS IN CAVITATING FLOW.

(b) Office of Naval Research, Department of the Navy.

(d) Experimental and theoretical; basic research.

(e) Experimental and theoretical studies are being carried out on the effect of model size on incipient cavitation.

(h) "Incipient Cavitation and Wake Flow behind Sharp-Edged Disks", R. W. Kermeen and B. R. Parkin, C.I.T. Hydrodynamics Laboratory Report No. E-35.3, (in preparation).

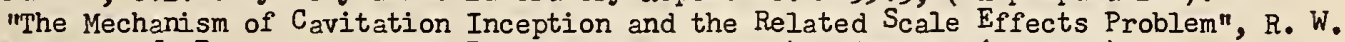
Kermeen, J. T. McGraw and B. R. Parkin, (in press). (Trans. A.S.M.E.).

(2051) EFFECT OF VISCOSITY ON CENTRIFUGAL PUMP PERFORMANCE.

(b) Standard Oil Company of New Jersey; Byron Jackson Company.

(d) Experimental.

(e) Investigation of the effects of Reynolds number on the internal and orer-all flow characteristics of a centrifugal impeller with a view to improving the performance by means of design changes.

(g) A small recirculating test facility has just been completed. It will permit the meas urement of over-oll chrracteristics in addition to the measurement of vane pressure distributions and internal flow losses. 
(2052) EXPERTMENTS ON SMALL SCALE PLANING SURFACES.

(b) Office of Naval Research and Bureau of Ordnance, Department of the Navy; ConsolidatedVultee Aircraft Corp.

(d) Experimental; basic and applied research.

(e) Measurement of the lift on small-scale ( 0.5 to 3 inches width) planing surfaces have been made in the Free Surface Water Tunnel to ascertain the nature of the scale effect, if any, and to develop methods of extrapolating such force data to full scale.

(g) Planing flat plates and circular cylinders have been studied, and it has been found that flat plates as small as 2 in. width show no scale effect on the lift. The situation for cylinders appears more uncertain and is still under investigation.

(h) "Experimental Study of Froude Number Modeling for Cylinders Planing on Water", T. Kiceniuk, Calif. Inst. of Tech. Hydrodynamics Laboratory Report No. E-24.4, Jan. 1952 (declassified January 1954).

"Lift Measurements, on $S_{\text {mall }} S_{\text {cale }}$ Flat Planing Surfaces", B. Perry, Calif. Inst. of Tech. Hydrodynamics Iaboratory Report No. E-2L.10, April 1954.

(2053) EXPERIMENTS ON STRUTS PIERCING THE WATER SURFACE.

(b) Bureau of Ordnance, Department of the Navy.

(d) Experimental; basic research.

(e) The mechanism by which air ventilates down aft of a surface-piercing strut such as might be used to support a hydrofoil boat, and the resulting force system is being experimentally investigated in the Free-surface. Water Tunnel.

(g) Data have been taken on rectangular and circular cylinder struts, and the resulting flow has been found to be closely related to two-dimensional cavity flow. Measurements have also been made on a symmetrical air-foil shape.

(h) "Experiments on Struts Piercing the Water Surface", B. Perry, Calif. Inst. of Tech. Hydrodynamics Laboratory Report (in preparation).

(2054) FORCES ON UNDER'NATER MISSILES RUNNING IN A CAVITY.

(b) Bureau of Ordnance, Department of the Navy.

(d) Experimental; basic and applied research and development.

(e) The hydrodynamic forces on missiles and simulated missile body components are being measured in water tunnels for cavity flow. Model studies of forces on individual body components of basic geometric shapes are being correlated with studies made on composite bodies.

(h) "Forces on a Cylinder Planing in a Vapor Cavity", R. W. Kermeen, Calif. Inst. of Tech. Hydrodynamics Laboratory Report No. E-12.14, Nov. 1953.

"Force and Moment Measurements on a Torpedo Afterbody with Three Tail Configurations Planing on a Free Water Surface", T. Kiceniuk, Calif. Inst. of Tech. Hydrodynamics, Laboratory Report No. E-54, Dec. 1953.

"Force Coefficients of Six Related Configurations in Cavitating Flow", R. I. Waid, Calif. Inst. of Tech. Hydrodynamics Laboratory Report No. E-51.1, Jan. 1954 .

UNIVERSITY OF CALIFORNIA, College of Agriculture, Department of Irrigation.

(2I) STUDY OF HYDRAULICS OF SPRINKLING SISIEMS.

(b) California Agricultural Experiment Station.

(c) Prof. V. H. Scott, Department of Irrigation, Univ. of California, Davis, Calif.

(d) Experimental; operation.

(e) Studies include water distribution and irrigation efficiency in orchards and field crops, characteristics of nozzle shapes and their effect on distribution patterns, cost analysis of sprinkler irrigation operation, and causes of aluminum pipe corrosion.

(g) Information is being secured which may lead to the design of new jets for more uniform distribution patterns. Several year's data will be secured on sprinkler irrigation efficiency of orchards.

(h) "Irrigation by Sprinkling", California Agr. Exp. Sta. Bul. 670, Revised by W. A. Hall. (subritted for publication). 


\section{(23) HYDROLOGY OF IRRIGATION SUPPLIES IN CALIFORNIA.}

(b) California Agricultural Experiment Station.

(c) Dr.F.J. Veihmeyer, Department of Irrigation, University of California, Davis, Calif.

(d) Experimental and field investigation; applied research and operation.

(e) Studies are being continued on the hydrologic effects of $v$ arious watershed practices on typical range and brush lands. Measurements are being made of ralnfall, runoff, erosion and soil moisture on small watersheds located throughout Californila on lands with widely varied climatic conditions, topography, soil and vegetation. Data are being collected on an individual storm basis to yield all possible correlations between precipitation, intensity and the other factors.

(g) Data from small watersheds are being analyzed to evaluate the effects of the management practices on water yield, infiltration, runoff and erosion. Results of earlier plot experiments have indicated that it is possible to remove brushy vegetation by fire with consequent revegetation by grasses, and that this management practice does not show any deleterious effect on the hydrologic elements.

(24) MEASUREMENT OF IRRIGATION WATER AND IMPROVEMENT IN FARM IRRIGATION STRUCTURES.

(b) California Agricultural Experiment Station.

(c) Prof. V. H. Scott, Department of Irrigation, University of Caltfornia, Davis, Callf.

(d) Experimental; design.

(e) Studies of farm irrigation systems for the improvement of design and efficiency of irrigation equipment are being continued. Work on prefabricated materials in small farm ditches and reservoirs is continuing. Methods of grading land for surface irrigation have been studied in detail. Such factors as land clearing, surveying, staking, as well as the various pieces of earth moving equipment have been investigated.

(g) Information is available on the seepage control of certain prefabricated materials, and on the best methods of grading land for surface irrigation.

(h) "Grading Land for Surface Irrigation", J. C. Marr, Callfornia Agr. Exp. Sta. Ext. Cir. 438,1954 .

"Irrigation Structures -- Siphons", V. H. Scott and I. J. Booher, California Agr. Ext. Service unnumbered leaflet, 1954.

(25) PHYSICAL AND CHEMICAL FACTORS AFFECTING SOIL INFILTRATION RATES.

(b) Calffornia Agricultural Experiment Station.

(c) Dr. L. D. Doneen, Department of Irrigation, Univ of California, Davis, Calif.

(d) Experimental and fleld; basic and applied research.

(e) Studies on the permeability of different soils are being continued. Cultivation in relation to soil structure and soll compaction is being investigated. Reasearch is continuing on factors affecting accumulation of salines in soil from irrigation water, the effect of quality of water on infiltration of water into soils, and treatment of irrigation waters to increase water penetration into soils.

(g) As a result of studies on the quality of water for Irrigation, a new method of calculating salinity of irrigation water has been devised. Analysis of an Irrigation water may show a high concentration of salts, but only a small portion of them may be effective in accumulation of soluble salts in the soil. Under the current system of classification, many waters would be condemned for use in irrigation, but when solubility effects are considered, these waters might be useful.

(h) "Salination of Soil by Salts in the Irrigation Water", L. D. Doneen, Irans. Amer. Geophys. Union 35:943-950, 1954 .

(1819) DRAINAGE IN RELATION TO IRRIGATION.

(b) California Agricultural Experiment Station.

(c) Dr. J. N. Iuthin, Department of Irrigation, University of California, Davis, Calif.

(d) Experimental and field investigation; basic and applied research.

(e) To improve drainage design by the development of methods of drainage investigation and design which will have wide application. Field work is in progress in several areas of California. Observation wells and water stage recorders have been located in selected sites, and drainage systems have been designed on Individual farms to serve as demonstrations. 
(g) Many areas of the State are affected by high water table conditions. In some areas salt concentration in the soil has resulted from poor drainage. Both the high water table and accumulated salt have caused a decrease in crop yield. Information concerning water table elevations, soil permeability and effectiveness of existing drains should alleviate the drainage problems in these areas.

(h) "Alfalfa and Water Table Levels", James N. Iuthin and William Bianchi, California Agriculture $8: 4-5,1954$.

(2055) THE PHYSICS OF SOII MOISTURE MOVEMENT.

(b) California Agricultural Experiment Station.

(c) Dr. J. N. Iuthin, Department of Irrigation, University of California, Davis, Calif; Dr. Paul $D_{a y}$, Department of Soils, University of California, Berkeley, Calif.

(d) Laboratory and theoretical studies; basic research.

(e) Studies of the movement of water in the unsaturated state, relationship between the capillary conductivity and soil moisture tension, and numerical solution of the nonlinear form of Laplace's equation where the capillary conductivity is pressure-dependent, are being conducted.

(g) The seepage from irrigation furrows was studied by means of a sand-tank model. Special conditions were imposed on the boundaries of the flow regions. Kirkham's drainage theory was applied to the problem.

(h) "Sand-Model Experiments on the Distribution of Water-Pressure Under an Unlined Canal", Paul R. Day and James N. Luthin, Soil Sci. Soc. Amer. Proc. 18:133-137, 1954.

(2056) THE HYDRAULIC CHARACTERISTICS OF WELL CASING PERFORATIONS.

(b) California Agricultural Experiment Station.

(c) Prof. V. H. Scott, Department of Irrigation, Univ. of California, Davis, Calif.

(d) Experimental; applied research.

(e) Studies have been initiated to theoretically analyze flow through well casing perforations followed by laboratory and field experiments to determine ( 1 ) head loss characteristics of various perforation shapes, and (2) the influence of the gravel pack on the hydraulic performance of the perforations.

(g) Study in preliminary stage.

UNIVERSITY OF CALIFORNIA, College of Agriculture, Department of Irrigation and Soils.

Inquiries concerning Projects 26, 27, 1058, 1302 and 1303, should be addressed to Prof. M. R. Huberty, Chairman, Department of Irrigation and Soils, University of California, Los Angeles 2L, California.

(26) DRAINAGE INVESTIGATIONS IN COACHELLA VALLEY, CALIFORNIA.

(b) Cooperative between the Coachella Valley County Water District, Coachella, Calif., U. S. Salinity Laboratory, Riverside, California; U. S. Bureau of Reclamation, Boulder City, Nev. (Now inactive); and this laboratory.

(d) Field investigations; applied research, and design.

(e) To develop and improve techniques for observing shallow ground water movement, for reclamation of saline and alkali soils, and installation of drainage devices and systems.

(g) No completed results not previously given.

(27) HYDROLOGY OF IRRIGATION WATER SUPPLIES IN CALIFORNIA.

(b) Laboratory project, coordinated with similar work under Dr. F. J. Veihmeyer, Department of Irrigation, University of California, Davis, Calif.

(d) Field experiments; applied research.

(e) To evaluate the effects of the burning of brush-covered watersheds on runoff and erosion in southern California.

(g) No new results not previously reported. 
(1058) SOLL PHYSICAI CONDITIONS IN RELATION TO IRRIGATION.

(b) California Agricultural Experiment Station.

(d) Laboratory and field studies; basic and applied research.

(e) Study of the soil properties wijich affect water flow into and through soils.

(h) "Soil Compaction Apparatus and Related Soil Properties", by L. $\nabla$. Weeks and S. J. Richards (in press).

(1302) OXNARD PLATN IRRIGATION AND RECLAMATION INVESTIGATIONS.

(b) Laboratory project.

(d) Field investigations; applied research and design.

(e) Investigations of drainage conditions, drainage mechamics, and irrigation efficiency with view towards improving reclamation of this rather saline-high water table area, and towards establishing more rational criteria for tile drainage design.

(g) Indications of a relatively simple time-rate relationship of water table recession under tile drainage are being checked by a theoretical analysis which is now being programmed for solution on a SWAC automatic high-speed computer.

(1303) HYDRAUIC CHARACTERISTICS OF IRRIGATION DISTRIBUTION PIPE SYSTEMS.

(b) Laboratory project, cooperative with College of Engineering, University of California, Los Angeles 2L, Calif.

(d) Basic and applied research.

(e) (1) A theory was developed for the initiation, because of air entrainment, of surge in an open-type pipe irrigation system, and the theory was checked by comparing an empirical mun with the solution of the equations obtained on the differential analyzer. (This work done by graduate student Philip Dahl working under Professor E. H. Taylor, and under E. c. Delaud for the differential analyzer solution). (2) Work is being initiated on the mechanics of semi-closed pipe irrigation systems.

(h) Results of (I) being prepared for publication.

UNIVERSITY OF CALIFORIIA, College of Engineering, Fluid Mechanics Laboratory.

Inquiries concerning Projects Nos. 35, 38, 40, LI, L6, 47, 280, 529, 1059, 1050, 1307, $1551,1552,1554,1557,1822$, to 1827 , inc1., 1829 to 1831 , incl., and 2057 to 2053, inci., should be addressed to Prof. J. W. Johnson, Department of Engineering, University of California, Berkeley L, Calif.

(35) OSCILLATORY WAVES.

(b) Laboratory project.

(d) Experimantal.

(e) To obtain experimental information on the details of the three dimensional problem of wind generated waves. Experiments are being conducted in a wind-wave tunnel $20 \mathrm{ft}$. long, $0.5 \mathrm{ft}$. deep by $4 \mathrm{ft}$. wide. Wave petterns and dimensions are being correlated with wind velocity and fetch length.

(h) "Nave Rumup on Sloping Structures", by Kenneth N. Grantham, Trans. Amer. Geophys. Union, Vol. 34, No. 5, pp 720-724, 1953.

(38) STRUCTURES EXPOSED TO WAVE ACTION.

(b) Laboratory and field research, Signal $0 i l$ and Gas Co.

(d) Experimental.

(e) To obtain experimental data for the design of offshore drilling structures. Present work involves the measurement of forces exerted on both model and field structural elements subjected to wave action. Work is also being done on the pressure distribution around a model cylindrical caisson as a function of wave length depth and angular position. Data to be compared with theory. Work being continued. 
(b) Laboratory project. Supported in part by Research Corporation.

(d) Experimental (basic and applied research, design).

(e) The flow characteristics of a gas-solids mixture ( $\mathrm{Al}_{2} \mathrm{O}_{3}, \mathrm{SiO}_{3}$ catalyst and air) are investigated in a $17 \mathrm{~mm}$. I.D. glass conduit for various gas flow and solids flow rates. Pressure drops across test sections are accurately measured for a series of air flow rates in which the solids to air ratio is varied fram zero to 11.0 pounds of solids per pound of air. The solids are introduced into the flow system through a mixing nozzle fed by a slide valve controlled weighing tank, and have a size distribution varying from particles less than 10 microns to particles greater than 220 microns. Investigation on the metering of solids-gas mixtures by nozzle and Venturi tubes has been carried out and at present preliminary studies on heat transfer to flowing gas-solids mixtures have been made. Metering studies to be continued using fixed size particles.

(g) Experimental data has been presented on the metering of gas-solids mixtures. Equipment for the study of the heat transfer characteristics of flowing mixtures has been set up and investigations started.

(41) PRESSURE DROP ACCOMPANYING TWO-PHASE, TWO-COMPONENT FLOWING PIPES.

(b) Laboratory project supported by Research Corporation.

(d) Experimental and theoretical, masters and doctoral thesis.

(e) To determine the conditions governing transition under which the gas and/or liquid phases are flowing in viscous and/or turbulent motion or in slug flow for isothermal flow in horizontal and vertical pipes. Mixtures of air and various liquids are made to flow through tubes. Pressure drop and fluid distribution with consideration of flow stability are determined for a range of liquid and gas rates which may be controlled separately.

(g) Work completed on vertical flow for viscous liquid, turbulent gas flow and slug flow.

(h) Report in preparation.

(46) THE MEASUREMENT OF TURBULENT VELOCITY COMPONENTS BY THE METHOD OF ELECTROMAGNETIC INDUCTION.

(b) Laboratory project.

(d) Experimental and theoretical investigations; faculty research.

(e) Velocity fluctuations are measured by determining the potentials induced in water cutting transversely across a steady magnetic field. An electrical probe consisting of two closely spaced fine wires is arranged to traverse the pipe cross section in the fluctuating potential gradient. The electrical impulses of the probe are amplified and measured by means of a thermal milliammeter.

(h) "The Measurement of Turbulent Velocity Components by the Method of Electromagnetic Induction", L. M. Grossman and A. F. Charwat, Review of Scientific Instruments 23, No. 12, p. 74I, Dec. 1952.

(47) GRAVITY WAVES AND RELATED PHENOMENON.

(b) Office of Naval Research, Department of the Navy.

(d) Theoretical and laboratory investigation; basic research.

(e) To develop methods of forecasting wind waves and swell, surf conditions and be ach changes; measurement of wave characteristics; and make laboratory investigations to provide experimental checks and other information. A wave channel, ripple tank, model basin, and other facilities are used in the laboratory investigations.

(h) "Summary of Wave Data for Cape Mendocino, California", J. W. Johnson, Report No. 116-356, Nov. 1953.

"Wave, Longshore Current and Beach Profile Records for Santa Margarita River Beach, oceanside, Calif., 1949", R. L. Wiegel, D. G. Patrick (USN), H. L. Kimberley (USN), Report No. 116-357, Nov. 1953.

"Some Ripple Tank Studies of Wave Refraction", Ning Chien, Report No. 116-358, Nor. 1953. "Statistical Analysis of Wave Records", R. R. Putz, Report No. 116-359, Jan. 1954. "Statistical Analysis of Ocean Waves", R. R. Putz, Report No. 116-360, Jan. 1954 . "Flow Over Reefs and Structures by Wave Action", O. Sibul, Report No. 116-361, Jan. 1954. "Laboratory Study of Gravity Waves Generated by The Movement of a Submerged Body", R. L. Wiegel, Report No. 116-362, June 1954. 
"Movements ondulations de la mer en profondeur constante on decroissante (Undulatory Morements of the Sea in Constant or decreasing Depth"), M. Miche, Report No. 116-363, June 1954.

"Operation Manual, Shore Wave Recorder, Mark IX, Model 5", L. E. Snodgrass, Report No. $116-364$, June 1954 .

"Hyperbolic Amplifier (Hydrodynamic Attenuation Equalizer), L. E. Snodgrass, W. W. Lund, Report No. 116-365, June 1954.

"Mooring Cable Forces Caused by Wave Action on Floating Structures", K. E. Beebe, Report No. 116-366, June 1954.

"Propagation of Radial Waves Generated by an Oscillatory Body", 0. Sibul and K. Pister, Report No. 116-367, June 1954.

"Asymptotic Developments of Water Waves Obliquely Incident to a Dock", R. G. Fuchs, Report No. 116-368, June 1954.

"Some References on Wave Motion", J. H. Sorenson, Report No. 116-369, June 1954.

"A Model Study of Wave Action on a Cylindrical Island", A.D.K. LaIrd, Report No. 116-370, June 1954 .

"Direct Reading Wave Meter", L. E. Snodgrass, Report No. 116-371, June 1954.

\section{(280) SEDTMENT TRANSPORT}

(b) Laboratory project, U. S. Corps of Engineers.

(d) Experimental and theoretical.

(e) Various fundamental problems in relating to sediment transport have been studied, and efforts have been made to apply the results of research to solve practical problems.

(g) The transport rate of wash-load was found to follow the bed-load function if the instantaneous bed composition is known.

The conventional suspended-load theory was improved by introduction of higher terms of the concentration and of the probability distribution for the turbulence velocities. The similarity conditions for distorted river models with movable bed were derived from the theoretical and empirical equations which have been found to describe the hydraulics and sediment transport in such rivers.

Various bed-load formulas were compared and a certain degree of uniformity among them was found.

The depth and slope of an alluvial channel were given graphically in terms of the unit discharge and sediment load to be carried, thus providing a more rational approach to the problem of alluvial channel design.

Lacey's regime theory was analyzed on the basis of the Einstein bed-load function. Functional relationships between the "silt factors" and the sediment characteristics were given for the channels in the Indian plain area. The general application of Lacey's regime theory to other than conditions in India and Pakistan is questionable as the "silt factor jur" then depends also on the characteristics of the flow, making its selection extremely difficult.

(h) "Similarity of Distorted River Models with Morable Bed", H. A. Einstein and Ning Chien, submitted to and accepted by ASCE for publication as a proceedings - separate. "The Present Status of Research on Sediment Transport", Ning Chien, submitted to and accepted by ASCE for publication as a proceedings - separate.

"Meyer-Peter Formula for Bed-Load Transport and Einstein Bed-Load Function", Ning Chien, Sediment Series, Corps of Engineers, Missouri Rivar Division (in press).

"Graphic Design of Alluvial Channels", Ning Chien, submitted to and accepted by ASCE for publication as a proceedings - separate.

"A Concept of Lacey's Regime Theory", Ning Chien, submitted to and accepted by ASCE for publication as a proceedings - separate.

\section{(529) LITTORAL SEDIMENT FLON ON A BEACH.}

(b) Beach Erosion Board, Dept. of the Army, Washington, D. C.

(d) Field, laboratory, experimental and theoretical research.

(e) The mechanics of movement of sand in relatively deep water around the end of rocky promontories off the coast of Southern California is being intensely investigated. The object of this work is to determine the source of sands on the beaches near Santa Barbara. Previous work had indicated considerable sand moved around various rocky promontories between Santa Barbara and the mouth of the nearest river, the Santa Ynez River, and the present investigation is designed to show how this sand moves. 
(h) "Bore Hole Studies of the Naturally Impounded Fill at Santa Barbara, California", Parker D. Trask and Theodore Scott, Beach Erosion Board, Corps of Engineers, Tech. Memo. No. 49, 36 pages, 1954.

"Sand Movement by Waves", Theodore Scott, Beach Erosion Board, Tech. Memo. No. 48, 37 pages, 1954 .

(1059) HEAT TRANSFER AND PRESSURE DROP IN COOLING TOKERS.

(b) Laboratory research.

(d) Experimental and analytical.

(e) To determine the heat transfer from water in contact with air in a mechanical draft, packed cooling tower as a function of water rate, air rate, water temperature and packing geometry. To determine the pressure drop as a function of the above-mentioned variables.

(g) Several results have been obtained and reported.

(1060) MASS TRANSFER TO RISTNG BUBBLES AND BUBBLE PLATES.

(b) Laboratory research.

(d) Experimental and analytical.

(e) A study of diffusion to bubbles and mass of bubbles.

(g) Some equipment has been completed: experimental research in progress on the mass transfer to single bubbles and to masses of bubbles on a $13^{\prime \prime}$ sieve plate. In addition a study is being made on the interfacial resistance to mass transfer by studying the growth and temperature variation of bubbles formed during boiling.

(h) "Mass Transfer in a Rising Bubble", G. Humphrey, Master of Science Thesis, June 1953.

(1307) DETERMINATION OF PRESSURE FLUCTUATIONS IN TURBULENCE IN LIQUID FLOW.

(b) Office of Naval Research, Department of the Navy.

(d) Experimental.

(e) Development of instruments and methods to measure pressure fluctuations in the free stream and at the flow boundaries.

(g) A Rutishauser pressure gage is tested for its applicability to the problem. The frequency response is measured and calculated for various measuring arrangements.

A first report is under preparation covering the description of the instrumentation and of its calibration for use in water and oil.

A set of wall measurements was made in a turbulent open channel flow of oil. The records are being analyzed.

A flow system to measure wall pressures as well as point velocities in pipes is under construction.

(1551) STUDY OF VERTICAL GAS-LIQUID FLOW IN PIPES.

(b) Laboratory project.

(d) Experimental and theoretical; basic research.

(e) Collection of data and photographs of gas-liquid flow in glass tubes less than one inch diameter. Analytical work to help explain flow transitions.

(g) Apparatus designed.

(1552) EFFECT OF WAVE LENGTH ON PIPE FRICTION IN TRANSITION REGION FOR WAVED GLASS TUBES.

(b) Laboratory project.

(d) Experimental; basic research.

(e) Collection of one component pipe friction data on waved glass tubes to study effect of wave length and amplitude on transition. Also to show rigid waved wall does not give exceptionally high iriction factors.

(g) Early transition shown and correlated; little increase of friction. 


\section{(1554) SEA WATER RESEARCH.}

(b) State of Calffornia.

(d) Experimental.

(e) The several investigations for demineralizing sea water carried on during the past year are: (1) Solar distillation, (2) low-temperature difference method, (3) skinming processes, (4) use of high liquid pressures in combination with appropriate permeable membranes (Osmotic Pressures), (5) thermodynamic analyses of separation methods, (6) computations on the use of a freezing process, involving sublimation and vapor compression, and (7) a survey of the possible use of clays for filtration of sea water.

(g) The first two investigations were described in the previous report. Progress since that time has resulted in the development of a plastic solar still, and in an equipment of the low temperature difference type which will make possible the gathering of dependable data.

Skiming Processes - These tests, made at the Los Angeles campus, are based on the large concentration gradient which occurs near any free surface. The first tests were devoted to various schemes for mechanically slicing thin layers of water from the surface and were not successful. Presently, efforts are directed toward forcing the water through very small pores and preliminary results appear to be encouraging.

Osmotic Membranes - These tests are also being conducted at the Los Angeles campus and are being financed by the United States Department of the Interior. This scheme is similar in some respects to the skiming process, in that water under pressure is exposed to a membrane having small pores. The major difference lies in the fact that the water remains in the liquid phase for the skimming process, while it vaporizes and condenses again in the osmotic process. The membranes are of different pore sizes and the pressures involved are different. Progress on this project so far is that of equipment development. A small unit was built on University of California funds and operated with an air gap. The unit now being built is designed to use oil or cellophane films in the gap. It is too soon to be sure of results.

Freezing Processes - The report on the Zarchin process necessarily contained assumptions as to properties of salt water below $32^{\circ} \mathrm{F}$ and as to appropriate design of $v$ apor components at high vacuua. Final conclusions on this very pramising scheme should be made only when dependable unextrapolated data on the above points are available. A thorough search of current literature will be made before any experiments on this point are made.

(h) rutilization of the thermal potential of the sea for the production of power and fresh water", by Andre Nizery, March 1954 (An address presented at Berkeley).

"Summary Report on the University of California Program", by E. D. Howe, for conference of the United States Department of the Interior contractors, April 1954.

"Feasibility of Using $S_{0 i l}$ as a Medium for the Reclamation of Saline Waters", by Martin R. Huberty, May $195 \mathrm{~L}$.

"A Demonstration of Distillation by Pressure Alone", by Gerald L. Hassler, June 1954. "Rate of Vapor Production by Water in Vacuum", by Lev Akobjanoff, July 1954.

"An Analysis of the Zarchin Scheme for Demineralizing Sea Water by Cold Distillation", by L. Shafer, S. F. Mulford and E. D. Howe, Aug. 195 L.

"Fresh Water from Salt Water", by Everett D. Howe, Trans. of the Amer. Geophys. Union, Vol. 33, No. 3, pp. 417-422, June 1952.

"Ttilization of Sea Water", by Everett D. Howe, UNESCO Proceedings, April 1954. "Fresh Water from the Sea", by Everett D. Howe, Science Counselor, Vol. 17, No. 2, June 1954 .

(1557) THERMAL CONDUCTIVITY OF POROUS MEDTA AS A FUNCTION OF FLUID SATURATION.

(b) Laboratory project.

(d) Experimental and theoretical, doctoral thesis.

(e) To obtain experimental confirmation of a theory of heat conduction in porous material which relates to the structure porosity of the material and the relative amounts of two different fluids contained in the pores. More camplete information may show that parameters determined by heat flow may have possible application to interpretation of borehole measurements and certain other applications. Thermal conductivities to be correlated with electrical conductivities.

(g) Experimental work completed: doctoral thesis and paper now in preparation. 
(1822) SHIP MOTION IN NON-UNIFORM AND SHORT-CRESTED WAVE STSTEMS.

(b) David Taylor Model Basin, Dept. of the Navy.

(d) Theoretical and experimental.

(e) To make theoretical studies of ship motion in wave systems and to compare the results with experimental data.

(h) "The Motion of a Floating Sphere in Surface Waves", R. C. MacCamy, Univ. of Calif., IER, Berkeley, Series 61, Is sue 4, Mar. 1954 .

"A Source Solution for Short-Crested Waves", R. C. MacCamy, Univ. of Calif., IER, Berkeley, Series 61, Issue 5, April 1954.

"The Oscillations of Ships in a Solitary wave", R. C. MacCamy, R. A. Leichs, O. Sibul, Univ. of Calif. IER, Berkeley, Series 61, Is sue 5, May 1954.

"The Motion of an L.C.I4. Underway in Waves", R. C. MacCamy, Univ. of Calif., IER, Berkeley, Series 61, Issue 7, June 1954.

(1823) THE MECHANICS OF BOTTOM SEDIMENT MOVEMENT WITH OSCILLATORY WAVES.

(b) Beach Erosion Board, Department of the Army.

(d) Experimental.

(e) To obtain experimental information on the criterion for initial and general movement of bottom sediment by wave action. Prototype conditions of the relative motion of water and bed were simulated by use of an oscillating plate in still water.

(1824) BEHAVTOR OF AIR ABOVE MECHANICAL OCEAN WAVE MODEL.

(b) Laboratory project.

(d) Experimental; basic research.

(e) Measurement of velocity distributions in air above a mechanical model of long-and-shortcrested ocean waves as a function of wind velocity, wave height and wave length. Drag forces as a function of distance from wave plane to a rigid ceiling determination.

(g) Preliminary model tested - being reinstalled.

(1825) WIND WAVES IN SHALLOW WATER.

(b) Beach Erosion Board, Department of the Army.

(d) Experimental.

(e) To obtain experimental information on the factors of wind velocity, wind duration, water depth, and bottom roughness as related to wave generation and wind tide produced in shallow water at limited extent. A glass-wall channel 70 feet long, 15 inches deep, and 12 inches wide has been constructed for this study.

(h) "Measurement of Water Surface Roughness and Wind Shear Stress by the Use of a Pilot Tube in a Laboratory Wave Channel", 0 . Sibul, Univ. of Calif., IER, Berkeley, Series 71 , Issue 2, Oct. 1954.

(1826) INVESIGATION OF UNSTEADY FLOW IN POROUS MEDIA BY MEANS OF A HELE-SHAW VISCOUS FLUID MODEL.

(b) Laboratory project.

(d) Experimental; basic research; for doctoral thesis.

(e) A Hele-Shaw apparatus, consisting essentially of an oil flowing through two closelyspaced glass plates, was constructed as a model analogy of flow in porous media. Steady flow measurements were used to calibrate the model. Unsteady flows, including sudden releases of oil into and out of the channel and damping of solitary sine waves, were studied by means of motion pictures.

(f) Completed.

(g) Sudden release flows were found to agree with earlier numerical solutions of unidirectional gas flow in porous media. The damping rate of sine waves was independent of both wave amplitude and period; whereas the damping distance was a function of the period but not of the amplitude.

(h) "Unsteady Flow in Porous Media by means of a Hele-Shaw Viscous Fluid Model", D. K. Todd, Trans. Amer. Geophysical Union (in press).

"Ground-Water Flow in Relation to a Flooding Stream", D. K. Todd (submitted for publication in Proc. Amer. Soc. of Civil Engineers). 
(1827) SIUDY OF SHOCK REFLECTION AND CHANNEL BLOCKAGE BY THE HYDRAULIC ANALOGY.

(b) Laboratory study.

(d) Experimental basic research.

(e) To study the behavior of shock reflection, channel blockage and wind-tunnel choking by the free-surface wave analogy. Cylinders and wedges are towed through still water in various channel widths.

(h) "A Study of Transonic Wind-Tunnel Wall Interference by the Hydraulic Analogy", George Lee, Master's Thesis, Oct. 1954.

(1829) SIUDY OF INCLINED GAS-LIQUID FLOW IN TUBES.

(b) Laboratory research project.

(d) Experimental and theoretical; basic research.

(e) Collection and correlation of data on several diameters of tubing at inclinations from horizontal to vertical.

(g) One inch diameter smooth tube data collected.

(1830) MEASUBEMENT OF THE DISTRIBUTION OF A GAS AND TWO LIQUIDS IN A POROUS MEDIUM BY X-RAY TECHNIQUES.

(b) Laboratory project.

(d) Experimental; applied research.

(e) Development of a calibration and measurement method for the distribution of three or more materials in a laboratory sample of sandstone.

(g) Apparatus tested.

(1831) SALT WATER INTEUSION PROJECT.

(b) California State Water Resources Board.

(d) Experimental; applied research.

(e) Development of basic information on sea water intrusion methods for its control.

(f) Corpleted.

(g) To prevent sea water intrusion the fresh water table must be held above sea level and some seaward leakage of fresh water will take place. Coastal injection wells cannot prevent intrusion unless they completely make up the local overdraft.

(h) "Basic Parameters of Salt Hater Intrusion and the Hydraulics of Injection Wells", report submitted to State Board of Water Resources, Sacramento, California.

"Final Report on $S_{e a}$ Water Intrusion", Sanitary Engineering Research Laboratory, Univ. of California, 1953.

(2057) PERFORMANCE OF THE PERIPHERY PUMP.

(b) Laboratory project.

(d) Experimental.

(e) Experimental investigation to determine the influence of clearance and other features on the performance of the turbulence pump.

(g) Laboratory investigation started.

(2058) STUDY OF EXCHANGE CHARACTERISTICS IN A TURBULENCE COLUMN.

(b) Laboratory project.

(d) Experimental.

(e) Exchange of various properties are studied and compared for various properties in a column with a reproducible turbulence pattern.

(g) The column is constructed. The measuring instrumentation is under development.

(2059) STUDY OF BED-LOAD MOTION IN A FLOW SUBJECTED TO COMPOSITE FRICTION.

(b) Laboratory project.

(d) Experimental.

(e) A granular bed is developed between a system of obstructions such as piles. It is attempted to determine the part of the flow resistance which determines the rate of sediment motion.

(g) The instrumentation is designed and under construction. 
(2060) ESTMMATING STREAMFLOW INTO A TIDAL ESTUARY FROM SALINITY MEASUREMENTS.

(b) Analytical study.

(d) Applied research; master's thesis.

(e) Continuous salinity records of water in Carquinez Strait are now available. These data, together with tidal data, enable estimates of discharge from the Sacramento-San Joaquin River system into San Francisco Bay to be made.

(g) Streamflow computations have been completed for two surmer months. Analysis of errors and methods of refining the method are under way. It is planned to compare the results with actual streamflow measurements recently completed by the California Division of Water Resources.

(2061) SHOCK WAVE FORMATION BY HYDROFOILS.

(b) Laboratory project.

(d) Theoretical and experimental.

(e) Limiting velocity on hydrofoils due to formation of a hydraulic pump at small submergence depths.

(g) Work continuing, -- photograph to be taken to show surface profile of hydraulic pump produced on a two-dimensional hydrofoil near the free-water surface of deep and shallow water.

(h) "Limiting Pressure on Hydrofoils at Small Submergence Depths", E. V. Laitone, Journ. of Applied Physics, Vol. 25, No. 5, May 1954.

(2062) STRESS-STRATN RELATIONSHIPS FOR SHEAR IN A SAND-WATER MIXTURE.

(b) Laboratory project.

(d) Experimental.

(e) The relationship is determined in an especially constructed rotating shear device for various normal pressures.

The results will be used to predict the behavior of a gramular stream bed subjected to high she ar by a flow.

(g) Preliminary results are obtained, calling for some improvement of the instrumentation.

(2063) METHODS OF IETECTING AND TRACING THE MOVEMENT OF GROUND WATER.

(b) U. S. Bureau of Reclamation.

(d) Experimental; doctoral thesis.

(e) In order to reduce seepage losses from canals, several methods have been suggested. Of the various geophysical methods, the electrical resistivity and earth potential methods have been most widely used in locating ground water; however, little has been done with them in tracing ground-water flows. The recent availability of radioisotopes has opened new fields of research in ground-water flow. It is anticipated that certain of these isotopes may be used effectively to study ground-water flow distributions, and to avoid density, absorption, and base exchange difficulties encountered in earlier studies employing dyes and salts.

(g) Initial phases of the research program include preparation of an abstract of literature, a review of methods and techniques indicating greatest possibilities of success, and design of appropriate materials and equipment.

UNIVERSTTY OF SOUTHERN CALIFORNIA, Research Foundation for Cross-Connection Control.

(49) RESEARCH FOUNDATION FOR CROSS-CONNECTION CONTROL.

(b) Laboratory project.

(c) Mr. Walter H. Albach, Research Engineer, Research Foundation for Cross-connection, University of Southern California.

(d) Experimental research and field investigations; basic research. 
(e) To determine by proper research the relative value and protection afforded by various backflow and back siphonage prevention devices.

(g) Establishment of standardized laboratory and field test procedures and minimum specification requirements for backflow prevention equipment and continuous evaluation and improvement of such procedures and specifications.

\section{CARREGIE INSTITUTE OF TECHNOLOGY, Department of Civil Engineering.}

Inquiries concerning Projects Nos. 1558, 1834, 1835, and 2064, should be addressed to Prof. F. T. Mavis, Carnegie Institute of Technology, Pittsburgh 13, $\mathrm{Pa}$.

(1558) CONVERGING AND DIVERGING STREAMS.

(b) Laboratory project.

(d) Theoretical and experinental; for undergraduate thesis.

(e) For converging streams, the depth after the junction is a function of the common depth before the junction and the ratio of the flows in each branch.

(g) Depths after a junction are smaller than the common depth before the junction; it is possible for the downstream depth to drop below the critical depth.

\section{(1834) AIR-WATER FLOW.}

(b) Laboratory project; J. Waldo Smith Fellowship of the American Society of Civil Engineers.

(d) Theoretical and experimental; for master's degree.

(e) An investigation to determine the amount of air that can be carried by flowing water. Experiments are conducted with free water jets and with air-water mixtures flowing in pipes at different slopes.

(h) "Air Entrainment in Jets and Pipes", R. E. Templeton, M. S. Thesis, Carnegie Institute of Technology, 1954.

(1835) MORNTNG-GLORY SPILLVAYS.

(b) Laboratory project.

(d) Theoretical and experimental; for undergraduate thesis.

(e) The design of a morning-glory spillway without negative pressures and other undesirable hydraulic characteristics is being studied.

(g) Pressures are measured on models shaped by conventional design methods. Depths, and velocities in the nappe are also measured.

(2064) VIRTUAL MASS.

(b) Laboratory project.

(d) Theoretical and experimental; for master's thesis.

(e) The virtual mass of partially submerged bodies is measured to determine their reaction to dynamic loads.

(h) "Virtual Mass of Partially Submerged Bodies", J. P. Murtha, M. S. Thesis, Carnegie Institute of Technology, 1954.

COLORADO A AND M COLLEGE, Department of Civil Engineering.

Inquiries concerning Projects Nos. 52, 538, 822, 828, 1074, 1076, 1313, 1314, 1318, 1565 to 1568, incl., 1570, 1839, 1839, 2066, 2070, and 2071, should be addressed to Dr. Maurice L. Albertson, Department of Civil Engineering, Colorado A and M College, Fort Collins, Colorado. 
(52) HYDRAULIC SAND SEPARATOR.

(b) Laboratory project.

(d) Experimental; applied research.

(e) To obtain data for design of hydraulic models, and to supply means of separating sand and gravel where a narrow size range is desired.

(f) Discontinued.

(g) An apparatus designed and built classifies sand according to fall velocity by a continuous flotation process. The process is purely dynamic in that sand is introduced directly into the flow. A check for duplication of results indicates that duplications within plus or minus one percent are obtained. Construction of a pilot apparatus is being completed to perform sand separation on a continuous basis of operation. Preliminary tests indicate satisfactory results.

(53) SAND TRAPS AND SLUICEWAYS.

(b) Agricultural Rese arch Service, Color ado Agricultural Experiment Station.

(c) Mr. R. L. Parshall and Mr. Carl Rohwer, Agricultural Research Service, Color ado A and M College, Fort Collins, Colorado.

(d) Basic research.

(e) To develop design data for sand traps useing vortex tubes, riffles, and deflectors alone, or in combination, and to perfect the design of sluiceways having a relatively flat grade which will effectively transport the bed load material from sand traps to a point of disposal.

(g) Several additional laboratory models were investigated. Some variations of riffle design and general arrangement were tried and the minimum velocity necessary to proride satisfactory action was studied. Some of the models were installed in actual canals and their prototype behavior is being observed. A general report on the work is being prepared.

(h) Trans. ASCE, Vol. 117 , p. 204.

(55) SNOW COURSE MEASUREMENTS AND FORECAST ANALYSIS.

(b) Soil and Water Conservation Research Branch, Colorado Agricultural Experiment Station, Bureau of Reclamation, State Engineer of New Mexico, and State Engineer of Wyoming.

(c) Mr. H. J. Stockwell, Soil and Water Conservation Research Branch, Colorado A and $M$ College, Fort Collins, Colorado.

(d) Field investigations; applied research.

(e) Systematic measurements of depths and water content of snow at high elevations in Colorado mountain areas for the purpose of forecasting the munoff of the principal rivers of the state in the interest of irrigation, power, domestic supplies, and other uses. The use of electrical resistance soil moisture units is being tested to determine a factor of soil moisture deficiency for water supply forecast purposes.

(g) Snow measurement data are correlated with munoff. Once the relationship is established, the snow measurement data are used to predict the runoff for the coming season.

(h) For 1954, Colorado Agricultural Experiment Station General Series Papers Nos. 557, 558, $559,567,568,569,573,574,575,577,578$ and 579. These are monthly snow survey reports for the Rio Grande, Colorado, and Platte-Arkansas Drainage Basin.

(287) PERFORMANCE OF WELL SCREENS.

(b) Color ado Agricultural Experiment Station, Agricultural Research Service, and various well screen manufacturers.

(c) Mr. C. H. Rohwer, Agricultural Research Service, Colorado A and M College, Fort Collins, Colorado.

(d) Experimental; applied research. 
(e) (1) Measurement of loss of head in different types of well screens for discharges suitable for each screen. (2) Determination of the size of opening in well screens, diameter of screen, thickness of gravel envelope, and size and gradation of sand or gravel for most effective control of flow of sands of different finenesses into the well with least loss of head. (3) Determination of the size of openings in well screens and diameter of screen for most efficient operation in natural sands and gravels of a given classification. An additional study is underway on the loss of head at interface of gravels of different sizes.

(g) Tests of gravel envelopes showed that the uniformity coefficient of the aquifer as well as the pack-aquifer size ratio was an important factor in controlling the movement of sand into wells.

(h) "Effect of Well Screens on Flow into Wells", Jack S. Petersen, Carl Rohwer, M. I. Albertson, ASCE Separate No. 365, Dec. 1953.

"Selection of Gravel"Pack for Wells in Fine, Uniform Unconsolidated Aquifers", John R. Lockman, Master's Thesis, Department of Civil Engr., Color ado A and M College, 1954. "Hydraulic Head Loss at the Interface between Uniform Sands of Different Sizes", Frank N. Leatherwood and Dean F. Peterson, Jr., Trans. Amer. Geophys. Union, Vol. 35, No. 4, Aug. 1954.

\section{(538) HYDRAULICS OF SPILLWAYS.}

(b) Laboratory project.

(d) Experimental; design and master's thesis.

(e) To obtain generalized design information for spillways having the shape of the underside of the nappe from a sharp crested weir. Generalized tests are being made to determine the shape of the nappe with various negative pressures under it. Ultimately, the discharge coefficient and the pressure distribution will be obtained for all practical degrees of submergence and ambient pressures. These data will permit the designer to determine in advance the necessary shape of a spillway crest if a certain negative pressure is desired for a given head on the crest.

(g) Using data reported by others, and data obtained in this laboratory, dimensionless design curves have been developed which permit solving directly for the design head, the discharge, the height of the spillway, or the shape of the spillway crest. Further data have been obtained which show the effect of downstream submergence on the discharge and the pressure distribution over the spillway. Data have also been obtained on the shape of the underside of the nappe from a sharp-crested weir for different negative pressures.

(h) "Nappe Characteristics for Flow Over Sharp Crested Weirs", Donald A. Thorson, Master's Thesis, Aug. 1953.

(820) THE STUDY OF SEEPAGE LOSSES FROM IRRIGATION CHANNELS.

(b) Agricultural Research Service, Bureau of Reclamation, Colorado Agricultural Experiment Station.

(c) Mr. A. R. Robinson, Agricultural Research Service, Colorado A and M College, Fort Collins, Color ado.

(d) Experimental and field investigation; applied research.

(e) To study the factors influencing seepage from irrigation channels and to perfect methods for making pre-investigations of seepage for the purpose of determining the seepage from existing canals, and predicting the seepage from proposed canals. Methods of measuring seepage were evaluated to determine the limitations and advantages of each. The effect of depth to ground water as well as effect of temperature on the seepage rate was also investigated.

(P) Active but in final stages.

(g) A report is in progress describing the results of the experiments. Several methods of measuring seepage were evaluated and the relative merits of each method were determined. The seepage rate was found to decrease as the ground water approached the ground surface. In some cases, the seepage rate was found to vary inversely as the temperature of the water.

(h) Final report in progress. 
(b) Colorado $A$ and $M$ Experiment Station.

(c) Mr. W. E. Code, Color ado A and M College, Fort Collins, Color ado.

(d) Field investigation; applied research.

(e) This is a continuing project in wich semi-annual measurements are made in about 240 observation wells. The data so gathered provides information on the impact of pumping or of replenishment factors. Some indication of the magnitude of pumping is gained from the compilation of the amount of electrical energy being used. Part of the data is being gathered by the U. S. Geological survey.

(g) The results of this work have served to outline the areas where pumping is causing a definite continuing decline in the water table. Similarly, those areas have become known that are reasonably certain of recovery under intensive pumping draught of a few years duration.

(h) Reports are included in U. S. Geological Survey Water Supply Papers.

(822) DIFFUSTON OF HEAT, VAPOR, AND MOMENTUM.

(b) Cooperative with Office of $\mathrm{Naval}$ Research, Department of the Navy.

(d) Experimental; basie research.

(e) A controlled study in a wind tunnel of the fundamental principles describing the process of diffusion of $v$ apor, heat and momentum from various surfaces. Eventually it is intended to use the fundamental information to aid in determining evaporation from free surfaces, land areas with various soil and crop covers, and plant surfaces, and heat and moisture losses from animals.

(g) A non-dirensional parameter containing the rate of evaporation is found to be a unique function of the Reynolds number in terms of shear velocity at the end of the evaporation surface. The results so presented are independent of the length of dry approach, and the regime of boundary layer flow. Sutton and Koehler-Iih solutions are found to yield identical vapor profiles, a theoretical curve for the rate of evaporation is calculated on the basis of sutton's theory of turbulent exchange as modified by Pasquill. This curve follows the data closely.

(h) "Vapor Transfer by Forced Convection from a Smooth Plane Boundary", J. E. Cermak and P. N. Lin, Colorado A and M College, Report No. 9, Jan. 1954.

(828) INFLUENCE OF SHAPE ON THE FALL VELOCITY OF SEDMENT PARTIGLS.

(f) Completed.

(h) "Influence of Shape on the Fall Velocity of sedimentary Particles", E. F. Schulz, R. H. Wilde, and M. L. Albertson, Corps of Engineers, P. O. Box 1216, Omaha 1, Nebraska, Missouri River Division Sediment Series No. 5, July 1954.

(1074) HYDRAILICS OF STIIITNG BASTNS.

(b) Laboratory and field project.

(d) Experimental; for design and master's thesis.

(e) To obtain generalized design information for stilling basins utilizing a scour hole created by a jet of water as well as stilling basins utllizing the hydraulic jump together with chute blocks, floor blocks, and sills.

(g) Studies have been completed using circular jets and two-dimensional jets. The variables considered were the depth of the pool, the fall velocity of the erodable material, the size of the jet, and the velocity of the jet. Results show that the depth and rate of scour depend upon the depth of water in the stilling basin, the size and velocity of the jet, and the size and gradation of the bed material. Studies are now being conducted to determine the influence of size gradation and the sorting of the finer materials which leaves the coarser materials as armor plating to protect the hole from further scour.

(1076) INVESTIGATION OF THE ECONOMICS AND PRACTICABILITY OF SPRINKILR IRRTGATION IN COLORADO.

(f) Compleţrí.

(h) When to Use Sprinkler Irmigation in Colorado", W. E. Code and A. J. Hamman, Colorado A and $M$ College Bulletin $405-A$, June 1950. 


\section{(1313) HYDRAULICS OF ALLUVIAL CHANNELS.}

(b) Laboratory project and Missouri River Division, Corps of Engineers, Dept. of the Army.

(d) Experimental and theoretical; basic research and design; for masters' and doctors' theses.

(e) A part of the laboratory study on the roughness of alluvial channels has been completed. Thirty runs were made in a variable slope flume $70 \mathrm{ft}$. long and $4 \mathrm{ft}$. wide. The following measurements were made for each mun: (1) water discharge, (2) total sediment discharge, (3) slope of water surface, (4) suspended sediment load, (5) velocity distribution, (6) average length and height of dunes, (7) depth of flow, (8) miscellaneous such as temperature, etc. The flume is now being extended to a length of $150 \mathrm{ft}$.

(g) The variation of Chezy's resistance coefficient with Reynolds number shows that for a given size of bed material relative to depth of flow the bed is plane and smooth at a low Reynolds number. but ripples and random dunes develop to create a maximum resistance as Rejnolds number increases. As Reynolds number increases still farther, the dunes increase in height and spacing (and become more uniform in shape and spacing) but the resistance decreases until the bed becomes plane and rough prior to development of antidunes at highest Reynolds numbers.

(h) Report on channel roughness for the Corps of Engineers is now in preparation. "Some Aspects of Roughness in Alluvial Channels", S. M. Ali and M. L. Albertson, submitted to AGU for publication.

\section{(1314) LAKE HEFNER MODEL SIUDY.}

(b) Bureau of Ships, Department of the Navy, and the U.S. Geological Survey.

(d) Experimental; basic and applied research.

(f) Completed.

(g) In the case of flat surrounding terrain, Reynolds analogy was found to be a promising means of estimating prototype evaporation. It was also found that the same relationship between the wind velocity at the 52.5 foot level and the shear velocity existed in both the prototype and the model.

(h) "Lake Hefner Model Studies of Wind Structure and Evaporation, Final Report, Part I", J. E. Cermak and H. J. Koloseus, Colorado $A$ and $M$ College, Department of Civil Engineering Report No. $54 \mathrm{dEC} 20$, Nov. 1953.

"Lake Hefner Model Studies of Wind Structure and Evaporation, Final Report, Part II", J. E. Cermak and H. J. Koloseus, Color ado $A$ and $M$ College, Department of Civil Engineering Report No. $54 \mathrm{JEC} 22,1954$.

(1318) REYNOLDS NUMBER FOR FLOW THROUGH SANDS AND GRAVELS.

(b) Laboratory project.

(c) Prof. D. F. Peterson, Colorado A and M College, Fort Collins, Colorado.

(d) Experimental; basic research for masters' and doctors' theses.

(e) The characteristics of porosity, particle shapes and size gradation of particles are not specifically considered in the usual equations of flow through porous materials. These fundamental characteristics are introduced into the equations of flow resulting in a standard Reynolds number.

(f) Completed.

(g) Beginning with the Hagen-Poisseuille-equations the more fundamental media characteristics of porosity, particle shape, and characteristic pore length are introduced theoretically to give $\quad v=\left(2 g_{\rho} d_{e}^{2} / c_{s} \mu\right)\left(n^{3} /(n-1)^{2}\right)(h / L)$, where $V$ is the bulk velocity, $C_{s}$ is a particle shape factor, $d_{e}$ is an effective particle diameter, $\mathrm{n}$ is the porosity, $\mathrm{h}$ is the piezometric head, $\mathrm{L}$ is the length of flow and $\rho, g$, and $\mu$ are the fluid density, acceleration of gravity and viscosity respectively. Experimentation verified the theoretical effect of porosity and showed $\mathrm{C}_{\mathrm{S}}$ to $\mathrm{vary}$ from 350 for spherical particles to 680 for micaceous river sands. An effective diameter for graded sands of $\sum P / \angle(P / D)$ where $P$ is the percentage between any two sieve sizes and $d$ is the mean diameter between those sizes was shown to give correct results. 
(1565) SEDIMENT CARRIING CAPACITY OF CLOSED CONEUITS.

(b) Armco Drainage and Metal Products, Inc., Middletown, Ohio, and Research Corporation, Santa Monica, California.

(d) Experimental and theoretical; basic research.

(e) To determine suspended load capacity of 12-inch diameter corrugated Helcor, and smooth pipes carrying sand and flowing full. To determine effect of boundary form on sand transport capacity. To develop design criteria for pipelines carrying sediment. Graded sediments are being used, with mean size from 0.1 to $0.8 \mathrm{~mm}$. Testing with $0.2 \mathrm{~mm}$ sand has been completed.

(1566) DIFHUSION OF GASES INTO AN AIR STREAM HAVING VARIOUS TEGREES OF STABIIITY.

(b) Air Force Cambridge Research Center, 230 Albany Street, Cambridge 39, Mass.

(d) Experimental and theoretical; basic research.

(e) By means of a horizontal, heated, metal plate placed in the floor of a wind tunnel, the effect of various artificially created lapse rates upon mean velocity profiles and turbulence structures is being investigated. Also the effect of lapse rates upon the diffusion of gases from a point source and a line source will be studied. In addition, simultaneous measurements of evaporation, boundary shear, and heat transfer will be conducted for a range of lapse rates.

(1567) BEHAVIOR OF SEAPLANE KULLS IN SIMPLE SEAS.

(b) Bureau of Aeronautics, Department of the Navy.

(d) Experimental.

(e) The behavior of model seaplane hulls when towed at different angles to a wave train has been studied experimentally. The model motions have been obtained from motion picture films made of the tests. In addition an electrical method for measuring these motions has been used.

(h) "Development of a Basin for Investigation of the Seaworthiness of Model Seaplane Hulls", E. F. Schulz, Colorado A and M College, Department of Civil Engineering Report No. 5LEFS11, 40 p., March 1954. "Tests of the Seaworthiness of Seaplane Hulls Having a High Length to Beam Ratio", E. F. Schulz, Colorado A and M College, Department of Civil Engineering Report No. 5LEFS12, 40 p., May 1954. (These reports may be obtained from the Navy Department, Bureau of Aeronautics).

"Equipment for Testing Model Ship and Seaplane Hulls in Oblique Seas", E. F. Schulz, Proceedings Conference of Ships and Waves, 1954.

(1568) BOUNDARY SHEAR IN OPEN CHANNELS.

(b) Laboratory project.

(d) Experimental; for J. Waldo Smith Fellowship of the A.S.C.E.

(e) To supply experimental data on the shear distribution along the boundary of open channels. This information is needed in connection with the new theory conceived by $\mathrm{E}$. W. Lane on the design of stable alluvial channels. The shear will be measured instead of calculated from other hydraulic measurements.

(g) The shear measuring device has been constructed and installed in the flume and shear measurements are now in progress.

(1570) DEVELOPMENT OF A CONSTANT FORCE BOTTOM FOR SEAPLANE HULLS.

(f) Completed.

(h) "Development of a Constant-Force Bottom Contour for Seaplane Hulls", E. F. Schulz, Colorado $A$ and $M$ College, Department of Civil Engineering Report No. 5LEFS31, 49 p. Nov. 1954. (Available from Department of the Navy, Bureau of Aeronautics.) 
(1836) EFFECT OF CANAL WATER DEPTH AND DEPTH TO WATER TABIE ON SEEPAGE FROM AN IDEALIZED CANAL.

(b) L aboratory project.

(c) Prof. D.F. Peterson, Jr., Colorado A and College, Fort Collins, Colorado.

(d) Experimental, master's theses.

(e) Study of seepage from an idealized canal to a shallow water table using sand models and electric analogue.

(g) Sand model studies to date indicate that in an isotropic media of unlimited breadth and depth, seepage to a shallow water table consists of the sum of two parts. The first part varies linearly with depth to the water table at a specified distance from the canal and the second part varies linearly with water depth in the cangl. The portion of seepage described first varies with $B .3$ and the remainder with $B .5$, where $B$ is the water surface width of the canal. Studies are being started for the cases of impermeable boundaries at finite depths using the electrical anelogue.

(h) Model Study of seepage Flow", S. Karaki, M. S. Thesis, 1954, Colorado A and M College Library.

(1837) SEDTENT LININGS FOR CANALS AND RESERVOIRS.

(b) U. S. Bureau of Reclamation, Colorado Agricultural Experiment Station, and various bentonite producers.

(c) Mr. R. D. Dirmeyer, Jr., Department of Civil Engineering Colorado A and M College, Fort Collins, Colorado.

(d) Experimental and field investigation; applied research.

(e) To develop a truly low-cost canal and reservoir lining method -- sediment linings. Briefly, sediment lining is a process involving the use of canal or reservoir water for the placement of an impervious filler or binder into the pervious or unstable materials of the canal or reservoir bed.

(h) Monthly progress reports obtainable upon request.

(1838) BEHAVIOR OF MODEL SHIP HULLS IN AN OBLIQUE SEA.

(b) David Taylor Model Basin through the office of Naval Research, Department of the Navy.

(d) Experimental.

(e) This investigation will yield information regarding the magnitude of the amplitude response operations for the motions of heave, pitch and roll of a model when towed at different angles to the wave front.

(h) "Development of a Facility for Testing the Performance of ship Hulls in Oblique Seas", E. F. Schulz, Colorado A and M College, Department of Civil Engineering Report No. 5LEFSIO, 39 p., March 1954. (This report can be obtained fran David Taylor Model Basin, Department of the Navy).

"Equipment for Testing Model Sinip and Seaplane Hulls in Oblique Seas", E. F. Schulz, Proceedings, Conference on Ships and Waves, 1954.

(1839) INVESTIGATION OF PEGTME THEORY OF SELF FOPRED GHAMELS.

(b) Cooperative project sponsored by Colorado A and M College, U. S. Engineers, U. S. Geological Survey, U. S. Bureau of Reclamation.

(c) Mr. D. B. Simons, University of Wyoming, Laramie, Wyoning.

(d) Field investigation; basic research.

(e) This is an investigation of regime channels to conditions related to channel stability. The fleld data being collected from selected straight reaches of canals having a reasonably steady discharge include the following: (1) slope of energy gradient, (2) Velocity profiles, (3) Discharge, (4) Shape of channel, (5) suspended sediment load, (6) Total sediment load when possible, (7) Samples of bed material, (8) Samples of side material, (9) Dune and ripple formations on the bed, (10) Temperature of water, and (11) Photographs of the reaches investigated for both empty and full supply conditions. The primary purpose of the study is to obtain information that will assist in establishing a more precise theory applicable to the design of stable channels in alluvium. The data collected should also be useful in the investigation of other related open channel problems. Field data has been collected and are currently being analyzed. 
(2065) FARM IRRIGATION STRUCTURES.

(b) Colorado A and M Experiment Station Field and Laboratory project.

(c) Mr. W. E. Code, Colorado A and M College, Fort Collins, Colorado.

(d) The project is principally a field investigation consisting of study of and experimentation with design, materials and methods of constructing farm irrigation structures.

(e) The purpose of this project is to develop better functional and hydraulic designs for hydraulic structures used in farm irrigation systems. Through purposeful observation and experimentation, it is hoped that ideas can be developed and passed on to farmers for building better and more efficient farm irrigation systems at the least cost.

(g) Work with concrete blocks of various materials gives promise of easily built checks, turnouts, and Parshall measuring flumes.

(h) A manuscript for a bulletin on the subject has been prepared.

(2066) STUDY OF OPEN CHANNEL CONSTRICTIONS IN A SLOPING FLUME.

(b) U. S. Bureau of Public Roads.

(d) Experimental; applied research.

(e) Models of spill-through and wing-wall bridge abutments are being studied in a rectangular variable slope flume having a variable width of 4 feet to 8 feet. Several degrees of constriction are being used with one bed roughness. Measurements are being made to determine backwater effect of the abutments. Objective of investigation is to obtain design criteria for prototype structures.

(2067) MODEL STUDY OF A TILE INTERCEPTOR DRATN.

(b) Agricultural Research Service, Colorado Agri. Experiment Station.

(c) Mr. A. R. Robinsen, Agricultural Research Service, Colorado A and M College, Fort Collins, Colorado.

(d) Experimental; applied research; for design and master's thesis.

(e) (1) Stucy the shape of the water table drawdown curve resulting from an interceptor drain installed in an area above an impermeable layer. (2) Determine the characteristics of drains placed at different levels above the barrier layer. (3) check the results of the model study by means of an electrical analogue.

(g) Project is in the initial phase and no results have been obtained.

(2068) A STUDY OF THE CHANNEL FORM OF NATURAL STREAMS IN ERODIBLE MATERIAL.

(b) U. S. Engineers, Department of the Army.

(c) Mr. E. W. Lane, Colorado A and M College, Fort Collins, Colorado.

(d) Field and library investigation and of fice computation, basic research.

(e) This project is an attempt to clarify and systematize the knowledge of the forms which natural streams assume when flowing in erodible material, in order to be able to predict the changes which will occur when these conditions are changed by the works of man. From a study of the conditions under which the various forms occur, it is hoped to determine the reasons for these formations and the quantitative relations between the various shapes and the factors causing them.

(2069) A COMPARISON OF IRRIGATION CANALS DESTGNED BY REGIME THEORY METHODS WTTH THOSE OBTAINED BY DESIGN METHODS RECENTLY DEVELOPED IN THE UNITED STATES.

(b) Laboratory project.

(c) Mr. E. W. Lane, Colorado A and M College, Fort Collins, Colorado.

(d) Office computation, applied research

(e) A comparison is being made of the cross sections for irrigation canals for a wide variety of conditions computed by various regime theory methods and the methods recently developed by the U. S. Bureau of Reclamation, to determine the extent of agreement on divergence of the results obtained by these methods. Study project for master's thesis. 
(2070) ROUGHNESS IN OPEN CHANDELS.

(b) Laboratory project.

(d) Experimental; basic research for master's and doctor's theses.

(e) Project intended to determine the fundamental aspects of roughness in open channels. Different types of roughness are being studied to determine their influence on the resulting velocity distribution resistance coefficient, and depth and pattern of flow.

(g) Certain results have been reported in previous issues of this publication. At present cooperating on project reported under Rocky Mountain Hydraulics Laboratory.

(2071) MANTFOLD DIFFUSER STILLING BASIN.

(b) Larimer and Weld Irrigation company.

(d) Experimental, laboratory and field study, applied research.

(e) To develop an economical structure to dissipate the energy of high-velocity flow econonically and in a small space.

(f) Completed.

(g) A box manifold was developed with sloping bottom and cross bars spaced across the horizontal open top. Water enters at $30 \mathrm{fps.,}$ dissipates its energy as the two-dinensional jets move vertically upward, and comes to the pool surface at about $4 \mathrm{fps}$. No bank rip rap is needed and cost is about one-fifth that of a standard stilling basin.

(h) Report in preparation.

UNIVERSITY OF COLORADO, Hydraulics Laboratory, Department of Civil Engineering.

Inquiries concerning Projects Nos. 1321 and 2072 should be addressed to Prof. Warren DeLapp, University of Colorado, Boulder, Colorado.

(1321) HYDRAULIC JUMP IN OPEN CHAMNEL TRANSITIONS.

(b) Laboratory project.

(d) Experimental; for design and master's thesis.

(e) Profile of hydraulic jump is being studied in rectangular channel contractions with various central angles.

(2072) FPEQUENCY CURVES OF FLOW IN COLORADO STPEAMS.

(b) Laboratory project.

(d) Analytical; for design and master's thesis.

(e) Data for all Colorado stream stations with more than thirty years of record are being studied to determine the frequency of moderate flood peaks.

COLUIBIA UNIVERSTTY, Fluid Mechanics Laboratory, Department of Civil Engineering.

(62) TYDRAULIC STRUCTURES.

(b) Laboratory project.

(c) Mr. J. W. Delleur, Department of Civil Engineering and Engineering Mecharics, Columbia Tniversity, New York 27, N. Y.

(d) Experimental and theoretical; doctoral thesis.

(e) The growth of the boundary layer in the intake reach of an open channel is studied theoretically and in a rectangular chamel in the laboratory.

(g) Ire boundaxy layer in horizontal open channel develops more slowly than for comparable conditions on a flat plate in an infinite fluid. Experiments also indicate an influence of secondary motion on the velocity distribution across the channel. 
(290) HYDRAULICS OF SHORT OUTLETS IN BODIES OF DAMS.

(b) Laboratory project.

(c) Prof. H. R. Henry, Department of Civil Engineering, Michigan State College, East Lansing, Michigan.

(d) Experimental and theoretical; doctoral thesis.

(e) An investigation of boundary layer development in short conduits. Pressure and velocity distributions are measured along the pipe and entrance section.

(1324) LOSSES IN TWO-DIMENSTONAL JUNCTIONS.

(b) Laboratory project.

(c) Mr. S. T. Tsakonas, Department of Civil Engineering and Engineering Mechamics, Columbia University, New York 27, N. Y.

(d) Theoretical and experimental; doctoral thesis.

(e) A study of flow patterns at junctions in rectangular conduits which can be considered two dimensional with particular attention to the influence of initial velocity distribution on the characteristics of the side jet.

UNIVERSITY OF CONNECTICUT, HYdraulic Research Laboratory, Department of Civil Engineering.

(1078) HYDROLOGIC FACTORS INFLUENCING RAINFALL-RUNOFF RELATIONSHIPS ON SMALI, WATERSHEDS IN EASTERN CONNECTICUT.

(b) Laboratory project.

(c) Prof. K. C. Tippy, Box U-37, University of Connecticut, Storrs, Conn.

(d) Field investigation; applied research.

(e) Rainfall and runoff measurements are being taken on small watersheds varying in size from 4 to 400 acres.

(1079) STUDY OF WIND EFFECTS ON STRUCTURES.

(b) Laboratory project.

(c) Mr. A. L. Mirsky, Box U-37, University of Connecticut, Storrs, Conn.

(d) Experimental; applied research.

(e) A study of wind action and flow on the roofs of various types of buildings and structures is to be conducted in a small wind tunnel.

(1080) STUDY OF HYDRAULIC DESIGN OF CURB INLETS.

(b) Laboratory project; State Highway Department.

(c) Prof. V. Scottron, Box U-37, University of Connecticut, Storrs, Conn.

(d) Experimental; for design.

(e) Tests are under way on influence of plan form of parallel bar gratings on hydraulic capacity. This is being coordinated with field tests on full-sized gratings.

(g) A report has been issued to the Connecticut Highway Department on the design of parallel bar gratings. This is being abstracted for distribution.

(2073) A STUDY OF SIEE FLOW INTO GUTTERS AND CHANNELS.

(b) Laboratory project.

(c) Prof. V. E. Scottron, Box U-37, University of Connecticut, Storrs, Connecticut.

(d) Experimental and analytical.

(e) Work is being started on the hydraulics of rectangular channels with sloping bottoms and uniformly entering side flow. 
UNIVERSITI OF CONNECTICUT, Soil Mechanics Laboratory, Department of Civil Engineering.

Inquiries concerning Projects Nos. 1574, 1575, and 1577, should be addressed to Prof. Edward V. Gant, Box U-37, University of Connecticut, Storrs, Conn.

(1574) VARIATION IN AMOUNT OF FROST HEAVE WITH DEPTH OF GRONND WATER TABLE.

(b) Laboratory project; State Highway Department.

(d) Experimental; applied research.

(e) Investigation is under way on a series of 12 tests cells, 6 containing silt and 6 glacial till at depths from $21 / 2$ to $6 \mathrm{ft}$. Observations taken on heave, depth-temperature variation, and water consumed from water table.

(h) "A Study of the Effect of Depth of Water Table on Frost Action in Soils", R. J. Leonard, Master's Thesis, University of Connecticut, 1954 .

(1575) EFFECT OF WASHED CONCRETE SAND IN INCREASING CAPILLARY RISE AND FROST HEAVING IN ADJACENT SOIL.

(b) Laboratory project; State Highway Department.

(d) Theoretical and experimental; applied research.

(e) Investigations are being made of the effect of washed concrete sand in raising the ground water table in adjacent silt or glacial till,

(h) "The Effect of Concrete Sand on Capillarity in a Parent Material", E. S. Budzik, Master's Thesis, University of Connecticut, 1953.

(1577) FIITER TESTS OF VARIOUS MATERIALS.

(b) Laboratory project; State Highway Department.

(d) Experimental; applied research.

(e) Factors affecting the stability of filters are being studied.

(h) "Some Aspects of Filter Action in Highway Underdrains", E. R. Phelisse, Master's Thesis, University of Connecticut,1954.

CORNELL UNIVERSITY, School of Civil Engineering.

Inquiries concerning Projects Nos. 1841, 1843, 1846 to 1848, incl., and 2074, 2075, and 2076 should be addressed to Prof. Andre L. Jorissen, Head, Department of Hydraulics and Hydraulic Engineering, School of Civil Engineering, Lincoln Hall, Cornell University, Ithaca, New Iork.

(1841) STUDY OF VENTURI TUBE CHARACTERISTICS.

(b) Builders-Providence, Inc., laboratory project.

(d) Experimental.

(e) Study of effect on Venturi tube coefficient of discharge of such factors as pressure taps loation, downstream throttling, mismatch between inlet pipe and Venturi.

(1843) VENTURI TUBE AND NOZZTE CALIBRATIONS.

(b) Builders-Providence, Inc.

(d) Experimental.

(e) The following are being calibrated; One $1^{n} \times 3^{n}$ Venturi tube, one $4^{n} \times 1.9^{n}$ nozzle, two $1^{n} \times 0.6^{\prime \prime}$ Venturi tubes, two $2^{n} \times 1.1^{n}$ Venturi tubes, two $3^{n} \times 1.8 "$ venturi tubes, two $5^{\prime \prime} \times 3.3^{\prime \prime}$ Venturi tubes and one $12^{\prime \prime} \times 4.5^{\prime \prime}$ Venturi tube. 
(18L6) CHECK VALVS TESTS.

(b) Williams Gauge Co., Pittsburgh, $\mathrm{Pa}$.

(d) Experimental.

(e) Tests on 5" $\mathrm{x} 14$ " check valves to determine pressure losses.

(f) Completed.

(1847) STUDY OF FLOAT-TYPE, VARIABLE AREA FLOW METERS.

(b) Fischer and Porter Co., Hatboro, $\mathrm{Pa}$. laboratory project.

(d) Theoretical and experimental.

(e) Study of effect of body length - diameter ratio.

(h) "Coefficients of Float-Type, Variable-Area Flow Meters", by V. P. Head. Discussion by A. I. Jorissen, Trans. A.S.M.E., August 1954 .

(1848) MOIEL SIUDY OF CORNELL UNIVERSITY ROWTNG TANK.

(b) Department of Buildings and Grounds, Cornell University.

(d) Experimental.

(e) Model study of flow conditions in rowing tank in order to obtain smooth flow conditions at desired velocity.

(f) Completed.

(1849) PUMP CAVITATION.

(b) Goulds Pumps, Inc., Seneca Falls, N. Y., laboratory project.

(c) Prof. Marvin Bogema, School of Civil Engineering, Cornell University, Ithaca, N. Y.

(d) Experimental.

(e) Determination of required net positive suction head when pumping hot water. Equipment permits wide variation in water temperature and suction head.

(2074) EFFECT OF INSTALLATION ON PERFORMANCE OF INFERENTIAL FLOW MELERS.

(b) Builders-Providence, Inc., laboratory project.

(d) Experimental.

(e) Study of effect of 2 short-radius elbows in orthogonal planes on coefficient of discharge of Venturi Tubes, Gentile Flow Tubes and Dall Flow Tubes. Effect of straightening vanes.

(2075) EXPANSION COEFFICIENTS FOR DALI FLOW TUBES.

(b) Builders-Providence, Inc., laboratory project.

(d) Experimental.

(e) Determination of expansion coefficients for Dall Flow Tubes measuring a compressible fluid (air).

(2076) 20" FLOW CONTROLLER TESTS.

(b) Builders-Providence, Inc.

(d) Experimental.

(e) Study of 20 " RCB flow controller: determination of head losses and discharge coefficients with different types of vanes.

(f) Completed. 
GEORGIA INSTITUTE OF TECHNOLOGY, School of Civil Engineering.

Inquiries concerning Projects Nos. 291, 1584, 1851, 1852, 1854, 1855, 1856, 2078, and 2079, should be addressed to Prof. C. E. Kindsvater, School of Engineering, Georgia Institute of Technology, Atlanta, $\mathrm{Ga}$.

(291) FLOW OF WATER OVER HIGHWY EMBANKMENTS.

(b) Laboratory project; currently sponsored by the American Society of Civil Engineers (J. Waldo Smith Fellowship).

(d) Experimental; research for master's thesis.

(e) Comprehensive tests on a 1:6-scale model and preliminary tests on a 1:12-scale model of a typical highway embankment section have been completed. Variables include roughness and shape of crown, slope and height of embankment. Data includes discharge calibration, water-surface profiles, and tailwater levels corresponding to (1) free flow, (2) incipient submergence, (3) lower limit of surface flow, (4) upper limit of plunging flow, and (5) submerged flow.

(f) Reactivated 1954 .

(1331) THE DIFFUSION MECHANISM OF FOREIGN PARTICLES IN A FLUID.

(b) Laboratory project.

(c) Mr. M. R. Carstens, School of Civil Engineering, Georgia Institute of Technology, Atlanta, Georgia.

(d) Experimental; basic research.

(e) The diffusion of macroscopic foreign particles is being studied in a vertical diffusion chamber. The turbulence within the column is uniform. The turbulence amplitude and frequency are controlled. The diffusion characteristics of spherical glass beads are being studied in the water-filled column.

(1584) FLOW OF WATER OVER WEIRS AND SPILLWAYS.

(b) Water Resources Division, Surface Water Branch, U. S. Geological Survey.

(d) Library search, re-analysis and correlation of published data, plus original research as required.

(e) A comprehensive study of the discharge characteristics of practical forms of weirs and spillways. Initial phase includes the preparation of bibliography and the collection of experimental data from all known sources. Objectives include the publication, in generalized form, of available experimental data and the preparation of a list of research problems.

(1851) EFFICIENCY OF HYDRAULIC TURBINE DRAFT TUBES.

(b) S. Morgan Smith Company, York, $\mathrm{Pa}$.

(d) Experimental; for design.

(e) Transparent plastic models of several different draft-tube designs were tested. Drafttube performance was evaluated on the basis of hydraulic efficiency. Test variables included a full range of artificially-produced discharge whirls and a limited variety of boundary modifications for each model.

(f) Completed.

(1852) DISCHARCE CHARACTERISTICS OF RECTANGULAR PLATE WEIRS IN RECTANGULAR CHANNELS.

(b) Laboratory project.

(d) Experimental and analytical; research for two master's theses.

(e) An investigation of the comprehensive discharge characteristics of the basic sharp-edged, rectangular-notch weir. An attempt to evaluate by experimental means the influence of the several variables excluded by restrictions on the standard weir formulas. Tests cover a full range of notch widths, weir heights, and heads. Investigation limited to free flows of water at normal temperatures.

(f) Research for one thesis complete. Additional tests will be made in a wider flume. 
(1854) TNFLUENCE OF BOUNDARY ROUGENESS ON ABRUPT ERLARGEMENTS IN ENCLOSED CONDUITS.

(b) Laboratory project, partially supported by the J. S. Ceological Survey.

(d) Expcrimental; for master's thesis.

(e) An experimental investigation of the influence of boundary roughness on the total energy loss due to abrupt area-enlargements in circuiar concuits. Variables include discharge, expansion ratio and roughness. Test data will include piezometric profiles and velocitydistribution curves.

(f) Work on one thesis scheduled for completion in Winter Quarter 1954.

(1855) TRANQUIL FLOW THROUGH SEVERAL OPENTNGS IN AN OPEN-CHANNEL WIDTH CONSTRICTION.

(b) Water Resources Division, Surface Water Branch, U. S. Geological Survey.

(d) Experimental; basic research.

(e) A preliminary objective will be to establish principles of flow division at a multiopening width constriction. A 14-foot wide by B0-foot long flume will be used in the experimental investigation. Channel shape, degree and pativern of boundary roughness and constriction geometries will be varied. Boundary conditions considered will be governed by highway bridge practice.

\section{(1856) DISCHARGE CHARACTERISIICS OF CULVERTS.}

(b) Water Resources Division, Surface Water Branch, U. S. Geological Survey.

(d) Analysis and correlation of published data, plus original research as required.

(e) A study of the discharge characteristics of culverts. The study will be limited to culvert shapes which are common in modern highway practice. Criteria for distinguishing between full (pressure) flow and sluice (open-channel) flow based on length, roughness, bed slope, head, submergence, and entrance geometry are sought.

(1857) REGIMES OF FLOW IN AN OPEN CHANNEL WITH A NON-PECTANGULAR CROSS SECTION.

(b) Laboratory project.

(c) Mr. M. R. Carstens, School of Civil Engineering, Georgia-Institute of Technology, Atlanta, Georgia.

(d) Theoretical and experimental; research for master's theses.

(e) A detailed analysis of the transition from subcritical flow to supercritical flow in an open channel with a non-rectangular cross section. The channel walls are parellel. In cross section, the bottom has uniform slope. Velocity traverses and water surface elevation determinations are made upstream and downstream from a stationary finite gxavity wave. Experiments have been performed with both the stationary breaking wave (hydraulic jump) and with the non-breaking wave.

(f) Research for two theses is complete.

\section{(2077) UNSTEADY FLOW IN SMOOTH PIPES.}

(b) Laboratory project; sponsored by the National Science Foundation.

(c) Mr. M. R. Carstens, School of Civil Engineering, Georgia Institute of Technology, Atlanta, Georgia.

(d) Experimental; basic research for three master's theses.

(e) The mean flow characteristics in a pipe line during the time flow is being established will be studied experimentally. The flow will be from a quiescent reservoir, through a rounded inlet, and thence through a straight, smooth pipe. Flow is to be established by instantaneously opening a downstream valve. Pressure-time and velocity-time measurements will permit calculations for shear which are to be compared with steady-state shear values. Particular attention is to be given to the transition from laminar to turbulent flow. 
(2078) INFLUENCE OF SEVRAL CEOMETRIC VARIABIES ON THE EFFICIENCY OF TWO MOIERN DRAFT TUBES.

(b) Research for master's thesis, partially supported by the S. Morgan Smith Company,

(d) Experimental.

(e) The object of this investigation was to determine the relative influence of several critical geometric variables on the hydraulic efficiency of a quarter-turn, elbow draft tube. Indentical test programs, involving systematic variations in certain boundary characteristics, were carried out on two basic draft-tube designs. The efficiency of the tubes as hydraulic diffusors was used as the principal criterion of performance.

(f) One master's thesis completed (J. Jones, 1954).

(2079) SURVEY OF THE LITERATURE ON DIFFUSERS.

(b) Laboratory project.

(d) Analytical; for master's thesis.

(e) The literature of diffusers through May 1954 was reviewed and abstracted. The literature review was restricted to circular and two-dimensional diffusers with smooth, straight walls. From the published velocity distributions the values of the kinetic energy correction coefficients were calculated. The value of the kinetic energy correction coefficient at the diffuser outlet and the energy efficiency were graphically presented as functions of the Reynolds number, kinetic energy correction coefficient at the inlet, area ratio, and the divergence angle.

(f) One thesis completed (Jacques H. Bureau, 1954).

HARVARD UNIVERSITY, Department of Mathematics.

(1335) MATHEMATICAL THEORY OF WAVES AND SHIP WAVE RESISTANCE.

(b) Office of Naval Research, Department of the Navy.

(c) Prof. Garrett Birkhoff, 2 Divinity Avenue, Cambridge 38, Mass.

(d) Theoretical; applied research.

(e) The purpose of present work is to perfect our methods of calculating Mitchell's Integral munerically. The methods are based on previous theoretical work (see 1954 edition Hydraulic Research Bulletin).

(h) "Theory of the Wave Resistance of Ships", Garrett Eirkhoff, Jack Kotik, B. V. KorvinKroukovsky, to appear in the Journal of the Society of Naval Architects and Marine Engineers.

"Some Transformations of Michell's Integral", Garrett Birkhoff and Jack Kotik, to appear in the Journal of The National Technical University, Athens, Greece.

"Asymptotic Expansion of Michell's Integral at Low Froude Numbers", Jack Kotik, unpublished.

UNIVERSITY OF IDAHO, Engineering Experiment Station.

Inquiries concerning projects Nos. 547, 1859, 2080 and 2081, should be addressed to Prof. c. C. Warnick, College of Engineering, University of Idaho, Moscow, Idaho.

(547) STUDY OF PRINCIPLES, DEVELOPMENT, AND USE OF HIGH ALTITUDE PRECIPITATION GACES.

(b) Laboratory project; cooperative with Civil Aeronautics Administration, Weather Bureau, Forest Service, Bureau of Reclamation, and Agriculture Research Service.

(d) Experimental; design and development. 
(e) A series of wind tunnel tests have been made on movemenv of air around precipitation gages using sawdust to simulate snow. Qualitative catch studies on a model basis have also been made to develop proper windshielding for several types of precipitation gages. Prototype gages and shields have been installed at remote mountain locations to check field performance against the results obtained from wind tunnel tests.

(g) Improved windshield designs developed through testing in a wind tunnel are showing similar advantages in actual field tests at remote mountain locations.

(h) "Mechanical Problems in Precipitation Gage Studies", D. L. Womeldorf, The Idaho Engineer, May 1954.

(1859) A STUDY OF THE EFFECITVENESS OF CANAL LININGS AND SOIL SEDIMENTS IN CONTROLLING SEEPAGE LOSSES.

(b) Laboratory project; cooperative with U. S. Bureau of Reclamation.

(d) Field investigation; basic and operational research.

(e) Different types of new lining materials and methods of lining irrigation canals are being studied in special field test sections. A study is also being made of the effectiveness of chemically treated soils and soil sediments in preventing seepage.

(g) Two years of field testing is completed and much data has been collected on seciment carried in operating irrigation canals.

(h) "Experimental Studies with Canal Linings and Soil sediments for Controlling seepage Losses n, C. C. Warnick, Progress Report No. 1, Engineering Experiment Station, University of Idaho, Moscow, Idaho.

(1860) APPLICATION OF ELECTRICAL RESISTANCE METHODS OF MEASURING SOIL MOISTURE IN IDAHO SOIIS.

(b) Laboratory and field project; under investigation in the Agricultural Experiment Station.

(d) Experimental.

(e) Laboratory and field comparisons of all the commercial types of soil moisture resistance blocks.

(g) One season of field testing of replicated installations has been completed. Methods of improving installations and accuracy of results are being devised when possible.

(h) Anmul progress report.

(1861) THE IMPROVEMENT AND DEVELOPMENT OF STRE AM FLOW MEASURING DEVICES.

(b) Laboratory project; cooperative with Agriculture Research Service, being carried on under the Agricultural Experiment Station.

(d) Experimental; applied research.

(e) Study is being made in a laboratory flume and in field streams with full-size models of stage-measuring devices (primarlly crest gages) under controlled conditions. Other stream-fllow measuring devices are also being developed.

(g) A new crest gage inlet device has been developed that results in very little drawdown at velocities normally encountered in streamflow. A direct reading current meter has been constructed. Velocities are read directly from a scale.

(h) Annual progress report.

(1862) DETERMTNATION OF ANNUAL RUNOFF FROM WATERSHED CHARACTERISTICS.

(b) Labcratory project; being carried on under the Agricultural Experiment Station.

(d) Experimental; applied research.

(e) To investigate statistically the correlation between various watershed characteristics and annual munoff on gaged watersheds, for application to ungaged areas.

(g) Work is in progress evaluating watershed characteristics. 
(2080) A STUDY OF RIME ICE AND SNOW CAPPING ON HIGH ALTTTUDE PRECIPITATION GAGES.

(b) Laboratory project; cooperative with $\mathrm{U}$. S. Weather Bureau and Agriculture Research Service.

(d) Field investigation; basic and applied operational research.

(e) Several gages are being installed near Bogus Basin skl area to study the phenomenon of capping of gages. Measurements of temperature and wind velocity will be made as well as photographic studies of conditions that cause rime ice and snow to collect on the gage.

(g) Work is being initiated this fall with installation of gages. Observations will be made during the winter season.

(2081) THE DESIGN AND EVALUATION OF SPRTNKKER IRRIGATION SISTEMS.

(b) Cooperative with Agricultural Research Service being carried on under the Agricultural Experiment Station.

(d) Field investigation; applied research.

(e) To evaluate the engineering design of existing sprinklers, obtain field data related to design and operation of systems and to establish sprinkler design criteria that are especially applicable to Idaho conditions.

(g) Only preliminary work has been completed.

IIIINOIS INSTITUTE OF TECHNOLOGY, Armour Research Foundation.

(2082) INVESTIGATIONS OF THREE-DIMENSTONAL CASCADES.

(b) Wright Air Development Center, Wright-Patterson Air Force Base, Dayton, Ohio.

(c) Mr. W. P. Green, Manager Heat-Power Research Department, Armour Research Foundation of Illinois Institute of Technology, Technology Center, Chicago 16, Illinois.

(d) Experimental and theoretical; basic research and doctor's thesis.

(e) A series of mixed-flow blade cascades have been constructed in accordance with vortextheory. Internal measurements of relative flow fields have been made with threedimensional spherical pitot probe mounted on rotating impeller using mercury-type rotary seals. Relaxation techniques are being applied to solve theoretical flow equations. Comparison is made with the measurements and are used as basis for ovaluation of design procedure and determination of the effects of changes in blade number, speed and load.

IIITNOIS STATE WATER SURVEY DIVISION, Champaign.

(551) RUNOFF FROM SMALI WATERSHEDS.

(b) Laboratory project, cooperative with U. S. Geological Survey.

(c) Mr. W. J. Roberts, Illinois State Water Survey, Box 232, Urbana, IIl.

(d) Field investigation; applied research, design.

(e) Measurements are being made of water shed rainfall and stream flow, of stage, discharge over the spillway, and municipal pumpage on five small water supply reservoirs in Illinois.

(g) Twenty-four years of contimuous measurements completed. Annual summaries 1946 to 1954 available for limited distribution.

(552) SEDIMENTATION OF IIUINOIS RESERVOTRS.

(b) Laboratory project, cooperative with Agricultural Research Service and Illinois Agricultural Experiment Station.

(c) Mr. J. B. Stall, Illinois State Water Survey, Box 232, Urbana, Illinois.

(d) Field investigation; applied research. 
(e) For design of water supply reservoirs, measurements of sediment accumulation have been made on eighteen lakes in Illinois. Sediment samples are being analyzed and conplete surveys of watershed soil type, slopes, land use, and conservation practices are being made.

(g) Results at Lake Decatur, Decatur, Ill., showed correlation between rate of sedimentation and land use on the watershed.

(h) Reports of Investigation Nos. 4, 7, 8,9, 10, 12, 15, 16, and 18; sedimentation surveys of Spring Lake, Ridge Lake, Lake Chautauque, Carbondale Reservoir, Lake Bracken, West Frankfort Reservoir, Lake Calhoun, Lake Springfield, and Lake Carthage, respectively. "Land and Water Resources of Crab Orchard Region."

(553) RADAR-RAINFALL PROJECT.

(b) Laboratory project, cooperative with signal Corps, Department of the Army.

(c) Mr. G. E. Stout, Illinois State Water Survey, Box 232, Urbana, Illinois.

(d) Field investigation; basic research.

(e) A radar installation is being used to track rain clouds, showing extent, movement, and intensity of each rain area. Two concentrated recording rain gage networks consisting of 24 and 50 rain gages each yield rainfall data which are correlated with photographic records of the radar PPI scopes. Precipitation praticle-size data are being collected in a volume of one-third cubic meter using high-speed photography. These data will be correlated with radar echo-return. Twenty-one rain gages concentrated with 300 square feet are collecting data on the $\mathrm{v}$ ariability of precipitation within a very small area.

(g) Results indicate that radar is capable of matching an equivalent rain gage spacing of at least the gage each 150 square miles.

(h) Reports of Investigation 13, 19, and 21, Illinois State Water Survey. Progress reports to Signal Corps.

\section{(555) EVAPORATION IN ILLINOIS.}

(b) Laboratory project.

(c) Mr. W. J. Roberts, Illinois State Water Survey, Box 232, Urbana, Illinois.

(d) Field investigation; applied research.

(e) Measurements are being made of evaporation at three stations in northern, central, and southerm IIlinois. Vapor pressure gradients are obtained at Four-Mile Crib in Lake Michigan and at Urbana. Evaporimeters constructed and installed adjacent to pans for year-round records.

(h) "Evaporation Records in Illinois", Illinois State Water survey Division Circilar No. 43,1954 .

"Report on Recording Evaporation Gage", Civil Engineering, October, 1954.

(561) GROUND WATER INVESTIGATION IN THE EAST ST. LOUIS AREA.

(b) Laboratory project.

(c) Mr. Jack Bruin, Illinois State Water survey, Box 232, Urbana, IIl.

(d) Field inrestigation; applied research.

(e) To evaluate the ground water resources of the American Botton (E. St. Louis region). Ground water levels are measured continuously. Pumpage, river stage, and rainfall data are collected. Chemical quality of ground water is measured. Areas of infiltration are determined, and all data are correlated with consideration of local conditions. Statistical studies have been made of the service lives of municipal wells.

(g) Average daily ground water pumpage in the area is between 100 and 110 million gallons. since 1941 there has been no recession of ground water except in areas of high concentrated pumpage. The data indicate the water-bearing formations are being recharged by water from the Mississippi River, local rainfall, and upland drainage.

(843) GROUND WATER RESOURCES IN JO DAVIISS, STEPHENSON, AND CARROLL COUNTIES.

(b) Laboratory project.

(c) Mr. H. F. Smith, IIlinois State Water survey, Box 232, Urbana, III.

(d) Field investigation; applied research. 
(e) To determine ground water resources of the area, water level contours of the sandstone aquifers, transmissibility and storage ccefficients of the aquifers, quantity of water available were obtained.

(g) Data indicate that piezometric surface conforms generally with topography, with a 500foot drop in about 30 miles with no apparent withdrawal. The sandstone aquifers are overlain with 100 to 300 feet and more of impervious limestone.

(1092) HYDROLOGIC CYCLE EVALUATION.

(b) Laboratory project; cooperative with the U. S. Geological survey.

(c) Mr. H. E. Hudson, Jr., Illinois State Water survey, Box 232, Urbana, III.

(d) Field investigation; applied research.

(e) Data from rain gage networks (gathered under Project 553) together with information from five stream-gaging stations and five ground water level recorders are being maintained. Data will be used in analyzing storm rainfall-runoff relationships on small watersheds and effect of munoff on water table. Analysis in progress.

(1336) DESIGN OF A 60-FOOT TILITNG FLUME.

(b) Laboratory project.

(c) Mr. H. E. Hudson, Jr., Illinois State Water Survey, Box 232, Urbana, IIl.

(d) Experimental; design.

(e) Design of versatile flume for hydraulic laboratory.

(f) Completed.

(1337) DESIGN OF BUBBLER SYSTEM FOR MEASUREMENT OF WATER LEVELS IN WELLS.

(b) Laboratory project.

(c) Mr. H. E. Hudson, Jr., IIlinois State Water Survey, Box 232, Urbana, Ill.

(d) Experimental; applied research.

(e) The bubbler system or purge method of liquid level measurement was applied to measuring well levels. The theory of operation was advanced and checked by laboratory tests.

(f) Completed.

(g) Laboratory accuracy obtained to 0.020 feet. Field accuracy comparable to float operated recording devices.

(13LI) CORROSION STUDY.

(b) Laboratory project.

(c) Dr. T. E. Larson, Illinois State Water survey, Box 232, Urbana, III.

(d) Experimental.

(e) A basic study of corrosion occurring at the steel electrodes under flow through a twenty foot plastic tower.

(1342) STUDY OF CORROSION AND DEPOSITION RATES WITH DIFEERENT FLOW RATES.

(b) Laboratory project.

(c) Dr. T. E. Larson, IIlinois State Water Survey, Box 232, Urbana, III.

(e) One-half inch pipes made of different material are in service. Changes in the flow due to corrosion and at constant head are being measured.

(1864) FLON THROUGH POROUS MEDIA.

(b) Mr. H. E. Hudson, Jr., Illinois state water Survey, Box 232, Urbana, Illinois.

(d) Basic research.

(e) Study of transition from viscous to turbulent flow in porous media.

(g) Data collection completed. Analysis in progress.

(h) "Transition from Laminar to Turbulent Flow through Granular Media", H. E. Hudson, Jr. and R. E. Roberts. Proceedings Second Midwestern Conference on Fluid Mechanics, ahio State University, 1952. 
(1865) HYDRAULIC DESTGN OF DROP INLET SPILLWAY STEWCTURES FOR SMALL RESERVOIRS.

(b) Laboratory project.

(c) Mr. H. E. Hudson, Jr., IIlinois State Water Survey, Box 232, Urbana, IIlinois.

(d) Experimental; applied research.

(e) The project will provide hydraulic criteria for the economic design of these structures. A field study of structures now in use is included.

(g) Preliminary findings indicate five states of flow in drop-inlet structures.

(h) Report in preparation.

TILINOIS STATE WATER SURVEY DIVISION, Peorla.

Inquiries concerning Projects Nos. 556 to 560, incl., 845, 1335, and 1866, should be addressed to Dr. Max Suter, Engineering Research subdivision, IIlinois State Water survey Division, Box 717, Peoria, III.

(556) PERMEABILITY OF GRADED SAND MIXXTHES.

(b) Laboratory project.

(d) Experimental; basic research.

(e) The permeabilities of known mixtures of graded sand are measured to determine functional changes.

(g) Sand mixtures containing 60 to 70 percent of fine material in 40 to 30 percent of coarser from 2 adjoining sieves of the $\sqrt{2}$ series have less permeability than the material of the fine screen alone. Evidence accululates that the permeability is not much influenced by the amount of roids but greatly by the size of the smallest opening between sand grains.

(557) TURBULENT FLOW THROUGH GRANULAR MEDIA.

(b) Laboratory project.

(d) Experimental; basic research.

(e) Critical flow is determined to define conditions under which turbulent flow occurs outside of well screens.

(g) In flow through gramular media, the Reynolds mumber camot be calculated from ordinary formulas. By assuming a critical Reynolds mumber as existing at the determined critical flow conditions, the corresponding pore size can be calculated. This has been done in preliminary tests, but further work is needed to get a correlation with screen analysis.

(558) STUDY OF CAUSES AND PREVENTION OF SAND BOIIS.

(b) Laboratory project.

(d) Field investigation; basic research.

(e) Sand boils occurring during floods in levied districts are mapped, classified, and sampled. Also sampled are river and nearby well waters.

(g) From chemical analyses and temperature measurements, it was found that the water flowing in typical sand boils (those free from pipe connections towards the river) is different from the river water and similar to well water in neighboring wells. Such sand boils can be stopped from flowing by damming them up to a level that is below that of the river stage. They are not caused by leaks through the levee.

(559) ARTIFICIAL RECHARCE OF GROUND WATER.

(b) Laboratory project.

(d) Experimental laboratory and field investigation; basic research.

(e) Experimental pilot plant consists of river intake, control tower with chlorination and measuring devices, gravel pit with bottom 10 feet below river pool stage, sides and bottom covered with sand. A model of $1 / 8$ of pit (centerline to diagonal) is available to study different types of pits and variations in ground water gradients. 
(g) Pit in operation for fourth winter. Seven months of uninterrupted operation gave silting in only the top 2 inches of the 6-inch sand laver. A cleaner of the swiming pool type is now being used to suck off silt on top of sand.

(h) Mimeographed reports for each of the first three seasons have been issued.

(560) GROUND WATER INVESTIGATION IN THE PEORIA, ILLINOIS, DISTRICT.

(b) Laboratory project.

(d) Field investigation; basic research.

(e) To determine the ground water resources of the district, inventory of wells was made, including construction and logs of wells. Ground water levels are measured continuously, pumpage data collected, river stages and rainfall recorded, chemical analyses for changes in composition of ground water are made, areas of infiltration are determined, and all data are correlated with consideration of local ground conditions.

(g) So far conservation measures have shown more effect than artificial recharge.

(845) EXTENSION OF THEIS' NON-EQUILIBRIUM THEORY FOR VARIABLE FLOW.

(b) Office project.

(d) Theoretical; basic research.

(e) Development of formulas that could be used for conditions of variable flow.

(g) Formulas developed for most important types of variable flow, but the series obtained have not been calculated for wide ranges.

(1335) GROUND WATER INVESTIGATION IN THE CHICAGO AREA.

(b) Laboratory project.

(d) Field study on variations of natural resources. Investigation of artesian well field with wells 1200 to 2200 feet deep, locally heavily pumped. Study of ground water level recession, interferences, transmissibilities, effect of additional demands.

(g) Results determine recession and give good data for future prediction. Collection of data continued.

(1866) GROUND WATER FORMULAS.

(b) Office project.

(d) Theoretical.

(e) Compilation of all published ground water theories and formulas and a comparative evaluation of their range of usefulness.

(h) Report in preparation.

\section{ILIINOIS STATE WATERWAYS DIVISTON, Springfield.}

(1863) EROSION CONTROL, IILINOIS SHORE OF LAKE MICHIGAN.

(b) State of Illinois

(c) Mr. Thomas B. Casey, Chief Engineer, Division of Waterways, $201 \mathrm{~W}$. Monroe Street, Springfield, Illinois.

(d) Field investigation; applied research.

(e) To obtain and correlate basic data on the several forces and factors involved in erosion processes along the IIlinois Shore of Lake Michigan to the end that future efforts toward the prevention of erosion might be founded upon a more definite and factual basis with a consequent greater degree of assurance that the works will serve the intended purposes. 
The project was initiated in 1950 and is continuing. Lines of study are as follows: Observation of lake stages, wave height and period, wind direction and velocity, and barometric pressures at Wilson Avenue Crib and Waukegan Harbor; shoreline and offshore topography; sampling and analysis of beach and bottom materials; wave refraction studies; detailed studies ot case histories of selected shore protection and harbor structures; periodic studies of selected recently constructed groin systems; detailed studies of effect of harbor structures upon littoral drift; measurements of littoral current, including magnitude and direction; and determination of areal extent and depth of offshore sources of beach material for artificial replenishment.

(g) Results are incomplete

UNIVERSITY OF IILINOIS, Fluid Mechanics and Hydraulics Laboratory, Department of Theoretical and Applied Mechanics.

Inquiries concerning Projects Nos. 1343, 1589, and 2083, should be addressed to Prof. W. M. Lansford, Department of Theoretical and Applied Mechanics, 219 Talbot Laboratory, University of Illinois, Urbane, IIl.

(1343) VELOCITY DISTRIBUTION STUDY IN A FLOOD-PLAIN CHANNEL.

(b) Laboratory project.

(d) Basic research.

(e) Data has been collected on quantities of flow varying from $1.59 \mathrm{cfs}$ to $11.5 \mathrm{cfs}$ in a flood plan channel. The channel is of wood 160+ feet long. The cross-section of the channel consists of a 1 foot $x 1$ foot main channel with a sloped flood plain on each side.

(g) Data being analyzed.

(1589) OPEN CHANNEL METER.

(b) Laboratory project.

(d) Experimental and analytical.

(e) Data has been collected on a meter which may be built in a sewer leading from a man hole after the sewer has been in service. The models tested were constructed of artists clay

(f) Inactive.

(2083) VELOCITY DISTRIBUTION IN AN OPEN CHANNEL HAVING A TRIANGULAR CROSS-SECTION.

(b) Laboratory project.

(d) Basic research.

(e) Data are being obtained on a channel artificially roughened by means of small Fitot tubes. It is hoped to obtain data giving velocities close to the walls and using various roughnesses.

UNIVERSITY OF ILLINOIS, Hydraulic Engineering Laboratory, Department of Civil Engineering.

Inquiries concerning Projects Nos. 564, 1095, 1096, 1097, 1591, 2084 to 2089 incl., should be addressed to Prof. J. J. Doland, University of Illinois, Urbana, Ill.

(564) HYDROLOGY OF URBAN AREAS.

(b) Laboratory project, cooperative with Illinois State Water Survey Division and U. S. Geological Survey.

(d) Experimental, theoretical, and field investigation; applied research and design. 
(e) Fourteen recording rain gages, one evaporation station including recording dew-point device, one radar station, and two recording stream gaging stations are installed for observation of rainfall and runoff for an area of about eight square miles. Analytical investigation includes frequency analysis of rainfall intensity, area-depth relationship for storms, ground-water depretion study, unit hydrograph analysis and consumptive use determination. New type of evaporimeter has been developed and check studies are being made.

(1095) SCALE MODEL STUDIES OF TNLET BOXES.

(b) Laboratory project, cooperative with Illinois Division of Highways and J. S. Bureau of Public Roads.

(d) Experimental, applied research, field, design.

(e) Model tests of inlet boxes with the aim of utilizing linetic energy of the falling jet to obtain higher velocity discharge in connecting pipes. Temperature studies are being conducted to determine the desirability of catch basins as heat reservoirs for winter grate operation.

(h) Preliminary report has been presented to the sponsor.

(1096) FULL SCALE GUTTER TESTS.

(b) Laboratory project, cooperative with the Illinois Division of Highways and U. S. Bureau of Public Roads.

(d) Experimental; applied research.

(e) Determination of roughness coefficients for very smooth concrete gutters. Tests section 120 feet long, six longitudinal slopes have been tested with maximum $Q=5.5$ sec-ft.

(h) Revised report in preparation.

(1097) CORRECTION OF SCOUR BELOW TWO-PIER HIGHWAY BRIDGE.

(b) Laboratory project, cooperative with Illinois Division of Highways.

(d) Experimental, applied research.

(e) A 1:50 scale model of an overflow bridge on flood plain of the Wabash River has been constructed as an aid in determining the cause of excessive scour just downstream from the bridge. Remedial dikes and topography changes have been tested in the model to determine their suitability.

(h) Revised report in preparation.

(1591) DETERMTIATION OF WATERWAY AFEAS.

(b) Laboratory project, cooperative with Illinois Division of Highways.

(d) Theoretical and field investigation; applied research and design.

(e) To determine the amount of water which will reach highway openings, such as bridges and culverts and provide a simple but scientific procedure for use of engineers in establishing the economical and adequate size of opening. Methods of investigation include a survey of existing structures, library study of literature, analyses of pertinent climatological and physical factors relating to the hydrologic and hydraulic features of the problem. The following studies were completed: (1) Compilation of formulas for waterway area determination, (2) historical review of engineering studies of the subject under consideration, (3) preparation of a bibliography of related literature that have been studied (4) Analyses of waterway area problems at Florence and Petersburg, Illinois, and (5) nationwide survey of waterway area design practice in state highway departments.

(h) Three preliminary reports and two field reports were produced.

(2084) HYDRAULIC CHARACTERISTTCS OF FUNNEL-TYPE ST'REET INLET.

(b) Departmental thesis study.

(d) Laboratory investigation, applied research.

(e) Scale model tests of a funnel type inlet structure, discharging vertically downward into a pipe elbow. Correlation of discharge characteristics with approach channel flow.

(f) Study completed.

(h) Thesis submitted to Graduate College. Preparation of report for general distribution is in progress. 
(2085) CALIBRATION AND USE OF CERTATN INLET GRATES.

(b) Illinois Division of Highways.

(d) Labor atory investigation, applied research.

(e) Full scale model tests of four standard Division of Highways inlets. Original and revised inlet grate designs have been tested.

(h) Report to sponsor is in preparation.

(2086) A STUDY OF FISHWAYS.

(b) Departmental graduate study.

(d) Laboratory investigation, basic research.

(e) Scale model tests of a pool type fishway to determine efficient orifice design and ladder pool length.

(2087) EFFECTIVENESS OF SUBWAY GRATTNGS FOR HICHWAY DRAINAGE.

(b) Departmental special study.

(d) Laboratory investigation, applied research.

(e) Full scale model tests of two subway grating designs are being tested in standard IIlinois Division of Highways, Type 11 inlet frame.

(2088) DISCHARGE CHARACTERISTICS OF RECTANGULAR TYPE INIET BOXES.

(b) Departmental study.

(d) Laboratory investigation, basic research.

(e) Scale model investigation of rectangular inlet box with long lucite discharge pipe to verify or disprove the weir-orifice discharge theory.

(2089) STUDIES OF DESILIING STRUCTURES FOR HIGHWAY DRAINAGE SISTEMS.

(b) Iaboratory project, cooperative with IIlinois Division of Highways and U. S. Bureau of Public Roads.

(d) Analytical; applied research and design.

(e) The study covers a comprehensive review of literature related to various subjects of the investigation, an analytical study of a topic area selected from the portion of the Congress Street Expressway at Chicago, IIlinois, a comparative study of the conventional "inlet box-catch basin" system as designed for the topic area and the "inlet box-desilting chamber" system as applied to the area, and other aspects concerning the hydraulic design of a desilting chamber.

(f) Completed.

(g) The results of this investigation reveal that the design of the catch basin under consideration is unsatisfactory. A possible kinetic sedimentation type stmucture utilizing the principle of a vortex-tube is developed and proposed for laboratory investigation.

(h) "Desilting Structures for Highway Drainage Systems", by John C. Guillou and Ven Te Chow, Civil Engineering Studies, Hydraulic Engineering Series No. 3, Department of Civil Engineering, University of IIlinois, Urbana, IIl., June 1954.

IOWA INSTITUTE OF HXDRAULIC RESEARCH, State University of Iowa.

Inquiries concerning projects should be addressed to the following, all at state Universit. of Iowa, Iowa City, Iowa:

Nos. 66, 1593, 1869, 1870..................................to Prof. J. W. Howe. Nos. 69, 568, 1101, 1107, 1597, 2093, 2095..................to Mr. Emmett M. Laursen.

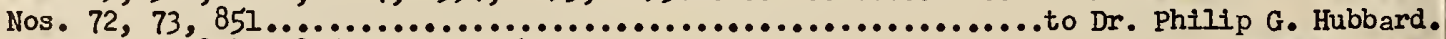
Nos. 1102, 187L, 1875, 2090, 2094.............................to Dr. Hunter Rouse. 


\section{(66) HYDROLOGIC STUDIES, RALSTON CREEK WATERSHED.}

(b) Cooperative with Department of Agriculture and Geological survey.

(d) Field investigation; applied research and master's theses.

(e) Study being made of relation between rainfall and runoff over a small area. Discharge from a 3-square-mile area measured by U. S. Geological survey; rainfall records at five automatic recording stations collected by Soil and Water Conservation Research Service. Contimous records since 1924 of precipitation, runoff, ground-water levels, and vegetal cover.

(g) Yearly records available for examination at Iowa Institute of Hydraulic Research.

(h) Reports prepared anmually since 1924 available in files at the Iowa Institute of Hydraulic Research.

67) COOPERATIVE SURFACE-WAIER INVESTIGATIONS IN IOWA.

(b) Cooperative with Geological Survey.

(c) Mr. V. R. Bennion, Iowa Institute of Hydraulic Research, Iowa City, Iowa.

(d) Field investigation; collection of basic stream-flow data.

(e) Stream-flow and sediment measuring stations maintained throughout the state of Iowa cooperatively on a contimuous basis. Records collected by standard methods of $U$. S. Geological survey.

(g) Records of stream flow and sediment discharge computed yearly.

(h) Records contained in Water-Supply Papers available through of fices of the Geological survey.

68) HYDROLOGIC STUDIES, RAPID CREEK WATERSHED.

(b) Cooperative with Department of Agriculture and Geological Survey.

(c) Mr. V. R. Bennion, Iowa Institute of Hydraulic Research, Iowa City, Iowa.

(d) Field investigation; applied research and master's theses.

(e) Study being made of relation between rainfall and munoff over a small area. Discharge from a 25-square-mile area measured and flood munoff on main sub-basins determined by ס. S. Geological Survey; rainfall records at four automatic recording stations collected by U.S. Weather Bureau. Contimuous records since 1941 of precipitation, runoff, and ground-water levels.

(g) Rainfall records published in Weather Bureau Climatological Bulletins and surface runoff and ground-water levels published in Geological Survey Water-supply Papers.

\section{9) RELATION OF SEDIMENT CHARACTERISTICS TO BED EROSTON.}

(b) Cooperative with office of Naval Research, Department of the Navy.

(d) Experimental; for doctor's thesis.

(e) To evaluate general relations between geometric and kinematic parameters of flow and mean size and grading of bed sediments for an arbitrary conditions of scour. Experiments conducted in glass-walled flume 15 feet long, 3 feet deep, 1-1/2 feet wide with a twodimensional horizontal jet. Selected geometrical proportions kept constant during all runs, the variables being the rate of flow, the mean diameter and standard deviation of the sediment, and time and depth of scour.

(g) Determination of the transport capacity of the flow as a function of the scour hole size, the sediment size and the jet velocity permitted the establishment of a relationship between the extent of scour relative to a limiting extent as a function of a time parameter $w t / a$ divided by a flow parameter $v \sqrt{a \Delta \gamma / P}$. The limiting extent of scour was found to be a function of the flow parameter and the ratio of the jet velocity to the fall velocity of the sediment $\mathrm{V} / \mathrm{w}$. The equipment has been modified for the contimuation of the study to include the effect of the grading of the bed sediments. 
(72) ELECTRICAL ANALOGY OF THREE-DIMENSTONAL FLOW.

(b) Cooperative with Office of Naval Research, Department of the Navy.

(d) Experimental; basic research.

(e) Various three-dimensional flow transitions have been tested in order to provide useful design data for mechanical and hydraulic engineers.

(g) A paper summarizing the work is in preparation.

(73) MEASUREMENT OF TURBULENCE IN FLOWTNG WATER.

(b) Cooperative with Office of Naval Research, Department of the Navy.

(d) Experimental and theoretical.

(e) Instruments, primarily electrical in operation, are being developed to measure the characteristics of turbulent flow under a wide range of laboratory and field conditions. Both sensing and computing elements are involved.

(g) The hot-wire anemometer has been used successfully, and dissipation of heat from plane surfaces is now being studied for possible application to the problem.

(h) "Constant-Temperature Hot-Wire Anemometry with Application to Measurements in Water", Philip G. Hubbard, Ph.D. Dissertation, State University of Iowa, 1954, (available on loan).

(79) CAVITATION.

(b) Cooperative with office of Naval Research, Department of the Navy.

(c) Dr. David W. Appel, Iowa Institute of Hydraulic Research, Iowa City, Iowa.

(d) Experimental and theoretical; basic research and graduate theses.

(e) Basic information is sought on cavitation for systematically varied boundary conditions. Tests are conducted in two variable-pressure water tunnels and a special cavitation tank. Studies of high-velocity submerged jets are being continued with measurements made of the local velocity and pressure fluctuations in the mixing zone. Instrumentation is being developed for measurement of the correlation between the velocity and pressure fluctuations to make possible prediction of the incipient cavitation index for given mean flow conditions. Previous measurements of the pressure distribution around various rounded, ellipsoidal, and conical head forms are being extended to various angles of yaw.

(81) MATHEMATICAI ANALYSIS OF PRESSURE DISTRIBUTION.

(b) Cooperative with Office of Naval Research, Department of the Navy.

(c) Dr. Louis Iandweber, Iowa Institute of Hydraulic Research, Iowa City, Iowa.

(d) Theoretical; basic research.

(e) Methods of applying irrotational-flow theory to problems of hydraulic design have been used to obtain information on specific problems. Both analytical and numerical methods were used, and whenever possible the results have been compared with available experimenta measurements. New methods of solving potential flow problems are also sought. A method of generating three-dimensional potential flows from two-dimensional ones has been discovered recently. Another method for the determination of flow about bodies of revolution and symmetrical two-dimensional forms in arbitrary states of motion, developed at the David Taylor Model Basin, is now being tested. This method is based on solutions of Fredholm integral equations of the first kind derived from application of Green's formulas

(568) SCOUR AT BRTDGE PIERS AND ABUTMENTS.

(b) Cooperative with Iowa State Highway Commission and U. S. Bureau of Public Roads.

(d) Experimental; applied research.

(e) To investigate the effects of pier and abutment geometry, sediment properties, and streamflow characteristics on the rate and pattern of scour, to the end of providing safe design criteria. 
(g) Initial phase, the study of pier and abutment geometry, has been inactive for the past year. The second phase, the study of the effect of stream-flow characteristics, and the third phase, the study of sediment characteristics, are almost camplete. If the bed-load movement is general and the flow sub-critical, the investigation shows that neither the velocity of flow nor the sediment size has any appreciable effect on the equilibrium depth of scour. The depth of flow, however, has an effect on the scour depth at equilibrium. Because of the limited range of the laboratory experiments this effect camnot be well established. Electrical measuring and recording equipment have now been installed at a chosen bridge site to determine the depth of erosion at a centrally located pier

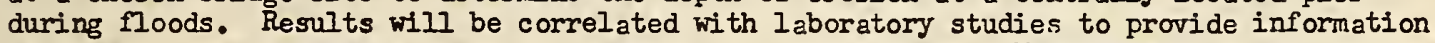
relative to the necessary depth of footings for bridge piers. Measurement of scour in the field obtained for several floods at one location. A $1: 12$ model of the prototype pier is being studied to help establish model-prototype conformity.

(851) A CONSTANT-TEMPERATURE HOT-WIHE ANEMOMETER FOR THE MEASJHEMENT OF TURBULENCE IN AIR.

(b) Cooperative with Office of Naval Research, Department of the. Navy.

(d) Experimental; instrument design.

(e) The anemometer was designed to measure fundamental properties of turbulence in a lowvelocity air tumel, with special emphasis on simple operation techniques and high sensitivity at low frequencies. The ains were accanplished by utilizing carefully designed electronic control circuits and maintenance of the wire temperature at a constant level, above that of the air stream.

(g) Improvements have been made which led to greater stability and a more nearly linear response to the magnitude of the velocity. Complete new design now available. During the year, a complete two-channel system with linear velocity vs. output-voliage characteristics was constructed for the David Taylor Model Basin. New techniques using a radically different sensing element are now under investigation.

\section{(854) BONNDARY-LAYER DEVELOPMENT ON SHOOTH AND ROGH SURFACES.}

(b) Cooperative with Office of Naval Research, Department of the Navy.

(c) Dr. Louis Landweber, Iowa Institute of Hydraulic Research, Iowa City, Iowa.

(d) Experimental and theoretical basic research.

(e) Purpose of work is to determine the relations between boundary-layer characteristics for smooth and rough boundaries of arbitrary shape. Presently being investigated is the boundary layer on a smooth glass plate. In order to improve the accuracy of the determination of the shear stress at the wall, the method of measuring this characteristic by means of total-head measurements with a tube in contact with the wall is being tried. It is planned to check the "inner" and "outer" laws of the boundary layer, determine the effect of the freestream turbulence upon the outer law, and to apply the results to the case of the flat plate in zero pressure gradient. Subsequently this work will be extended to flows with pressure gradients.

(h) "Boundary-Layer Characteristics for Smooth and Rough Surfacesn, F. R. Hama, Trans. of the Society of Naval Architects and Marine Engineers, Vol. 62, 1954 .

"On the Velocity Distribution in the Laminar Sublayer and Transition Region in Turbulent Shear Flows", F. R. Hama, Jour. of the Aeronautical Sciences, Vol. 20, No. 9, Sept. 1953.

1101) MOVEMENT OF SEDIMENT IN HIGHWAY DRATNAGE SYSTEMS.

(b) Cooperative with Iowa State Highway Commission and U. S. Bureau of Public Roads.

(d) Experimental; for basic research and graduate theses.

(e) A study of the movement of sediment in pipes, including the pattern of sand transport and the accompanying hydraulic energy losses for quasi-uniform flow in a circular conduit. Both full-pipe and free-surface flows have been studied.

(f) Complete except for final report.

(g) Relationships adequate for design established for the energy loss, the blockage, and the limiting condition of residual deposition as a function of the discharge, the sediment load, the pipe size, and the sediment size. Experiments now include pit-run sand and slag. 
(I102) HISTORY OF HYDRAULICS.

(b) Institute project.

(e) To trace the historical development of the important theories of hydraulics, covering the fundamental ideas of the science, the critical periods of 1 ts development, and the personalities whose contributions were of major importance.

(h) Now appearing as bilingual supplement to La Houille Blanche.

(1107) TRANSPORTATION OF SEDTMENT AS SUSPENDED AND TOTAL LOAD.

(b) Cooperative with of fice of Naval Research, Department of the Navy.

(d) Experimental; basic research.

(e) To determine the suspended and total load as a function of hydraulic and sediment parameters A recirculating flume 3 feet wide, 15 inches deep, 100 feet long, and of variable slope has been in operation for several years (see Proj. 569, 1950). Distribution of sediment, as well as total load is measured. Effect of sediment transport on velocity distribution, energy loss, and other hydraulic characteristics will also be evaluated.

(1345) DESIGN OF HIGHWAY FIILS FOR SAFE OVERTOPPING BY FLOOD WATERS.

(b) Iowa Highway Research Board.

(c) Prof. C. J. Posey, State University of Iowa, Iowa City, Iowa.

(d) Experimental; applied research pertaining to design.

(f) Completed.

(g) Flume tests show that highway fills built of fine material can be protected by graded layers meeting requirements of Terzaghi-Vicksburg criteria for inverted filters. Binding the top layer tightly in wire sausages makes it unnecessary to carry the filter up to uneconomical rock sizes.

(h) "Rock Sausages Provide Economical Protection Against Erosion", C. J. Posey, Engine ering News-Record, May 13, 1954, p. 45, progress report. Final report in preparation.

(1593) PRESSURE CONDITIONS AT THE OUTLET OF A PIPE.

(b) Laboratory project.

(d) Experimental; basic investigation for master's thesis.

(e) Location of the line of piezometric head just upstream from the outlet of a pipe in relation to the Froude number.

(f) Completed.

(g) Projection of grade line intersects the outlet section at a level which varies from above the top to below the center of the pipe, depending on the Froude number. Negative pressures exist in the flow several diameters upstream from the outlet.

(h) "Pressure Conditions at the Outlet of a Pipe", Daniel Rueda, M. S. Thesis, 1954. Loan copy available from Iowa Institute of Hydraulic Research, Iowa City, Iowa.

(1594) UNSTE ADY PHENOMENA IN FLUID FLOW AND IN HEAT TRANSFER.

(b) Laboratory project.

(c) Dr. Chia-Shun Yih, Iowa Institute of Hydraulic Research, Iowa City, Iowa.

(d) Theoretical.

(e) To study certain unsteady phenomena in fluid flow and in heat transfer. Unsteady boundary conditions and internal heat sources are treated by a technique similar to the Duhamel principle of heat conduction. This technique is applicable to a wide variety of problems in the field of lubrication.

(f) Completed.

(g) Results for unsteady fluid flow and heat transfer between concentric cylinders have been obtained. 


\section{(1597) A STUDY OF THE EFFICIENCY OF SAND TRAPS.}

(b) J. S. Bureau of Public Roads and Iowa State Highway Commission.

(d) Experimental; for master's thesis.

(e) A study of the effects on the efficiency of sand traps of the geometry of the trap and the ratio of velocity of flow to settling velocity of particles. Various trap proportions, sand sizes, and rates of both sediment and water transport have been varied.

(g) Efficiency of trap shown to be a function of relative trap dimensions and ratio of conduit velocity to fall velocity of sediment. Experiments continuing to check tentative relationships.

\section{(1598) A STUDY OF THE EFFECT OF LIP ANGLE ON FLOW UNDER A TAINTER GATE.}

(b) Laboratory project.

(c) Prof. D. E. Metzler, State University of Iowa, Iowa City, Iowa.

(d) Experimental; for master's thesis.

(e) Experimental data obtained on a model Tainter gate in a horizontal channel. The results, presented in three dimensionless diagrams, show the discharge coefficient as a function of the ratios of headwater elevation to gate radius, tailwater elevation to gate radius, gate opening to gate radius, and trunnion height to gate radius.

(f) Completed.

(g) "Discharge Characteristics of Tainter Gates", Arthur Toch, Proceedings ASCE Separate 295, oct. 1953.

(1869) AERATION DEMAND OF A STANDARD SHARP-CRESTED WEIR.

(b) Laboratory project.

(d) Experimental; basic research; master's thesis.

(e) Air was fed to space under weir nappe in quantity necessary to keep this space at atmospheric pressure. Quantity of air required in relation to weir height and head investigated.

(f) Completed.

(g) Air intake relative to discharge found to increase with ratio of head to weir height and with relative height of fall. Maximum air demand is of the order of 5 percent of water discharge for normal weir.

(h) "Aeration Demand of a Sharp-Crested Weir", Go-Chean Shieh and Arturo Obadia, M. S. Thesis 1954. Loan copy available from Iowa Institute of Hydraulic Research, Iowa City, Iowa.

(1870) EFFECT OF SHAPE OF VERTICAL DRAFT TUBES ON THEIR EFFICIENCY.

(b) Laboratory project.

(d) Experimental; master's thesis.

(e) Comparative study of conical, Prasil, White, and Moody draft-tube efficiency under indentical conditions.

(1871) CAVITÁTING FLOW AROUND HYDROFOILS.

(b) David Taylor Model Basin, Department of the Navy.

(c) Dr. David W. Appel, Iowa Institute of Hydraulic Research, Iowa City, Iowa.

(d) Experimental project.

(e) Hydrofoils of the NACA 66-series and EPH-series of various thickness and camber are to be tested in a variable-pressure water tunnel having a closed-throat test section 6 by 24 inches to provide information on the effect of cavitation on the characteristics of twodimensional hydrofoils at various angles of attack. Model hydrofoils supported at one end and spanning the width of the water tumel will be tested to determine the lift, drag, and pitching moment at various angles of attack and with various degrees of cavitation. A balance has been designed and is now being built which will give electrical indications of the instantaneous forces on the models. This will be installed in the water tunnel and the tests begun early in 1955 . 
(1873) STABILITY OF LAMIINAR PARALIEL FLOW WITH A FHEE SURFACE.

(b) Laboratory project.

(c) Dr. Chia-Shun Yih, Iowa Institute of Hydraulic Research, Iowa City, Iowa.

(d) Theoretical and basic research.

(e) The stability of parallel laminar flow of a liquid film along a solid boundary is studied. The object is to obtain the relationship between the Reynolds number and the wave length of the disturbance for neutral stability.

(f) Completed.

(g) The relevant Sommerfeld-orr equation is solved by an expansion in ascending powers of the Reynolds number. The curve for neutral stability giving the relationship between the Reynolds number and the wave length of the disburbance is provided by the secular equation obtained from the boundary conditions. The flow is found to be unstable at very low Reynolds numbers.

(h) "Stability of Laminar Parallel Flow with a Free surface", C. S. Yih, Second U. S. National Congress of Applied Mechanics, June 1954.

(1874) DIFFUSION OF TURBULENCE ON SLEEP SLOPES.

(b) Laboratory project.

(d) Experimental; basic research for master's thesis.

(e) Extension of Project (1100) to include effects of side walls and piers on the disturbance of the free surface on spillways.

(f) Inactive.

(h) "Diffusion of Turbulence From Piers and Abutments of Spillways", Luis Fernandez, M. S. Thesis, Aug. 1954. (Copy available on loan).

(1875) CHARACTERISTICS OF STABLE EDDIES.

(b) Laboratory project.

(d) Experimental; basic research for master's thesis.

(e) Distributions of velocity, pressure, and turbulence will be measured in an air tunnel throughout the vicinity of separation zones produced by abrupt changes in flow section, to the end of establishing the primary eddy characteristics as functions of the boundary geometry.

(2090) MODEL STUDY OF CRAWFORD STATION.

(b) Commonwealth Edison Company, Chicago, Illinois.

(d) Experimental; applied research.

(e) 1:60 model of a reach of the Chicago Sanitary Canal and the inlet and outlet of the Crawford steam power plant is being used to study the recirculation of heated water. possible changes in design of inlet and outlet to minimize recirculation are under study.

(2091) RESEARCH ON SHIP THEORY.

(b) Cooperative with Office of Naval Research, Department of the Navy.

(c) Dr. Louis Landweber, Iowa Institute of Hydraulic Research, Iowa City, Iowa.

(d) Experimental and theoretical basic research.

(e) To determine the laws governing the forces, moments and motions of ships in smooth and disturbed seas, in order to furnish design data to the naval architect. A towing tank 10 feet wide, 10 feet deep, and 300 feet long is being constructed. Theoretical work on the effect of the form of a body on its added mass coefficients, and the relations between these coefficients and the singularity distributions which may be considered to generate the body, is under way. 


\section{(2092) STABILITY OF STRATIFIED FLOW.}

(b) Office of Ordnance Research, U. S. Army.

(c) Dr. Chia-Shun Yih, Iowa Institute of Hydraulic Research, Iowa City, Iowa.

(d) Basic research; theoretical and experimental.

(e) The stability as well as the mixing characteristics of stratified flow is studied. The stability aspect is analyzed by the method of small disturbances. Experiments are performed in a recirculating water tunnel permitting the flow of two liquids of different densities in opposite directions.

(2093) MODEL STUDY OF KEOKUK DAM.

(b) Sverdrup and Parcel, St. Louis, Missouri.

(d) Experimental; applied research.

(e) Several modifications developed for minimizing erosion at toe of spillway using a two-bay, sectional model. Effect of thickening of piers or discharge coefficient checked.

(f) Completed.

(g) Best hydraulic solution for low tailwater conditions: depressed stilling basin with blocks. Less extensive works needed for medium and high tailwaters. simplest solution for low tallwater: flip bucket to move point of active erosion.

(h) Report subnitted to sponsor.

(2094) HYDRAULIC LABORATORY DESIGN.

(b) Foreign Operations Administration and University of the Phillipines.

(d) Design.

(e) Planning of special equipment and recommendation of commercial equipment for a hydraulics laboratory for undergraduate and graduate instruction and research.

(f) Completed.

(h) Detailed plans and specifications submitted to sponsor.

(2095) MODEL STUDY OF 'NESIEY SEALE DAM.

(b) Ambursen Engineering Corporation.

(d) Experimental; applied research.

(e) Pressure distribution on automatic flashboard gates and discharge coefficient for various headwaters, tailwaters, and gate settings determined from 1:20 sectional model.

(2096) REMOVAL OF CAPIILARY WATER FROM HIGHWAY SUBGRADES BY EVAPORATION.

(b) Iowa Highway Research Board.

(c) Prof. C. J. Posey, Engineering Bldg., State University of Iowa, Iowa City, Iowa.

(d) Experimental; applied research pertaining to design.

(e) Removal of excess "held" soil moisture by evaporation requires an efficient and correctly located circulation system for air. Possibilities of a combination drainage and air circulation system powered by prevailing winds and/or pulses from vehicles are being investigated.

(2097) A POLICY FOR FLOOD CONTROL.

(b) Laboratory project.

(c) Prof. C. J. Posey, Engineering Building, State University of Iowa, Iowa City, Iowa.

(d) Theoretical, doctoral thesis.

(e) Flood frequencies and flood damages are related to reservoir protection, channel and levee improvements, and flood insurance with determination of proper balance for minimum total cost. Equitable allocation of proportionate costs of improvements, to be kept essentially the same for all components of a complete protection system, is shown to be a necessary prerequisite for achieving proper balance.

(f) Completed

(g) Incertain not uncommon situations, determinable by methods given in the thesis, the inclusion of flood insurance as a part of the over-all plan will permit great economies.

(h) "A Policy for Flood Control", I. M. Mostafa El Assiouty, Ph.D. Dissertation, June 1954. Available on inter-library loan. 
THE JOHNS HOPKINS UNIVERSTTY, Applied Physics Laboratory.

ANALYSTS OF DYNAMIC OPERATION OF HYDRAULIC (FORCE) AMPLIFIER TRANSFER VALVES.

(b) Bureau of Ordnance, Department of the Navy.

(d) Theoretical and experimental; basic development and research.

(e) Theoretical and experimental project designed to develop a set of linearized differential equations to describe the operation of the single and double nozzle type, hydraulic force amplifier, transfer valves.

(g) Comparison of theoretical and experimental data nearly completed.

(h) Report on experimental data and preliminary non-linear equations complete - APL/JHU, TG No. 198.

(1877) ANALYSIS OF STATIC AND DYNAMIC OPERATING CHARACTERISIICS OF HYDRAULIC SERVO MECHANISMS.

(b) Bureau of Ordnance, Department of the Navy.

(d) Theoretical and experimental; basic development and research.

(e) Phase (1); static operating characteristics of closed-loop servo mechanisms. Phase (2); dynamic operating characteristics of closed-loop servo mechanisms, including effects of complex mechanical loads.

(f) Phase one; nearly complete. Phase two; proceeding.

(g) Phase (1); some specific recommendations have been derived for system and component design. Phase (2); with the use of analogue computers, the non-linear differential equations of the servo mechanism have been solved. These equations include effect of oil compressibility and complex mechanical loads. Excellent agreement has been obtained between experimental and theoretical results. Analysis is in process to develop a technique to linearize equations and solve for servo transfer characteristics and stability problems without the aid of analogue computers.

(h) Phase (1); Bumblebee Report No. CM-717-A.

Phase (2); report in preparation.

THE JOHNS HOPKINS UNIVERSITY, School of Engineering.

Inquiries concerning Projects Nos. 855, 856, and 1111 should be addressed to Dr. John C. Geyer, The Johns Hopkins University, Baltimore 18, Md.

(855) HYDRAULIC BEHAVIOR OF STORM WATER INLETS.

(b) Baltimore City, Baltimore County, and the Maryland State Roads Commission.

(d) Experimental, basic research, and design.

(e) Model studies of curb, gutter, deflector and combination inlets for various gutter geometries. Attempt has been made to design a "best" inlet for given street conditions.

(f) Model studies have been suspended. Final report is now in progress.

(g) A short-type grate of $2.5 \mathrm{ft}$. length (no transverse bars) appears to be hydraulically efficient for normal street conditions. Width of the grate depends upon design flow. Short span permits use of moderate size cast iron bars.

(h) "Calculation of Rating Curves for Gutter and Combination Inlets", Oct. 1954. Conmittee Report (available for loan by request).

"A Simplified Method of Determining Capacities of Single and Multiple Inlets", Now. 1954. Co: mittee Report (available on loan by request).

"Progress Report on The Storm Drainage Research Project", J. C. Geyer and P. Bock, June 1954. (Available on loan by request).

(856) HYDROLOGY OF STORM DRATNAGE STSTEMS IN URBAN AREAS.

(b) Baltimore City, Baltimore County, and the Maryland State Roads Comnission.

(d) Field Investigation, basic research, and design. 
(e) Study of rainfall and runoff relationships as affected by various drainage area parameters. At present, runoff from 7 urban areas ranging in size from 10 to 400 acres are gaged, 4 by a newly developed flow meter, and 3 by stage measurements only. Two recording systems which simultaneously record rainfall on and munoff from 14 inlet areas provide good opportunity for detailed study. About 4 years of rainfall records now exist for a network of 10 recording gages covering an area of about 50 square miles.

(g) The past year of rainfall data support previous findings of extreme variations in areal distribution of storms. A study of the 20 highest recorded flows in 4 years for a drainage area of about 100 acres shows the time between peak rainfall and peak minoff averaged about 10 mimutes. Further analyses are under way.

(IIII) DEVELOPNENT OF FLOW GAGE FOR STORM SEWER DISCHARCSS.

(b) Baltimore City, Baltimore County, and the Maryland State Roads Commission.

(d) Experimental, applied research.

(e) The development of gages for measuring both depth and velocity of the debris-laden shooting flow commonly found in storm sewers. The search is for a method generally adaptable to existing storm sewers that does not require extensive alterations of the sewer channel.

(g) During the past year, "Pigmy"type cup (Price) current meters in a special mount to give shielding against debris have been installed in 3 storm sewers. It appears that successful operation of the flow meters depends upon the type and amount of debris present. Velocity and depth of flow are recorded alternately on a single chart. Further refinement of the instrument, calibrations, and analysis of the data are under way.

IEHIGH UNI VERSTTY, Fritz Engineering Laboratory.

Inquiries concerning Project Nos. 90, 1713, 1602, and 1603, incl., should be addressed to Prof. M. B. McPherson, Department of Civil Engineering and Mechanics, Fritz Laboratory, Iehigh University, Bethlehem, Penna.

(90) STUDIES OF PFESSURE VARIATIONS CAUSED BY BOUNDARI MISAITGNENT IN THEIR FELRION TO CAVITATION IN HYDRAULIC STRUCTURES.

(b) A.S.C.E. Subcomittee on Cavitation and the Iehigh Institute of Research.

(d) Experimental; basic research; master's thesis.

(f) Inactive.

(1113) A STUDY OF SHARP CRESIED GIRCULAR VEIRS.

(b) Laboratory project.

(d) Experimental; undergraduate thesis.

(e) Study of the effects of variations in head, approach depths and diameter. Weirs are circular in plan, radial in approach.

(f) Experimental work with water completed

(h) "Morning Glory Shaft Spillways: Determination of Pressure-Controlled Profiles". Proceedings Separate No. 432 , Discussion by M. W. White and M. B. McPherson; in A.S.C.E. Proceedings Separate No. 491.

(1602) PRESSTRE DISTRLBUTION IN CONDUIT BENDS.

(b) Iaboratory project.

(d) Experimental; applied research, for professional degree thesis, undergraduate and graduate special problem.

(f) Bend studies using air with rectangular cross-sections are being continued. Electricalanalogy study of bends of circular cross-section has been initiated.

(h) "The Characteristics and Accuracy of Rectangrular Bends Used as Flow (Air) Meters", by W. Van Ormeren, graduate special problem Fritz Laboratory, July 10, 1953. "Elbow Meter Performance", by D. C. Taylor, M. B. McPherson, Jour. of Amer. Water Works Assn. Vol. $46, \mathrm{pp} .1087$ - 1095, Nov. 1954. 
(1603) BUTTERFLY VALVE STUDY.

(b) C. D. C. Controls Services, Inc., Hatboro, Pa.

(d) Experimental; applied research, Master's Thesis.

(f) Inactive - 1953 to 1954 .

LOUISIANA STATE UNIVERSTTY AND A AND M COLLECE, School of Hydraulic Engineering.

(2098) LOWLAND RECLAMATION IN LOUISIANA.

(b) Laboratory project.

(c) Prof. Thomas M. Lowe, Louisiana State University and A and M College, Baton Rouge 3, La.

(d) Experimental; master's thesis.

(e) Investigation into the possibilities of reclaiming waste land in the state of Louisiana.

(h) "Engineering aspects of lowland reclamation possibilities in Louisiana", William P. Kohl. Master's Thesis, 1954 .

UNIVERSTTY OF MARYLAND, Glenn L. Martin College of Engineering and Aeronautical Sciences.

(2099) TRANSITION FLOW PATTERNS IN PIPES.

(b) Office of Scientific Research, Air Research and Development Command, U. S. Airforce.

(c) Dr. John R. Weske, University of Maryland, College Park, Md.

(d) Experimental (primarily) and theoretical; basic research. One side problem is being investigated by a graduate student as a master's thesis in Physics.

(e) In the present phase of the investigation certain discrete vortex formations are studied which arise spontaneously or may be generated at will in the transition range from laminar to turbulent flow in a pipe and in the boundary layer of a flat plate. Experimental work is done both in water and in air.

(g) None available at this time.

(h) A $16 \mathrm{~mm}$ color movie of 600 feet in length completed June 1954 showing discrete vortex patterns in a pipe is available on loan.

(2100) DESTGN OF LABORATORY EQUIPMENT TO STUDY FLUID FLOW BY VISUAL MEANS.

(b) L $\mathrm{L}_{\mathrm{aboratory}}$ project.

(c) Prof. J. B. Cournyn, University of Maryland, College Park, Md.

(d) Experimental; for design and for master's theses.

(e) The equipment is being built for the investigation of several phases of flow in clear pipes by means of visual methods.

MASSACHUSETTS INSTITUTE OF TECHNOLOGY, Department of Civil and Sanitary Engineering, Hydrodynamics LABORATORY.

Inquiries concerning Projects Nos. 307, 577 to 580, incl., 1355, 1608 to 1610, incl., 1881 and 2101 to 2103, incl., and requests for reprints and Technical Reports should be addressed to Dr. Arthur T. Ippen, Professor of Hydraulics, Hydrodynamics Laboratory, Massachusetts Institute of Technology, Cambridge 39, Mass. 


\section{(307) STABIIITY OF FLOW STRATIFIED DUE TO DENSITY DIFFERENGES.}

(b) Laboratory project.

(d) Theoretical and experimental; graduate research.

(e) (1) Theoretical and experimental investigations have been made on steady-state uniform density current flows including determination of velocity distributions, resistance laws and interfacial stability. (2) Investigation of control structures for stratified flow.

(g) Experimental work on phase (2) now in progress. Initial studies were concerned with the design of curtain walls for condenser water intakes in which the source of water consists of a warm layer overlying a cold layer. Experiments to determine the maximum rate of flow which can be discharged under the curtain wall without drawing in water from the upper layer have been completed. Experimental investigations of other types of control structures are now being made.

(h) "Sluice Gate Discharge of Stratified Flow", C. C. Jacobson and N. R. Rosen, M. S. Thesis, 1954.

(577) CHARACTERISTICS OF SOLITARY WAVES.

(b) Office of Naval Research, Department of the Navy.

(d) Experimental; basic research.

(e) (1) Experimental investigation of solitary wave characteristics in a horizontal channel. Measurements of attemuation for various bottom roughnesses. (2) Investigation of amplitude change, profile deformation and breaking characteristics of the solitary wave on a sloping beach. (3) Measurement of unsteady velocities in the boundary layer region.

(g) Phases ( 1 ) and (2) of the program have been essentially completed. Work on phase (3) has included the development of a new differential pressure gage for the determination of small unsteady velocities. Gage is being utilized to measure the boundary layer development at a given station due to the passage of a solitary wave. Velocity distributions in the lower regions of a representative solitary wave have been obtained at various positions along the wave.

(h) "Attemation and Shoaling Characteristics of the Solitary Wave", A. T. Ippen and G. Kulin, Fifth Conference on Coastal Engineering, Grenoble, France, Sept. 1954.

"The Measurement of Low Velocities in Unsteady Flow", M. A. Raza, M. S. Thesis, 1954.

(578) TURBULENCE MEASUREMENTS IN FREE SURFACE FLOW.

(b) Office of Naval Research, Department of the Navy.

(d) Experimental; development of instrumentation.

(e) Studies of turbulence characteristics in open channel flow.

(g) Turbulence measurements in water with a Pitot tube-pressure cell combination have been obtained with a frequency response of the order of $250 \mathrm{cps}$. Oscilloscope records have been analyzed by means of a digital computer and auto-correlation curves, mean intensity spectra and macro-turbulence scale have been obtained. The results compare favorably with the work of other investigators in air.

Present and future work will be concerned with the study of turbulent wakes and the decay of turbulence behind screens in open channels.

(h) "Characteristics of Pitot Tube-Pressure Cell Combination for Turbulence Measurements", B. S. Tankin, M. S. Thesis, 1954.

(579) INVESTIGATION OF FLOW CHARACTERISTICS IN UNSTEADY MOTION.

(b) Office of Naval Research, Department of the Navy.

(d) Experimental: basic research and development of instrumentation.

(e) Study of the basic flow characteristics in unsteady motion. Flows involving both frictional and separation effects have been investigated in unsteady flow water tunnel. 
(g) High frequency response electronic cells were developed for direct measurement of transient pressure differentials. These cells were employed in experiments to determine loss of head in a one-inch pipe during unsteady flows with accelerations up to $40 \mathrm{ft} / \mathrm{sec}^{2}$. A servo-mechanism has been developed to regulate the pressures governing the acceleration rates.

The first phase of experimental work in which head losses were measured at various acceleration rates has been completed. Experiments on the second phase are concerned with the measurement of losses for unsteady flow through flow metering devices. Accelerating and decelerating tests on orifices of various diameter ratios have also been completed. Further tests on Venturi-type meters are planned. Results indicate that unsteady flow effects are important when separation occurs.

(h) "Resistance Coefficients for Decelerated Flow through Orifices", R. W. Olive, M. S. Thesis, 1954.

\section{(580) FUNDAMENTAL RESEARCH ON METHODS OF AIR DISPERSTON IN AERATION PROCESSES.}

(b) Federal Security Agency, Public Health Service.

(d) Experimental; basic research.

(e) Study of the mechanics of oxygen absorption by water with the purpose of increasing the efficiency of aeration processes in the treatment of sewage and industrial wastes.

(g) The first objective of the research program, a quantitative evaluation of the mechanism of oxygen absorption from air and oxygen bubbles has been completed. Present investigations are concerned with a quantitative determination of the mixing coefficient in the diffusion equation which is a measure of the degree of turbulence associated with freely rising bubbles in a liquid column. Such information permits the prediction of air flow rates necessary to maintain material of given physical characteristics in suspension. Mixing coefficients have been obtained by measurements of sediment concentrations in a vertical column by means of a sensitive pressure cell.

(h) "Basic Factors of Oxygen Transfer in Aeration Systems", A. T. Ippen and C. E. Carver, Jr., Sewage and Industrial Wastes, Vol. 26, No. 7, July 1954 .

\section{(1355) CAVITATION INCEPTION FOR SIEADY MOTION.}

(b) Office of Naval Research, Department of the Navy.

(d) Experimental; basic research.

(e) Cavitation inception for steady motion is being studied for systematic variations in boundary layer development and in the turbulence level for the zone of minimum pressure.

(g) A closed-jet water tunnel with a rectangular test section has been developed. The working section is arranged so that the boundary layer growth is controlled by a systematic change of its shape. Provision is also made for control of turbulence level, pressure intensity, and air content.

Experiments involving the effect of velocity variation on incipient cavitation and on the influence of dissolved air content have been completed. Information on the turbulence of the flow in the cavitation region is being obtained by high-speed photographs of the cavitation bubbles.

(h) "Factors Affecting the Inception of Cavitation in a Turbulent Boundary Layer", I. Vivaldi, M. S. Thesis, 1954 .

(1608) FLOW CHARACTERISTICS OF SWING AND BALI CHECK VALVES.

(b) Atomic Energy Commission.

(d) Experimental; development.

(e) Hydraulic characteristics of the components of a heat exchange circuit are being determined. Major objective of program is the testing of development models of check valves to meet strict specifications regarding head loss, magnitude of reverse flow to cause valve closure and stability of valve components.

(g) Test circuit consists of an 8-inch pipe approximately 60 feet long with associated pressure measuring and flow metering equipment. Tests on various designs of swing and ball check valves are being continued. Interior geometry of valves are modified to obtain dynamic stability of movable components. In addition, tests have been conducted on a filter, an expansion joint, a model of an electro-magnetic pump duct and a Pitot tube of special design.

(h) "The Head Loss Characteristics of Various Control and Check Valves", R. E. DuBois, M. S. Thesis, $195^{\circ}$. 
(1609) EXPERTMENTAL STUDY OF THE SORTING OF BEACH SEDIMENTS BY WAVE ACPION.

(b) Beach Erosion Board, U. S. Army Corps of Engineers.

(d) Experimental; basic research.

(e) Quantitative study of the sorting action and selective transport of beach material by shallow water waves moving on a granular beach.

(g) Equipment consists of a wave channel 30 inches wide, 36 inches deep and 100 feet in length together with a piston type wave generating mechanism. The wave generator is controlled by a hydraulic servomechanism which permits continuous variation of both wave amplitude and frequency during operation. Beaches consist of graded materials of selected sizes and variable physical properties. The results of the sediment transport and sorting studies are related systematically to the various wave characteristics such as shape, celerity, frequency and internal velocities. A systematic series of observations of sediment particle velocities for a particular beach slope and roughness and for waves of varying characteristics has been completed. A second series of tests on a beach of different roughness is in progress. Both size and specific gravity of the spherical particles which compose the movable sediment have been varied. A series of tests on a smooth beach is also planned.

(h) "Experimental Study on Sediment Sorting by Wave Action", W. G. Kratz and W. McCollam, Jr., M. S. Thesis, 1954 .

(lól0) WATER TABLE EXPERIMENTS FOR THE STUDY OF BLAST EFFECT ON STRUCTURES.

(b) U. S. Air Force.

(d) Experimental; basic research.

(e) Investigation of water table techniques as a means of obtaining experimental information on transient shock wave diffraction pressures on structures of various shapes.

(f) Completed.

(g) Hydraulic shock waves of variable strength are created by a surge generator. As the surge impinges on an obstacle, the depth-time relationships at designated points are obtained by a capacitance type electronic depth probe. A modified hydraulic analogy has been developed for conversion of water table results to equivalent aerodynamic data. Quantitative pressure distributions as a function of time and incident shock strength have been obtained for nine structural models. Results have been compared on a dimensionless basis with shock tube tests in air on geometrically similar models. It is concluded that the water table results are quantitatively reliable with an accuracy of from 5 to $15 \%$ depending on the complexity of the model. Analysis time is estimated as one-tenth of that required for shock tube data.

(h) "Water Table Experiments on Transient Shock Wave Diffraction, Part II, Experimental Results and Evaluation", D. R. F. Harlemen, O. A. Boedtker and S. Wolf, M.I.T. Hydrodynamics Laboratory Tech. Report No. 13, Oct. 1954. "The Range of Application of the Hydraulic Analogy in Transonic and Supersonic Aerodynamics", D. R. F. Harleman and A. T. Ippen, Riabouchinsky Anniversary Volume, Pub. Scientifiques et Tech. Du Ministere De L'Air, Paris, France, May 1954.

(1881) WAVE FORCES ON OFFSHORE STRUCTURES.

(b) Humble Oil and Refining Company.

(d) Experimental; basic research.

(e) Objective is the determination, by means of model tests, of the design forces to be expected on offshore stmuctures subjected to shallow water wave action.

(g) Experimental equipment includes a 100-foot wave tank, an oscillatory wave generator of variable amplitude and frequency and a force balance for measuring dynamic forces caused by the wave motion. A systematic series of 20 tests on vertical cylinders of various diameters in waves of varying height and length have been completed. Force and moment due to wave motion are continuously recorded together with the wave profile (by means of a capacitance-type depth recorder). The data is being correlated with a theory to permit extrapolation of the model data to the range of interest in the field. Additional tests on interference effects and pile groups have been made. Further tests on submerged cylinders and barge shapes to determine both lift and drag are planned. 


\section{(2101) PELIGRE DAM (HAITI) MODEL STUDY.}

(b) Brown and Root, Inc., Houston, Texas.

(d) Experimental; design.

(e) Model to study the performance of the stilling basin under all possible operating conditions of discharge through sluices and over spillway.

(g) 1 to 40 scale model has been completed. Tests of stilling basin performance for various sluice operation conditions are in progress. Rating curves for the spillway and sluices will be obtained, and certain modifications to pier shapes at the spillway crest will be undertaken to obtain an improved distribution of flow over the face of the spillway.

\section{(2102) FREQUENCY OF DEPTH OF AFEAL RAINFALL.}

(b) Laboratory project.

(d) Analysis of data.

(e) Previous studies have usually been confined to considerations of the frequency of point rainfalls. Purpose is to develop frequency of storms over areas of different sizes in order to establish the frequency of known storms in a given area.

(g) Study has been completed for two large areas: North Atlantic Region and the Gulf coast Region. Data from the Department of the Army - Weather Bureau storm Study Program covers recurds of 115 storms over areas up to $50,000 \mathrm{sg}$. miles with durations from 6 to 96 hours.

(h) "Frequency of Depth of Areal Rainfall for North Atlantic and Gulf Coasts", R. S. Braden and T. J. Henderson, M. S. Thesis, 1954.

\section{(2103) ENERGY DISSTPATION IN STILIING BASTNS.}

(b) Laboratory project.

(d) Experimental; graduate research.

(e) General study of the basic fluid mechanics associated with energy dissipation in stilling basins.

(g) A study of the characteristics of the hydraulic jump at an abrupt drop has been made for a range of initial Froude numbers from 2.5 to 6.5 for a drop height 2, 3 and 4 times the initial depth. A second investigation of the reduction of bottom velocities in stilling basins for various lengths of basin is underway.

(h) "The Characteristics of a Hydraulic Jump at an Abrupt Drop", M. H. Silverman, B. S. Thesis, 1954 .

"Reduction of Botton Velocities in Stilling Pool", A. A. Vulgaropulos, B. S. Thesis, 1954.

MASSACHUSETTS INSTITUTE OF TECHNOLOGY, Department of Mechanical Engineering.

Inquiries concerning projects should be addressed to the following, all at Massachusetts Institute of Technology, Cambridge 39, Mass.

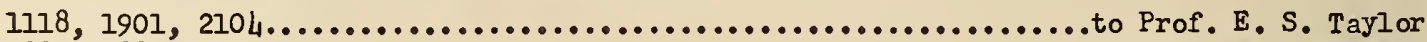

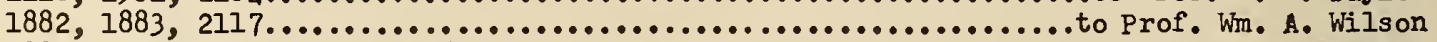

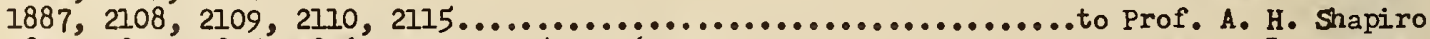

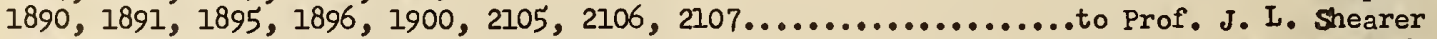

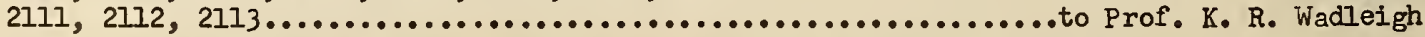

(880) RECOVERY FACTORS AND HEAT-TRANSFER COEFFICIENTS FOR SUPERSONIC FLOW OF AIR IN A TUBE.

(b) Office of Naval Research, Department of the Navy.

(c) Prof. Joseph Kaye, Mechanical Engineering Department, Massachusetts Institute of Technology, Cambridge 39, Massachusetts.

(d) Experimental and theoretical; basic research for M. S. and Sc.D. degrees.

(e) The project objectives are to measure reliable heat-transfer coefficients for supersonic flow of air in a tube to study characteristics of such flow by investigation of the fundamental differential equations, and to measure boundary layer characteristics such as velocity and temperature profiles for such flows.

(g) The publications summarize results obtained to date. 
(h) Measurements of Friction Coefficients for Supersonic Flow of Air in the Entrance Region of a Tube With and Without Heat Transfer", by J. Kaye and T. I. Toong, Sept. 1, 1953. "An Inexpensire Supersonic Wind Tunnel for Heat-Transfer Measurements, Part I - Apparatus, Data, and Results for a Laminar Boundary Layer Based on a Simple One-Dimensional Flow Model $\pitchfork$, by J. Kaye, J. H. Keenan, G. A. Brown, and R. H. Shoulberg, June 1, 1954.

- In Inexpensive Supersonic Wind Tunnel for Heat-Transfer Measurements, Part II - Results for a Laminar Boundary Layer Based on a Two-Dimensional Flow Model for the Entrance Region of a Tube", by J. Kaje and G. A. Brown, Oct. 1, 1954.

"A New Examination of the Concepts of Adiabatic-Wall Teroperature and Heat-Transfer coefficient", by T. Y. Toong, Nor. 15, 1954.

Wixperimental Velocity Profiles for Supersonic Flow of Air in a Tube With and Without Heat Transfern, by J. Kaye, G. A. Brown, J. J. Dieckmann, and E. A. Sziklas, Nov. 15, 1954.

(II18) THREE-DIMHSIONAL FLOWS IN CASCADES.

(b) Ceneral-Electric, Westinghouse, Curtiss-Wright, Allison.

(d) Experimental and theoretical in estigation; basic research in fluid dynamics.

(e) Experimental work is performed on a rectilinear cascade in a low-speed wind tunnel. Detailed pressure of stream direction measurements are made in the three-dimensional flow (end-wall) region. Resuits are intended to give a better understanding of flow through turbo-machinery. The behavior of boundary layers on casings and blades is of particular concern.

(g) Empirical data on secondary flow and boundary layer behavior in a rectilinear cascade. Theoretical consideration of boundary layer behavior.

(h) Effect of Tlp Clearance and Moving Wall on Lift Characteristics of Stationary Blades", K. V. Christie, P. J. Cunavalis, B. S. Thesis, 1954. "Effects of Moving and Tip Clearance on Secondary Flow in a Cascade", E. M. Rex, M. S. Thesis, 1954 .

Wffects of Slotted Blade TIps on Secondary Flow in a Compressor Cascade", R. F. Roache, L. R. Thomas, M. S. Thesis, 1954.

"Secondary Flow Investigation in a Ninety Degree Diffusing Bend", G. M. Wood, M. S. Thesis, 1954 .

"Secondary Flow in Axial Compressors", R. C. Dean, Jr., ScD Thesis, 1954.

"Pressure and Temperature Wakes for Stream-Iine Tracing in Three-Dimensional Flow", J. Johnston, W. Nelson, M. S. Thesis, 1954.

"A Preliminary study of Streamline Tracing and Secondary Losses in a Compressor Cascade", E. Poulos, M. S. Thesis, 1954 .

"Secondary Flow, Preliminary Report on Progress 1952-53, GTL Staff, Sept. 1954.

These reports may be obtained in photostat or microfilm from VIT Librarian, or from MIT

Gas Turbine Laboratory.

(1882) INVESTIGATION OF FLOW OF FLUIDIZED SOLIDS.

(b) Laboratory project under Grant-in-Aid from M. W. Kellogg.

(d) Analytical and experimental.

(e) The objective of this project is to produce several regimes of fluidized solids flow under controlled conditions and to retionalize the observed behavior.

(g) Properties of dense-phase down-flows have been measured.

(h) "The Properties of Fluidized Solids in Vertical Down-Flow", Master's Thesis by c. Kojabashian.

(1883) INVESTIGATION OF "REGENERATTVE TURBINE" PUMPS.

(b) Laboratory project under Grant-in-Aid from Worthington Corporation.

(d) Analytical and experimental.

(e) The objective of this project is the rationalization of the performance characteristics of "friction" pumps and the determination of the relationship between these characteristics and the design parameters.

(f) Inactive. 
(g) A satisfactory theoretical model has been devised and shown to be adequate to account for the performance of at least one commercial unit. The relationship of performance to casing geometry has been measured and rationalized.

(h) "Experimental Investigation of Variables Affecting Regenerative Pump Performance", M. A. Santalo, Master's Thesis.

"A Hypothesis of the Fluid Dynamic Mechanism of Regenerative Pumps", W. A. Wilson, M. A. Santalo, John Delrich, ASME Preprint 54-A-59.

"Relationship of Regenerative Pump Performance to Casing Geometry", W. A. Wilson, M. A. Santalo, John Oelrich, ASME Preprint 54-A-60.

\section{(1884) EXPERTMENTAL AND ANALYTICAL INVESTIGATION OF A CYCLONE DUST SEPARATOR.}

(b) Sponsored by Jabez-Burns and Sons, Inc., New York City.

(c) Prof. Joseph H. Keenan, Massachusetts Institute of Technology, Cambridge 39, Mass.

(d) Effect of variation of geometry of separator on separating efficiency.

(e) A fine dust is fed continuously over a time interval to the air stream entering a cyclone separator. The amount of dust separated is measured for various inlet and outlet dimensions.

(h) Master's Theses by R. Shuart, and R. T. Salter.

(1887) THEORY OF DISCHARCE COEFFICIENTS FOR ROUNDED-ENTRANGE FLOWMETERS AND VENTURIS.

(b) Laboratory project.

(d) Theoretical; applied research.

(e) A theory of rounded-entrance flowmeters, based on a consideration of the potential and boundary layer flows in a converging nozzle, is constructed. Curves are presented showing the discharge coefficient as a function of diameter Reynolds Number, with the "total equivalent length-diameter ratio" of the nozzle as a parameter. An investigation of the frictional equivalent length-diameter ratio of the contraction section of the A.S.M.E. long-radius nozzle shows this ratio to decrease from a value of about 0.56 at a diameter Reynolds Number of $1,000,000$ to a value of about 0.25 at a diameter Reynolds Number of about 1,000; in the range of diameter Reynolds Numbers from about 1 to 1000 , the equivalent length-diameter ratio is about 0.2. The theoretical curves of discharge coefficient vs. Reynolds Number are in good agreement with experiment.

(f) Completed.

(g) A rational theory for rounded-entrance flowmeters has been developed, agreeing with known experimental data.

(h) "On the Theory of Discharge Coefficients for Rounded-Entrance Flowmeters and Venturis", by Miguel A. Rivas, Jr. and Ascher H. Shapiro. To be published by A.S.M.E.

(1890) STATIC AND DYNAMIC CHARACTERISTICS OF PRESSURIZED AIR BEARTNGS.

(b) Laboratory project.

(d) Basic and applied research.

(e) In order to gain a better understanding of the behavior of pressurized, journal bearings having no external flow resistances, basic studies have been made of the flow between closely spaced flat plates. The results of this basic work were applied to the design of a pressurized air bearing which was used in an experimental investigation of dynamic characteristics of this type of bearing.

(g) Non-dimensionalized graphs have been obtained showing the pressure distribution for various flow configurations between parallel and non-parallel flat plates. A design procedure has been worked out to make it possible to design a bearing to meet specified steady-state requirements, and a bearing has been built and tested which verifies the design procedure. This same bearing has been analyzed dynamically and the analysis and experimental dynamic tests indicate that this bearing is adequate for a wide range of applications.

(h) "A Study of Pressurized Air Bearing Design Steady Loading -- No Rotation", by S. K. Grimell, S. M. Thesis, Massachusetts Institute of Technology, Feb. 1954. M.I.T. Library will furnish quotation on microfilm or photocopy upon request. 
(1891) DYNAMIC GHARACTERISTICS OF PFESSURIZED IIQUID BEARTNGS.

(b) Laboratory project.

(d) Applied research.

(e) Analytical and experimental techniques are employed to study the dynamic performance of pressurized liquid bearings. Electronlc analogue studies are plamed to augment the experimental work and provide useful design data for bearings of this kind.

(f) Completed.

(g) The work that has been done shows that the dynamic performance of pressurized liquid bearings is adequate for a wide range of applications and that the analytical techniques developed are useful in estimating the dynamic performance of these bearings. of particular interest is the major role played by so-called squeeze action of oil in the clearance spaces in providing adequate system damping.

(h) "Dynamic Analysis of Extermally Pressurized Bearings", by Max Luming, S. M. Thesis, Massachusetts Institute of Technology, Feb. 1954. M.I.T. Library will furnish quotation on microfilm or photocopy upon request.

(1895) EFHECTS OF FLUID MASS AND COMPEESSIBILITY ON CONTROL VALVE STROKTNG FORCES.

(b) Bureau of Ordnance, Department of the Navy, U. S. Air Force, Wright Air Development Center.

(d) Basic research.

(e) I fundamental investigation has been made into the nature of the dynamic flow forces uncountered in valves when the mass of the fluid in the connecting passages is significant. This work has also been extended to a study of situations that occur when both fluid mass and compressibility are significant.

(g) A thorough analysis reveals that the mass of the fluid in the passages of a valvecontrolled hydraulic system can have an important influence on the dynamic forces. exerted by the fluid on the moving member of the control valve. Experimental results were inconclusive because of insufficient instrunentation and the compromising effects of fluid compressibility. It was found that in many cases it is necessary to consider the effects of contimuously distributed fluid mass and compressibility in the lines leading to a hydraulic valve.

(h) "Stability of Flow Control Valves", by George Friedensohn, S. M. Thesis, Jan. 1954, Mechanical Engineering, M.I.T., 77 Massachusetts Avemue, Cambridge 39, Mass., M.I.T. Library will furnish quotation on microfilm or photocopy upon request.

A Doctoral thesis investigation is now being carried on by $\mathrm{Nr}$. F. D. Ezekiel, Dept. of Mech. Eng., Massachusetts Institute of Technology, Cambridge 39, Mass.

(1896) FUNDAMENTAL SIUDY OF THE DESIGN OF PNEUMATIC CONTROL SISTEMS.

(b) Bureau of Ordnance, Department of the Navy.

(d) Applied research and design.

(e) A comprehensive design study has been made of a typical valve-controlled-ram-plus-load system. The approach was made in the most general manner possible so that the results could be applied to a wide variety of pneumatic systems. Since the characteristics of some of the system components were not thoroughly known, part of the effort was expended on gaining a better understanding of the basic processes involved in the operation of a system of this kind. Although no work has been done on this project with contimously distributed effects such as long lines, it is vital that some of these effects be studied in terms of over-all system performance.

(g) A doctoral thesis in estigation has been completed which shows how to employ analytical and graphical representations of system components in over-all system analyses, using linear techniques to the fullest extent possible. A non-linear analogue study and experiments with a typical system in the laboratory revealed the extent to which a linearized analysis may be carried with reliability. As a result of the dynamic studies of the valve, ram, and load system, a clear evaluation was made of various means of attaining adequate system damping.

(h) "Contimuous Control of Motion with Compressed Air", by J. L. Shearer, Sc.D. Thesis, Massachusetts Institute of Technology, June, 1954. Quotations on microfilm or photocopy available on request from the M.I.T. Library. 
(1900) PRESSURE-FLOW CHARACTERISTICS OF PNEUMATIC VALVES.

(b) Bureau of Ordnance, Department of the Navy.

(d) Applied research.

(e) Flow versus pressure curves at various valve openings have been obtained analytically for various 3-way valve configurations and experimental curves are being obtained for a number of real valves.

(g) An experimental study of a large-scale, two-dimensional model of the flow in a slide $v_{a l v e}$ has been completed which revealed that there are two possible flow regimes in this type of valve. With one regime, the flow discharge coefficient is nearly 1.0, and with the other, the discharge coefficient is approximately 0.8 .

Quantitative measurements have been made of the pressure-flow characteristics of a closedcenter, slide-type, three-way valve ${ }^{2}$. The effects of side leakage in the clearance spaces of the valve is evident at small $v$ alve opening conditions, but otherwise the results seem to agree well with analytically derived characteristics.

Measurements have also been made of a flapper-type three-way valve3. In addition to pressure-flow characteristics, the steady-state flapper force characteristics have been measured.

(h) "An Experimental Study of Two Dimensional Gas Flow Through Valve-Type Orifices", A. H. Stenning, presented at the 1954 Annual Meeting of the ASME, preprints available from the ASME.

"Continuous Control of Motion with Compressed Air", J. L. Shearer, (See separate chapter on Valve Characteristics), M.I.T. Sc.D. Thesis, Cambridge 39, Mass. M.I.T. Library will furnish quotation on microfilm or photocopy upon request.

SC.D. Thesis by G. Reethof, Assistant Prof. of Mech. Eng., M.I.T. nearly complete. This thesis will have a separate section on valve characteristics.

\section{(1901) CENTRIFUGAL DIFFUSER STUDY.}

(b) General Electric Co., Allis on, Westinghouse, Curtiss-Wright.

(d) Experimental and theoretical; applied research.

(e) The project is aimed at understanding and in proving the behavior of centrifugal compressor diffusers. The ultimate goal is to evolve a rational method of design.

(g) (1) Experimental data on flow in a centrifugal diffuser, and (2) theoretical analysis of wall boundary layer flow.

(h) "Experimental and Theoretical Study of Vaneless Diffuser Flow with Supersonic Entry", C. R. Faulders, Gas Turbine Laboratory, Massachusetts Institute of Technology, Cambridge 39, Mass., 1952 .

"An Aerodynamic Investigation of Vaned Diffusers for Centrifugal Compressors", C. R. Faulders, Gas Turbine Laboratory, Massachusetts Institute of Technology, Cambridge 39, Mass., Jan. 1954.

"Experimental Data on Three-Dimensional Flow in a Centrifugal Compressor Diffuser", J. P. Johnston, Report of Research Activities 1953-1954, Gas Turbine Laboratory, Massachusetts Institute of Technology, Cambridge 39, Mass., Dec. 1954.

\section{(1903) TNVESTIGATION OF ROTATING STALI IN AXIAL COMPRESSORS.}

(b) National Advisory Committee for Aeronautics.

(c) Prof. A. H. Stenning, Massachusetts Institute of Technology, Cambridge 39, Mass.

(d) Applied research.

(e) A theoretical and experimental study of rotating stall, using a stationary circular cascade fitted with windows for Schlieren observation, and a single stage axial compressor. The object of the study is to obtain a fundamental understanding of the phenomenon of rotating stall observed in turbo-compressors.

(g) Rotating stall has been obtained in the stationary cascade and measurements of propagation velocity, number of stall cells, and pressure fluctuations are being made.

(h) "Stall Propagation in Cascades of Airfoils", by A. H. Stenning, Journal of Aeronautical Sciences, Oct. 1954, pp. 711-713.

"Stall Propagation in a Cascade of Airfoils", by A. H. Stenning, Gas Turbine Laboratory Report No. 25, M.I.T., May 1954 .

"A Cascade Tunnel for Investigation of Rotating Stall", by A. R. Kriebel and A. H. Steming, Gas Turbine Laboratory Report No. 26, Aug. 1954 .

These publications are progress reports to the N.A.C.A. and may be obtained only through the N.A.C.A. 
(2104) THHEE-DIMENSIOHAL FLOWS IN COMPEESSORS.

(b) Office of Naval Research, Department of the Navy.

(d) Project is applied research using both experimental and theoretical methods. Thesis work (bachelor's, master's and doctor's) is carried out on the project.

(e) Three-dimensional flows in a single stage axial compressor are being studied. The complete flow pattern throughout a stage is observed to provide a clear picture of the nature of flow through a turbomachine. Methods of predicting the flow with accuracs are being sought.

(g) A method of calculating "secondary velocities" which arise when a stream with a stagnation pressure gradient flows around a $90^{\circ}$ bend was derived. A theory of vorticity transport through a blade row has been evolved. An approximate method of designing axdal turbomachines based on the "simple radial equilibriurn" assumption has been devised. The method does not require the use of calculating machines.

(h) "Shear Flow in Bends", H. P. Eichenberger, Office of Naval Research Technical Report, 1952. - Worticity and Vortex Sheets in Axial Turbomachines", G. L. Kellor, S. M. Thesis, Sept. 1954 .

"Investigation of Velocity Profile Generators", L. H. Bartolink, S. M. Thesis, Sept. 1954.

(2105) A MTIITUES VALVE ACTUATOR - HYDRAULIC AND PNEUMATIC CONTROL SFSTEMS.

(b) Bureau of Ordnance, Department of the Navy, J. S. Air Force, Wright Air Development Center.

(d) Design and development.

(e) Iminiature valve-controlled hydraulic servomotor employing an electro-mechanical torque motor and mechanical feedback has been developed to stroke precision control valves with simplicity, reliability and speed of response as major objectives in the design.

(g) A single unit has been operated successfully for a limited period of time. It is capable of delivering an output motion of .050 inch with an available force of $50 \mathrm{lb}$ when operating with hydraulic oil supplied at $2000 \mathrm{psi}$. The natural frequency of this unit is 400 cycles/sec when operating with a maximum output stroke of .030 inch. A second unit of this type has been designed to have increased force level (150 lb) and increased stroke (.060 in.). This new unit is under construction.

(h) "Development of a Miniature Electrohydraulic Actuator", by S.-Y. Lee and J. L. Shearer, ASE Paper No. 54-\$-196, prepared for presentation at the 1954 Annual Meeting of the $\triangle S W E$. Preprints available from the ASME.

(2106) DESIGN OF A POSTTIVE DISPLAGEMENT ROTARY AIR MOTOR.

(b) U. S. Air Force, Wright Air Development Center.

(d) Design and development.

(e) unit is being designed to operate on air at room temperature and pressures up to 500 psi with a maximum speed of about $5000 \mathrm{rpm}$.

(h) K. S. Thesis by H. Kolm in preparation,

(2107) A STUDY OF THE STATIC AND DYNAKIC CHARACTERISTICS OF A "JET PIPE" TYPE CONTROL VALVE.

(b) Laboratory project.

(d) Basic research.

(e) A fundamental study is planned to try and discover the upper limits of performance that may be obtained with this type of flow moculating device. This is to be a doctoral thesis investigation.

(2108) FRTCTION IN TUBE ENTRY FOR LAMTIAR COMPFESSIBLE FLOW.

(b) Laboratory project.

(d) Theoretical; applied research.

(e) A simple, approximate method for determining longitudinal pressure and Mach Number variations for laminar flow in a tube entry is developed for the case where the boundary layer is thin compared with the tube radius.

(f) Completed 
(g) Results of the theory are presented in convenient form for practical calculations. Good agreement exists between the approximate, simple method and experimental data.

(h) "Theoretical Investigation of Frictional Effects for Laminar Compressible Flow in a Tube Entry", by Tau-Yi-Toong and Ascher H. Shapiro, to be published in the Anniversary Volume on Fifty Years of Boundary Layer Theory.

(2109) FRICIION IN TUBE ENTRY FOR LAMINAR, INCOMPRESSIBLE FLOW.

(b) Office of Naval Research, Department of the Navy and National Advisory Committee for Aeronautics.

(d) Experimental and theoretical; applied research for doctoral theses.

(e) The apparent friction factor for steady, incompressible flow in the laminar entry region of a smooth tube was studied experimentally and theoretically.

(f) Completed.

(g) Experimental and theoretical results are worked out fully, and are in good agreement with each other.

(h) "Friction Factor in the Laminar Entry Region of a Smooth Tube", by Ascher H. Shapiro, Robert Siegel, and Stephen J. Kline, to be published in Prcseedings of second U. S. National Congress of Applied Mechanics.

(2I10) GASDYNAMICS OF ARBITRARY FLUID.

(b) Laboratory project.

(d) Theoretical; basic research.

(e) Four common, simple, steady one-dimensional motions were examined for a single-phase pure fluid substance: (1) Isentropic flow, (2) Rayleigh curve process, (3) Normal shock waves, (4) Fanno curve process.

(f) Completed.

(g) The behavior of the several flows is shown to depend on the curvature of the pressurevolume isentrope and on whether the constant-volume pressure-entropy derivative is positive or negative.

(h) "One-Dimensional, Steady Gasdynamics for an Arbitrary Fluid", by S. J. Kline and A. H. Shapiro, Extrait des Memoires sur la Mécanique des Fluides, offerts a M. D. Riabouchinsky a l'occasion de son Jubilé Scientifique, Publications Scientifiques et Techniques du Ministere de 1'Air, Paris, 1954, pp 171-202.

(2III) STUDY OF ATOMIZATION OF IIQUIDS INJECTED INTO HIGH VELOCITY GAS STREAMS.

(b) Office of Naval Research, Department of the Navy.

(d) Theoretical and experimental applied research carried out under several theses.

(e) To study the formation of liquid water droplets injected axially into a high-velocity gas stream, a drop-size measuring probe and a photometric drop-size measuring instrument are being developed. In the probe, measurements of static pressure variation caused by droplets decelerating in a stagnant gas indicate drop size. In the photometric instrument, measurements of light intensity which passes through a suspension indicate drop size. Future work utilizing these instruments will study experimentally the influence of variations in operating parameters on drop size, drop-formation distance, and spatial distribution of drops.

(g) Initial tests of both probe and photometric device using glass beads in oil and air for calibration have indicated feasibility of methods. Development contimues.

(h) "A Study of an Optical Method for Measuring Particle Sizes in Aerosols", John McGrew, Thesis for S. B. degree, M.I.T., 1954 .

"The Photometric Measurement of Particle Size", J. B. Cheatham, Jr., Thesis of M. E. degree, M.I.T., 1954.

"Measurement of Droplet Size in Aerosols by Modified Impact Probe", G. E. Keeler, Thesis for S. B. Degree, M.I.T., 1954.

"Theoretical and Experimental Investigation of a Deceleration Probe", Jules Doussord, Thesis for Sc.D. degree, M.I,T., 1954. 
(2112) STUDY OF TWO-STROKE ENGINE SCAVENGING PROCESS.

(b) Laboratory project.

(d) Study of the effects of geometry and valve timing on scavenging.

(e) A special cylinder with variable inlet porting and poppet exhaust valves in the head whose timing and lift can be varied.

(f) Engine in construction.

(g) Test cylinder $50 \%$ complete.

(2I13) DEVELOPMENT OF INSTRUNENTATION TO MEASURE PROPERTIES OF HIGH-VELOCITY GAS STREAMS CONTAINING IILUID DROPLETS IN SUSPENSION.

(b) Office of Naval Research, Department of the Navy.

(d) Theoretical and experimental; applied research carried out under several theses.

(e) Special instruments are being developed for the following purposes: (1) Measurement of local specific humidity of high-speed stream of mixture of air-water vapor and liquid droplets by withdrawal of sample of gas phase alone. (2) Measurement of total water content of above stream by withdrawal of representative sample of liquid-vapor mixture. (3) Measurement of local stagnation pressure of gas with suspended liquid droplets.

(g) Suitable probes to. withdraw representative samples of vapor phase alone and of vaporliquid mixtures have been tested with generally satisfactory results. A probe for measurement of gas stagnation pressure of liquid-vapor streams has been developed.

(h) "An Experimental Investigation of a Small-Scale Aerothermopressor", K. R. Wadleigh, Thesis for SCD degree, M.I.T., 1953.

"Techniques for Measuring Specific Humidity of a High-Temperature, High-Speed Gas Stream", H. K. Larson, Thesis for S. M. degree, M.I.T., 1954.

"A Sampling Technique for the Measurement of Water-Air Ratio of a High Speed Spray", R. E. Kosiba and F.H.E. Vose, Thesis for Naval Arch. and Eng. Degree, M.I.T., 1953. "Theoretical and Experimental Investigation of a Deceleration Probe", Jules Doussord, Thesis for ScD degree, M.I.T., 1954.

(2114) A TRANSITIONAL PHENOMENON FOR FLOW IN THE ENTRANCE REGION OF A TUBE.

(b) Laboratory project.

(c) Prof. T. Y. Toong, Massachusetts Institute of Technology, Cambridge 39, Mass.

(d) Theoretical; basic research for master's thesis.

(e) Flow characteristics, upstream and downstream of a sudden transition in a stream of a compressible fluid, have been analyzed with the use of equations of continuity, momentum, and energy. The computations were made for two particular forms of velocity profile on the two sides of the transition.

(f) Suspended.

(g) Downstream center-line Mach number, change of entropy flux, and static-pressure ratio across the transition have been calculated for different values of upstream center-line Mach mumber and boundary-layer thickness-ratio. Physical significance of this work is to be studied.

(h) "A Transitional Phenomenon for Flow in the Entrance Region of a Tube", T. N. Chen, S. M. Thesis, 1953.

(2115) THEORETICAL INVESTIGATION OF FRICTIONAL EFFECTS FOR LAMINAR COMPRESSIBLE FLON IN A TUBE ENTRY.

(b) Laboratory project.

(d) Theoretical; basic research.

(e) An approximate integral method is used for calculating the longitudinal pressure distribution of a laminar compressible flow in the entrance region of a tube. The method is based on the observation that when the boundary layer is thin, its growth along the tube is approximated by that for laminar flow over a flat plate.

(f) Completed 
(g) The integral method has been used to compute the longitudinal pressure distribution, the mean pressure-gradient coefficient and the mean apparent friction factor for a laminar compressible flow in the entrance region of a round tube, for several entrance Mach numbers and thermal conditions at the wall. In the case of constant values of specific heat, absolute viscosity and thermol conductivity of the compressible fluid, the computed approximate results are compared with those obtained by solving exactly the partial differential equations of motion. In the region where the integral method is considered to be valid, the agreement is within $5 \%$, thus indicating the reliability of the procedure.

In the case of temperature-dependent viscosity and thermal conductivity, the computed results are compared with those obtained experimentally at an entrance Mach mumber of 2.8 , and the agreement is within $8 \%$.

(h) "Theoretical Investigation of Frictional Effects for Laminar Compressible Flow in a Tube Entry", T. Y. Toong and A. H. Shapiro. Prepared for the Anniversary Volume on Fifty Years of Boundary Layer Theory, Göttingen, Germany, June 1954.

(2116) THERMODYNAMIC TEMPERATURE MEASURING PROBE.

(b) Wright Air Development Center.

(c) Prof. John A. Clark, Dept. of Mechanical Engineering, Massachusetts Institute of Technology, Cambridge 39, Mass.

(d) Experimental and theoretical; master's thesis.

(e) A study of the fluid mechanics of the flow into the entrance of an open probe and the effect of the flow on the determination of the static thermodynamic temperature of the stream.

(f) Completed.

(g) At room temperature the static temperature of air streams were measured reproducibly within 1\% for Mach numbers up to 0.60 . Results indicate an improved accuracy at higher subsonic Mach numbers.

(h) Technical Report No. I, DIC Project 5-7130, by J. A. Lehtinen, J. A. Clark, W. M. Rohsenow.

(2117) TNVESTIGATION OF RADIAL INFLOW TURBINE PERFORMANGE.

(b) Laboratory project under Grant-in-Aid from Electrolux Corporation.

(d) Analytical and experimental.

(e) The objective of this project is to determine the existence of and quantitative character of the effect of centrifugal field on irreversibilities in the flow through simple radial flow expander impellers.

(f) Inactive.

(g) An effect has been demonstrated and measured quantitatively for a few combinations of the several independent variables of design and operation.

(h) "The effect of the Centrifugal Field on Losses in a Radial Inflow Turbine Rotor", J. A. Meyer, Master's Thesis.

"Loss Coefficients in Centrifugal Turbine Rotors", D. E. Magnus, Master's Thesis.

MASSACHOSETTS INSTITUTE OF TECHNOLOGI, Department of Naval Architecture and Marine Engineering.

(1904) THE CHARACTERISTICS OF A SERIES OF CONTROLLABLE PITCH PROPELLERS.

(b) Office of Naval Research. Department of the Navy.

(c) Prof. F. M. Lewis, Propeller Tunnel, Department of Naval Architecture and Marine Engineering, Massachusetts Institute of Technology, Cambridge 39, Mass.

(d) Applied research.

(e) A Series of Controllable Pitch Propellers is being tested in the Model Tunnel under both cavitating and non-cavitating conditions for a range of pitch settings and operating conditions. 
(2118) FORCES ON ADJACENT STRUCTURE CAUSED BY A PROPELIER.

(b) Laboratory project.

(c) Prof. F. M. Lewis, Propeller Tunnel, Department of Naval Architecture and Marine Engineering, Massachusetts Institute of Technology, Cambridge 39, Mass.

(d) Applied research; for naval engineer thesis.

(e) A model of a strut will be mounted in the Propeller Tunnel upstream of a propeller operated under various conditions. The forces on the strut caused by propeller action will be messured. This project is associated with, but not actively sponsored by, The Society of Naval Architects and Marine Engineers, under a program investigating the hydrodynamic forces associated with propeller action on ships.

(2119) THE EFFECT OF HYDROFOIIS ON THE WAVEMAKING AND SEAKEEPING CHARACTERISTICS OF SHIPS.

(b) Office of Naval Research, Department of the Navy.

(c) Prof. M. A. Abkowitz, Director, Ship Model Towing Tank, Department of Naval Architecture and Marine Engl neering, Massachusetts Institute of Technology, Cambridge 39, Mass.

(d) Experimental; applied research.

(e) The use of a hydrofoil to produce a low pressure field and wave hollow at the proper location on a ship in order to recuce overall wave resistance is being investigated. Model tests with hydrofolls placed at the bow or stern are being conducted. Tests are also being conducted in waves to investigate the seakeeping aspects of the ship with attached hydrofoils.

(h) "A Device for Reducing the Wave Resistance of a Ship", John Randolph Paulling, Jr., S. B., M.I.T. Thesis, NA+ME Department. "Hydrodynamic Control of Trim and Wavemaking at High Speeds", S. M., M.I.T. Thesis, NA+ME Department.

"The Effect of a Swept-Back Hydrofoil upon the Resistance Coefficient of a Ship", S. B., M.I.T. Thesis, NA+ME Department, Anselm L. Beal and Abraham Zakay.

"The Ship Model Towing Tank at M.I.T.", M. A. Abkowitz and J. R. Paulling, Jr., The Soc. of Naval Architects and Marine Engineers, 1953.

"Model Seaworthiness Testing Technique and the Effect of Anti-Pitching Fins", J. R. Paulling, Jr., S. M. Thesis, NA+ME Department, M.I.T.

(2120) SEAKEEPING QUALITIES OF SHIPS.

(b) The Society of Naval Architects and Marine Engineers.

(c) Prof. M. A. Abkowitz, Director, Ship Model Towing Tank, Department of Naval Architecture and Marine Engineering, Massachuestts Institute of Technology, Cambridge 39, Massachusetts.

(d) Experimental, applied research.

(e) The project consists of testing a serles of ship models in waves to determine those features of a ship's design which contribute to better seakeeping qualities. The wave size and height are varied as well as the model speed. Design features which are to be investigated include variations in displacement, flare, freeboard, sheer, shape of bow, and shape of stern. The parent model is the series 60 , Block 0.70 design.

UNIVERSTTY OF MASSACHUSETTS, Department of Civil Engineering.

(1905) DETERMINATION OF LIFT COEFFICIENTS OF CILTNDERS PLANING IN TROUGHS.

(b) Laboratory project.

(c) Dean George A. Marston, Director of Engineering Research Institute, University of Massachusetts, Amherst, Mass.

(d) Master's thesis.

(e) Iift forces on cylinders planing in trough and on plane water surfaces are being determined by means of a beam and SR-4 gage arrangement.

(f) Completed.

(g) Data relating lift coefficient to Froud number was obtained. 
(2121) EFFECT OF AIR POCKET FORMATION AT THE SUMIT OF A PRESSUEE PIPE SYSIEM ON FLOW THROUGH THE SISTEM.

(b) Laboratory project.

(c) Dean George A. Marston, Engineering Research Institute, University of Massachusetts, Amherst, Mass.

(d) Experimental; applied research.

(e) The purpose of the investigation is to correlate the amount of air pocket formation, and the resultant head loss, with the angle of a vertical bend and the velocity of flow through a system.

MICHIGAN STATE COLIEGE, Department of Civil Engineering.

Inquirles concerning Projects Nos. 2122 and 2123 should be addressed to Prof. Harold R. Henry, and concerning Projects Nos. 2125 to 2128, incl., should be addressed to Mr. E. H. Kidder, Civil Engineering Dept., Michigan State College, East Lansing, Mich.

(2122) DEVELOPMENT OF THE BOUNDARY LAYER IN THE ENTRANGE TO A PIPE.

(b) Laboratory project.

(d) Experimental and theoretical, basic research for doctor's thesis.

(e) Velocity and pressure measurements obtained to determine boundary layer growth and characteristics. Also analytical study used in interpreting and analyzing experimental results.

(g) As of the present the tests have been of a preliminary and exploratory nature.

(2123) DEVELOPMENT OF A BOUNDARY LAYER IN A DIFFUSER NEAR THE ENTRANCE OF A PIPE.

(b) Laboratory project.

(d) Experimental and theoretical; basic research.

(e) A diffuser section increasing from two inches diameter with an included angle of $6^{\circ}$ is attached to a two-inch pipe at various distances from the pipe entrance. Velocity traverses are made and pressure drop recorded. An analytical study conducted in parallel is used as a guide.

(g) In preliminary stage.

(2124) AVALLABILITY OF GROUND WATER IN ARTESIAN AQUIFER UNDERLYING THE MICHIGAN STATE COLLEGE CAMPU'S AND FARM AREA.

(b) Michigan State College.

(c) Norman E. Tufford, Mechanicel Engineer Buildings and Utilities Department, Michigan State College, East Lansing, Michigan.

(d) Field research for purposes of development.

(e) Geophysical studies through use of aquifer performance testing advocated by Jacob and Theis and others, and also through use of earth resistivity methods.

(g) Nothing definite has been concluded as yet but some very encouraging and useful tests have been conducted.

(2125) SEDTMENT TRANSPORT IN RUNOFF WATER FROM SMALL AGRICULTURAL WATERSHEDS.

(b) Mich. Agr. Exp. Sta.

(d) Field investigation; for design.

(e) Semples of runoff water from small watersheds will be collected to determine the concentration and size of sediment in transport. Punoff gagisu stations are being operated and samples obtained from two watersheds in a drainage type topography. An attempt will be made to determine the source of sediment. 


\section{(2126) SURFACE AND SUBSURFACE DRAINAGE.}

(b) Michigan Agr. Exp. Sta.

(d) Experimental, field investigation; applied research.

(e) To study the effect of bedding, bedding and moling, bedding and tile and tile drainage on the yields in a sub-marginal cropping area. Crop yields in a grain-grain-hay-hay rotation are measured in increments away from the drainage feature.

(g) Sixty-feet spacing, tile and bedding, produced the highest oat yields; two-rod spacing, tile only, produced the highest hay yields.

(2127) AN INVESTIGATION OF THE STABILITY AND DURABTLITY OF SUBSURFACE DRATNS PLACED IN MUCK.

(b) Michigan Agricultural Experiment Station.

(d) Experimental, field investigation; applied research.

(e) To study the stability and durability of subsurface drains in muck soils, four different materials and different lengths of these materials were pleced in a newly cleared muck area (pH of 6.0). Concrete and clay tile in one and two foot lengths; perforated steel pipe in eight-foot lengths and perforatea fiber pipe in six-foot lengths were installed. Elevations and quality of these materials are checked periodically.

(2128) FROST PROTECTION OF PLANTS BY THE CONIINUOUS APPLICATION OF WATER THROUGH OVERHEAD IRRIGATION SYSTEMS.

(b) Nichigan Agricultural Experiment Station.

(d) Experimental and field investigation; applied research for the development of design criteria for irrigation systems used for frost protection.

(e) Tests have been conducted in the field to determine the minimum water application rate, sprinkler rotationel speed, sprinkler spacing and other design factors on the effectiveness of this method for varying temperatures on different crops.

(g) Strawberry blossoms, tomatoes and peppers have been protected against temperatures as low as $20^{\circ} \mathrm{F}$.

(h) "Frost Protection by Sprinkler Irrigation: A Field Survey", W. Bilanski, J. R. Davis and E. M. Kidder, Michigan Agricultural Experiment Station, Quarterly Bulletin Article 36-45, May 1954.

"Protection of Garden Crops against Frost Damage by the Use of Overhead Irrigation", Walter Bilanski, Master's Thesis, Michigan State College, June 1954. (Available on loan).

UNIVERSITY OF MICHIGAN, Department of Civil Engineering.

(2129) DEVELOPMENT OF OPEN CHANNEL FLOW CONTROL.

(b) Rackham Research Grant.

(c) Prof. v. L. Streeter, 322 W. Engineering Bldg., Ann Arbor, Michigan.

(d) Basic research.

(e) To apply the principle of a nonlinear spring single orifice flow control to open channel flow.

(2130) MODEL STUDY OF BLACK RIVER HARBOR.

(b) Michigan State Waterways Commission.

(c) Prof. E. F. Brater, 320 W. Engineering Bldg, Ann Arbor, Michigan.

(d) Experimental.

(e) To determine the breakwater arrangement which will produce the most effective economical harbor. 


\section{(2131) THE DETERMINATION OF THE EFFECT OF WAVE ACTION ON FLOATTNG DRTHUING BARCES.}

(b) Bethlehem Steel Company.

(c) Mr. J. E. Steele, Chief of Design, Bethlehem Steel Company, Shipbuilding Division, Beaumont, Texas.

(d) Experimental.

(e) To determine the action of anchored and towed barges under the influence of storm waves.

(f) Completed.

(g) The information obtained was used to prepare the final design.

UNIVERSITY OF MICHIGAN, Experimental Naval Tank.

Inquiries concerning Projects Nos. 585, 1127, 1128, 1378, 1906, and 2132 should be addressed to Prof. L. A. Baier, 326 West Engineering Building, University of Michigan, Ann Arbor, Mich.

(585) RESIST ANCE OF BARCF TOWS.

(b) Corps of Engineers, Department of the Army.

(d) Experimental; design.

(e) To determine resistance of several formations of certain barge types relative to nonrestricted straight channels and to selected channels restricted in width and depth. Each run will consist of movement of one model formation, at one draft and one depth of water for a given channel condition through a range of velocities sufficient to define a curve of functions of resistance versus velocity.

(f) Tank work completed.

(h) Report in preparation.

(1127) TRANSOM TMERSTON ON HIGH-SPEED MOTORBOATS.

(b) Laboratory project.

(d) Research; design.

(e) Tests are being conducted to determine the most efficient transom inmersion for $v$ arious high speed hull forms.

(1128) COMMERCIAL VESSELS, 150 to 250 FEET IN LENGTH.

(b) Fairbanks, Morse, and Company.

(d) Experimental; design.

(e) A large family of hull forms is being tested in order to provide design data for the future design of commercial vessels, 150 to 250 feet in length.

(1378) VIBRATION ELIMTNATION.

(b) Laboratory project.

(d) Experimental.

(e) Design and testing of fins fitted to both single and multiple screw hulls in way of propeller aperture in order to eliminate fantail vibration. Emphasis placed on twin screw fantall vibration.

(1906) FORM DESIGN, GREAT LAKES CARRIERS.

(b) Bradley Transportation Line.

(d) Experimental.

(e) Design and testing of four types of hull forms suitable for large cargo carriers on the Great Lakes, including self-propelled tests.

(f) Completed. 
Missouri School of Mines and Metallurgy

Oniversity of Missouri

Newport News Shipbuilding and Dry Dock Company

(2232) SKEEG DESIGN FOR CONTROL OF YAW.

(b) Laboratory project.

(d) Experimental; applied research.

(e) Design and testing of varlous types of skegs for use on towed barges where control of yaw is required. The purpose is to obtain positive operating skegs with a minimum of resistance and cost of installation.

(f) $75 \%$ completed.

(h) Report of present status to be given as a paper before the Gulf section of the Society of Naval Architects and Marine Engineers, Spring Meeting, 1955.

MISSOURI SCHOOL OF MINES AND METALLURGY, Department of Civil Engineering.

(2133) CHARACTERISTICS OF COMPHESSIBLE ORIFIGE FLOW.

(b) Laboratory project.

(c) Prof. Clifford D. Muir, Civil Engineering Department, Missouri School of Mines and Mettalurgy, Rolla, Mo.

(d) Experimental.

(e) Primarily a study of oriflce coefficients using compressed air as the test fluid. It is felt that this project will confirm sone proposed orifice coefficients and serve as a basis for an enlarged study of several orifice characteristics, such as head loss, shape offect, etc.

(f) Recentiy activated.

UNIVERSITY OF MISSWRT, Department of Civil Engineering.

(2134) HEAD LOSSES IN STORM DRATN JUNCTIONS.

(b) Cooperative with State Highway Department of Missouri and the U. S. Bureau of Public Roads.

(c) Prof. H. W. Wood, Department of Civil Englneering, Jniversity of Missouri, Columbia Mo.

(d) Experimental; applied research.

(e) To determine the extent of head losses in storm drain junction boxes as affected by variations in size of box relative to pipe size, change of pipe size at junction, arrangement and relative sizes of pipes, and means for reducing loss.

NEWPORT NEWS SHPBUILDING AND DRY DOCK COMPANY.

Inquiries concerning Projects Nos. 123, 124, 896, 901, 1132, 1133, 1136, and 1634, should be addressed to Mr. C. H. Hancock, Hydraulic Laboratory, Newport News Shipbuilding and Dry Dock Company, Newport News, Virginia.

(123) HYDRAULIC TURBINE TESTS.

(b) Laboratory project.

(d) Experimental; for design data.

(e) Scale model turbines, using either Francis or propeller type mumers, are tested for power and efficiency at various speeds. 


\section{(12L) METER CALIBRATION TESTS.}

(b) Laboratory project.

(d) Experimental.

(e) To establish calibration curve for determining correction for various rates of flow. Meters are tested at various heads and rates of flow by weighing tank method. Time is recorded electrically by chronograph.

\section{(896) VANE MOMENT TESTS ON ADJUSTABLE BLADE RUNNERS.}

(b) Laboratory project.

(d) Experimental; for design data.

(e) Tests are to determine $v$ ane moment diagrams. The turbine load is applied by an electrical dynamometer and the gate openings are controlled by governor. The blades adjust automatically and the blade moment is measured by a spring dynamometer.

(901) SHIP MODEL RESISTANCE TESTS.

(b) Laboratory project.

(d) Experimental; for design data.

(e) Scale ship models are towed to determine the effective horsepower, bare hull, required by the ship. Because of their small size, several models may be towed in a short period of time thus allowing much preliminary work to be done on the choice of lines. The final lines are checked by the David Taylor Model Basin. To eliminate a large portion of this preliminary testing, a schedule of systematic models was arranged in which the beam-draft ratio, the displacement-length ratio, and the prismatic coefficient are varied over a wide range. Towing of this set of models is contimuing and when completed will provide design data for a standard offset series covering a wide range.

(1132) HIDRAULIC PUMP TESTS.

(b) Laboratory project.

(d) Experimental; for design data.

(e) Scale model pumps centrifugal and propeller types, are tested at constant speeds for head developed, power consumption, and efficiency at various rates of discharge. Cavitation tests are sometimes conducted by lowering the suction head to a point where the developed head and efficiency bread down.

(1133) CAVITATION TESTS OF HYDRAULIC TURBINE MODELS.

(b) Laboratory project.

(d) Experimental; for design data.

(e) Scale model turbines are tested on cavitation stand to determine sigma at which cavitation starts.

(1136) WAVE TESTS ON SHIP MODELS.

(b) Laboratory project.

(d) Experimental; for design data.

(e) Ship models are tested with scaled waves to determine the speed reduction in waves for the pull required for various still water speeds. Pitching periods and angles are determined from light trace photographs. Wave tests were conducted for the ICSH Seaworthiness Committee and the results were reported at the Seventh International Conference on Ship Hydrodynamics in Scandinavia in August 1954. These tests were made on a Todd-Forrest Series 60 , Block 0.60 model, at three radii of gyration, at five towline pulls, in four wave lengths of a single wave height. Wave tests are being made in conjunction with the ATTC Seaworthiness cormittee program. The parent model for these tests is the Todd-Forrest Series 60 , Block 0.60 . Tests have been completed on three models of a flare series, all models having the same shear line and radius of gyration. The models were tested at five towline pulls in five wave-lengths and two wave-height ratios. Shear and other variations will be tested as time permits. 
(1634) RESEARCH AND TEST OF MAIN INJECTION SCOOPS AND OVERBOARD DISCHARCE.

(b) Bureau of Ships, Department of the Navy.

(d) Experimental.

(e) To determine the principal criteria governing the flow in ship circulating systems and to obtain some design data on the various circulating components. Model components are tested separately in a water channel. Dynamic similarity is enhanced by modeling the boundary layer thickness and shape to scale. Stagnation, secondary flow, etc, are observed through transparent plastic models.

NEW YORK UNI VERSTY, Department of Chemical Engineering.

Inquiries concerning Projects Nos. 590, 1138, 1635, 1911, 2135, and 2136, should be addressed to Prof. John Happel, Department of Chemical Engineering, New York University, Bronx 53, New York.

(590) PHESSUPE DROP DUE TO FLUID FLOW THROUGH ASSEMBLAGES OF SPHERES.

(b) Texas Company; laboratory project.

(d) Experimental and theoretical; for doctoral thesis.

(e) The pressure drop caused by the slow flow of a viscous fluid through constrained cubical assemblages of spheres was measured at different void volumes. A theoretical treatment involving a pertubation of Stokes' velocity field is being employed.

(f) Experimental work completed; theoretical active.

(g) Completed results indicate that assemblage approach velocities calculated from pressure drop data do not approach Stokes' Law at infinite dilution due to the presence of a bounding wall.

(h) "Viscous Flow in Multiparticle Systems - Cubical Assemblages of Uniform Spheres", J. Happel and N. Epstein, Ind. Eng. Chem. L6, pp. 1187-1194, June 1954.

(1138) EFFECT OF VARIATION OF SOLTD TO FLUID DENSTTY RATIO ON FLUIDIZATION CHARACTERISTICS.

(b) Laboratory project.

(d) Experimental; for one doctoral and one master's thesis.

(e) Screened particles of very light solid substances were fluidized in a 2 -inch glass tube and the fluidization characteristics observed. The primary objective will be the determination of the optimum ratio of solid to gas density for smooth fluidization.

(g) Preliminary results indicate that the range of smooth fluidization and slugging zones can be graphically correlated on a single plot.

(1635) A CRITICAL STUDY OF THE PRTME VARIABLES IN A FLUIDIZED BED.

(b) Texas Company, laboratory project.

(d) Experimental; for doctoral thesis.

(e) The parabolic flow pattern was converted to a uniform flow pattern by means of a properly constructed bed screen support, and the velocity profile was measured with a pitot tube. The effect of flow pattern and height of column to diameter ratio on the variables in a fluidized bed, together with the results of projects 590, 1379 and 1910, will be used to separate and determine the effect of the various variables present on fiuidization tendencies and pressure drop.

(1911) STEADY STATE VISCOUS FLOW IN UNBOUNDED CUBICAL ASSEMBLAGES OF SPHERES.

(b) Texas company, laboratory project.

(d) Theoretical; for doctoral thesis.

(e) The Stokes-Navier Equations neglecting inertial terms will be approxinately solved to obtain a theoretical relation between pressure drop, fluid velocity, and voidage in packed and fluidized beds consisting of uniform spheres in an unbounded cubic assemblage. 
(2135) EFFECT OF A CYLINDRICAL BOUNDARY ON STEADY VISCOUS FLOW PAST SHHERES.

(b) Texas Company, laboratory project.

(d) Experimental; for doctoral thesis.

(e) A study of the effect of a cylindrical boundary on steady flow past spheres as a function of Reynolds number, sphere-to-cylinder diameter ratio, distance of spheres from axis of cylinder and void volume by simultaneous measurement of drag on the spheres and pressure drop caused by their presence.

(2136) EFFECTS OF BOUNDARY PROXIMITY IN DILUTE, FLUIDIZED AND SEDTMENTING SISIEMS OF UNIFORM SPHERICAL PARTICLES.

(b) Research Corporation of America; laboratory project.

(d) Theoretical; basic research.

(e) An attempt to reconcile the theoretical and experimental discrepancies observed in the determination of pressure drop caused by slow viscous flow in bounded and unbounded media at identical voidages and velocities.

NEW YORK UNI VERSITY, Fluid Mechanics Laboratory.

(1912) DISCHARCE CHARACTERISTICS OF A SIDE WEIR.

(b) Laboratory project.

(c) Prof. A. H. Griswold, New York University, New York 53, N. Y.

(d) This is an applied research project in which a theoretical analysis is to be checked experimentally.

(e) Because of the wide divergence between the results that can be obtained using generally accepted equations, a theoretical and experimental study of the discharge characteristics of a sharp-crested side weir is underway.

(f) A test program has been completed that included tests of two widths of chamel, two lengths of crest and two crest heights. The analysis of this data is now underway.

NORTH CAROLINA STATE COLIEGE OF AGRICULTUEE AND ENGTNEERING OF THE ONI VERSTTY OF NORIH CAROLINA, Department of Engineering Research.

(593) DHNAMIC STMIILARTTY OF SMALL HYDRAULIC MOLELS.

(b) Laboratory project.

(c) Prof. L. W. Long, Dept. of Engineering Research, North Carolina State College of Agriculture and Engineering of the University of North Carolina, Raleigh, N. C.

(d) Experimental and theoretical; basic research.

(e) To make a theoretical study of dynamic similarity of small hydraulic models at large scale ratios.

(f) Experimental work completed.

(1636) RAINFALU INIENSITY - DURATION - FREQUENCY - CURVES FOR NORTH CAROLINA.

(b) Laboratory project.

(c) Prof. Charles Smallwood, Dept. of Engineering Research, North Carolina State College of Agriculture and Engineering of the University of North Carolina, Raleigh, N. C.

(d) Experimental.

(e) The collection and analysis of data pertaining to intensity, durability and frequency of rainfall in North Carolina. 
NORTHWESTERN UNI VERSITY, The Technological Institute.

Inquiries concerning Projects Nos. 127 and 904 should be addressed to Prof. M. B. Gamet, Projects 326 and 1637 to Prof. W. S. Hamilton, and Project No. 2137 to Prof. Wm. F. Stevens, Northwestern Technological Institute, Evanston, IIl.

(127) FELIEF FROM WATER HAMMR BY MECHANICHL-PNEUMATIC SURCE SUPPRESSORS.

(b) Laboratory project.

(d) Experimental; for design.

(e) To determine extent to which surge pressures in pipe lines may be relieved by a preloaded, gas-filled, compression chamber in which the gas is separated from the liquid in the pipes by a stainless stee? bellows.

(f) Inactive, to be continued.

(g) Work has shown this type of unit to be free from fatigue failure and capable of protecting pipe systems from severe shock. Some field tests have been conducted.

(326) CAVITATION DAMAGES UNDER CONTROLLED CONDITIONS.

(b) Laboratory project.

(d) Experimental; basic research; for theses and staff papers.

(e) The pressure in a vertical column of liquid is caused to fluctuate by a motor-operated piston and bellows arrangement, thereby forming and releasing a cavity at the top of the column. The amount of damage to various materials will be related to size of cavity and proximity of material to point of cavity collapse.

(g) Pits have been caused in brass, lucite, and mortar. An elastic-tube strain gage has been constructed for pressure measurements. Tests on mortar samples and other materials continue.

(904) BULK MODULUS OF PETROLEUM PRODUCTS, INCLUDING CRUDE OILS AND GASOLTNE.

(b) Laboratory project.

(d) Experimental; basic research for design.

(e) Tests have been conducted on three crude oils, one gasoline, and on distilled water at temperatures from $60^{\circ} \mathrm{F}$ to $130^{\circ} \mathrm{F}$ and at pressures ranging from 0 to $1500 \mathrm{psig}$.

(f) Inactive; to be continued.

(g) Tests indicate high modulus with low temperatures and rapidly increasing modulus at low pressures after which leveling off takes place with nearly constant modulus above 1000 psig.

(1637) SPRAY FORMATION.

(b) Bureau of Aeronautics, Department of the Navy.

(d) Theoretical and experimental; for design.

(e) The effects of different variables in causing a jet of water to break up into spray were being investigated.

(f) Initial phase completed.

(g) A cylindrical jet is unstable; beads are caused by surface tension when air traction is small. The edges of thin flat jets roll up into cylinders and disintegrate by forming beads. Transverse ridges in flat jets grown rapidly into waves because of air pressure differences. Longitudinal ridges of small size disappear. Photographs of flat jets produced in the laboratory and of seaplaine spray show the same characteristics break-up processes,

(h) "Liquid Jet Disintegration", John Dundurs, and w. S. Hamilton, Jan. 1954. "Some Laboratory and Field Studies of Water Jet Disintegration", John Dundurs, and W. S. Hamilton, Jan. 1954.

Reports submitted to BuAer. 
(2137) SPRAY DROPLET FORMATION AND VAPORIZATION.

(b) Laboratory project, supported in part by Project sauID, Princeton University.

(d) Experimental and theoretical investigation, involving basic research, in part for thesis work.

(e) In order to understand more completely the operation of a spray nozzle, information is being sought concerning the mechanism of droplet formation and vaporization. Studies are presently being carried out to determine the force and velocity distributions within the nozzle, the droplet size distribution, and the effect of nozzle valocity on the $\checkmark$ aporization rates.

(h) Project SQUID, Semi-annual Progress Reports, October 1, 1954 - pp. 53-57, April 1, 1954 pp. $48-54$.

UNIVERSITY OF NOTRE DAME, COllege of Engineering.

(1642) COMPUTATION OF EMPIRTCAL DISCHARGE CURVES.

(b) Laboratory project.

(c) Dr. S. Kolupaila, Department of Civil Engineering, University of Notre Dame, Notre Dame, Indiana.

(d) Design, and theoretical and experimental investigation.

(e) The experimental work involves the design and installation of several hydrometric screens in a new $4^{\prime} \times 2.51$ hydrometric flume and measurements of discharge thereby.

(g) Results may be obtained when available by writing to project director.

(2138) FORGES ON OSCIILATING HYDROFOTLS.

(b) Office of Naval Research, Department of the Navy.

(c) Dr. A. G. Strandhagen, Department of Engineering Mechanics. University of Notre Dame, Notre Dame, Indiana.

(d) Basic theoretical research.

(e) Investigation to determine the hydrodynamic forces acting on an oscillating submerged hydrofoil moving below a free surface with steady translationed velocity.

(h) Reports submitted to sponsor.

PELTON WATER WHEEL COMPANY.

Inquiries concerning Projects Nos. 1146 and 1915 should be addressed to Mr. R. M. Bacchi, Pelton Water Wheel Company, 2929 19th Street, San Francisco 10, Calif.

(1146) HEAD EFFECT ON IMPULSE TURBINE MODEL TESTING.

(b) Laboratory project, sponsored by the Mountain Laboratory Group.

(d) Experimental; applied research.

(e) To establish model law for testing impulse turbines under various operating pressures. Tests are being made under heads of 100 to $2000 \mathrm{ft}$. The effect of housing size and shape is under study.

(g) Reduced head testing now under way.

(1915) BUCKET SHAPE TESTING.

(b) Laboratory project.

(d) Experimental; applied research.

(e) A new bucket shape is being tested to determine its characteristics. 
PENNSYLVANIA STATE UNI VERSITY, Hydraulics Laboratory, Department of Civil Engineering.

Inquiries concerning Projects Nos. 1917, to 1920, incl., and 2139, should be addressed to Prof. Sam Shulits, Hydraulics Laboratory, Department of Civil Engineering, Pennsylvania State University, State College, $\mathrm{Pa}$.

(1917) BED LOAD FORMLAS.

(b) Laboratory project supported by Research Corporation and University Council on Research.

(d) Analytical; applied research.

(e) Examination and analytical comparison of existing bed load formulas and their theoretical and experimental bases, to determine whether the formulas can be synthesized into one or a reduced number.

(1918) IESIGN OF STILLING BASINS.

(b) Laboratory project supported by Research Corporation.

(d) Experimental; applied research.

(e) Investigation in a plexiglas-walled flume, of rational basis of design of stilling basins, to reduce dependence on model studies.

(g) Nappes covered by tailwater and free nappes with a repelled jump have been measured on a sloping spillway face for subsequent comparison with theory.

(1919) DOWNSTREAM DISTURBANCE OF ORIFICE METERS.

(b) Laboratory project.

(d) Experimental; applied research; master's thesis.

(e) Measurement of minimum distance downstream from an orifice meter at which various pipe fittings may be placed without altering meter reliability.

(g) Five orifices of different diameters have been calibrated in a 2-inch pipe. The downstream disturbing effect of a gate valve will now be measured.

(1920) EQUATION OF RIVER-BED PROFIIES.

(b) Laboratory project.

(d) Analytical; basic research.

(e) Quantitative study of profiles of various rivers to prove whether a rational equation of river-bed profiles is attainable.

(f) Suspended.

(g) Plots of low-water slope against distance yield a linear relation on semi-log paper, as analysis would predict.

(2139) VEFIFICATION OF THEORY OF STANDING-WAVE FLUNE.

(b) Laboratory project.

(d) Experimental; basic research; master's thesis.

(e) A measuring flume of the sritical-depth type, with rectangular throat, will be built into circular flume with a free water surface. The measured water surface profiles will be compared with theory. Some discharge coefficients will be obtained.

(g) Literature search conpleted; design of model started.

PENNSILVANIA STATE UNIVERSITY, Ordnance Research Laboratory.

(328) FLOW PAST SLOTS IN SURFACES.

(f) Suspended. 
(605) FUNDAMENTILS OF SURFAGE CAVITATION.

(b) Laboratory project for Bureau of ordnance (Contract Nord 7958), Department of the Navy.

(c) Mr. A. F. Lehman, Ordnance Research Laboratory, P. O. Box 30, State College, Pa.

(d) Experimental; basic research.

(e) A laboratory-size eggbeater apparatus is used in which the noise inception point is correlated with the composition and nature of the liquid and the surface of the propeller.

(f) Major activity completed.

(g) The effect of blade size and shape, fluid air content, fluid surface tension, and fluid temperature were investigated as to their ef fect on the incipient cavitation index.

(h) The Effect of Some Fluid Properties on the Inception of Cavitation", A. F. Lehman, M. S. Thesis, The Pennsylvania State University, Aug. 1954.

(921) PROPELLERS FOR OPERATION IN STMMETRIC WAKES.

(b) Bureau of Ordinance, Department of the Navy (Contract NOrd 7958).

(c) Dr. B. W. McCormick, Ordnance Research Laboratory, P. 0. Box 30, State College, Pa.

(d) Theoretical and experimental; applied research.

(e) The problem is the design of optimum-eficiency and cavitation-free propellers for operation behind bodies of revolution. It is being attacked through consideration of the physics of propeller action. Design methods resulting from the theory are being tested by experiment on an 8-inch diameter model torpedo in the 48-inch Water Tunnel.

(g) Work with propellers designed for optimum efficiency indicates that the performance can be predicted with reasonable accuracy. Emphasis is now being directed toward the design of cavitation-free propellers. An analysis has been made of the effect of finite hub size on the optimum propeller. The results of this analysis have been incorporated in the present design methods.

(1150) HYDRODHNAMTC PERFORMANCE OF L8-INCH WATER TUNREL.

(b) Laboratory project for Bureau of Ordnance (Contract NOrd 7958), Department of the Navy.

(c) Dr. G. F. Wislicenus, Ordnance Research Laboratory, P. 0. Box 30, State college, Pa.

(d) Experimental; applied research.

(e) Velocity distributions and pressures are being measured in all portions of the 48 -inch Water Tumel at velocities up to $80 \mathrm{fps}$.

(f) Major activity completed.

(g) The flow measurements in the working section show excellent flow conditions at least to within the precision of the measuring equipment and techniques. The static pressure coefficient is constant to within 0.0005 in the core outside of the boundary-layer region. The extreme variation in velocity in the central core does not exceed $0.5 \%$. The pressure gradient in the working section decreases slightly with increasing Reynold's number. The working section cavitation inception index is 0.3 for all speeds. This inception is measured with acoustic listening gear and lower operating indices are possible for visual observation.

(h) Water Tumel Diffuser Flow Studies", J. M. Robertson and Donald Ross, Part I--Review of Literature, ORL Report, Serial No. NOrd 7958-139, May 16, 1949.

"Water Tunnel Diffuser Flow Studies", J. M. Robertson and Donald Ross, Part II--Experimental Research, ORL Report, Serial No. NOrd 7958-143, July 8, 1949.

"Water Tunnel Diffuser Flow Studies", J. M. Robertson and Donald Ross, Part III--AnaIytical Research, ORL Report Serial No. Nord 7958-230, March 1, 1952. Trlow in Closed-Jet Working Section", Donald Ross and J. H. McGinley, ORL Report, serial No. Nord 7958-283, Feb. 5, 1954 .

(1151) DESION AND CONSTRUCTION OF 12-INCH WATER TUNNEL.

(b) Laboratory project for Bureau of Ordnance (Contract NOrd 7958 and Nord (f) 1445), department of the Navy.

(c) Mr. A. F. Lehman, Ordnance Research Laboratory, P. 0. Box 30, state College, Pa.

(d) Design. 
(e) The Tunnel was planned for general supplementary research. There are two interchangeable working sections: one, circular closed-jet (12 inches in diameter), and the other, rectangular closed-jet working section ( 4 l/2 $\times 20$ inches), the design velocity for the circular working section is 70 feet per second, but speeds of 80 feet per second are obtained with the rectangular working section.

(f) Major activity completed.

(g) The Tunnel is in operating condition and basic proofing is completed. In the rectangular working section, velocity variations were in the neighborhood of two percent from the average velocity outside of the boundary layer.

(1152) DESIGN AND CONSTRUCTION OF L8-INCH AIR TUNNEL.

(b) Laboratory project for Bureau of Ordnance (Contract Nord 7958 and NOrd (f) 1445), Department of the $\mathrm{N}_{\mathrm{avy}}$.

(c) Dr. G. F. Wislicems, Ordnance Research Laboratory, P. 0. Box 30, State College, Pa.

(d) Design.

(e) Closed circuit tunnel planned for supplementary research; working section 48 -inch octagon, 16 feet long; maximum design velocity including honeycomb and screens, 200 feet per second.

(f) Construction is completed.

(g) Working section turbulence level $0.1 \%$ Velocity profile uniform to within $t 1.25 \%$

(h) "The Design of a Small Subsonic Air Tunnel", G. L. Calehuff, M. S. Thesis, The Pennsylvania State University, August 1952, (available on loan).

(1386) CAVITATION STUDIES.

(b) Laboratory project; Office of Naval Research and Bureau of Ships, Department of the Navy.

(c) Mr. J. W. Holl, Ordnance Research Laboratory, P. 0. Box 30, State College, Pennsylvania.

(d) Experimental; basic research.

(e) Investigation of cavitation scaling on two-dimensional hydrofoils. The size of the hydrofoil, water velocity, and water temperature are varied to determine their effect on the inception of cavitation.

(1387) STUDY OF TIP VORTEX CAVITATION.

(b) Laboratory project; of fice of Naval Research, Department of the Navy.

(c) Dr. B. W. McCormick, Ordnance Research Laboratory, P. O. Box 30, State College, Pa.

(d) Experimental; basic research.

(e) Attempt to predict the minimum pressure in the trailing vortex system behind a wing.

(g) A semi-empirical method has been developed for the prediction of the minimum pressure in a trailing vortex system behind a wing. The prediction method is based on the thinking that the thickness of the tip-vortex core and consequently the magnitude of the minimum pressure coefficient is determined by the thickness of the boundary layer on the lower side of the wing at the trailing edge of the tip.

(h) "Tip-Vortex Cavitation", B. W. McCormick, Paper presented at the Joint Admiralty--U.S. Navy meeting on Hydrobaliistics, September 9 to 15, 1954, Admiralty Research Laboratory, Teddington, England.

"A Study of the Minimum Pressure in a Trailing Vortex System", B. W. McCormick, PhD Thesis, The Pennsylvania State University, 1954 .

(1388) TURBULENT BOUNDAPY LAYERS.

(b) Laboratory project, Office of Naval Research, Department of the Navy.

(c) Ordnance Research Laboratory, P. 0. Box 30, State College, Pennsylvania.

(d) Experimental; basic research.

(f) Major activity suspended.

(g) Further investigations of the conical diffuser studied by Ur am having various exit conditions was conducted to determine the possibility of extending Ross 1 analysis of twodimensional turbulent boundary layers to the axisymetric case. The results of the test indicate that with certain modifications, it may be possible to extend Ross' two-dimensional theory to the axisymmetric case. 
(h) "Investigation of the Growth of a Turbulent Boundary Layer in a Conical Diffuser Followed by a Straight Pipe", J. W. Holl, Informal Report ONR Project NR062-139-3, June 30, 1954.

(1389) REDUCTION OF STRUT WAKE.

(f) Suspended.

PENNSYL VANIA WATER AND POWER COMPANY.

Inquiries concerning Projects Nos. 1154, 1156, and 1157, should be addressed to Dr. S. K. Waldorf, 405 Fulton Bank Building, Lancaster, $\mathrm{Pa}$,

(1154) MEASUREMENT OF WATER VELOCITIES WITH ULTRASONICS.

(b) Laboratory project.

(d) Experimental; applied research.

(e) To develop an improved method of measuring large quantities of water, particularly the discharge of large hydroelectric units having short intake conduits with large rectangular cross sections. An ultrasonic transducer rod is placed at each of two parallel opposite walls of the rectangular duct in which water velocity is to be measured. The transducers are displaced from each other along the principal axis of flow. The phase angle between the transmitted and received ultrasonic signals is a measure of the water velocity.

(f) Completed.

(g) The validity of the new ultrasonic method was established in the laboratory where errors of $1 \%$ and less were obtained with water velocities of 1 to 10 feet per second in a 5-inch by 9 -inch steel conduit. These tests of accuracy also showed that the method is affected to only a negligible amount by turbidity, temperature and departures from uniform velocity distribution that are normally encountered in straight flow sections. Its practicality was demonstrated by the measurement of the discharge through a hydraulic turbine intake 25 feet high by 16 feet wide. In this application an absolute test of precision could not be made, but the reproducibility and consistency of readings, along with their close agreement with those from installed piezometers, give confidence in the reliability of the ultrasonic flowmeter when measuring large quantities of flowing water.

(h) "The Ultrasonic Measurement of Hydraulic Turbine Discharge", R. C. Swengel, W. B. Hess, S. K. Waldorf, 1954 Anmual Meeting of the American Society of Mechanical Engineers, Paper 54-A-5L.

"Demonstration of the Principles of the UItrasonic Flowmeter", R. C. Swengel, W. B. Hess, S. K. Waldorf, Electrical Engineering, Vol. 73, No. 12, pp 1082-4, Dec. 1954 . "Principles and Application of the Ultrasonic Flowmeter", R. C. Swengel, W. B. Hess, S. K. Waldorf, 1955 Winter General Meeting of the American Institute of Electrical Engineers, Paper 55-28.

(1156) AIR BUBBLER SYSTEM TO MAINTAIN OPEN CHANNEL IN SHEET ICE.

(b) Laboratory project.

(d) Field investigation; applied research.

(e) Three experimental 1000-foot and one 1500-foot lengths of galvanized steel pipe, with holes at intervals for discharging compressed air, are laid on the reservoir bottom. perpendicular to the dam. The warmer water caused to rise with the bubbles maintains an open channel in the reservoir sheet ice. The pipes are widely spaced to avoid interaction and are placed so that open channels will direct the movement of pack ice over the dam at selected gates. If successful, a system of such pipes extended farther upstream is expected to reduce the possibility of ice jams.

(g) Results are encouraging, but not conclusive because of recent mild winters. Experiments with flexible tubing revealed some inherent difficulties with tubing which have not been overcome. 


\section{(1157) SEDTMENTATION IN RESERVOIR OF SAFE HARBOR HYDRCELECTRIC STATION.}

(b) Laboratory project.

(d) Field imestigation; applied research

(e) With a U.S. D-43 sampler, suspended sediment in the Susquehanna River is measured at the head of the Safe Harbor Reservoir. The suspended sediment in the discharge of the reservoir is measured at the station discharge and dam overflow by special means applicable to turbulent water. The rate of silting in the reservoir is measured periodically by fathometer soundings.

(f) Discontinued.

(g) Suspended sediment has been measured for flows of 4,000 to 450,000 cfs. Recorded extremes of flow of the susquehanna are 2,000 and almost 900,000 cfs. The fathometer soundings revealed the occasional presence of fluffs on the river bottom.

\section{RENSSELAER POLYTECHNIC INSTITUTE.}

\section{(1660) HIGH SPEED HYDRAILIC COMPONENTS.}

(b) Frankford Arsenal, Ordnance Corps, Department of the Army.

(c) Associate Professor Frederick J. Bordt, Mechanical Engineering Department, Rensselaer Polytechnic Institute, Troy, New York.

(d) Experimental; applied research, development.

(e) Continuing investigation of control of a high speed hydraulic torque system. The system, with a constant high speed input, is to have a variable torque and speed output.

(g) Unique constant pressure variable flow valve has been developed.

(h) No reports or publications available before completion of project.

\section{ROCKY MOUNTAIN HYDRAULIC LABORATORY.}

\section{(21LO) EVALDATION OF OPEN-CHANREL FRICTION LOSSES.}

(b) National Science Foundation, State University of Iowa, Ohio State University, and Colorado $A$ and $M$ College Cooperating.

(c) Prof. C. J. Posey, Director, Rocky Mountain Hydraulic Laboratory, Iowa State University, Engineering Bldg., Iowa City, Iowa (winter address), Allenspark, Colorado (sumer address).

(d) Experimental; basic.

(e) Variable-slope flume long enough to permit accurate evaluation of open channel friction losses will be tested at slopes into the steep range. Roughness and shape variables will also be investigated.

(f) Planning during winter months, active experimentation during surmer months. Flume headworks with capacity to $100 \mathrm{cfs}$ under construction, 1954.

RUTGERS UNIVERSTTY, Department of Botany.

\section{(1662) PINE REGION HYDROLOGICAL RESEARCH PROJECT.}

(b) Cooperative with Groundwater Division of the U. S. Geological Survey, New Jersey, Department of Conservation and Economic Development, and United States Forest Service.

(c) Mr. Murray F. Buell, Rutgers University, New Brunswick, New Jersey.

(d) Field investigation; basic research.

(e) Study of water relations of two watersheds, one of which will be burned according to recently developed silvicultural practices and the other will be left to natural forest succession. 
ST. ANTHONY FALLS HYDRAULIC LABORATORY, University of Minnesota.

Inquiries concerning Projects Nos. 100, 924, 1665, 1669, 1671, 1672, 1923, 1926, 1927, 1928, and 2141 to 2148 incl., should be addressed to $\mathrm{Dr}$. Lorenz G. Straub, Director, St. Anthony Falls Hydraulic Laboratory, Hennepin Island, Minneapolis 14, Minnesota.

Inquiries concerning Projects Nos. 111, 1168, 1398, and 1929 which are conducted in cooperation with the Agricultural Research Service, should be addressed to Dr. Robert Salter, Chief, Soil and Water Conservation Research Branch, Agricultural Research Service, Plant Industry Station, Beltsville, Maryland.

Inquiries concerning Projects Nos. 194, 196, 985, 1206, 1977, and 2199 which are conducted in cooper ation with the Corps of Engineers, should be addressed to the District Engineer, Corps of Engineers, Department of the Army, St. Paul District, St. Paul, Minn. (These projects are listed on pages 122, 123, and 12L.)

(100) AIR ENTRATNMENT RESEARCH.

(b) Office of Naval Research, Department of the Navy.

(d) Theoretical and experimental; basic and applied research.

(e) Investigation of self-aeration of high velocity open-channel flow. Air concentration distributions in the flow have been measured for equilibrium aeration conditions at a number of discharges up to $10 \mathrm{cfs}$ and slopes up to $45^{\circ}$ by means of specially developed electrical instruments. The measurements were made for a single channel roughness condition.

(g) Air concentration distribution indicates that the flow consists of two parts: (1) open channel flow in lower region with air distributed by turbulent mixing, (2) upper region consisting of water particles or spray generated by intense transverse velocity fluctuations that carry water particles through the surface. Roughness coefficient for aerated flow appears to be less than that for unaerated flow. Mean concentration of air depends upon slope and discharge.

(h) Project report in preparation.

(III) CLOSED CONDUTT SPILLWAY.

(b) Agricultural Research Service, U. S. Department of Agriculture, in cooper ation with the Minnesota Agricultural Experiment Station and the St. Anthony Falls Hydraulic Laboratory.

(d) Experimental; applied research for development and design.

(e) Tests have been made on three different sizes of lucite pipe set on slopes ranging from $2.5 \%$ to $30 \%$ to verify the similarity relationships. Information on discharges, pressures, and flow conditions has been obtained. Future studies vill be on the effect of different types of inlet on the flow conditions and hydraulic losses.

(f) suspended.

(g) Theory has been developed, verified, and published. Generalized methods for analysis and reporting results have been developed. Pipe culverts laid on steep slopes will flow completely full even though the outlet discharges freely. Entrained air did not invalidate the Froude model law.

(h) "Hydraulic Fundamentals of Closed Conduit Spillways", by Fred W. Blaisdell. American Society of Civil Engineers, Proceedings-Separate No. 35L, Nov. 3.953.

(924) FREE-JET WATER TUNNEI STUDIES.

(b) Office of Naval Research, Department of the Navy.

(d) Experimental; applied research and design.

(e) Tests are being conducted in a 10-inch free-jet water tunnel to determine steady-state cavity dimensions resulting from various geometries of head form. Emphasis is on tests at low sigma values. Tests at sigma $=0.005$ have been made. 
(1268) A STUDY OF CANTILEVERED OUTLETS.

(b) Agricultural Research Service, J. S. Department of Agriculture, in cooperation with the Minnesota Agricultural Experiment Station and the St. Anthony Falls Fydraulic Laboratory.

(d) Experimental; applied research for design.

(e) Pipe outlet conduits for small spillways are frequently cantilevered beyond the toe of the earth dam. Attempts will be made to determine quantitatively the size of the scour hole to be expected under various field conditions.

(f) suspended.

(1398) STRAIGHT DROP SPILLWAY.

(b) Agricultural Research Service, II. S. Depertment of Agriculture, in cooperation with the Minnesota Agricultural Experiment Station and the St. Anthony Falls Hydraulic Laboratory.

(d) Experimental; applied research for development and design.

(e) Spillway is used as a grade control structure in ditches and streams. Study will result in general design rules for the spillway and outlet. Outlet studies have been completed. Present studies are to determine spillway performance and capacity with various approach channel shapes.

(g) Minimum basin length is equal to distance at which upper nappe strikes basin floor plus 2.55 times the critical depth of flow. Floor blocks $0.8 d_{c}$ high by $0.4 d_{c}$ wide must occupy $50 \%$ to $60 \%$ of basin width. End sill is $0.4 \mathrm{~d}_{c}$ high. Flaring triengular wingwalls are used. Approach channel design affects basin performance. Longer stilling basins are required with high tailwater levels because the nappe floats.

(h) "straight Drop Spillway Stilling Basin", by Charles A. Donneliy and Fred W. Blaisdell. St. Anthony Falls Hydraulic Laboratory Technical Paper No. 15, Series B, Oct. 1954 . Available from the St. Anthony Falls Hydraulic Laboratory at \& per copy.

(1665) LOW VELOCITY WIND INSTRUMENTATION.

(b) O. S. Army, Signal Corps.

(d) Experimental design and development.

(e) Development studies on thermal enemometer for measuring speed and direction of winds from 1 to $50 \mathrm{fps}$ and from ground to $1000 \mathrm{ft}$ elevation.

(h) "A Survey of Measuring Instruments for Low Velocity Winds", by John F. Ripken, St. Anthony Falls Hydraulic Laboratory Project Report No. LO, Dec. 1953.

(1669) EXPERTMENTAL INVESTIGATION OF BASIC EQUIPMENT AND METHODS ASSOCIATED WITH LABORATORY WAVE STUDIES.

(b) David Taylor Model Basin, Department of the Navy.

(d) Experimental; basic and applied.

(e) Objective of the study is the investigation of equipment and methods associated with laboratory surface-wave studies. Three items were proposed for study; namely, absorbers, filters, and generators, with major emphasis on absorbers.

(g) A brief surmary of literature and a translation of several foreign reports have been prepared in the form of project reports. Experimental studies of wave filters and absorbers were conducted with emphasis on absorbers. Data were obtained on the effect of permeability and slope on the absorption characteristics of permeable absorbers with both continuous and discontimuous slopes.

(h) "Laboratory Surface Wave Equipment, A Summary of Literaturen, by James A. Ross and C. E. Bowers, St., Anthom Falls Hydraulic Laboratory Project Report No. 38, Nov. 1953. "Laboratory Wave-Generating Apparatus", by F. Biesel, F. suquet and others, Translation of a Series of French Articles from La Houille Blanche by Meir Pilch, St. Anthony Falls Hydraulic Laboratory Project Report No. 39, Oct. 1953. (A limited number of copies of of these reports may be made available by the sponsor.) 


\section{(1671) CAVITATION TESTING IN WATER TUNNELS.}

(b) David Taylor Model Basin, Department of the Navy.

(d) Experimental; basic and applied research.

(e) An experinental program to study some of the factors believed to affect a measured pressure at which water cavitates and to determine if a measured pressure is a better datum than the vapor pressure in computing the cavitation index. Incipient bubbling cavitation is of primary interest.

\section{(1672) SLOTTED-WALL TEST SECTION FOR WATER TUNNELS.}

(b) David Taylor Model Basin, Department of the Navy.

(d) Experimental design.

(e) Studies of a number of slotted-wall test sections in a 6-inch recirculating tunnel are being made to determine primarily the optimum test-section geonetry, the flow quality in the test section, the head losses, and the cavitation characteristics.

\section{(1923) DRAG OF AN ACCELERATED SPHERE.}

(b) Laboratory project.

(d) Experimental; master's thesis.

(e) Spheres of $21 / 2$ to 6 in. diameter of various materials were dropped through $16 \mathrm{ft}$ of water in a large tank. Accelerations were determined from a position-time graph and tne resistance was computed using this acceleration and the known weights.

(f) Completed.

(g) Resistance coefficient was best coordinated when plotted against the parameter $\mathrm{AD} / \mathrm{v}^{2}$ where $A$ is the instantaneous acceleration, $D$ is the diameter of the sphere, and $V$ is the instantaneous velocity. It was shown that the resistance coefficient approaches the steady flow value when $\mathrm{AD} / \mathrm{v}^{2}$ is small and tends to approach the theoretical value $2 / 3 \mathrm{AD} / \mathrm{v}^{2}$ when $\mathrm{AD} / \mathrm{v}^{2}$ is large. The experimental equipment was not accurate enough, however, to adequately check the results for high $\mathrm{AD} / \mathrm{V}^{2}$. Reynolds numbers for the experiments were in the range where the steady flow resistance coefficient for spheres is relatively constant.

(h) "The Resistance to Accelerated Motion of Spheres in Water", by Giorgio Bugliarello. Master's Thesis, University of Minnesota, July 1954.

(1926) STUDY OF HYDROELECTRIC TURBINE SETTING.

(b) Northern States Power Company, Minneapolis, Minnesota.

(d) Experimental design.

(e) Test of hydroelectric turbine model to determine influence of flume setting on performance of propeller turbines installed in the reconstruction project at the Lower Dam Hydroelectric Plant at St. Anthony Falls.

(f) Completed.

(1927) ULTRASONIC AND OTHER VISCOSITY MEASUREMENTS.

(b) Laboratory project.

(d) Experimental; basic research.

(e) Investigations of Newtonian and non-Newtonian liquids, mixtures, and suspensions using commercial ultrasonic viscosimeter in conjunction with conventional apparatus (rotating cylinder, capillary).

(f) Completed.

\section{(1928) DEPRESSED TEMPERATURE SEDIMENT STUDTES.}

(b) Missouri River Ditision, Corps of Engineers.

(d) Basic research; analytical and experimental.

(e) An investigation of the effect of temperature changes on the suspended load in natural streams. The experimental program includes measuring in a flume the amount and size distribution of sediment carried in suspension by water whose temperature is held constant at several levels between freezing and well above room temperature. 
(f) Completed except as relates to total load sediment studies.

(g) Both sediment size and concentration of suspended sediment are notably affected by temperatures, both increasing with lowering of temperature. The effect of a temperature decrease of $40^{\circ}$ (to about $35^{\circ} \mathrm{F}$ ) was to increase the suspended sediment concentration by a factor of between 2 and 4 depending on the relative depth. For this same temperature range, the median sediment size increased $35 \%$ or 2.5 times by weight.

(h) "Terminal Report on Transportation Characteristics, Missouri River Sediment", by Lorenz G. Straub, St. Anthony Falls Hydraulic Laboratory Technical Paper No. 5, Series A, April 1954.

(1929) DRAIN TILE JUNCIION LOSSES.

(b) Minnesota Agricultural Experiment Station in cooperation with the Agricultural Research Service, U. S. Department of Agriculture and the St. Anthony Falls Hydraulic Laboratory.

(c) Prof. Philip W. Manson, Professor of Agricultural Engineering, University of Minnesota, St. Paul Campus, St. Paul, Minnesota.

(d) Experimental; applied research for design.

(e) The junction losses in drain tile flowing full will be determined for laterals of different sizes entering mains of different sizes at various angles.

(214I) TACONITE HARBOR BREAKWATER STUDY.

(b) Erie Mining Company.

(d) Experimental design.

(e) To investigate the design of the breakwaver for Taconite Harbor on the Ninnesota shore of Lake superior. The breakwater is of stone construction and is approximately $1300 \mathrm{ft}$ long extending to water depths of $100 \mathrm{ft}$. Model scale is 1:50. Purpose of testing is to determine the stability of the proposed breakwater design under various wave conditions.

(g) Not complete.

(2142) THE ABSORPTION OF ULTRASONIC RADIATION BY SUSPENDED SEDTMENT IN WATER AS A MEASURE OF PARTICLE SIZE AND CONCENTRATION.

(b) Laboratory project.

(d) Experimental; master's thesis.

(e) The absorption of a 25 megacycle plane wave of ultrasonic radiation as affected by $v$ arious concentrations of suspended sediment is measured for particle sizes of $44-500$ microns and concentrations of 100-2200 parts per million by volume.

(2143) EXPERTMENTAL AND ANALYTICAL SIUDIES OF THE MECHANICS OF SELECIED METHODS OF SURFACE WAVE ABSORPTION.

(b) Office of Naval Research, Department of the Navy.

(d) Experimental; basic research.

(e) Initial objective of the study is the procurement of quantitative data on wave attenuation caused by a surface current induced by jets of water and air.

(g) Tests have been conducted on the attenuation of both deep and shallow water waves as a result of submerged air jets; results for deep-water waves compared fav orably with available theory. Tests of vertical and horizontal water jets indicated that the horizontal water jets were the most efficient. These tests were conducted in a small wave channel; additional studies will be conducted in a larger channel $9 \mathrm{ft}$ wide, $6 \mathrm{ft}$ deep, and 250 ft long.

(2144) EXPERTMENTAL AND ANALYTICAL STUDIES OF HYDROFOILS.

(b) Office of Naval Research, Department of the Navy.

(d) Experimental and analytical; basic research.

(e) Objective of the study is the determination of the principal effects of dihedral on the performance of hydrofoils. 
(g) An appraximate theory was developed whereby the lift of a surface-piercing foil at high speed can be determined as a function of the angle of attack solely from two-dimensional wind tunnel data. A theory for the trailing vortex drag was developed for both deeply submerged and surface-piercing dihedral hydrofoils. An analysis of the wave drag of surface-piercing hydrofoils was developed and compared with experimental data.

(h) Report in preparation.

(2145) FLOW OF WATER THROUGH PERMEABLE MIXTURES OF SAND PARTICLES OF DIFFERENT SIZES.

(b) Laboratory project.

(d) Experimental and basic; for master's thesis.

(e) Resistance coefficient is being measured for sieved separates of a natural sand and for $v$ arious combinations of the separates such that the mean size is constant and the distribution standard deviation is varied systematically.

(21L6) MODEL SIUDY FOR MENOMONTE POWER PROJECT.

(b) Northern States Power Company, Minneapolis, Minnesota.

(d) Experimental design.

(e) Experimental design of spillway apron. Study of gate operation.

\section{(2147) TOTAL LOAD SEDTMENT STUDIES.}

(b) Missouri River Division, Corps of Engineers.

(d) Basic research; analytical and experimental.

(e) An investigation of the total sediment load in a recirculating laboratory flume. The experimental program includes the measurement of sediment concentration and size of the suspended sediment and of the total load. The bed load to be obtained by subtracting the suspended load from the total load. The effect of water temperature on total load is to be studied.

(2148) AIR-WATER MIXTURES IN CLOSED CONDUITS.

(b) David Taylor Model Basin, Department of the Navy.

(d) Theoretical and experimental; basic and applied research.

(e) The investigation has been divided into two parts; namely, (1) production of air-water mixtures in closed conduits, and (2) flow of air-water mixtures in closed conduits. only (I) has been pursued extensively so far. The experimental work has been done on aspirator type mixers and has consisted of measuring bulk water and air input and bubble size of the resulting mixture as a function of the aspirator characteristics. Air-water ratios from zero to one (measured at atmospheric conditions) have been used.

(g) A theory for the aspirator has been developed, predicting air-water ratios. This theory is supported by the experimental data. The back-pressure produced on an aspirator by the conduit downstream is important in determining the output of the aspirator; a tentative assumption that the friction factor in this conduit is the same for the air-water mixture as for a homogenous fluid appeared to be in agreement with the experimental data. A special apparatus was designed to sample the flow in order to measure bubble sizes. Bubble size could not be predicted by theory, but experimental measurements were correlated by dimensional analysis. Maximum bubble diameters produced by an aspirator can be controlled to a limited extent by controlling water and air inflow and back-pressure on the aspirator.

(h) "Generation of Air-Water Mixtures in Closed Conduits by Aspiration", by E. Silberman, St. Anthony Falls Hydraulic Laboratory Project Report No. 45 , (in press). 
THE SOCIETI OF NAVAL ARCHITECTS AND MARINE ENGINEERS.

(895) THE COMPIIATION OF FESISTANCE AND PROPULSION DATA.

(b) Office of Naval Research, Department of the Navy.

(c) Capt. W. N. Landers, Secretary, The Society of Naval Architects and Marine Engineers, 74 Trinity Place, New York 6, N. Y.

(d) The project is concerned with the effective and systematic presentation of existing experimental data on ship model resistance and propulsion.

(e) Ship model resistance data for models of various types are assembled on standard data sheets designed for ready reference and aimed towards further analysis to determine the influence of hull form on wavemaking resistance. Standard data sheets for reporting data on self-propelled models and model propellers are also devised, and representative data presented thereon. The dual purposes of this compilation work are to foster the adoption of standard forms for reporting model data and to facilitate the analytical analysis to determine the influence of geometry on resistance and propulsion.

(g) One hundred and fifty-nine resistance data sheets for models for various types have been assembled. These data have been requested by mumerous shipyards, design agents, consulting naval architects, students, etc. Towing tanks in this country have unofficially adopted the form of the data sheet and are actively proposing it for intermational use. The self-propulsion data sheets and propulsion data sheets are still in preliminary form. Empirical analysis so far has indicated which form factors have the major effect on wavemaking resistance. The need for basic research in the hydrodynamics of ship resistance is, however, apparent.

(h) "Model Resistance and Expanded Data Sheets",

$$
\begin{array}{ll}
\text { Models } 1-50 & \$ 10.00 \text { to members } \$ 11.00 \text { to non-members } \\
\text { Models } 51-100 & \$ 10.00 \text { to members } \$ 11.00 \text { to non-members } \\
\text { Models } 101-150 & \$ 10.00 \text { to members } \$ 11.00 \text { to non-members }
\end{array}
$$

Explanatory notes are available with each order on request. Single data sheets are av ailable at $\$ 1.00$ each. "Index to Model and Expanded Resistance Data Sheets, Nos. 1-150", Bulletin 1-14, $\$ 1.00$ per copy.

SOUTHERN METHODIST UNIVERSITY, HYdraulics Laboratory.

(2149) THE HYDRAULICS OF THE CITY OF DALLAS STORM WATER INLET.

(b) City of Dallas (Department of Public Works) and Laboratory Project.

(c) Prof. I. W. Santry, Jr., School of Engineering, Southern Methodist University, Dallas 5, Texas.

(d) Experimental; operation and design; undergraduate thesis.

(e) The project is designed to determine the efficiency of the present storm water inlet of the city of Dallas and to determine criteria for use. Also consideration will be given to the possibility of changing the design for better operations.

(g) The project has just started and therefore no results will be available until late in 1955.

STANFORD UNI VERSITY, HIdraulic Laboratory.

Inquiries concerning Projects Nos.627, 1171, 2150 and 2151, should be addressed to Prof. John K. Vennard, and Projects Nos. 1943 to 1946 , incl., should be addressed to Prof. Ray K. Linsley, Stanford University, Stanford, Califormia. 
(627) STUDY OF TURBULENT BOUNDARY LAYERS.

(b) Laboratory project.

(d) Experimental; Ph.D. thesis.

(e) Study of the zone of boundary layer transition in smooth pipes of various diameters.

(f) Completed.

(g) Semiempirical relationships derived.

(h) Engineer theses by S. M. Barnes and C. T. Chen completed. Ph.D. thesis by Karl Brenkert, $\mathrm{Jr}$., completed.

(1171) STUDY OF MANIFOLD PORTS.

(b) Laboratory project.

(d) Experimental; engineer thesis.

(e) Measurement and interpretation of pressure variation near outlet ports in manifold pipes and obtaining hydraulic coefficients for various flow geometries.

(f) Completed.

(g) Appropriate coefficients obtained and justified.

(1943) DEVELOPMENT OF IMPROVED STREAM FLOW ROUTING ANALOGUE.

(b) U. S. Weather Bureau.

(d) Experimental; applied research.

(e) Using a Beckman anal ogue computer equations of the type $S=a I^{X}+b 0^{z}=x I^{n} 0^{m}$ are being tested to determine if they are superior to the ordinary Muskingum type equation. Special components for introducing the inflow current and for raising the necessary numbers to powers are being designed.

(f) Inactive.

(g) A circuit design has been completed and a pilot model is under construction by the sponsor.

(1944) STUDY OF METHODS OF ESTIMATING RESERVOIR EVAPORATION.

(b) U. S. Weather Bureau.

(d) Field investigation, applied research.

(e) Evaporation from a small reservoir is being compared with that from four different evaporation pans. Data is also being collected to test the applicability of the energy balance theory and the mass transfer theory.

(1945) ESTTMATING RAINFALL INTENSTTY FROM TOPOGRAPHIC PARAMETERS.

(b) U. S. Bureau of Public Roads.

(d) Statistical study, applied research.

(e) Hourly rainfall intensity is being correlated with various topographic parameters as a basis for estimating intensities appropriate for drainage design in the absence of observations. Three preliminary techniques are being evaluated prior to further basic studies.

(g) A preliminary correlation is completed, for California north of $35^{\circ}$ Lat.

(h) Preliminary report prepared. Copies available through project director.

(19L6) SYNTHESIS OF HYDROGRAPH FOR SMALL AREAS.

(b) Laboratory profect.

(d) Theoretical and field investigation, basic research.

(e) A study of the mechanics of overland flow in an attempt to develop a universal method of estimating the hydrograph of runoff from small areas for drainage design.

(g) Theoretical study of profile of overland flow completed.

(h) "The Fundamental Hydraulics of Overland Flown, Eugene Richey, Ph.D. Thesis, Nov. 1954. 
(2150) STUDY OF FLOW FROM SLOTIED PIPES.

(b) Laboratory project.

(d) Experimental; engineer thesis.

(e) Extension of the manifold port problem to a contimious slot.

(f) Experimental work completed; thesis being written.

(2151) MOLEL STUDY OF PETERS DAM CHUTE SPILLWAY.

(b) Laboratory project.

(d) Experimental; engineer thesis.

(e) Comparison of spillway performance and design predictions.

STEVENS INSTITUTE OF TECHNOLOGY, Experimental Towing Tank.

MISCELIANEOUS PROJECTS.

The Experimental Towing Tank carries out an extensive research program of a classified nature for the Bureau of Ships, Bureau of Ordnance, Office of Naval Research, and the Bureau of Aeronautics, Department of the Navy. A large number of projects involving comercial vessels of many different designs for private clients are also undertaken for the determination of effective horsepower, the resistance, directional stability of barges, the determination of shaft horsepower for river towboats and comparable vessels, resistances under sailing conditions of sailing yachts, and the hydrodynamic characteristics of flying boats and seaplane floats.

(3LO) PLANING SJRFACES.

(b) Office of Naval Research, Department of the Navy.

(c) Mr. Daniel Savitsky, Experimental Towing Tank, Stevens Institute of Technology, 711 Hudson Street, Hoboken, N. J.

(d) Theoretical and experimental; basic research.

(e) A continuous series of theoretical and experimental studies of the basic hydrodynamic processes involved in the planing action of seaplane hulls and high speed surface craft. In particular, the pressure distribution, wake and main spray formation are being studied.

(g) Investigations have extended from elementary planing surfaces of several deadrises, through surfaces in the shape of Vee planform; also surfaces planing parallel to each other and combinations of forebody with an afterbody planing in its wake.

(h) Fifteen papers on the results of research conducted under the subject contract have been prepared and published. Two reports are presently in preparation. One is concerned with the main spray of planing surfaces and the other with the two step planing of seaplane hulls.

\section{(1407) SEAWORTHINESS OF SHIPS.}

(b) Society of Naval Architects and Marine Engineers.

(c) Prof. B. V. Korvin-Kroukovsky, Experimental Towing Tank, Stevens Institute of Technology, 71 Huds on Street, Hoboken, N. J.

(d) Experimental; basic research.

(e) To determine the vertical forces and pitching monents acting on a restrained ship model moving against head seas. This project supplements the project on seaworthiness me del tests conducted at David Taylor Model Basin and Massachusetts Institute of Technol'gy.

(g) Model tests obtained in waves of the length equal to length of ship model, and wav : length to height ratio of 40 are completed, and are partially analyzed.

(h) "Progress Report on Determination of Forces and Moments Exerted by Waves on a Restrained Ship Model", an informal letter report, No. 525, describes the results of the tests. 
(1LO9) BENDING MONENT OF SHIPS IN WAVES.

(b) Society of Naval Architects and Marine Engineers.

(c) Mr. Edward V. Lewis, Experimental Towing Tank, Stevens Institute of Technology, 711 Hudson St., Hoboken, N. J.

(d) Experimental method to check calculations.

(e) Stress measurements of jointed model of T2-SE-Al tanker to determine external bending moment underway in waves, for comparison with calculated bending moment in "stationary" wave.

(f) Completed.

(g) In regular waves of length equal to the model length and of height equal to $1 / 20$ of the length, the measured bending moments were found to be appreciably lower than those obtained by the conventional static method of calculation, although an upward trend appeared as speeds in head seas were extended above the service speed of this ship.

(h) "Ship Model Tests to Determine Bending Moments in Waves", by Edward V. Lewis, presented at the November 1954 meeting of the Society of Naval Architects and Marine Engineers, New York.

\section{(1410) SELF-PROPELLED TESTTNG.}

(b) Office of Naval Research, Department of the Navy.

(c) Mr. Edward V. Lewis, Experimental Towing Tank, Stevens Institute of Technology, 717 Huds on St., Hoboken, N. J.

(d) Experimental; developmental research.

(e) To determine if successful self-propelled testing can be conducted using models of less than 12-foot length and to determine causes of scale effect in propulsion factors.

(g) Open-water tests have been completed on three different sized models of a propeller designed by the Netherlands Model Basin for the Victory type cargo ship. Hull models of the Victory ship, 7-l/2 feet and 9 feet in length, have been tested self-propelled. This work is being carried out in cooperation with the Netherlands Model Basin who are testing models 9 feet long and above.

(h) Second part is covered in E.T.T. Report No. 542, "A Study of Ship Propulsion Scale Effects", by Edward V. Lewis, August 1954, and in abstract in a contribution to the Seventh International Towing Tank Conference by Allan B. Murray, Gothenburg, Aug. 1954 .

(1680) COMPUTATION OF WAVE RESTSTANCE OF SHIPS.

(b) Society of Naval Architects and Marine Engineers and Office of Naval Research, Department of the Navy.

(c) Prof. B. V. Korvin-Kroukovsky, Experimental Towing Tank, Stevens Institute of Technology, 71 Huds on Street, Hoboken, N. J.

(d) Theoretical; applied research.

(e) To verify the applicability of methods and tables developed by R. Guilloton to the calculation of wave-making resistnace of ships of practical shape. To verify validity of certain second order corrections.

(h) "Calculation of the Wave-Making Resistance of Ships of Normal Commercial Form by Guilloton's method and comparison with experimental data", by B. V. Korvin-Kroukorsky and Winnifred R. Jacobs, E.T.T. Report No. 54 .

(1681) TO EVALUATE RESISTANCE AND MOTION IN STTLL WATER AND IN WAVES WITH BULB VARTATIONS FROM 0\% TO ABOOT 13\% OF THE IMMERSED MIDSHIP AREA.

(b) U. S. Maritime Administration.

(c) Mr. Edward V. Lewis, Experimental Towing Tank, Stevens Institute of Technology, 711 Huds on St., Hoboken, N. J.

(d) Experimental; model testing.

(e) Resistances of $v$ arious models being measured in smooth water and in head seas. Bow accelerations and bow pitching being measured in head seas.

(f) Completed.

(g) The effect of bulbous bow size and resistance and motion has been evaluated.

(h) Paper by E. Scott Dillon and Edward V. Lewis presented to the chesapeake Soction of the Society of Naval Architects and Marine Engineers, March 1955. 
(1947) THE DETERMINATION OF RESISTANCE AND AMPLITUDES OF PITCH AND HEAVE OF A MERCHANT SHIP MOLEL IN WAVES.

(b) International Towing Tank Conference, Committee on Seakeeping Qualities.

(c) Mr. Edward V. Lewis, Experimental Towing Tank, Stevens Institute of Technology, 711 Hudson St., Hoboken, N. J.

(d) Experimental; model testing.

(e) Resistance of David Taylor Model Basin Series $60 \mathrm{ship}$ model is being measured in smooth water and in waves of various lengths; amplitudes of pitch and heave are being determined by analysis of moving picture records, and by means of a new apparatus for recording pitch, heave, surge, and wave profile simultaneously.

(g) Results have been forwarded to the sponsor for analysis and comparison with results from other model basins.

(h) Report presented by sponsor to seventh Intermational Towling Tank Conference, Gothenburg, August 1954 .

(1948) SYSTEMATIC INVESTIGATION OF THE TURNING CHARACTERISTICS OF A SHIP MODEL FITTED WITH VARIOUS COMBINATIONS OF APPENDAGES.

(b) Office of Naval Research Department of the Navy (DTMB Technical Supervision).

(c) Mr. Edward V. Lewis, Experimental Towing Tank, Stevens Institute of Technology, 711 Huds on St., Hoboken, N. J.

(d) Experimental; applied research.

(e) To obtain data on the influence of appendages on the turning characteristics of a twinscrew surface ship; the appendages under consideration are skegs and bilge keels, with rudders and propellers of different sizes.

(g) Tests have established the magnitude of the rudder-on-hull interaction effects and its variation with skeg and propeller size. Data on the rudder moments required to provide various turning radii with different sizes of skegs and propellers is believed to be of general applicability to design problems. It is shown that a study of hull-on-rudder interaction is needed to complete the picture.

(h) "A Study of the Effect of Appendages on Surface Ship Turming", by Edward V. Lewis and Nishan M. Eskigian, E.T.T. Roport No. 545 .

(2152) PLANING SURFACES IN ROLL AND YAW.

(b) National Advisory Comittee for Aeronautics.

(c) Mr. Daniel Savitsky, Experimental Towing Tank, Stevens Institute of Technology, $7 \mathrm{l}$ Hudson Street, Hoboken, N. J.

(d) Experimental; basic research.

(e) To conduct an exploratory investigation to define generally the nature of the flow in unsymmetrical planing, the magnitude of steady-state forces and moments, and their variation with yaw and roll angle.

(g) Tests have been conducted on two simple machined plaming surfaces of zero deadrise and $20^{\circ}$ deadrise. Resistance, side force, pitching moment, rolling moment, yawing moment, and planing area were measured simultaneously over the folloting range of independent variables: trim, $6^{\circ}$ to $30^{\circ}$; roll, $0^{\circ}$ to $\pm 15^{\circ}$; yaw, $0^{\circ}$ to $20^{\circ}$; speed coefficient $\mathrm{C}_{\mathrm{V}}, 7.0$ to 17.5 ; load coefficient, $\mathrm{C}_{\Delta}, 2.5$ to 49.0 .

(2153) EVALUATION OF WAKE FRACTION AND THRUST DEDUCTION OF A SHIP PROPELLER.

(b) Office of Naval Research, Department of the Navy (DTMB technical supervision).

(c) Prof. B. V. Korvin-Kroukovsky, Experimental Towing Tank, Stevens Institute of Technology, 711 Hudson Street, Hoboken, N. J.

(d) Theoretical, basic research.

(e) Traditionaliy the wake fraction and thrust deduction for design of a ship propeller are obtained by means of model tests of a specific ship form and its propeller. The general dependence of these characteristics on ship form is known only empirically. In the attempts at rational solution, the mathematical difficulties required drastic simplifying assunptions as to physical conditions, which underwine the practical value of the results. In the present project the wake fraction and thrust deduction is obtained by conputational methods as functions of the hull form and the thmust distribution over the propeller disk. 
While the expression of many hydrodynamical relationships involved in the problem in a corpact mathematical form proved to be prohibitively difficult, these relationships are basically simple and are amenable to the computational procedure, treating one aspect of a problem at a time. In this approach to the problem the physical conditions of it are realistically represented.

(g) An introductory investigation of a body of revolution with a hypothetical propeller is completed. The work is contimued with application to a "Victory" ship form.

(h) "Stern Propeller Interaction with a Streamline Body of Revolution", by B. V. KorvinKroukousky, E.T.T. Report No. 544.

(2154) TIVESTIGATION OF SHIP MOTIONS.

(b) Office of Naval Research, Department of the Navy.

(c) Prof. B. V. Korvin-Kroukov skg.

(d) Theoretical and experimental basic research.

(e) The development of the method of calculation for predicting ship motions caused by the head or following seas. Towing tank tests of ship forms differing widely from the forms currently used in practice in search of considerable improvement in seakeeping qualities of ships.

(g) The preliminary calculations of the coupled pitch and heave motion of a model of DTMB Series $60,0.50$ block hull were completed. The calculated pitching and heaving motions are found to agree reasonably well with the available towing tank test data.

(h) "Ship Motions in Regular and Irregular Seas", by B. V. Korrin-Kroukorsky and Edward V. Lewis, E.T.T. Tech. Memo. No. 106.

(2155) INVESTIGATION OF THE SEAKEEPING QUAITTIES OF SEIPS, WITH PARTICULAR FEFERENGE TO NOTIONS IN IRREGULAR HEAD SEAS.

(b) Office of Naval Research, Department of the Navy (DTHB Technical supervision).

(c) Mr. Edward V. Lewis, Experimental Towing Tank, Stevens Institute of Technology, 71 Huds on st., Hoboken, N. J.

(d) Theoretical and Experimental; basic research.

(e) A method of producing realistic irregular long-crested waves in the model tank is being developed and applied to the comparative study of the motions of two ship models of the same proportions but different forebody form. Results are to be compared with the motions calculated by recently developed methods from model performances in regular waves of a wide range of frequencies.

(g) The development of irregular waves has been completed; test results have not yet been analyzed.

(h) "Irregular Waves in Model Tanks", by Edward V. Lewis. "Observation of Ship Motions by. Models", by Professor B. V. Korvin-Kroukovskg, Both papers presented at the Conference on ships and Waves, sponsored by the Council on Wave Research and the Society of Naval Architects and Marine Engineers, Hoboken, N. J., October 1954.

"Ship Motions in Regular and Irregular Seas", by B. V. Korvin-Kroukovskg and Edward V. Lewis, (ETT TM No. 106) to be published in an early issue of the Intermational Shipbuilding Progress, Rotterdam.

(2156) MOTION AND STABILITY OF HYDROFOIL SYSTEMS.

(b) Office of Naval Research, Department of the Navy (technical supervision by David Taylor Model Basin, at present).

(c) Mr. Paul Kaplan, Experimental Towing Tank, Stevens Institute of Technology, 71 I Hudson St., Hoboken, N. J.

(d) Theoretical; basic research.

(e) To determine the longitudinal stability characteristics of tandem hydrofoil configurations in smooth water and in waves, both controlled and uncontrolled. The resulting motions of the system and the loadings on the foils can then be determined. 
(g) A theoretical analysis of motion in smooth water has been completed. A preliminary analysis of forces and moments in waves has been completed and tests will bo made for comparison with theory. These results have been incorporated into a preliminary study of motions in waves.

(h) "Theoretical Analysis of the Longitudinal stability of a Tandem Hydrofoil systems in Smooth Water", by W. C. Hugli, Jr. and Paul Kaplan, E.T.T. Report No. 479.

\section{(2157) WAYE AND DOWNWASH OF HYDROFOILS.}

(b) Office of Naval Research, Department of the Navy.

(c) Mr. Paul Kaplan, Experimental Towing Tank, Stevens Institute of Technology, $7 l$ Hudson St., Hoboken, N. J.

(d) Theoretical; basic research.

(e) To evaluate analytical expressions for wake and downwash aft of hydrofoils in order to determine the effect of this flow field on the forces acting on a tandem foil located aft.

(g) The two-dimensional wake and downwash of a hydrofoil in waves has been determined in a form applicable to stability and motion analyses in waves. A determination of the threedimensional flow field aft of a finite span hydrofoil in smooth water is contimuing and a report is in preparation.

(h) "The-Two-Dimensional Wake and Dowmwash of a Hydrofoil in Wares", by Paul Kaplan, E.T.T. Report No. 497.

\section{(2158) COMPAFISON OF STREAMLIMED BODIES AND PROLATE SPHEROIDS.}

(b) Office of Naval Research, Department of the Navy (technical supervision by David Taylor Model Basin).

(c) Alice Winzer, Experimental Towing Tank, Stevens Institute of Technology, 7Il Hudson Street, Hoboken, N. J.

(d) Theoretical; basic and applied research.

(e) Calculations based on a theoretical analysis of the three added mass coefficients for a series of rotationally symmetric streamlined bodies; comparison of these calculations with those based on a simplified semi-empirical formula for the added mass coefficients.

(g) A simple semi-empirical formula is established from which the added mass coefficient $k_{1}$ for longitudinal motion can be obtained for a family of bodies. This is found to be in much better agreement with the true $k_{1}$ of the body than the one used thus far, namely the $k_{1}$ of a prolate spheroid of same fineness ratio.

(h) "A Comparison of the Virtual Mass Coefficients of an Airship and of its Equivalent" Ellipsoid", by A. Winzer, E.T.T. Note No. 252.

UNIVERSITY OF TENNESSEE, Hydraulic Laboratory, Department of Civil Enginoering.

Inquiries concerning Projects Nos. 944, 2159, and 2160, should be addressed to Dr. Harry H. Ambrose, Associate Professor of Civil Engineering, Dept. of Civil Engineering, University of Tennessee, Knoxville 16, Temmessee.

\section{(944) HYDRATLIC FRTCTION.}

(b) Partially sponsored by the David Taylor Model Basin, Department of the Navy.

(d) Experimental; basic research.

(e) A long-term investigation has been made to determine the effect of certain roughness characteristics upon the boundary resistance and the velocity distribution in turbulent flows through pipes. Tests were made in a four-inch plastic pipe which was roughened by the insertion of sleeves.

(f) Experimental work completed, final report in preparation.

(g) Resistance coefficients for both depression-type and projection-type roughnesses show persistent viscous effects throughout the test range. 
(2159) DISCHARGE COEFFICIENTS FOR TAINTOR GATES ON SPILLWAYS.

(b) Cooperative with the Tennessee Valley Authority.

(d) Experimental; for master's thesis.

(e) Discharge coefficients were determined for a generalized model of a taintor gate on a spillway. The effect of the trunnion location was investigated as well as that of the relative head and of the relative gate opening.

(f) Experimental work completed, thesis in preparation.

(2160) CHARACTERISIICS OF A THREE-WAY FLOW REGULMTOR.

(b) Fulton Sylphon Division, Robertshaw-Fulton Controls Company.

(d) Experimental; applied research.

(e) Three-way flow regulators of $2,21 / 2,3,4,5$, and 6-inch nominal diameter were tested for discharge-r8-differential-head characteristics.

(P) Completed.

(g) The regulators are generally more efficient for dividing flow than for miding flow.

URI VERSTTY OF TEXAS, Department of Civil Engineering.

Inquiries concerning Projects Nos. 948, 1683, to 1685, inc1., and 2162, should be addressed to Dr. Walter I. Moore, Department of Civil Engineering, Mustin 12, Texas.

(948) DIFTUSION OF A TWO-DIMENSIONAL SUBMEROED JET.

(b) National science Foundation.

(d) Experimental; basic research.

(e) An investigation is being made of the diffusion of momentum in a two-dimensional jet as influenced by the proximity to a plane boundary. Apparatus was constructed for measuring the velocity field in the diffusion rogion of an air jet $0.05 \mathrm{ft}$. thick and $3.0 \mathrm{ft}$. wide with a plane parallel boundary at various distances from the axis of the jet.

(g) Measurements are nearly complete covering a range of boundary distance from 0 to $1.8 \mathrm{ft}$. Results indicate that the boundary has a stabilizing influence and tends to reduce the rate of diffusion. As the distance to the plane boundary is increased the diffusion increases. Mean flow streamlines obtained in the diffusion region defined a stable eddy between the jet and the boundary and indicated a linear spread of the jet downstream from the eddy. Velocity profiles in the zone of linear spread were all reductble to a single dimensionless curre.

(h) Unpublished anmul report to National Science Foundation is available on two weeks loan.

(1683) THE EQUIVAIENT PIPE CONCEPT IN RELATION TO THE GENERAL HESISTANCE DIAGRAM.

(b) Laboratory project.

(d) Theoretical; basic research.

(e) An analytical study to clarify the conditions for the validity of the equivalent pipe concept and to modify the parameters of the conventional general resistance dilagram making it more courenient for problems with pipes in serles, branching pipes, and pipe networks.

(f) Temporarily inactive.

(g) The concepts are all clarifled and limited application of the proposed method indicates reasonable results with adrantages orer other methods. The method seems to combine the convenience of the equivalent pipe method with the completeness of the general resistance dilagram. The approximations made in the interest of convenience are made evident in contrast to the conventional equivalent pipe method. 
Btah state Agricultural college

(1684) FLOW PATTERES AS SOCIATED WITH THE VENTIIATION OF A LARCE AREA.

(b) Laboratory project.

(d) Experimental; applied research.

(e) The flow patterns associated with a conventional plan for the ventilation of a large area will be studied by visual observations in a model of a portion of a large underground garage. Water will be used as the fluid and colored dye to trace the flow patterns. The effectiveness of alternative flow patterns will be investigated.

(g) The model has been completed and ventilation patterns recorded by photographing the movement of a front of dyed fluid sweeping through the area. Additional observation and analysis remain to be done.

(1685) THE INFLUENCE OF ENTRANCE CONDITIONS ON THE FLOW IN SPIILWAYS.

(b) Texas Board of Water Engineers.

(d) Experimental.

(e) Tests were made on three typical spillways stmuctures chosen from the Board of Water Engineers files. General observations were made of the flow patterns, surface profiles were recorded, and a photographic record made. Results are being reported for the benefit of interested engineers.

(f) Completed.

(g) Results indicated instances of satisfactory and unsatisfactory performance and suggested some modifications for improrement of flow conditions.

(b) A Report on Model Spillway Studies, Board of Water Engineers, State of Texas", Sept. 1, 1954, Austin, Texas. A motion picture of the tests is being edited.

(216I) CHARACTERISTICS OF A HYDRAULIC JUMP AT IN ABRUPT CHANGE IN BOTTOM ELEVATION.

(b) University of Texas Research Institute and Bureau of Enginoering Research.

(c) Prof. C. W. Morgan, Department of Civil Engineering, University of Texas.

(d) Experimental.

(e) Experimental determinations will be made of the flow characteristics at two-dimensional channel drops and rises. The veloctty distribution and surface profile will be determined (1) throughout the length of the jump for various relative changes in bottan elevation. The longitudinal location of the jump in relation to the change in bottom elevation will be varied over a broad range in distinction to previous related investigations in which relative location of the jump was held constant.

(g) For a given entering flow condition, three different types of the hydraulic jump may form at an abrupt drop. The form of the jump, the transition between types, and the longitudinal location of the jump relative to the drop are dependent on the downstream depth.

(2162) HYDROLOGIC SIUDIES, WALIER CHEEK WATERSHED.

(b) Cooperative with J. S. Geological survey.

(d) Field Investigation; applied research.

(e) Measurements of rainfall and runoff for a 4 square mile portion of the Waller Creek watershed will be made to provide basic information for estimating runoff from small urban watersheds in the Southwest area. Efforts will be made to correlate runoff with rainfall and characteristics of the drainage basin when sufficient data have accumulated. The streamflow station has been completed and arrangements for the rain gages are being made.

UTAH STATE AGRICULTURAL COLIECE, Agricultural Experiment Station.

\section{(359) DRATNAGE OF IRRIGATED LANDS.}

(b) Laboratory and field project.

(c) Mr. A. Alvin Bishop, Irrigation Department, Utah State Agricultural College, Logan, Utah.

(d) Field studies; applied research and master's theses. 
(e) The major purposes are to find low cost, effective methods of drainage of arid-region waterlogged saline and alkali lands. In the past year work has been concentrated in Utah and Weber Counties with preliminary studies being made in Cache County.

(g) Piezometers were used to measure the hydraulic head in the area affected by the Hooper Pilot Drain and flow patterns were constructed for conditions before construction of the drain and after the drain was completed. The effect of the drainage construction on the ground water flow pattern was significant.

(h) "Drainage of the Cache Valley Lowlands", Willard Gardner and 0 . W. Israelsen, Utah Agricultural Experiment Station Bulletin No. 368, Logan, Utah, May 1954.

(1686) CONSIMPTIVE USE OF WATER AND IRRIGATION REQUIREMENTS.

(b) Laboratory project, cooperating with Agricultural Research Service, U. S. Geological survey and Utah State Engineer.

(c) Prof. Wayne D. Criddle, Irrigation Department, Utah State Agricultural College, Logan, Utah.

(d) Field investigation; applied research.

(e) To obtain basic information regarding consumptive use of water by agricultural crops, pastures, and native vegetation; and to study methods of measurement of consumptive use of water.

(g) Results being obtained are used currently in administration of the surface and underground waters of Utah.

(h) "Consumptive use of water by major farm crops in the Escalante Valley of Utah", Glen L. Steed, Thesis, Utah State Agricultural College, Logan, Utah, 1954.

(1955) A STUDY OF FARM IRRIGATION EQUIPMENT AS RELATED TO OPERATION CHARACTERISITCS, COSTS, LABOR REQUIREMENTS AND TIME STUDIES INVOLVING IRRIGATION SCHEDULES AND SYSTEM CAPACITIES.

(b) Laboratory project, cooperative with Reynolds Metals Company.

(c) Prof. Wayne D. Criddle, Irrigation Department, Utah State Agricultural College, Logan, Utah.

(d) Field investigation; applied research.

(e) To evaluate irrigation equipment being used in the field and to develop criteria for the use of various types of equipment.

(2163) WATER RESOURCES PHASE OF INDUSTRIAL SURVEY SOUTHWESTERN UTAH, TRI-COUNTY AREA (Kane, Iron, and Washington Counties).

(b) Utah Committee on Industrial and Employment Planning.

(c) Prof. Wayne D. Criddle, Department of Irrigation and Drainage Engineering, Utah State Agricultural College, Logan, Utah.

(d) Field investigation; basic research.

(e) The purpose of this study is to provide complete inventory of all water resources of the area and also to examine extent and economic value of losses, shortages, and wastes. Recommendation for more efficient utilization of the resources will be made. Findings to be integrated with other phases of the survey.

(g) Results not yet available.

(2164) EVALUATION OF FACTORS AFFECTING WATER YIELDS FROM HIGH WATERSHEDS.

(b) Laboratory project.

(c) Mr. Gregory L. Pearson, Soil Conservation Service, Salt Lake City, Utah, Mr. Cleve H Milligan, Utah State Agricultural College, Logan, Utah.

(d) Field investigation, statistical studies; applied research.

(e) The purpose of the project is to improve the accuracy of prediction of sumer irrigation water supplies based on snow and rainfall measurements, base stream flow, soil moisture conditions, etc. These predictions provide a basis for efficient water and farm management, including reservoir operation, cropping practices, and flood control.

(g) As a consequence of these studies, it is now possible to estimate summer streamflow on many Utah streams within 10 percent, and on some streams within 5 percent, as compared to actual U.S.G.S. streamflow measurements.

(h) "Federal-State Cooperative Snow Surveys and Water supply Forecasts for Utah", published annually in mimeographed form. Available: Soil Conservation Service, Salt Lake City, Utah or Utah Agricultural Experiment Station, Utah State Agricultural College, Logan, Utah. 
UTAH STATE AGRICULTURAL COLIEGE, Engineering Experiment Station.

(1956) INVESTIGATION OF FRICTION LOSSES IN FITTINGS AND VALVES FOR PORTABLE SPRTNKLER IRRIGATION EQUIPMENT.

(b) Cooperative with Irrigation Equipment Company and Utah Agricultural Experiment Station.

(c) Mr Alvin Bishop, Irrigation Department, Utah State Agricultural College, Logan, Utah.

(d) Experimental; design research for master's thesis.

(e) To obtain head loss factors for fittings and valves used in portable sprinkler irrigation systems and to compare hydraulic performance of valves partially closed with valves fully opened.

(f) Completed.

(g) Valves tested showed a friction loss for a condition of seven-tenths open to be less than for the same valve operated under full open conditions. Speclal hydraulic characteristics of the valves were determined.

(h) "An Investigation of Friction Losses in Valves for Portable Sprinkler Irrigation Equipment", by Nukruk Paholyotin, Thesis, Utah State Agricultural College, Logan, Utah, May 1954.

STATE COLLEGE OF WASHINGTON, Department of Civil Engineering and Division of Industrial Research.

(1689) STUDY OF FLUID FLOW IN PIPE NETWORKS.

(b) Laboratory project.

(c) Prof. Charles L. Barker, Hydraulic Laboratory, Washington State College, Pullman, Wash.

(d) Experimental.

(e) Using the McIlroy flow network analyzer the following studies are to be made: (I) Effect of eliminating small pipes in a distribution system in the Hardy-Cross analysis, (2) effect of combining loads in a network, and (3) the effect of pipe roughness on pumping costs on network flow.

(1690) PLACEMENT OF AIR VENTS IN IRRIGATION PIPELINES.

(b) Concrete Products Association of Washington.

(c) Prof. Charles L. Barker, Hydraulic Laboratory, Washington State College, Pullman, Wash.

(d) Experimental; applied research for design.

(e) The minimum distance that an air vent is to be placed from the inlet of a pipeline (where air enters the pipeline) is a function of the rise velocity of the atr bubbles, the velocity of water in the pipe, and physical characteristics of the structure. An attempt will be made to determine the rise velocity of bubbles as a function of bubble size, and Reynolds number.

(h) Publication in press.

(1691) PHESSURE RELIEF STRUCTURE.

(b) Concrete Products Association of Washington.

(c) Prof. C. L. Barker, Hydraulic Laboratory, Washington State College, Pullman, Wash.

(d) Theoretical and experimental; for design.

(e) Former research has shown that air releases from small vents in irrigation pipelines may generate water hamer. An air dome used in conjunction with the small vent pipe will reduce the magnitude of pressure generation. Design dimensions of the air dome are being evaluated as a function of vent size, pressure reduction desired, size of main pipe, length of main pipe.

(h) Publication in press.

(2165) THE INFLUENCE OF LOGGING OPERATIONS ON RUNOFF FROM PRECIPITATION.

(b) Division of Industrial Research.

(c) Mr. E. Roy Tinney, State College of Washington, Pullman, Wash.

(e) Study of cutting records of lumber companies and of precipitation and runoff records for the same period of time. 
(2166) MODEL STUDY OF NOXON RAPIDS DAM ON THE CLARK FORK RI VER, NOXON, MONTANA.

(b) Washington Water Power Company and Ebasco Services Incorporated.

(c) Mr. Paul Ruff, State College of Washington, Pullman, Wash.

(d) Study of cofferdam construction procedures, spillway capacity, training wall design, etc.

(e) Model 1 to 5 of same 3000 feet of river section has been constructed. Flow up to 7500 gpm representing $250,000 \mathrm{cfs}$ is being used.

UNIVERSITY OF WASHINGTON, Department of Civil Engineering.

(1692) SHORT RANGE FORECASTS OF SNOW-MELT RUNOFF IN COLUMBIA RIVER BASTN.

(b) Bonneville Power Administration, cooperative with the Geological survey, Tacoma, Wash.

(c) Prof. T. H. Campbell, Civil Engine ering Dep't. Univ. of lash, Seattle 5, Wash.

(d) Theoretical; applied research, for doctor's thesis.

(e) To develop a procedure whereby increased flow from snow melt can be forecast for periods of five to ten days from wheather bureau records or from forecasts of weather in the Columbia River Basin.

(1693) SHORT RANCE FORECASTS OF RUNOFF FROM PRECIPITATION IN COLUMBIA RIVER BASIN.

(b) Bonneville Power Administration, cooperative with the Geological Survey, Tacoma, Wash.

(c) Prof. T. H. Campbell, Civil Engineering Dept't. Univ. of Wash., Seattle 5, Wash.

(d) Theoretical; applied research.

(e) To develop a practicable procedure for estimating the flow of streams in the Columbia River Basin for periods of five to ten days in advance during periods of rainfall.

(h) "Short Term Streamflow Forecasting from Precipitation Data", Ernest C. Pogge, 110 pages. Applies to St. Maries River, St. Joe River, and Coer d'Alene River Basins. Unpublished Master's Thesis, University of Washington, library.

(1705) A HYDROGRAPHIC STMMARY OF THE STREAMS IN THE STATE OF WASHINGTON.

(b) State of Washington, Department of Fisherles.

(c) Prof. Harold K. Moritz, Hydraulies Laboratory, University of Washington, Seattle 5, Wash.

(d) Fleld investigation, operation.

(e) Comparative hydrographic study of streams in the State on basis of high year, low year, and mean year.

(2167) THE USE OF A HICH SPEED WATER JET FOR DETERMTNINO THE HYDROSTATIC CHARACTERISTICS OF PLANING SURFAGES.

(b) Laboratory project.

(c) Prof. Harold K. Morltz, Hydraulics Laboratory, University of Washington, Seattle 5, Wash.

(d) Experimental, basic, for Master's Thesis.

(f) Completed.

(h) Unpublished Master's Thesis in University of Washington library, by Richard A. Balser, 26 pages.

ONIVERSTTY OF WISCONSIN, Hydraulic Laboratory.

Inquiries concerning Projects Nos. 956, 958, and 1181 should be addressed to Dr. J. R. Villemonte, and Projects Nos. 959, 1707 and 1709, to Dr. Arno T. Lenz, Hydraulic Laboratory, University of Wisconsin, Madison 6, Wisconsin. 
(956) HEAD LOSSES IN FLOW OF LIQUIDS IN PIPES UNDER HICH LITE PRESSURES.

(b) Cooperative with Ladish Company, Cudahy, Wisconsin.

(d) Experimental; for master's and doctoral theses.

(e) Low pressure studies of fitting losses with laminar flow are in progress.

(g) Tests have been completed on $1 / 4,1 / 2,1$ and 2-inch seamless steel tubes over a Reynolds ' number range of 50 to 150,000 . The relation between the friction factor $f$ and Reynolds' number is consistent, provided the temperature and pressure effects on fluid properties are known.

(958) HEAD LOSSES IN FLOW OF LIQUIDS IN WELDING PIPE FITTINGS AND VALVES.

(b) Cooperative with Ladish Company, Cudahy, Wisconsin.

(d) Experimental; for doctoral, master's and bachelor theses.

(e) Additional tests since those reported in Hydraulic Research in tine United States, 1954, have been made on 2-inch pipe bends and elbows.

(f) Inactive.

(g) Coefficients $K$ in $H=K v^{2} / 2 g$ in the Reyno'ds' mumber range from 25,000 to 500,000 were found to be as follows:

$\begin{array}{lc} & \underline{K} \\ \text { One-cut miter bend } & 1.4--1.7 \\ \text { Short radius welded elbow } & 0.3--0.6 \\ \text { Long radius welded elbow } & 0.2--0.7 \\ \text { Standard short radius threaded elbow } & 0.6--1.0\end{array}$

The minimum value of $K$ occurred at an $\mathrm{N}_{R}$ value of 100,000 for all bends and elbows tested.

(h) Wriction Losses Due to PIpe Elbows", R. K. Espe, D. S. Loos, D. G. Poss, B. S. Thesis, June 1954. (Available on loan.)

(959) HYDROLOGIC INVESTIGATION OF LAKE MENDOTA DRATNACE BASTN.

(b) Part of a larger project entitled norigin and quantities of algal fertilizers tributary to Lake Mendota". Cooperative study sponsored by University of Wisconsin.

(d) Field in estigation; applied research for Ph.D., M. S. and B. S. Theses.

(e) Seren stream gaging stations have been installed to measure tributary inflow to Lake Mendota and Iahara River outflow. Precipitation records are being obtained from fourteen recording rain gages. Current efforts are concentrating on publication of surmary of results to date.

(g) Three M. S. and six B. S. Theses completed. (Available on loan.)

(1181) VORTEX FLOW FROM HORIZONTAL THIN-PLATE ORIFICES.

(b) Cooperative with M. J. C. Stevens, Portland, Oregon.

(d) Theoretical and experimental; for Ph.D., M.S. Theses.

(e) Existing fundamental considerations are being studied and a new practical approach has been developed. Initial vorticity can be completely controlled, and measurements of head, discharge, and surface profile can be made. Orifice diameters will vary from 2 to 8 inches with the existing apparatus.

(g) Tests have been completed on 2-, 4-, and 6-inch diameter sharp-edged orifices. Tests on an 8 -inch dia orifice are now in progress.

(1707) PROBLEMS OF SCOUR AT BRIDGE AND CULVERT OPENINGS.

(b) Consolidated's Civic Foundation, Inc.

(d) Experimental; for M. S. and B. S. Theses.

(e) Hydraulic model studies are in progress to determine methods of estimating probable scour pattern for a proposed structure having certain physical site characteristics and conditions of flow. Remedial methods will also be studied so scour at existing structures will be reduced or eliminated. 
(g) Causes of scour at one location have been correlated with topography and water levels. study of the design of training walls to get better flow under the bridge structure is in progress.

(h) "Approach Improvements to Reduce Scour, Buckhorn Bridge Model", J. C. Fingenoldus, M. S. Thesis, Juns 1954. (Available on loan.)

(1709) CALIBRATION OF V-NOTCH WEIRS AT ENDS OF CULVERTS.

(b) WHsconsin Culvert co.

(d) Experimental; for M. S. and B. S. Theses.

(e) $190^{\circ} \mathrm{V}$-Notch is installed in a rectanguiar flume and is being used as a control for flows up to and above the top of the weir plate.

(g) Mathematical interpretation of the flows as the sumation of V-Notch and rectangular wir flows was made and coefficients determined to express the total flow as a function of the head above the bottom of the V-Notch.

(h) "Calibration of $\nabla$-Notch Weirs at Ends of Culvert Pipes", M. W. Busby and L. R. Hafeman, B. S. Thesis, June 1953. (Available on loan.)

WORCESTER POLYTECHNIC INSTITUTE, Alden Hydraulic Laboratory.

Inquiries concerning Projects Nos. 961, 1712, 1713, 1961, and 2168 to 2170, incl., should be addressed to Prof. I. J. Hooper, Alden Hydraulic Laboratory, Woroester Polytechnic Institute, Worcester 2, Mass.

(961) VALVE TESTS.

(b) Chapman Valve Company.

(d) Experimental; for design.

(e) Head loss measurements for various discharges are made on a 24-inch disc type check valve. Closure time and pressure changes are recorded photographically for various flows up to 45 gps.

(1712) CROMBY MOVEABLE BED MDIEL.

(b) Philadelphia Electric Company.

(d) Experimental; for design.

(e) A distorted model (1:15 vertical scale, 1:45 horizontal scale) was constructed of a section of the Schuylkill River including prorision for heating water pumped through the condensers. Studies were made of re-circulation of hot water discharged from condensers.

(f) Inactive - work will be contimed.

(1713) LITTLETON HYDROELECTRIC DEVELOPMENT.

(b) Connecticut River Power Company.

(d) Experimental; for design.

(e) A 1:60 model was constructed of the chute spillway and section of the Connecticut River to study flow conditions in the chute and in the river adjacent to the chute.

(f) Completed. Model kept in readiness to check details during construction.

(1961) HOGBACK DAM WATER SUPPLY DEVELOPMENT.

(b) The Water Bureau, Hartford, Conn.

(d) Experimental; for design.

(e) A 1:50 model of the dam, spillway, diversion tunnel, Kill Brook diversion and adjacent river topography was constructed to study flow conditions for diversion and flood flows. Water surface profiles in diversion tunnel and spillway channel were determined.

(f) Completed. Model maintained to provide information during construction. 


\section{(2168) HOGBACK DAM WATER SUPPLY DEVELOPMENT}

(b) The Water Bureau, Hartford, Conn.

(d) Experimental; for design.

(e) A 1:9 model of a section of the spillway was installed in the 3 foot glass sided flume. Tests were made to determine the discharge coefficient and the pressures on the surface near the crest.

(f) Completed.

(2169) EDGAR STATION.

(b) Bost on Edison Co., through Jackson Moreland Company.

(d) Experimental; for design.

(e) A 1:250 model of the Edgar Station steam plant was installed in a wind tunnel $\left(5^{\prime} \times 5^{\prime} \times 8^{\prime}\right.$ test section) to determine the effect of various devices on the smoke pattern from the stacks.

(2170) TITEFLEX COUPLINGS.

(b) Titeflex Corporation.

(d) Experimental; for design.

(e) A series of quick disconnect couplings in various pipe sizes up to 2 inches were tested for head loss and leakage. Several combinations of valve and check arrangements were studied.

(f) Completed.

MISSISSIPPI STATE COLLEGE, Engineering and Industrial Research Station.

Inquiries concerning Projects Nos. 4, 5, 1631, and 2171 should be addressed to Dr. Harold Flinsch, Box 1516, State College, Miss.

(4) DEVELOPMENT OF SURFACE WAVES BY WIND.

(b) Laboratory project.

(d) Theoretical and experimental research.

(e) Research on the theories of surface wave origin and growth, on measurements in the laboratory and in nature, and on the comparative results of theory and measurement.

(g) A paper on the proposed theoretical approach of the project is in preparation. New experimental equipment has been acquired.

(5) SHIP STABILITY AND ROLLTNG PERIOD.

(b) Laboratory project.

(d) Theoretical and experimental research.

(e) Exact and approximate formulas determining certain characteristics of ships, such as rolling period, metacentric height, etc., are compared with the results of experiments on ship models.

(g) Preliminary experiments have been performed on a basic model, and some of the results assembled in a brief report.

(1631) THE EFFECT OF WAVES ON BEACHES.

(b) Laboratory project.

(d) Experimental, theoretical, and field investigation; basic research.

(e) Determination of relationship between wave energy and beach profile and contours.

(g) Equations and formulas for beach slopes and beach contours have been confirmed. 
(2171) THE PERFORMANCE OF SATIING VESSELS.

(b) Laboratory project.

(d) Field investigation; applied research.

(e) Records of sailing vessels, with particular reference to speed and direction of vessel and wind, are examined, to determine the performance of these vessels. Field tests are run on available sailing vessels.

(g) A small mumber of field test results are available. 
U. S. DEPARTMENT OF AGRICULTURE, AGRICULTURAL RESEARCH SERVICE, Soils and Water Conservation Research Branch.

Eastern Soil and Water Management Section.

(1966) SOII AND WATER MANAGEMENT STUDIES, TNCLUDTNG DRATNACF AND IRRIGATION.

(b) In cooperation with the following State Agricultural Experiment Stations and other agencies throughout the 31 Eastern States: Alabama, Florida, Georgia, IIlinois, Indiana, Iowa, Maine, Maryland, Kissouri, New Jersey, New York, North Carolina, Ohio, Pennsylvania, South Carolina, Virginia and Wisconsin. Hydraulic measurements are necessary for determining the effects of land management practices on runoff, soil moisture and erosion. Research is contimally being carried on to improve these hydraulic measurements, since few data are available on measurement of silt and trash laden flows fram small agricultural areas. Since the type of studies conducted at different locations within the many states are similar except for variations in soils, climate and cropping, they are being consolidated under a single he ading.

(c) Mr. L. B. Nelson, Eastern Soil and Water Managerent Section, Plant Industry Station, Beltsville, Maryland.

(d) Field and laboratory investigations; basic and applied research for design purposes.

(e) To determine the (1) effects of different land use and farming practices upon surface runoff, soil losses and groundwater supply and movement; (2) soil characteristics that are basically related to soil and moisture conservation principles as a basis for desiguing conservation practices; (3) relation of water runoff and soil erosion to the topography and other physiographic conditions of the drainage area, and to climatological conditions; ( 4 ) design of effective and economical structures and cultural practices for erosion control, water disposal and molsture conservation; (5) requirements for control of surface water and ground water where agricultural production is prevented or limited by excess or deficiency of moisture; (6) practical methods and means of installing and maintaining land drainage improvements in the $\mathrm{E}$ ast; (7) water requirements for irrigation in the East; ( 8 ) best sources of irrigation water and how it may be most economically stored and applied to the land; (9) best techniques for measuring and evaluating the infiltration rates and permeability characteristics of soils throughout the Eastern Section of the United States and to determine the magnitude of change that may result from changes in management and varying soil treatments; and (10) principles underlying the flow of water into and through soils.

(g) Rainfall, munoff and erosion data from land in different crops and receiving different. cultural and fertilizer treatments in many locations, are being tabulated on standard forms for early analysis.

(h) "Preliminary Tests of Homemade Drainage Pumpsn, E. Q. Diseker. Special Report No. 62, Eastern Soil and Water Management Section, SWC, ARS, in cooperation with the North Carolina Agricultural Experiment Station, Raleigh, N. C., May 10, 1954. "Engineering Applications of Soil Permeability Data", T. W. Edminster. Presented before the Conmission VI (Soil Technology) Fifth International Congress of Soil Science, Belgian Congo, August 16-22, 1954. (See 1954 Int. Soll Sci. Soc. Abstracts). "Changes in Air-Water Relationships Due to Structural Improvement of Soils", V. C. Jamison, Soll Sci. 76: 143-151 (1953).

"Improving Land Conditions for Conservation and Production with Chemical Soil Conditioners", R. W. Pearson and V. C. Jamison, Jour. Soll and Water Conserv. 8 (3): 130-135 (1953). "How to Operate Sprinklers Most Efficiently", J. R. Carreker, Amer. Frutt Grower 73 (6): 11,42 (1953).

Machinery Aspects of Land Drainagen, I. I. Saveson, Agr. Eng. 34: 303-306 (1953). "Results of Brapo-transpiration and Root Distribution Studies", W. B. Land and J. R. Carreker, Agr. Eng. 34: 319-322 (1953).

Soll-Plant Relationships Section.

(26) DRATNAGE INVESTIGATIONS IN COACHELLA VALIEY, CALIFORNIA.

See Oniversity of California, College of Agriculture, Division of Irrigation and Soils, page 8 . 
(1194) PRINCIPLES UNDERLYING THE MOVEMENT OF AIR AND WATER INTO AND THROUGH SOILS.

(b) Laboratory project.

(c) Mr. H. E. Hayward, J. S. Saliinity Laboratory, P. 0. Box 672, Riverside, California.

(d) Experimental; applied research.

(e) To investigate the factors that influence the flow of water and air into and through soils. The ratio of air to water permeability is used as a measure of the stability of soil structure, and the effect of $v$ arious treatments on the stability of soil structure is being evaluated.

(g) Exchangeable sodium has been shown to be the principal cation which adversely affects soil physical condition. Exchangeable potassium and magnesium have been found to have little adverse effect upon soil structure.

(h) "A Comparison of the Effects of Exchangeable Sodium and Potassium upon the Physical Condition of Solls", R. C. Reeve, C. A. Bower, R. H. Brooks, and F. B. Gschwend, Soil sci. Soc. Amer. Proc. 18: 130-132, 1954.

(2172) MOVEMENT OF WATER AND SOLUTES IN THE ROOT ZONE.

(b) Laboratory project.

(c) Dr. L. A. Richards, P. 0. Box 672, Riverside, California.

(d) Field investigation; applied research.

(e) Involves measurement of water intake rate, and at various depths over a period of time, hydraulic head, hydraulic gradient, suction, temperature, and salinity are measured. The rate of lowering of the static zone through the soil is determined and is related to the rate of evaporation from the soil surface.

(h) Multiple Tensiometer for Deteimining the Vertical Component of the Hydraulic Gradient in Soiln, I. A. Richards, Soil Sci. Soc. Amer. Proc. Vol. 18, No. 1, pp. 7-10 (1954).

(2173) MOVEMENT OF WATER AND SALTS FROM A WATER TABLE.

(b) Laboratory project.

(c) Dr. Milton Fireman, P. 0. Box 672, Riverside, Californta.

(d) Experimental; applied research.

(e) Involves soil-column studies on evaporation as affected by depth to ground water, amount of incident heat, humidity, soil texture, bulk density, salt content of ground water, and moisture transmission properties of the soil. Data are collected on rate of ev aporation, rate of accumulation and mode of distribution of salt, moisture distribution, and the relation of moisture content and capillary conductivity to soil moisture morement.

(2174) MATHEMATICAL THEORY FOR THE MOVEMENT OF SOLUBLE SALTS BY LEACHING.

(b) Laboratory project.

(c) Dr. W. R. Gardner, P. 0. Box 672, Riverside, California.

(d) Theoretical and experimental; basic and applied research.

(e) Purpose is to derive a mathematical theory for the leaching of soluble salts fram soils. The soil properties which govern the amount of leaching are determined. Mathematical results are checked experimentally in laboratory soil columns.

(g) Tentative theory for leaching curing saturated flow has been derived. Laboratory experiments to check theory are in progress.

Watershed Hydrology Section.

(150) EXPERIMENTAL WATERSHED STUDIES.

Also included Project number 1965 which appeared in Miscelleneous Publication 210, 1954.

(b) Cooperative with State Agricultural Experiment Stations, Soil Conservation Service, University of Iowa, St. Anthony Falls Hydraulic Laboratory, Central and Southern Fiorida Flood Control District, and the Wisconsin Valley Improvement Campany.

(c) Mr. William C. Ackermann, Watershed Hydrology Section, Plant Induatry Station, Beltsville, Maryland.

(d) Experimental; field and laboratory; for design of Watershed Protection and Flood Prevention projects and general information in planning farms for soil and water conservation. 
(e) Rainfall and runoff are measured on watersheds ranging from 1 to 40,000 acres. In addition to rainfall and runoff measurements, studies are made on small Governmentoperated areas of evapo-transpiration, moisture storage, moisture transmission through the soil, hydrologic effect of physiography, tillage, and ground surface conditions, vegetal covers and soils and geology, and the effect of conservation farming on runoff and erosion, as well as the characteristics of flood runoff from agricultural watersheds. Studies are being carried on at, Tombstone and Safford, Arizona; Ft. Lauderdale, Florida; Alhambra, Edwardsville and Monticello, Ill.; Iowa City, Iowa; Skowhegan and Presque Isle, Maine; College Park, Md.; East Lansing, Mich.; Hastings, Neb.; Freehold, N. J.; Albuquerque and Santa Rosa, New Mexico; Cohocton, N. Y.; Coshocton, Ohio; Stillwater, Oklahoma; Riesel, Texas; Blacksburg, Virginia; and Colby, Fennimore, and Madison, Wis.

(g) Conservation practices have appreciably reduced peak rates of runoff for all storms for areas as large as 300 acres, Runoff volume is appreciably reduced for some storms. Data comparing areas larger than 300 acres under conserv dtion with similar untreated areas are not available due to the difficulty of finding comparable treated and untreated areas.

(h) "The Role of Soil in the Hydrologic Cycle", L. L. Harrold, 5th Inter. Congress of Soil Sci. Brussels, Aug. 16-22, 1954.

"Soil Type and Land use Ef fects on Percolation of Soil Water through Monolith Lysimeters", F. R. Dreibelbis, Soil Science Society of America, Proceedings Vol. 18 No. 4, Oct. 1954.

(1723) THE HYDRAULICS OF CONSERVATION STRUCTURES.

See St. Anthony Falls Hydraulic Laboratory Projects - 111, page 78; 1168, 1398, page 79; and 1929, Page 81 .

Also included are Project Numbers 152, 153, 1722, and 1964 which appeared in Miscellaneous Publication 210, 1954 .

(b) Cooperative with the OKlahoma and Minnesota Agricultural Experiment Stations, and the St. Anthony Falls Hydralic Laboratory.

(c) Mr. hilli am C. Ackermann, Watershed Hydrology section, Plant Industry Station, Beltsville, Maryland.

(d) Experimental; applied research for developnent and design.

(e) Field studies are made to determine the causes of deterioration of drainage ditches, terrace outlets, and hydraulic structures that have failed in service. Laboratory experiments in methods of preventing such deterioration are supplemented by field tests of those measures or devices that appear promising. Models of hydraulic structures are built and tested in the laboratory; and when the design has been developed to seemingly satisfactory operation, full-scale structures are tested before they are recommended for field use. By laboratory and field studies, determinations are made of the suitability of certain grasses for preventing erosion of terrace-outlet channels and other farm waterways, and of the different grasses in checking the velocity of flow. Studies are being carried out at the Outdoor Hydraulic Laboratory at Stillwater, Okla., and the St. Anthony Falls Hydraulic Laboratory, Minne apolis, Minn.

(g) Studies of various grasses have shown that smooth brome and fescue (Kentucky 31) can be used for erosion control in waterways but even in the best condition should not be used where velocities will exceed 5 feet per second.

A suitable formula for the determination of the tailwater depth required to insure satisfactory performance of the straight drop spillway was developed.

(h) "The Use of Grass in Waterways", W. 0. Ree, Proc., Sixth International Grassland Congress, 1952.

"Characteristics of Tipping Bucket Devices", H. L. Cook and D. A. Parsons, Trans. Am. Geophys. Union, 34:85-9L, 1953.

"Hydralics of Closed Conduit Spillways", F. W. Blaisdell, St. Anthony Falls Hydraulic Laboratory, Tech. Paper 12, Series B.

(2175) SEUIMENTATION IN RESERVOIRS, STREAMS AND VALLEYS.

(b) Cooperative with State Agricultural Experiment Stations in Mississippi, Nebraska and New York.

(c) William C. Ackermann, Watershed Hydrology Section, Plant Industry Station, Beltsville, Maryland.

(d) Experimental; field and laboratory, for design of Watershed Protection and Flood Prevention Projects and general information in planning farms for soil and water conservation. 
(e) Field studies are made to determine sediment sources in watersheds, the character and amount of sediment carried out of watersheds, the nature and rate of movement in channels, the nature and rete of stream-bank erosion, and the nature and rate of deposition of sediment in channels, on flood plains and in reservoirs and harbors. Field studies generally are confined to watersheds of less than 100 square miles in area. Evaluation studies are made of various types of control measures to determine their effectiveness in reducing sedimentation damages. The work is oriented to meet the immediate and specific needs for information for the planning and design of watershed treatment programs in connection with soil conservation and flood prevention work. Studies are being carried on at State College, Miss.; Lincoln, Neb.; and East Aurora, New York.

(g) In Nebraska, areas with 4 to 6 inches of sediment deposited on them yielded 45 percent more corn per acre than a check plot in the same field which received no sediment. Areas with 6 to 8 inches of topsoil removed by scour during the flood yielded 26 percent less corn per acre than the check plot. Yields of corn on plots receiving sediment were 96 percent greater than those on plots where scour occurred.

(h) "Water Erosion Problems and Control on Non-Irrigated Agricultural Lands", L. M. Glymph, Jr., Trans. Am. Geophys. Uni on 35:2L6-252, April 1954 .

"Coshocton-Type Runoff Samplers", D. A. Parsons, Soil Conservation Service Tech. Publ. 124, April 1954.

WESTERN SOIL AND WATER MANAGEMENT SECTION.

(53) SAND TRAPS AND SLUICEWAYS.

See Colorado $A$ and $M$ College, page 18.

(55) SNOW COURSE MEASUREMENTS AND FORECAST ANALYSIS.

See Color ado $A$ and $M$ College, page 18.

(287) PERFORMANCE OF WELL SCREENS.

See Colorado A and M College, page 18.

(820) THE STUDY OF SEEPAGE LOSSES FROM IRRIGATION CHANNELS.

See Colorado A and M College, page 19.

(2067) MOLEL STUDY OF A TILE INTERCEPTOR DRAIN.

See Colorado A and M College, page 24.

(2176) USE OF WATER IN THE SANTA MARGARITA RIVER BASIN, CALIFORNIA.

(b) Field project in cooperation with State of California, Department of Public Works, Division of Water Resources.

(c) Mr. Harry F. Blaney, 1509 Post office and Court House Bldg., Los Angeles, Calif.

(d) Experimental; applied research.

(e) To determine the consumptive use of water by agricultural crops, native vegetation and evaporation. To obtain data on irrigation practices and farm irrigation use.

(f) Field work on consumption use complete. Evaporation, humidity, temperature and wind movement data still being recorded at three stations.

(g) Long-term mean consumptive use of water by agricuitural crops, native vegetation, and ev aporation losses have been computed for the area. These values have been computed by the $\mathrm{Blaney}$-Criddle method which utilizes weather records for estimating consumptive use.

(h) "Irrigation and Consumptive Use Investigations, in the Santa Margarita River Basin, Riverside and San Diego Counties, California", by William W. Donnan and G. Marvin Litz.

(Mimeographed). Revised report being prepared. 
(2177) WATER REQUIREMENTS IN THE IRRIGATED AFEAS OF THE PACIFIC SOUTHWEST.

(b) Field project in cooperation with Western States' Agricultural Colleges, State Engineer, Soil Conservation Service, and Bureau of Reclamation.

(c) Mr. Harry F. Blaney, 1509 Post Office and Court House Bldg., Los Angeles, Calif.

(d) Field experiments and office analysis.

(e) (1) To determine the consumptive use of water by agricultural crops and native vegetation and water requirements for Irrigated crops. (2) To compile and prepare for publication available data relating to irrigation requirements and consumptive use as determined by field experiments. (3) To estimate water requirements from climatological and other data.

(f) Investigation has been underway for several years and has not been completed.

(g) Normal rates of consumptive use and water requirements have been estimated and provisional reports are prepared for several western states and Colorado River Basin. These values have been computed by the Blaney-Criddle formula; $U=K F$. Where $U$ is a consumptive use in inches, $\mathbb{K}$ is an empirical coefficient based on experimental measurements and $F$ is a factor determined from monthly mean temperatures and percent day-time hours.

(h) "Consumptive Use of Water in the Irrigated Areas of the Upper Colorado River Basin", by Harry F. Blaney and Wayne D. Criddle, SCS, USDA, pp. L9, illus., 1949. wetermining Water Requirements in Irrigated Areas from Climatological and Irrigation Data", by Harry F. Blaney and Wayne D. Griddle. SCS, USDA, pp, L8, illus., 1950. "Consumptive Use and Irrigation Water Requirements of Crops in Arizona", by Harry F. Blaney and Karl Harris. USDA, SCS, pp. L9, 1llus., Dec. 1951.

"Consumptive Use of Water Rates in the Lower Colorado Basin", by Harry F。 Blaney and Karl Harris. (Mimeo.)

(2178) DETERMIIATION OF THE CHARACTERISTICS OF THE SUSPENDED SILT LOAD OF TEXAS STREAMS.

(b) Laboratory project.

(c) Mr. Dean W. Bloodgood, 302 W. 15th St., Austin, Texas.

(d) Experimental; basic and applied research.

(e) (1) To determine the relationship between the suspended silt load and the discharge of Texas streams; (2) to establish criteria for planning surface reservoir storage based on suspended silt to be handled; (3) to determine the characteristics of silt deposited in reservoirs for use in evaluation of the life of a given reservoir; (4) to secure data necessary to determine the effect of silt load on the cost of preparing water for domestic and industrial use; and (5) to determine the relationship between silt load and the management of the tributary watersheds.

(h) "silt Load in Texas Streams", Annual report.

(2179) EVAPORATION AND CONSUMPTIVE USE OF WATER TNVESTIGATIONS IN THE SAN FRANCISCO BAY AND ADJACENT AREAS.

(b) Field study.

(c) Mr. Dean C. Muckel, P. 0. Box 180, Berkeley, Calif.

(d) Primarily applied with some field tests.

(e) To determine rates of evaporation from fresh water surfaces, the consumptive use of water by phreatophytes and the consumptive use of water by salt grass at varying depths to water table for the following periods: (a) Average annual for the period 1921-52, and (b) Monthly during the calendar years 1923, 1924, 1930, 1931 and 1951.

(f) First stage of field work is now completed and rates of evaporation and consumptive use outlined under objectives have been determined for various locations in the. San Francisco Bay area. A continuation of the project has been requested in order to obtain longer and more complete coverage of the area.

(h) "Rates of Evaporation and Consumptive Use in the San Francisco Bay and Adjacent Areas", by Harry F. Blaney, Dean C. Muckel and G. Marvin Litz - Preliminary Report. Jan. 28, 1954. (Typed) 70 pages, Illus. 
(2180) EVAPORATION LOSSES FROM FESERVOIRS.

(b) Field project in cooperation with State of California and County Flood Control Districts.

(c) Mr. Harry F. Blaney, 1509 Post Office and Court House Bldg., Los Angeles, California.

(d) Experimental; compilation and data.

(e) To determine evaporation losses from reservoirs and lakes in California and conpile and prepare for publication reliable evaporation and related data measured since 1945 in cooperation with the State Engineer of California.

Field measurements are being made in cooperation with the state and local agencies on 15 stations ranging in elevation fram -2L, ' below sea level at Salton Sea to $9,194^{\prime}$ at Kaiser Pass in the Sierra-Nev ada mountains.

(g) Monthly evaporation from pans, temperature, humidity, wind movement, and precipitation are being compiled for the various stations.

Evaporation from Lakes' surface is being computed by reduction factors.

In the mountain areas, records are being kept at Shaver Lake (elevation 5,376 ft.); Huntington Lake (elevation 6,954 ft.); Florence Lake (elevation 7,345 ft.); Kaiser Pass (elevation 9,194 ft.). Data is being compiled to bring up-to-date California state Bulletin No. 54, "Evaporation From Water Surfaces in California (A Summary of Pan Records and coefficients $1881-1946) n$.

(h) "Evaporation From and Stalibization of Salton Sea Water surfacen, by Harry F. Blaney, (Mimeographed).

(2181) STORAGE OF WATER UNDERGROUND FOR IRRIGATION IN CAIIFORNIA.

(b) Laboratory and field project.

(c) Mr. Leonard Schiff, P. 0. Box 513, Bakersfield, Calif.

(d) Experimental; basic research.

$(\theta)$ To determine the factors affecting the percolation rate on water-spreading areas, and to devise ways and means to increase the percolation rate. In some soils the percolation rate decreases during spreading, and the objectives are to determine the cause of the decrease and to find practical methods of maintaining the high initial rates. Field tests are being made on test ponds and strips.

(2182) PAYETTE VALTEY DRATNAGE INVESTIGATIONS, GEM COUNTY, IDAHO.

(b) Field project.

(c) Mr. R. William Nelson, P. 0. Box 835, Boise, Idaho.

(d) Basic and applied.

(e) The objectives of this study are: (1) to obtain basic physical data necessary to design drainage systems and reclaim water-logged and alkaline-saline lands in the Payette Valley and (2) to develop methods and techniques that might be applied to the solution of drainage and salt problems on the lands in the intermountain and northwestern states. Future work is dependent upon an action program directed toward construction of the drainage facilities recommended for the solution of the problem.

(g) The sources of water causing the drainage have been determined and a plan for the remoral of these waters has been formulated.

(h) "Progress Report on Drainage Investigations", George B. Bradsahw, June 1953. "Progress Report on Drainage Investigations, Emmett Valley, Gem County, Idaho", Ceorge B. Bradshaw, May 1954 .

(2183) DRATNACF INVESTIGATIONS IN THE FITEBAUGH AND OTHER CENTRAL VALTEY, CALIFORNIA SOIL CONSERVATION DISTRICTS.

(b) Laboratory and field.

(c) Mr. Leonard Schiff, P. 0. Box 513, Bakersfield, Calif.

(d) Experimental; applied research.

(e) To obtain basic physical data necessary to design and adequate drainage systems to control the ground waters in various Soil Conservation Dlstricts in the Central Valley of California and to develop methods and techniques that might be applied to the solution of similar problems in other areas. 
(2184) DRAINACE OF IRRIQATED LAND IN THE UPPER COLORADO RIVER BASIN.

(b) Field and laboratory.

(c) Mr. Minoru Amemiy a, P. O. Box 786, Grand Jct., Color ado,

(d) Basic and applied research.

(e) (1) To develop procedures for making drainage investigations involving the source, amount and distribution of excess water. (2) To evaluate the effects of water logging on soil permeability and crop response.

Work has been underway on field tests using a drainage well and pump tests.

(2185) SPRINKLING AS A METHOD OF APPLYING WATER TO IRRIGATED FARM LANDS, ITS PROBLEMS AND LTMITATIONS.

(b) Field project.

(c) Mr. Claude H. Pair, P. O. Box 835, Boise, Idaho.

(d) Basic and applied research.

(e) The objectives of this study are: (1) To obtaiu more precise information for the design, layout, installation and operation of sprinkler irrigation systems on various soil types, slopes and crops under various weather conditions; (2) To determine the effect of sprinkling upon various soils and crops; (3) To determine the economic limitations in the use of sprinkler irrigation systems; (L) To assist in the development and testing of better sprinkler equipment and more efficient operating procedures.

Work is continuing on items (1) and (2) of (e) along with testing pressure regulating valves for use in sprinkler systems.

(g) Results from 19 sprinkler efficiency tests near Caldwell, Idaho show that 66\% of the water delivered to the sprinkler system could be accounted for as soil moisture in the root zone depth of the crop. Individual efficiency measurements varied from $49 \%$ to $97 \%$.

(h) "Annual Progress Report, Cooperative Surface and Sprinkler Irrigation Investigations, Black Canyon Project, Canyon County, Idaho", Claude H. Pair, Dec. 1953.

(2186) RELATTONS BETWEEN SOTL CHARACTERISTICS AND PROPER IRRIGATION PRACTICES.

(b) Field project.

(c) Mr. Claude H. Pair, P. O. Box 835, Boise, Idaho.

(d) Basic and applied.

(e) The objectives of this study are: (1) To obtain more precise information on the design, layout, constmuction, and operation of farm irrigation systems on new and old irrigated lands; (2) To determine the irrigation efficiencies and water requirements for those irrigated lands; (3) To determine procedures to assist in adequate land classification on proposed and existing irrigation projects.

Work is continuing on items (1) and (2) listed in the objectives above.

(g) Results from twelve irrigation efficiency measurements near Caldwell, Idaho show that $36 \%$ of the water delivered to the downhill furrow plots could be accounted for as soil moisture in the root zone depth of the crop.

The effect of irrigation on the infiltration rate of virgin soils show a decline from $0.44 "$ per hour to 0.10" per hour from May 1949 to August 1953.

(h) nAnnual Progress Report Cooperative Surface and Sprinkler Irrigation Investigations, Black Canyon Project, Canyon County, Idaho", Claude H. Pair, Dec. 1953.

J. S. DEPARTMENT OF AGRICULTURE, FOREST SERVICE, California Forest and Range Experiment Station.

(261) WATERSHED MANAGEMENT PESEARCH, CALIFORNIA.

(b) Laboratory project.

(c) Dr. George M. Jenison, Director, California Forest and Range Experiment Station, P. 0. Box 245 , Berkeley 1 , Calif.

(d) Experimental; fleld investigations; basic and applied research. 
(e) Purposes are (1) to determine how watersheds function: what happens to the precipitation, and how water and soil movement are influenced by conditions of vegetation, soil, geology, and topography; and (2) to develop methods of watershed management, including treatment of areas denuded by fire, to insure maximum yielf of usable water and satisfactory flood and erosion control. Major work center is the San Dimas Experimental Forest situated in the San Gabriel Mountains of southern California. Here rainfall, runoff, and erosion are measured on two major drainage areas, on 10 large and 7 small watersheds within these areas, and on 24 experimental plots. Vegetation cover on the watersheds is mostly mature brush or chaparral, unburned for 35 years or more. However, in 1953 about one-third of one large watershed was burned-over by wildfire and in 1938 one-fourth of another large watershed, 3 small watersheds, and 9 plots were denuded by wildfire. Fifteen other plots are equipped to obtain detailed information on the disposition of rainfall from annual ryegrass, native scrub oak-chaparral, and a 27-year-old Coulter pine plantation. Twentysix large lysimeters furnish comparisons of water use and surface runoff control by five species of native shrubs, one species of pine, and a bunchgrass association. Climatic data are obtained from several meteorological stations. Ways of improving the vegetation cover to reduce soil movement on mountain slopes are being studied in the Los Angeles River watershed. Measurements to determine kinds, rates, and volumes of soil movement (soil, rock, and organic debris) are made on five study sites representing typical watershed soil and vegetation conditions. Studies of runoff and erosion as influenced by logging and by fire are in progress elsewhere in California.

(g) The first storm after the 1953 fire produced a peak flow of $429 \mathrm{csm}$ from the partially denuded watershed. Analysis of streamflow records from the burned and from a comparable unburned watershed showed that this flow was about 68 times the probable flow, had the watershed been unburned. A peak flow of $297 \mathrm{csm}$ during the second storm was about 16 times the expected flow. Erosion from the burned area during these storms was estimated from field measurements as 55,500 cu yds / sq mi. No erosion was observed in adjacent unburned watersheds during either storm.

Analysis of 8 years of runoff data from the large San Dimas lysimeters indicates a general decrease in surface runoff with increase in age of cover. This decrease in runoff varied from species to species and ranged from zero for Coulter pine cover to over one inch per year for scrub oak cover.

The first year's measurements of soil (debris) movement from the five study sites in the Los Angeles River watershed showed that slopes above rejuvenated channels had higher rates of soil movement than slopes above non-rejuvenated channels. The highest movement was on a south-rejuvenated slope which produced debris at the rate of 3,600 tons/sq $\mathrm{mi} / \mathrm{yr}$. This was about 36 times the rate of debris movement from the lowest producing site, a northfacing, non-rejuvenated slope.

The dry season movement of soil, by sliding and creep, amounted to about half of the total vearly movement at the rejuvenated sites and ranged from one-fifth to one-third of the total movement of the non-rejurenated sites. Winter storms, however, produced the highest short-term rates.

(h) "Annual Report - California Forest and Range Experiment Station", Forest Service, U. S. Department of Agriculture, pp. 44-56, 1953.

"Fire-Flood Sequences on the San Dimas Experimental Forest", San Dimas technical staff, California Forest and Range Experiment Station, Tech. Paper No. 6, 29 pp., illus., March 1954.

"Erosion in the San Gabriel Mountains of California", J. D. Sinclair. Trans., Amer. Geophy. Union, Vol. 35 (2), pp. 264-268, illus., April 1954.

"Suspended Sediment Discharge as Related to Streamflow, Topography, Soil, and Land Use", H. W. Anderson. Trans., Amer. Geophy. Union, Vol. 35(2), pp. 268-281, illus. April $195 \dot{L}$. "Rainfall Sampling on Rugged Terrain", E. L. Hamilton. U. S. Department of Agriculture Tech. Bulletin No. 1096, Dec. 1954.

U. S. DEPARTMENT OF AGRICULTURE, FOREST SERVICE, Intermountain Forest and Range Experiment $S_{\text {tation, }}$ Ogden, Utah.

Inquiries concerning Projects Nos. 652 to 655, incl., should be addressed to the Director, Intermountain Forest and Range Experiment Station, Ogden, Utah. 
(b) Branch of Research, Forest Service, U. S. Department of Agriculture.

(d) Experimental and field investigation; basic and applied research.

(e) Tests on plots and small watersheds of the effects of forest, brush, and herbaceous plant cover in natural, depleted, and restored condition on the infiltration, storage, fertility, biology and stability of forest and range land soils; to determine land use practices for stabilizing eroding watershed soils and for maintaining soil stability under the impact of grazing, logging, and other wild land uses. Studies are underway on forest and range lands having coarse, granitic soils of southwestern Idaho; various soils on steep slopes of the Wasatch Mountain in northern Utah; and on heavy limestone soils in central Utah.

(g) Completed installation of 20 sediment catchment dams and observation plots on 20 compartments of the Boise Basin Experimental Forest near Idaho City, Idaho, for evaluating effects of ponderosa pine timber cutting and logging on sediment production.

Completed installation of erosion control measures on logging roads and skidways of four ponderosa pine timber sale areas on the Boise and the Payette River watersheds to determine best logging practices for minimizing sediment production.

Contimued erosion control studies at the Wasatch and the Great Basin Field Research Centers. Completed drafts of following reports: "Plant Cover Establishment in Relation to Soil Moisture on Granitic soil Foothill Watersheds in Southwestern Idaho", "Nitrogen Loss from Granitic Soils on Cheatgrass Browse Range", "The Intermountain Type F Infiltrometer", and "Indicators of Watershed Damage."

\section{(653) WATER RELATIONS (IN WATERSHED MANAGEMENT AND PROTECIION).}

(b) Branch of Research, Forest Service, U. S. Dept. of Agriculture.

(d) Experimental and field investigation; basic and applied research.

(e) Tests on watersheds of the effects of forest, brush, and herbaceous plant cover, and of mechanical soil stabilization structures, on runoff characteristics of mountain watersheds; to determine land use treatments required for flood control and for maximum yields of usable streamflow.

(g) Continued streamflow records on experimental watersheds at the Wasatch and the Great Basin Field Research Centers. Artificial reseeding, supplemented by some contour trending resulted in immediate control of summer storm runoff and erosion on a formerly depleted high elevation subalpine-herbaceous range watershed at the Great Basin Field Research Center.

Analysis of 17 years of records indicate restoration of plant cover on formerly depleted flood source areas in the headwaters of a stream in the Davis County Experimental Watershed has brought about a 15 percent decrease in anmal runoff, but has also prevented the recurrence of derasting surmer storm mud-rock floods.

Completed drafts of following reports: "Runoff and Erosion Trends on Two Subalpine Water sheds in Central Utah", and "Floods from Western Mountain Lands."

\section{(654) PLANT RELATIONS (IN WATERSHED MANAGEMENT AND PROTECTION).}

(b) Branch of Research, Forest Service, U. S. Dept. of Agriculture.

(d) Experimental and field investigation; basic and applied research.

(e) Tests on plots and watersheds of the effect of forest, brush, and herbaceous cover on interception and evapo-transpiration losses; to determine the kind of plant cover required for producing maximum yields of useful runoff from watersheds.

(g) Campleted installation of Colman soll moisture units on 16 plots in the Davis County Experimental Watershed to determine the effect of seasonal use of range forage on water available for streamflow.

Completed exploratory study of the effect of four kinds of herbaceous range cover on soil depletion moisture.

Initiated a 6 year study of soil moisture characteristics on about 150 sites in Utah, Nevada and southern Idaho, in cooperation with the U. S. Corps of Engineers. Completed draft of report on "Consumptive Water Losses from Perennial Grass and Anmal Plant Cover in Southwestern Idaho."

(h) "Water Yields from Snow as Affected by Consumptive Losses", Goorge W. Craddock, proceedings of the Western Snow Conference, 1954. 


\section{(655) CLIMATIC RELATIONS (IN WATERSHED MANAGEMENT AND PROTECTION).}

(b) Branch of Research, Forest Service, U. S. Dept. of Agriculture.

(d) Experimental and field investigation; basic and applied research.

(e) Measurements and studies of climatic factors including percipitation, temperature, etc., that have a bearing on the hydrologic behavior of forest and range watershed areas at the Boise Field Research Center, Boise, Idaho; Wasatch Field Research Center, Farmington, Utah; Great Basin Field Research Center, Ephraim, Utah; and the Inland Empire Field Research Center, Spokane, Washington.

U. S. DEPARTMENT OF AGRICULTURE, FOREST SERVICE, Northeastern Forest Experiment Station.

Inquiries concerning Projects Nos 656, 966, 1187 and 1188 , should be addressed to Dr. Ralph W. Marquis, Direct or, Northeastern Forest Experiment Station, 102 Motors Aveme, Upper Darby, $\mathrm{Pa}$.

(656) FOREST INFLUENCES INVESTIGATION (VTATERSHED MANAGEMENT) •

(b) Laboratory project; in cooperation with the Pennsylvania Department of Forests and Waters and U. S. Geological Survey.

(d) Field investigation; basic and applied research.

(e) Studies have been started on the Delaware-Lehigh Experimental Forest, Monroe County, Pa., to determine the water economy for a watershed covered with scrub oak. Afterwards, the cover will be converted by planting and fire protection to a cammercially valuable type, and the effect on water relations will be measured. Installations have been established to evaluate all components of a water balance equation for the watershed.

(966) FOREST INFLUENCES TNVESTIGATION (WATERSHED MANACEMENT), POCONO EXPERTMENTAL FOREST.

(b) Laboratory project.

(d) Field investigation; basic and applied research.

(e) Studies have been started on the Pocono Experimental Forest, Wayne County, Pa., to determine effects of forest management practices and logging operations upon the quantity and quality of water yielded by a small watershed. Installations have been established to measure precipitation, streamflow and rainfall interception.

(1187) FROST STUDIES IN THE NORTHEASTERN UNITED STATES.

(b) Laboratory profect.

(d) Field investigation; applied research.

(e) To determine the effect of land use and condition upon type and depth of frost formation. Periodic observations of frost type and depth, snow depth, and water content are made upon a large number of plots in New England, New York, and northern Pennsylvania, selected to sample a variety of land uses and conditions within certain land use classes. A system of 186 plots were established and observations made thereon during the winters 1950-51 and 1951-52. Data are now being, analyzed.

(1188) FOREST INFLUENCES INVESTICATION (WATERSHED MANAGEMENT), FERNOW EXPERIMENTAL FOREST.

(b) Laboratory project.

(d) Field investigation; basic and applied research.

(e) Studies have been started on the Fernow Experimental Forest, Tucker County, W. Va., to determine the effect of different levels of cutting practices and different logging methods upon water quantity and quality. Five watersheds have been equipped with streamgaging stations and raingages. No logging will be done on these watersheds during a calibration period. Measurements are now being made on areas adjacent to the gaged watersheds to determine erosion rates on logging roads as influenced by length and steepness of grade and various erosion control measures. 
(h) "Do We Need Watershed Research in West Virginia", Sidney Weitzman, W. Va. Conservation, March 1954.

"Forests are Important on the Watershed", G. R. Trimble, Jr., W. Va. Conservation, March 1954.

"Effects of a Hardwood Forest Canopy on Rainfall Intensities", G. R. Trimble, Jr. and Sidney Weitzman. Trans. Amer. Geophys. Union 35: 226-234, 1954 .

"Home-Made Gadgets and Forest Influences Research", Burley D. Friedley, Jour. Forestry 51: 907-908, 1953.

J. S. DEPARTMENT OF AGRICULTURE, FOREST SERVICE, Pacific Northwest Forest and Range Experiment Station.

\section{(969) EFFECT OF LOGGING AND OTHER FOREST OPERATIONS ON STREAM FLOW.}

(b) Laboratory project.

(c) Mr. R. W. Cowlin, Director, Pacific Northwest Forest and Range Experiment Station, Post Office Box 4059 , Portland 8, Oregon.

(d) Field investigation, applied research.

(e) H. J. Andrews Experimental Forest, in the McKenzie River drainage of west central Oregon. Streamflow from three small experimental watersheds in virgin Douglas-fir has been measured for two years by means of trapezoidal flume stream gages. These observations are the beginning of a pretreatment calibration which will be carried on for 4 years or more. Planned treatments will test effect of two systems of timber cutting on water yield and erosion.

(2187) EFFECT OF CATTLE GRAZING ON EROSION.

(b) Labor atory project.

(c) Mr. R. W. Cowlin, Director, Pacific Northwest Forest and Range Experiment Station, Post Office Box 4059 , Portland 8, Oregon.

(d) Field investigation; applied research.

(e) To test the effect of he avy, moderate and light grazing on erosion and sediment production, Starkey Experimental Forest and Range. Sediment catchment basins have been constructed in small drainages, one in each of six pastures in which are tested three rates of grazing and two systems of management: deferred-rotation and season-long use. Major effect on erosion will be determined by volume of sediment accumulated in the basins.

J. S. DEPARTMENT OF AGRICULTURE, FOPEST SERVICE, Rocky Mountain Forest and Range Experiment Station.

Inquiries concerning Projects Nos. 376, 377, 657, 1967 to 1971, incl. and 2188, should be addressed to Mr. Raymond Price, Director, Rocky Mountain Forest and Range Experiment Station, Room 221 Forestry Building, Fort Collins, Colo.

(376) WATERSHED MANAGEMENT RESEARCH, MANITOU EXPERTMENTAI FOREST.

(b) Laboratory project.

(d) Field investigation; applied research.

(e) Studies of the influence of grazing, timber cutting, and revetation of depleted watershed lands upon water supplies, and upon erosion and sedimentation, to solve problems in watershed management for the forest and range-corered watershed lands of the Rocky Mountain Front Range such as: (I) Effect of grazing intensity on the water absorption of granitic soils, (2) Runoff and erosion from natural storms on bunchgrass plots, (3) Runoff and erosion from natural storms on young pine plots, (4) Effect of type conversion on runoff and erosion from small watersheds, and (5) Characteristics of runoff from cloudburst storms on a large watershed.

(g) The recording of rainfall, munoff, and erosion from plots and watersheds representing different complexes of soil, vegetation, and treatment have been continued in conformance with the long-term nature of the study. 
(377) WATERSHED MANAGEMENT BESEARCH, FRASER EXPERIMENTAL FOREST.

(b) Laboratory project.

(d) Field investigation; applied research.

(e) To determine influence of lodgepole pine and spruce-fir forests and of the management of these forests for wood products on factors associated with the yield of water, largely from stored snow. The purpose is to solve problems in the management of forested watersheds of the high altitude zone of the Rocky Mountains for maximum yields of usable water.

(g) Logging on one 714-acre watershed was started during 1954. One-half of the timbered area is being cleared in a strip-wise pattern. Streamflow records during 11 years before $l o g-$ ging and continuing after logging will enable detection of the effects of timber remoral on total water yield and its distribution in time.

(h) 1953 Annual Report, Rocky Mountain Forest and Range Experiment Station, Fort Collins, Color ado.

(657) WATERSHED MANACEMENT RESEARCH, TEMPE, ARIZONA.

(b) Laboratory project.

(d) Experimental; basic and applied research.

(e) The purpose is: (1) To study the disposition of rainfall as influenced by watershed vegetation, and (?) to determine the influence of various types and densities of natural vegetation as well as vegetation modified by cultural treatment such as grazing and timber harrest, on streamflow, water uses, water losses, and erosion and sedinent yields. At Sierra Ancha Experimental Watersheds in central Arizona, rainfall, runoff, and erosion are measured on three watersheds in the pine-fir vegetation types at high elevation, on two watersheds in the ponderosa-chaparral type, and four watersheds in the grasslandchaparral type at intermediate elevation, and on nine small watersheds in the semidesert chaparral type at low elevations. Water use by different types of plants in different soils is studied on 11 large lysimeters.

(g) Four of the watersheds in the semidesert chaparral type at low elevations were reseede to Boer and Lehmann love-grasses (Eragrostis chloromel as and E. lehmanniana) after the chaparral had been grubbed out and spread over the area as a mulch. Gully banks were sloped to prevent sloughing and to provide a seedbed for grasses. The weather during 1953 was favorable to the establishment of grass and a good stand of Boer and Lehmann lovegrass was established. Soil loss and erosion from the reseeded watersheds decreased materially as the result of this reseeding.

(1967) WATERSHED MANAGEMENT FESEARCH, ALBUQUERQUE, NEW MEXICO.

(b) Laboratory project.

(d) Applied research.

(e) Evaluation of reseeded rangelands for infiltration, soil stabilization, and soil productivity in woodland-sagebrush zone of north central New Mexico.

Rocky Mountain infiltrometer was used to measure infiltration and erosion rates from reseeded and adjacent native rangelands under grazing and nonuse. Measurement of selected vegetation and soil factors included in this study.

(i) Field study completed. Conducted during sumers of 1952, 1953 and 1954 .

(g) Labor atory analyses to be completed by March 1955 . In process of analysis of data.

(h) Two publications planned -- one to be released in spring of 1955.

(1968) WATERSHED MANACEMENT RESEARCH, ALBUQUERQUE, NEW MEXICO.

(b) Laboratory project.

(d) Applied research.

(e) Range and watershed condition, trend, and potential in north central New Mexico. Rocky Mountain infiltrometer is used to measure infiltration and erosion rates from about 50 fenced-in enclosures installed on native rangelands in 1939 and 1940 and fram adjacent open range. Detailed soil and vegetation measurements are taken at each infiltrometer plot location. In addition, re-exanination and quantitative measurement of vegetation are taken inside and outside the enclosure for comparison with measured vegetation conditions in $1939-40$.

(f) Field studies in 1953 and 1954 have been completed for most of the woodland-sagebrush zone

(g) Work plan, May 1953. 
(1969) WATERSHED MANAGEENT FESEARCH, ALBUQUERQUE, NEW MEXICO.

(b) Cooperative study with the Bureau of Land Managenent and Geological Survey.

(d) Applied research.

(e) Range-watershed evaluation of small watersheds in Rio Puerco. Three watersheds, ranging fram 370 to 735 acres, are located adjacent to one another about 8 miles north of San Luis (Dominguez) and west of the Rio Puerco. Waterflow and sediment are measured by inflow into small reservoirs formed by dams. Precipitation and vegetation measurements are taken currently. After an adequate calibration period, two watersheds will be treated and the other grazed at the present intensity to serre as a climatic control for evaluating fluctuations in climate. Watershed treatments will be concerned with grazing control, revegetation, and water retardation measures.

(h) Annual Reports of the Southwestern and Rocky Mountain Forest and Range Experiment Stations.

(1970) WATERSHED KANAGEMENT FESEARCH, GRAND JUNCTION, COLORADO.

(b) Laboratory project.

(d) Field investigation; applied research.

(e) Object is to determine biological and physical characteristics of the oak bmash type in West-Central Colorado as a guide to land capability.

In 1953 a preliminary study of ground cover, soils, and topograph was completed, and some tentative guides were set up for conversion of oak brush to herbaceous corer. In 1954 the object of the study was to determine when and where oak brush (Quercus gambelii) has spread in the past and how rapidly it is spreading now. To accomplish the latter objective annual ring counts were made on 45 representative sites.

(g) Oak brush covers about 1 million acres in western Colorado. On many areas the brush is so dense that it prevents livestock grazing and crowds out desirable range plants. In certain localities, especially on steep slopes, oak brush is largely responsible for holding the soil in place and preventing flash runoff. In general, it appears that conversion may be desirable only where the following conditions exist: (1) Pure oak brush stands, (2) Brush dense enough to be inaccessible to livestock, (3) Gentle slopes (less than 40 percent), (4) Deep surface soil (over 12 inches), (5) Adequate natural seed supply of desirable range plants, and (6) Erosion not serious. ( 5 and 6 apply only where reseeding is not planned.) Results of the 1954 study of the spread of brush are not available.

(1971) WATERSHED MANAGENENT RESEARCH, GRAND JUNCTION, COLORADO.

(b) Laboratory project, in cooperation with Bureau of Land Management, Bureau of Reclamation, and Geological survey.

(d) Experimental; applied research.

(e) Purpose of experiment is to determine the effect of exclusion of livestock grazing on erosion and munoff from semidesert lands in western Colorado, eastern Utah, and southern Wyoming.

Study area is located in the Badger Wash drainage 30 miles west of Grand Junction, Colorado, at an elevation of 4,500 feet.

It is characterized by steep to rolling topography, a sparse corer of salt-desert shmub vegetation, and soils derived principally from Mancos shale. Although average anmual precipitation is less than 10 inches, cloudburst storms result in extensive runoff and erosion. Cattle and sheep graze the area during winter months.

Eight experimental watersheds are included in the study, ranging from 20 to 100 acreas in size. Four watersheds have been fenced to exclude livestock for a period of 20 years, and four will contime to be grazed. An earth dam at the mouth of each watershed has been constructed to collect runoff and sediment. Pretreatment measurements of infiltration, erosion, vegetation, gully cross sections and reservoir bottans have been completed

(g) None are available yet as the pretreatment measurements were not completed until Nov. 1954. 
(2168) WATERSHED MANAGEYENT FESTARGH, ALBUQUERQUE, NEW MEXICO.

(b) Laboratory project.

(d) Applied research.

(e) A study of eraporation - transpiration losses in the molst woodl and zone. A record of precipitation and soil moisture is maintained under three ground-cover conditions under pinyon trees? in grassland, in a woodland opening, and from a bared area in woodland opeming kept free of any vegetation by chemical spraving. Colman soil electrical units are spaced 3 inches apart in depth between $1-1 / 2$ and $22-1 / 2$ inches and one unit at 30 inches. Soil is derived fram limestone and is mostly less than 30 inches in depth in the general vicinity.

(g) In process of analysis.

U. S. IEPARTMENT OF AGRICULTURE, FOREST SERVICE, Southeastern Forest Experiment station.

(380) FOREST INFLUENCES INVESTIGATIONS - WATER EESOURCE AND WATERSHED MANACEMENT RESEARCH.

(b) Laboratory project.

(c) Mr. E. L. Denmon, Director, Southe astern Forest Experiment Station, U. S. Forest Service P. 0. Box 2570 , Ashevilile, N. C.

(d) General and complete investigation of forest influences in southeastern United States. Includes fundamental hydrologic research and applied research in water resources and watershed management.

(e) To determine the effect of regetation on the phases of the hydrologic cycle. To find out the effect of land use and land management practices on water yield and water quality. To develop standards and methods of watershed management so as to derive the greatest benefit from the land and water resources in the southeastern United States. Most of the actual research experiments and hydrologic data collection is carried out on the 5600-acre Coweeta Hydrologic Laboratory which is located in the zone of maximum precipitation in the eastern United States (Nantahala Range of the Southern Appalachian Mountains). Within this experimental area are approximately 35 individual watersheds whose streamflow is being continuously gaged and which are either being treated experimentally or being used as control checks. In addition to the streamflow gaging, there are 13 recording and 80 non-recording (standard) rain gages, 21 recording and 19 nonrecording ground water wells, 8 recording hygrothermographs, 2 recording anemometers, and one evaporation pan. Water samples for quality analysis are collected on a woekly and storm period basis from selected experimental watersheds.

The Calhoun Experimental Forest near Union, South Carolina, has been established and is doing basic research on how piedmont soils influence water resources and plant growth. studies include measurement of infiltration, daily changes in field moisture, and runoff from several small watersheds.

Research projects include determination of effects of (1) permanent remoral of all major vegetation and cutting all natural regrowth, (2) temporary remor al of all vegetation followed by natural regrowth, (3) removal of corer-site forest vegetation, (4) removal of laurel and rhododendron shmub vegetation, (5) rehabilitating a depleted steep-land agriculture watershed, (6) rehabilitating a grazed woodland watershed, (7) improved techniques for removing wood products and retaining high quality water values on mountain watersheds, and (8) removing deficient age classes in a forest stand for changing water yields.

(g) Land use studies on woodland grazing and mountain farming have shown changes in soil due to trampling are reflected in infiltration, permeability total porosity, increases in storm peaks, surface drainage characteristics, changes in time of watershed concentration daring storm periods and stream turbidities. Data analyzed this year shed new light on the short time required to alter watershed conditions on undisturbed forested drainages converted to mountain agriculture and grazing the woodl and.

Results from fundamental studies covering the storage and depletion of ground water, anmual water balance, and control of storm water has made it possible to interpret some of the hydrologlc processes taking place on small tributary watersheds having a forest cover. 
A simple graphic solution was devised this year for appraximating the length of time required to detect significant differences between treatments on experimental watersheds. Piedmont studies are showing that the organic layers of forest soils are a valuable diagnostic tool for timber and watershed management. They can be changed by modifications of the vegetation on the site. Where forest soils need improving, steps should be taken to manage the stands so that some rapidly decomposable hardwood litter will be incorporated.

(h) "Applying Unit Area Control to Watershed Management", T. C. Nelson and E. A. Johnson, Jour. of Forestry, 52(2), Feb. 1954.

"USDA - AIB 217 - Waters of Coweeta", 22 pp.

"A Study of the Effect of Grazing upon Changes in Vegetation on a Watershed in the Southern Appalachian Mountains", Jerry G. Williams. Thesis for M. S. Degree, Michigan State College, $138 \mathrm{pp}, .1954$.

"Methods of Soil Moisture Determination Under Field Conditions", D. F. Olson, Jr., and M. D. Hoover, Southeastern Forest Experiment Station Paper 38, April 1954, 28 pp.

"Soil Sampling for Pore Space and Percolation", M. D. Hoover, L. J. Metz, and D. F. Olson, Southeastern Forest Experiment Station Paper 42, June 1954, $29 \mathrm{pp}$.

Watershed Management Affecting Current Water supplies", E. A. Johnson. Symposium on Water Management, University of South Carolina, July 1954.

"Forest Floor in the Piedmont Region of South Carolina", I. J. Metz, Soil Science Society of America Proceedings, 18(3): 335-338, July 1954.

U. S. DEPARTMENT OF THE ARMY, CORPS OF ENGINEERS, Beach Erosion Board.

Inquiries concerning Projects Nos. 181, 184, 399, 660, 661, 663, 972, 973, 975, 977, $1459,1725,1727,1972,1973$, and 2189 to 2195 , incl., should be addressed to the Resident Member, Beach Erosion Board, 5201 Little Falls Road, N. W., Washington 16, D. C.

(181) EQILIBRIUM PROFILE OF BEACHES.

(b) Laboratory project.

(f) Completed.

(h) "Laboratory Study of Equilibrium Profiles of Beaches", Beach Erosion Board Technical Memorandum No. LI, Aug. 1954 .

(184) STUDY OF MODEL SCALE EFFECTS.

(f) Suspended until completion of Project 399; thereafter further testing scheduled.

(399) DESIGN AND CONSTRUCTION OF SIX-FOOT WAVE TANK.

(b) Laboratory project.

(d) Experimental; design.

(e) To design and construct a wave tank for the study of the effect of waves 6 feet high and 300 feet long. Various types of wave generating mechanisms, the power required by the generator to form the waves, and the action of the waves on a beach which is placed at an angle to the axis of the tank have been studied in a $1: 12$ scale model.

(g) The large wave tank is completed and is 635 feet long, 15 feet wide, and 20 feet deep. Generation of the waves is to be accomplished by a pusher-type wave generator which is under construction with completion expected in 1955.

(660) OBSERVED WAVE CHARACTERISTICS.

(b) Labor atory project; additional research by New York University.

(d) Field investigation; basic research.

(e) To secure a more thorough knowledge of the characteristics of ocean vaves. A number of electrical recording weve gages have been installed in coastal waters and these records are analyzed for significant height and period. 
(661) REPORTS ON BEACH PROCESSES BASED ON EXISTING MISSION, ANAHEIM, AND SANTA MONICA BAY FIELD DATA.

(b) Laboratory project.

(d) Field investigation; basic research.

(e) A study of the relation between movement of beach material and natural forces such as wave, tides, and littoral currents. Fourteen million cubic yards of sand have been placed on Hyperion Beach, Santa Monica Bay, and one million cubic yards have been placed on Sunset Beach, Anaheim Bay, California. Rate of movement of this material from the placement areas is being studied by frequent hydrographic surveys. Intensity and direction of waves are being recorded.

(f) Field work completed.

(h) "Coast Erosion and the Development of Beach Profiles", Per Brunn, Beach Erosion Board Technical Memorandum No. 44, June 1954.

(663) SAND MOVEMENT AND WAVE STUDY, LONG BRANCH, NEW JERSEY.

(b) Laboratory project.

(d) Field investigation; basic research.

(e) To determine if sand placed in deep water will be moved onto the beach by wave action. Six hundred thousand cubic yards of sand have been placed in 38 feet of water at Long Branch, New Jersey. Movement of $s$ and is being studied by frequent hydrographic surveys. Wave intensity and direction is being recorded for comparison with any sand movement. An effort is being made to measure the amount of sand moving along the bottom and the amount thrown into suspension by the waves.

(f) Reactivated to determine disposition of dumped sand after 3 years (October, 1949 to October, 1952).

(g) There is no evidence that material moved ashore from the stockpile or that the shore has benefited by the operation. Shore erosion continued during the 4 years subsequent to placement of the material.

(h) "Restudy of Test-Shore Nourishment by Offshore Deposition of Sand, Long Branch, N. J. ", Beach Erosion Board Technical Memorandum No. 62, Nov. 1954.

(972) STRUCTURAL DESIGN OF SHORE STRUCTURES.

(b) Laboratory project.

(d) Experimental; basic research.

(e) To aid in the preparation of a handbook on the design of shore structures. Field and model tests on the wave pressures caused by breaking waves which act on structures will be made in order to fill such gaps in our present knowledge of these forces not covered by other current investigations.

(f) Laboratory pressure measuring tests completed.

(g) Measurements have been made of the shock pressure of breaking waves on a vertical structure (maximum wave height about 7 inches). Wave pressures of more than 18 psi were measured. The high pressures lasted for a very short time. The time-pressure integral was also measured, the highest being about 0.02 psi-seconds. Froudian model scale relations indicated that the time-pressure integral should $v$ ary with three-halves power of the scale of the wave.

(h) "Laboratory Study of the Pressures Developed by Breaking Waves", Beach Erosion Board Technical Memor andum No. 59 (expected publication Feb. 1955).

\section{(973) CONSTRUCTION OF COAST MODEL BASTN.}

(b) Laboratory project.

(d) Experimental; basic research.

(e) To study beach problems involving waves, littoral currents and tides. The basin is 300 feet long, 150 leet wide, and 3 feet deep.

(g) The basin has been completed; ten portable wave machines have been constructed, tested and accepted as satisfactory. The tidal system is now under construction. 
(975) METHODS OF BI-PASSING SAND PAST DRLTS.

(b) Laboratory project.

(d) Field investigation; applied research.

(e) To study methods and requirements for pumping sand past inlots and to determine the applicability of the methods in stabilization of beaches adjacent to inlets. A component of this study is the correlation of effectiveness of the South Lake Worth Inlet, Florida, By-Passing Plant with rate of drift reach plant. Data were collected (3/6/52 to $6 / 10 / 52$ ) which included daily recorded wave heights and perfods, daily observed littoral currents, measured volume of material pumped at by-passing plant, and sand samples.

(f) Completed.

(g) The following relationship between the rate of nearshore littoral movement and the shallow water wave energy was developed from the data:

$$
Q=0.0011\left(E_{t}\right)^{0.9}
$$

where $Q$ is the southerly rate of nearshore littoral drift in cubic yards per day, and $E_{t}$ is the southward component of wave work or energy for the corresponding perlod.

(977) DEVELOPMENT OF WAVE HEIGHT AND WAVE DIPECTION GAGES.

(b) Laboratory project.

(d) Experimental; development.

(e) To develop wave height and wave direction gages for use in securing accurate records of wave characteristics.

(g) Additional development of recording parallel wire resistance gages for laboratory use has been made to obtain constant linear calibration characteristics.

(1459) WAVE TANK STUDY OF EFFECT ON BEACH PROFILES OF VARYING WAVE PERIODS.

(b) Laboratory project.

(d) Experimental; basic research.

(e) It is believed that constant period wave trains as presently used in most small scale tanks unduly accentuate profile irregularities peculiar to the wave period used. In these tests the wave period will be varied both rapidly and slowly from 10\% to $30 \%$ from a mean period. Profiles obtained with varying periods will be compared with those obtained with a constant period equal to the mean of the varying period in order to determine how much and how frequently the wave period should be varied in wave tank tests in order to eliminate irregularities due to the use of a fixed period and thereby approximate more nearly a profile resulting from a "significant" wave period with its multitude of components.

(f) Completed.

(g) The offshore bar and trough formations, which are inherent in constant period tests of this type, were greatly reduced by the variable period tests, the plus or minus 30 percent period variation and the 10-mimute changes being the most effective.

(h) "Laboratory Study of the Effect of Varying Wave Periods on Beach Profiles", Beach Erosion Board Technical Memorandum No. 53, Sept. $195 \mathrm{~h}$.

(1725) SIUDY OF EFFECT OF TIDAL FLUCTUATIONS ON WAVE-PRODUCED BEACH PROFIIES.

(f) Completed.

(h) "Laboratory Study of the Effect of Tidal Fluctuations on Beach Profiles", Beach Erosion Board Technical Memor andum No. 52, (expected publication Jan. 1955).

(1727) STATISTICAL WAVE DATA FOR GREAT LAKES AND ATLANTIC COASTS.

(b) Laboratory project.

(d) Applied research development.

(e) To compile statistical wave data, by hindcasting from weather maps, into a form suitable for engineering usage. The present study includes five stations on Lake Michigan, four on Lake Erie, three on Lake Ontario, and four on North Atlantic, from which data are being obtained and compiled. 
(h) Wave Statistics for the North Atlantic Coast", T. Saville, Jr., Beach Erosion Board Technical Memorandum No. 55, (expected publication Dec. 1954). "Wave Hindcasts for the North Atlantic Coast Based on Unified Wave Theory", O. Kewmann and R. W. James, Beach Erosion Board Technic al Memorandum No. 57, (expected publication Jan. 1955).

(1972) TSUNAMI STUDY.

(b) Laboratory project.

(d) Experimental; basic research.

(e) To study the action of Tsunani waves orer shore areas, with particular application to Hilo Harbor, Hawaii.

(f) Completed.

(g) It was found that relative run-up (the ratio of the vertical distance to which water in a wave will rise over the shore line to wave height $=\mathrm{R} / \mathrm{H}$ ) may be related to wave steepness (the ratio of wave height to length $=\mathrm{H} / \mathrm{L}$ ). The average relationships between $\mathrm{R} / \mathrm{H}$ and $\mathrm{H} / \mathrm{L}$ for a 1:60 contimuous slope, considered representative of Hilo Bay conditions, for a reflecting type wall and for a dike type wall installed in turn at the shore line on the $1: 60$ slope were:

$$
\begin{array}{ll}
\text { for the } 1.60 \text { slope } & \mathrm{R} / \mathrm{H}=0.206(\mathrm{H} / \mathrm{L})^{-0.305} \\
\text { for the reflecting type wall } & \mathrm{R} / \mathrm{H}=0.436(\mathrm{H} / \mathrm{L})^{-0.285} \\
\text { for the dike type wall } & \mathrm{R} / \mathrm{H}=0.418(\mathrm{H} / \mathrm{L})^{-0.283}
\end{array}
$$

For the Hilo Bay conditions this study indicates that a run-up of at least two wave heights $\left(\mathrm{H}_{\mathrm{S}}\right)$ at the shore line is possible.

(h) "Labor at ory" Study of Tsunami Run-Up", Kenneth Kaplan, Beach Erosion Board Technical Memor andum No. 60, (expected publication March 1955).

(1973) EFFECTS OF SOUNDING METHODS ON INDICATED NAVIGATIONAL IEPTHS.

(b) North Atlantic Division of the Corps of Engineers.

(d) Experimental; basic research.

(e) Experimental sounding leads of various shapes were fabricated and tests were made to compare these leads with sounding leads currently being used. The laboratory tests were conducted with an objective of selecting or devising a more suitable size, shape, and weight of sounding lead which would indicate the elevation of bottom material of minimum consistency which has detrimental effects on navigation.

(f) Completed.

(g) These tests show that a spherical lead with a diameter of from 5 to 6 inches gives more consistant results than leads of other sizes and shapes. The most desirable weight of the lead was not determined in these tests.

(h) "Laboratory and Field Tests Sounding Leads", Beach Erosion Board Technical Memorandum No. 54, (expected publication Dec. 1954).

(2189) LABORATORY STUDY OF THE REFORMING OF WAVES AFTER BFEAKING.

(b) Laboratory project.

(d) Experimental; basic research.

(e) To determine the conditions under which waves break over an offshore bar and the amount of the original energy propagated into deeper water behind the bar for given initial wave and bar conditions.

(g) Preliminary results indicate that the energy propagated into deeper water behind the bar varies inversely as the initial wave height.

(h) "A Statistical Study of the Effect of Wave Steepness on Wave Velocity", R. P. Savage, Bulletin of the Beach Erosion Board, Vol. 8, No. 4, Oct. 1954. 
(2190) STUDY OF THE EFTECT OF A GROTN SISTEM ON THE RATE OF ITTTORAL MOVELENT.

(b) Laboratory project.

(d) Experimental; basic research.

(e) To study the effect of groins on the rate of littoral drift passing a groin system. The test is presently being set up in the coast model test basin (973) where waves will be generated at a 30-degree angle to the sand beach containing a groin system. Measurements of the material passing the system will be made in a trap at the downbeach end.

(2191) SAND YOVEMETT STUDY AT MORTCHES INET, LONG ISTAND, NEW YORK.

(d) Field investigation; basic research.

(e) To investigate the pattern of morement and deposition of the littoral material in the vicinity of a newly opened inlet. Morement of the littoral material is being traced by means of hydrographic surveys of both the ocean and bay sides of the inlet, and through $\nabla$ ariation in size characteristics and heavy mineral composition of the littoral material. An attempt is being made to correlate movement of the littoral material with the natural forces involved.

(2192) REGIONAL STUDIES OF THE NEW JERSEY SEACOAST; DELAWARE SEACOAST FROM KITTS HUMMOCK, DELAWAFE BAY TO THE IELAWARE-MARYLAND STATE LINE; AND THE LAKE MI GIGAN SHORE.

(d) Field investigation; basic research.

(e) To compile all existing factual data pertinent to shore processes on a regional scale. Report to consist of five chapters: geomorphology, littoral forces, littoral materials, shore line history, and sunmary and conclusions. Subject matter to include physiography, geological development of the shore region, sources of littoral materials, waves, tides or water level fluctuations, currents, physical characteristics of the littoral materials, interrelation of sedimentary properties, relation of properties of littoral materials to position in the littoral zone, changes in shore line configuration, and the volumes of accretion and erosion.

(2193) SHORE PROTECTION PLANNING AND DESIGN.

(d) Design.

(e) To assemble in a single volume, insofar as practicable, a manual of practice for shore protection. Attempt to include a detailed sumnary of applicable methods, techniques and useful data pertinent to the solution of shore protection problems.

(g) The report has been completed and published in loose-leaf form, but it. will be kept active in order to provide up-to-date information in the form of addenda sheets.

(h) "Shore Protection Planning and Design", Technical Report No. 4, Beach Erosion Board, Office of the Chief of Engineers, June, 1954. For sale by the superintendent of Documents, U. S. Goverment Printing Office, Washington 25, D. C. Price $\$ 2.25$.

(2194) FACTORS EFFECTTNG THE ECONOMIC LIFE OF TTMBER IN COASTAL STRUCTURES.

(d) Design.

(e) The purpose is to report on the various factors that effect the economic life of timber in coastal structures. This report includes a discussion of the calses of deterioration and protection method to increase the economic life.

(2195) BE-EXAMTNATION OF ARTIFICIALLY NOURISHED AND CONSTRUCTED BEACHES.

(d) Field investigation; applied research.

(e) The purpose of this study is to evaluate the effectiveness and economic life of beach fills through artificial nourishment. A selected number of locations where beach fills have been made are being re-examined.

(h) "Artificially Nourished and Constructed Beaches", Jay V. Hall, Jr., Beach Erosion Board Technical Memor andum No. 29, Dec. 1952. 
ט. S. DEPARTMENT OF THE ARMY, CORPS OF ENGINEERS, Bonneville Hydraulic Laboratory.

Inquiries concerning Projects Nos. 1198, 1462, 1464, 1465, 1466, 1729, 1974 to 1976 , incl., 2196 and 2197, should be addressed to the District Engineer, Portland District, Corps of Engineers, 628 Pittock Block, Portland 5, Oregon.

(1198) FRICTION IOSSES IN CORPUGATED METAL PIPE. (CW-828).

(b) Office, Chief of Engineers, U. S. Army, Washington, D. C.

(d) Experimental; applied research.

(e) Tests were conducted to determine values of Manning's "nn for corrugated metal pipe of 3-, 5-, and 7-foot diameters with velocities from 1 to $16 \mathrm{fps}$. Open-channel flow was tested with the two smaller sizes and full-pipe flow was investigated with the three pipe diameters. Similar tests were made with inverts of 5-foot diameter pipe paved with asphaltic compound covering one-fourth and one-half the circumference; the 7-foot diameter pipe was tested with one-fourth of circumference paved. Velocity distribution at various sections of the pipe and pressure distribution along the corrugations were also obtained.

(f) Tests completed.

(g) Results indicated that "n" varies between: $0.0236,0.0245$, and 0.0234 for Reynolds Numbers of $3 \times 10^{5}, 9 \times 105$, and $4 \times 10^{6}$, respectively, for the 3-foot pipe; 0.0238 , 0.0243 , and 0.0240 for Reynolds Numbers of $1 \times 10^{6}, 2 \times 10^{6}$, and $4 \times 10^{6}$ for the 5-foot pipe; and $0.0234,0.0237$, and 0.0230 , for Reynolds Numbers of $1 \times 10^{6}, 3 \times 10^{6}$, and $5 \times 10^{6}$ for the 7-foot pipe. With the pipe circumference one-fourth paved, "n" varied between: 0.0211 and 0.0207 for Reynolds Numbers of $1.5 \times 10^{6}$ and $4 \times 10^{6}$, respectiyely, for the 5-foot pipe; and 0.0208 and 0.0203 for Reynolds Numbers of $2.5 \times 10^{6}$ and $5 \times 10^{6}$ for the 7-foot pipe. With the circumference of the 5-foot diameter pipe one-half paved " $n$ " varied between 0.0180 and 0.0174 for Reynolds Numbers of $1.5 \times 10^{6}$ and $4 \times 10^{6}$.

(h) Five preliminary or memor andum reports have been issued on results of the tests. Final report being prepared.

(1462) GENERAL MODEL STUDY OF THE DALLES DAM, COLUMBIA RIVER, THE DALLES, OREGON .

(b) Department of the Army, Corps of Engineers, Portland District, Portland Oregon.

(d) Experimental; for design.

(e) A 1:80-scale undistorted fixed bed model reproduces 2.7 miles of the Columbia River at the dam site. The original layout consisted of a circular arc 30-bay spillway, a 22unit powerhouse, an 86 - by 675 -foot navigation lock, a rock-fill non-overflow section, and facilities for passing fish over the dam. Maximum head is 90 feet. Revised layout has a straight 23-bay spillway. Purposes are to study the stmuctures alignment and flow conditions affecting navigation, power generation, cofferdam placement, rock-fill dam construction, and fish passage.

(g) Four major layout plans were tested and the most econonical plan that effected satisfactory hydraulic conditions was selected. Tests indicated ability to reduce length of spillway and to reduce forebay excavation by 30 feet. Data relative to water-surface elevations and velocities in the tailrace, and the effects of excess fill placed in the forebay have been obtained. Flow conditions during various stages of construction and with the project completed have been observed.

(h) Twenty-six memor andum reports have been issued to date.

(1464) MODEL STUDY OF ROCK FUI, THE DALLES DAM, COLUMBIA RIVER, THE DALLES, OREGON.

(b) Department of the Army, Corps of Engineers, Portland District, Portland, Oregon.

(d) Experimental; for design.

(e) The 1:40-scale model of the 600-foot wide closure section of the rock-fill non-overflow section of The Dalles Dam includes portions of the river channel upstream and downstream therefrom and the eight partially-completed units at the upstream end of the powerhouse through wich the river flow will be diverted as the closure fill is constructed. A study of the rock sizes and placement procedure required to construct the fill at a river flow of 200,000 cfs and for stability at $300,000 \mathrm{cfs}$ is being made. 
(g) The fill has been successfully constructed to closure by placing quarry-run rock (1000 $\mathrm{lb}$ and less) in 10-foot lifts in velocities of $15 \mathrm{fps}$ with a river discharge of 200000 cfs. This type of fill was placed on two different alignments and was found to be stable in either position when subjected to a flow of 300000 cfs. Preliminary tests have indicated that the fill may be placed with material of the same size by end-dumping from one side of the river channel.

(h) Three memorandum reports have been issued.

(1L65) MODEL STUDY OF THE DALLES DAM SPILLWAY, COLUMBIA RIVER, THE DALLES, OREGON.

(b) Department of the Army, Corps of Engineers, Portland District, Portland, Oregon.

(d) Experimental; for design.

(e) Three bays of the spillway are reproduced to a scale of $1: 36$ to study the hydraulic characteristics of the spillway crest, piers, gates, stilling basin and baffle piers.

(f) Suspended.

(g) The increased crest efficiency indicated by the model, in conjunction with a crest shape designed for 75 percent of maximu head, permitted a reduction in the number of spillway bays. The stilling basin was shortened 50 feet to a total length of 170 feet, and one row of baffle piers, of the Bluestone type, was eliminated. The capacity of the stilling basin would not be materially reduced by erosion of the shelf located downstream from the basin.

(h) Sixteen memorandum reports have been issued on results of tests to date.

(1466) MODEL STUDY OF THE DALLES DAM NAVIGATION LOCK, COLUMBIA RIVER, THE DALLES, OREGON.

(b) Department of the Army, Corps of Engineers, Portland District, Portland Oregon.

(d) Experimental; for design.

(e) A 1:25-scale model of the 86- by 675-foot lock chamber including its culvert systems and portions of the upstream and downstream approach channels is reproduced. Maximum lift is 90 feet. Studies are being made of various types of filling and emptying systems to determine the most advantageous from the standpoints of rate of operations, degree of turbulence, and economy. The several proposed plans include lateral culverts within the lock chamber combined with several locations of intake ports, longitudinal culverts, and outlet works.

(g) Designs have been selected for all features of the lock. A change in valve-opening schedule resulted in a filling time of 12.5 minutes and a maximum hawser forces of 8 tons without supplemental use of the upstream lock tainter gate. The lock emptied in 16 minutes. Studies are being made to determine if staggered valve operation will reduce maximum hawser forces.

(h) Six memorandum reports have been issued.

(1728) MODEL STUDY OF THE DALLES DAM FISH LADDERS, COLUMBIA RIVER, THE DALLES, OREGON.

(b) Department of the Army, Corps of Engineers, Portland District, Portland, Oregon.

(d) Experimental; for design.

(e) The 1:8-scale model reproduced a straight portion of a fish ladder containing ten stilling pools. Tests were made to study flow conditions with 1 adder slopes of 1 on 16 and 1 on 20 and to determine the most efficacious orifice sizes for ladder widths of 24 and 30 feet.

(f) Inactive.

(g) Results indicated insignificant differences in flow conditions between 1 on 16 and 1 on 20 slopes. Orifices 21 by 23 inches and 25 by 26 inches have been selected for the 24 and 30-foot ladders, respectively.

(h) Four memorandum reports have been issued on results of tests to date.

(1729) MODEL STUDY OF THE DALLES DAM POWERHOUSE TNTAKE, COLUMBIA RIVER, THE DALLES, OREGON.

(b) Department of the Arrny, Corps of Engineers, Portland District, Portland, Oregon.

(d) Experimental; for design. 
(e) The 1:25-scale model contains a test unit consisting of intake and scroll case, two adjacent units with intakes only, and a semi-circular forebay in which flow can be introduced from any desired direction. Tests were made to determine the effect of the direction of approach flow on velocity distribution in the intake, discharge distribution through the scroll case, and head loss.

(f) Inactive.

(g) Results indicate that oblique approach flows, at an angle of $15^{\circ}$ from the powerhouse axis, have little effect on the efficiency of the unit, as indicated by head loss and flow distribution in the intake and scroll case, when trash racks are installed on the noses of the piers to function as guide vanes.

(h) Six memorandum reports have been issued on results of tests to date.

(1974) MODEL STUDY OF THE DALLES POWERHOUSE FISHWAY DIFFUSER, COLUMBIA RIVER, THE DALLES, OREGON.

(b) Department of the Army, Corps of Engineers, Portland District, Portland, Oregon.

(d) Experimental; for design.

(e) To determine means of baffling auxiliary flow in diffusion chambers to obtain uniform distribution into the fish collection channel by means of a $1: 8$-scale model of one diffusion chamber and a portion of the collection channel.

(f) Inactive.

(g) Vertical strip baffles placed downstream from the regulating valve produced satisfactory flow distribution.

(h) Three memorandum reports have been issued on the results of tests to date.

(1975) MODEL STUDY OF THE DALLES POWERHOUSE SKELETON UNIT, COLUMBIA RIVER, THE DALLES, OREGON.

(b) Department of the Army, Corps of Engineers, Portland District, Portland, Oregon.

(d) Experimental; for design.

(e) To design for adequate discharge capacity and to determine pressures and velocities on exposed rock surfaces in eight skeleton powerhouse units that will be used for diversion during construction of a rock-fill non-overflow section. A 1:25-scale model reproduces one skeleton unit.

(f) Tests completed.

(g) The required size of the draft tube openings and the areas requiring protection from high velocities were determined. The effect of $v$ aried tailwater elev ations and of operation with one or two of the three intake bays per unit was observed.

(h) Three memor andum reports have been issued on tests to date.

(1976) MODEL STUDY OF BONNEVILLE DAM STILLING BASTN, COLUMBIA RIVER, BONNEVILLE, OREGON.

(b) Department of the Army, Corps of Engineers, Portland District, Portland, Oregon.

(d) Experimental; for design.

(e) A 1:36-scele model reporduces three bays of the spillway and stilling basin for the purpose of studying the need of maintaining the stilling basin baffle piers. Additional tests were made to determine the resisions required to improve pressure conditions on the baffles and to eliminate scour of the river bed adjacent to the apron downstream from the stilling basin.

(f) Tests completed.

(g) Results indicated that baffles with a sloping front face were required because of their close proximity to the spillway bucket. Placing elliptical side curves on the leading edges of the baffles and revising the second row to a solid sill of similar cross section improved pressure conditions on the baffles and eliminated the erosion of bed material downstream from the stilling basin.

(h) Two memor andum reports have been issued.

(2196) MODEL STUDY OF FISH LADDER SURGE FOR THE DALIES DAM, COLUMBIA RIVER, THE DALLES, OREGON.

(b) Department of the Army, Corps of Engineers, Portland District, Portland Oregon.

(d) Experimental; for design. 
(e) A 1:10-scale model reproduces the 30-foot-wide, I on 16 slope, East fish ladder from weir 96 to weir 155. Included are 14 weirs of the downstream tangent, the 180-degree bend, the 47 weirs of the upstream tangent, the 116-degree 45 -minute bend, and three weirs upstre an therefrom. Provision was made for $\nabla$ arying the slope of the fish ladder. The occurrence and best means of controlling the surge are to be investigated.

(g) Results to date have indicated that a bi-nodal surge occurs with or without the orifices in the weirs open. Reduction in surging has been accomplished by: (a) various designs and arrangements of baffles placed at the quarter points, normal to the downstream sides of the weirs; (b) varying the width of the ladder by changing wall widths in groups of pools; and (o) changing the curred-top weirs (design) to square-top weirs.

(2197) FINGERLING MORTALITY STUDY: FISHERIES ENGINEERING FESEARCH.

(b) Department of the Army, Corps of Engineers, Narth Pacific Division, Portland, Oregon.

(c) District Engineer, Portland District, Corps of Engineers, 628 Pittock Block, Portland 5, Oregon.

(d) Experimental; applied research.

(e) The effects of reduced pressure, high velocity impingement against walls placed at various angles and turbulence on salmon fingerling, either free-swimming or encased in gossamer bags of various types, to be investigated. Results of tests will be used in evaluating studies of passage of fingerling through spillways and powerhouse turbines. Apparatus to utilize approximately $25 \mathrm{cfs}$, including device to lock the fingerling salmon into the test sections, is under construction.

(f) Under construction.

J. S. DEPARTMENT OF THE ARMT, CORPS OF ENGINEERS, LOS Angeles District.

Inquiries concerning Projects Nos. 980, 1203, 1732, and 2198, should be addressed to the District Engineer, Los Angeles District, Corps of Engineers, P. 0. Box 17277, Foy Station, Los Angeles 17, California.

(980) MOLEL STUDY OF WHITTIER NARROWS FLOOD-CONTROL BASTN.

(b) Laboratory project.

(d) Experimental for design.

(e) Earth dam with gated outlets and spillway. Three models are being used: A 1:24-scale model of the outlet works for tests on the operation of the four $30 \mathrm{ft}$. by $19 \mathrm{ft}$. radial sluice gates with maximum head of $50 \mathrm{ft}$; a 1:42-scale model of a half plan of the spillway for tests on the operation of the nine $50 \mathrm{ft}$. by $29 \mathrm{ft}$. tainter gates with maximum head of $34 \mathrm{ft} . ;$ a 1:60-scale general model of the flood-control basin for tests on the over-all operation of the project.

(f) Conpleted.

(g) A complete set of calibration curves was obtained for the radial sluice gates in the outlet works; two-foot increments were used for the partial gate openings.

(1203) MODEL SIUDY OF LOS ANGELS RIVER CHANEL IMPROVEMENT, RTO HONDO TO PACIFIC OCEAN.

(b) Laboratory project.

(d) Experimental for design.

(e) In the reach from Rio Hondo to Spring Street (44,500 ft.) the improvement proposed is a paved trapezoidal chamnel with $300-\mathrm{ft}$. base and 1 on $21 / 4$ side slopes. Normal velocity would be supercritical ( $25 \mathrm{fps}$ ) but numerous bridges would produce Class "B" flow and attendant hydraulic jumps upstream of the bridges. From Spring Street to Pacific Ocean (17,600 ft.) the channel will be trapezoidal with a base width varying between $530 \mathrm{ft}$. and $470 \mathrm{ft}$., the 1 on 2 sides slopes will be paved, the bottom unpaved, and the velocity subcritical (12 fps.). The design discharge is $140,000 \mathrm{cfs}$ in the first reach and 146,000 cfs in the second reach. A $1: 50-s c a l e$ model will be used to study flow conditions at confluences, at bridges, and at the junction of the paved and unpaved channels. The model tests will be accamplished in stages. 
(g) Tests are in progress to determine the proper design of the structure which will form the junction between the paved channel and the unpaved channol.

(1732) MOLEL STUDY OF SPILLWAY AND OUTLET WORKS FOR SAN ANTONIO DAM.

(b) Laboratory project.

(d) Experimental for design.

(e) Earth dam with maximum height of 160 feet and length of 3850 feet. The outlet works designed for a maximum discharge of 10,000 cfs will be at right abutment and will consist of an intake with 3 gated openings 5 feet 8 inches by 10 feet high converging into a circular conduit 14.5 feet in diameter and 621 feet long. The spillway designed to pass 54,000 cfs will be in right abutment and will consist of a concrete ogee 200 feet long and a concrete side channel and chute 1075 feet long which will terminate in a flip bucket at stream bed. Three models are being used to study various designs: a 1:20scale model of the outlet works made of transparent plastic; a 1:36-scale model of the ogee and side channel of the spillway; and a 1:48-scale general model of the spillway.

(g) Tests were made in the 1:20-scale outlet works model to determine head-discharge relationships for partial gate openings.

(2198) MODEL STUDY OF SUPERELEVATED FLOW IN CURVED OPEN CHANNELS.

(b) Laboratory project.

(d) Experimental for design.

(e) Tests are being made to determine the characteristics of flow in curved trapezoidal channels and the effectiveness of spiral easement curves in maintaining equilibrium of flow in the curve and in the downstream tangent. A 1:25-scale model of a trapezoidal channel having a base width of $621 / 2$ feet and side slopes of 1 on $21 / 4$ is being used for the test. The radius of curve is 850 feet. The discharges are 35,000 cfs and 45,000 cfs. The channel slopes are 0.003, 0.006, 0.008 and 0.010 .

(g) Tests completed on simple curves without spirals indicate that waves developed in the curve will continue for a distance of 1500 feet into the downstream tangent.

DEPARTMENT OF THE ARMY, CORPS OF ENGINEERS, ST. PAUL DISTRICT.

In cooperation with St. Anthony Falls Hydraulics Laboratory.

Inquiries concerning Projects Nos. 194, 196, 985, 1206, 1977, and 2199, should be addressed to the District Engineer, Corps of Engineers, St. Paul District, 1217 U. S. Post Office and Custon House, St. Paul 1, Minn.

\section{(194) A STUDY OF METHODS UEED IN THE NEASUREMENT AND ANALYSIS OF SEDTMENT LOADS IN STREAMS.}

(b) Federal Interagency River Basin Comittee, Subcomittee on Sedimentation.

(d) Experimental; applied research and development.

(e) Plans and specifications for point- and depth-integrating suspended sediment samplers and associated laboratory apparatus have been prepared. Sediment sampler designs include a light-weight depth sampler ( $4 \mathrm{lb}$ ) hand operated, medium-weight depth sampler (62 lb), point sampler (100 lb), and heavy point sampler (300 lb) for use in deep swift streams. Designs for a sediment sample splitter, a bottom withdrawal tube, a hand operated bed material sampler, a heavy bed material sampler (100 lb), the visual accumulation sedimentation tube and particle size analyzer for recording the sedimentation size distribution (fall or settling velocities) of sand particles have also been prepared.

(g) Instruments and apparatus required for sampling and analyzing fluvial sediments are being manuf actured in quantities sufficient to satisfy the current needs of Federal agencies. Field testing of an improved 100-pound bed material sampler and the visual accumulation tube method of determining particle-size gradations of fluvial sediments in the sand size range is progressing. 
(196) MISSISSIPPI RIVER, FIILING AND EMPTYING SISTEMS FOR NEW 1200-FOOT LOCK AT LOCK AND DAM NO. 19, KEOKOK, IOWA.

(b) Rock Island District, Corps of Engineers, U. S. Army.

(d) Experimental; for design.

(e) Model 3, 3 to 100 scale, simulated a lock 110 feet wide by 1,200 feet long, with a normal lift of 38.2 feet. An existing model culvert system was adapted to similate the performance of the prototype dual wall culverts with lateral culvert diffusers in the bottom of the chamber. The upstream emergency and service gates were of the vertical lift submergible type designed for overflow.

(f) Tests completed.

(g) The forces required to $\mathrm{r}$ aise and lower the emergency and service gates were measured and the relative effect of slight modifications to the superstructure and pier shapes were determined. A method of operating the service gate was devised to supplement filling through the culvert system and recuce the filling time with a minimum of disturbance to barge tows of various sizes and locations in the lock chamber. Stresses in the linkage between individual barges in a tow were measured.

(985) FILIING AND EMPTYING SISTEMS FOR HIGH-IIFT LOCKS.

(b) Office, Chief of Engineers, U. S. Army, Washington, D. C.

(d) Experimental; applied research.

(e) To develop adequate criteria for the design of filling and emptying systems for highlift locks. Tests will be conducted in prototype locks, in model locks for definite projects, and in a general lock model simulating a maximum lift of 150 feet.

(g) Culvert valve models were tested to measure head losses due to stoplog and valve recesses, vibration, forces required to raise a Tainter valve, and surges in the culvert and pressures on a Tainter valve during sudden closure resulting from failure of the operating mechanism. A wall port filling system was tested with a wall dividing the culvert into two conduits from the valve to the middle lock manifold port to establish initial flow simultaneously in two ports but no improvement in operation was noted.

(1206) CONDUIT GATE STRUCTURES AND TRANSITIONS.

(b) Office, Chief of Engineers, U. S. Army, Washington, D. C.

(d) Experimentel; applied research.

(e) A general model study was conducted to establish gate operating procedures for multiple gate conduits and design criteria for conduit transitions downstream from single and multiple control gates. Influence of conduit length in dampening undulating flow in the conduit was also investigated. The model included a complete outlet conduit with upper pool reservoir, multiple control gates in conduit intake, and a stilling basin.

(f) Testing has been completed.

(g) Spiral or undulating flow was found to originate at the gate and transition sections. The degree of disturbance varied with the type of conduit boundary, being most severe with circular conduits. Guide vanes located on the conduit walls downstream from the intake transition reduced spiral or turbulent flow resulting from the operation of one gate alone in multiple gate intake structures.

(h) Report is in preparation.

(1977) MOIEL STUDY FOR GREENUP AND MARKLAND LOCKS, OHIO RIVER.

(b) Huntington and Louisville Districts, Corps of Engineers, U. S. Army.

(d) Experimental; for design.

(e) The hydraulic systems of the two locks which are of similar design are being tested in a 3 to 100 scale model. The proposed locks will be 110 feet wide and 1,280 feet long with lifts of 32 and 35 feet, respectively. The filling and emptying systems are combined in two culverts, one in each wall, with lateral culvert diffusers in the lock floor and flared outlets discharging into the river below the dan.

(f) Tests completed. 
(g) The model was revised to simulate a prototype design for introducing flow from one wall culvert in the upper half of the lock and inflow from the other culvert, in the downstream half of the lock chamber. The hawser pull exerted by large and small barge tows during typical lockage operations was less than that obtained with a system introducing flow from both culverts in the middle third of the chamber. Port extensions on the lateral culvert diffusers were the most effective means of reducing cross currents. A delay in the operations of one valve did not reduce disturbances in the lock.

(2199) MOLEL STUDY OF FIIUING AND EMPTYING SYSIEMS FOR ROBINSON BAY AND GRASS RIVER LOCKS, ST. LAWRENCE SEAWAY.

(b) Buffalo District, Corps of Engineers, U. S. Army.

(d) Experimental; for design.

(e) The hydraulic systems of the two locks are of similar design and will be tested in a 1 to 24.24 scale model. The filling and emptying systems are combined in two culverts, one in each wall, with intake in the upper gate sill, ports in the chamber walls, and diffusers in the lower approach channel. A model simulating a single wall port discharging into a segment of the proposed lock chamber was constructed to a scale of 1 to 36.2 .

(f) General model design and testing of a single wall port model are in progress.

(g) The vertical and horizontal angles, velocity, and spread of the jet issuing fram ports of various designs were measured for the subsequent selection of a proper design for the two locks.

U. S. DEPARTMENT OF THE ARMY, CORPS OF ENGTNEERS, Waterways Experiment Station.

Inquiries concerning Projects Nos. 211, 218, 226, 230, 236, 419, 425, 673, 674, 678, $682,783,986,992$ to 994 , incl., 998 to 1002, incl., 1004, 1207, 1210 to 1212, incl., 1467 to 1472 , incl., $1474,1475,1735$ to 1741 , incl., 1978 to 1985, incl., 1987, 1988, and 2200 to 2204 , incl., should be addressed to the Director, Waterways Experiment Station, Corps of Engineers, P. 0. Box 631, Vicksburg, Miss.

(2II) MODEL STUDIES OF OUTLET WORKS, SPILLWAY AND STILILING BASIN, GARRISON DAM, MISSOURI RIVER, NORTH DAKOTA.

(b) The District Engineer, Garrison District, Corps of Engineers, Bismarck, N. D.

(f) Testing Completed.

(h) Final report in preparation.

\section{(218) CONDUIT INTAKE MODEL TESTS.}

(b) Office of the Chief of Engineers, Department of the Army, Washington, D. C.

(d) Experimental; applied research.

(e) Scale models are being used for a general study of the hydraulic characteristics of entrance curves for (1) rectangular conduits in which the entrance is flared in four directions, (2) a gated tunnel having a rectangular entrance with floor at same elevation as approach channel (entrance flared in three directions), and (3) a rectangular conduit in which parallel side walls are extended upstream from the entrance and only the roof flared (entrance floor at $s$ ame elevation as approach channel). Tests involve determination of pressures and discharge coefficients.

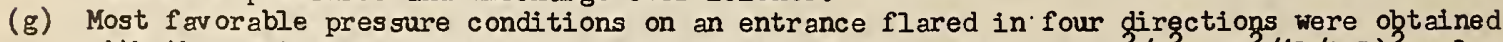
with the upstream portion of the entrance shaped to the ellipse $x^{2} / D^{2}+Y^{2} /(I / 3 D)^{2}=1$, and the downstream portion of the entrance shaped to the ellipse $x^{2} / D^{2}+I^{2} /(1 / 6 D)^{2}=1$. In the above equations $D$ is the distance across the conduit in the direction concerned.

(h) Report of tests with conduit flared in four directions in preparation. 


\section{(226) POTAMOLOOY INVESTIGATIONS.}

(b) The President, Missisappl River Comnission, Corps of Engineers, Vicksburg, Mississippi.

(d) Experimental and field investigations; applied research.

(e) These investigations, to determine the governing principles for the design and over-all planning of river improvements and bank stabilization, consisted of model studies conducted at the Waterways Experiment Station and field studies made at selected sites along the Mississippi River. The purposes of the model studies were to: (I) provide means of predicting future channel changes in meandering of the Mississippi River. and the need for bank protection, (2) study revetment stability, (3) study and develop methods of channel stabilization by means other than the use of revetment, and ( 4 ) develop and test plans for improvement of specific troublesome reaches of the Mississippi River. The field investigations consisted of (1) soil surveys to determine the nature, characteristics, and physical properties of the banks of the Mississippi River to permit recognition of soil factors affecting bank stability, (2) hydrographic and hydraulic surveys to provide information in specific revetted reaches of the river to permit recognition of hydraulic and hydrographic factors affecting revetment stability, and (3) turbulence surveys to determine the magnitude and extent of the forces of turbulence engendered at the boundary layer of the Mississippi River and the effects of these forces on revetment stability to permit adequate and economical revetment design.

(f) Model tests and field investigations completed.

(g) A model-operating technique was developed that can be used to forecast with reliable accuracy the future courses of regimen changes in any troublesome reach of the Mississippi River. In addition, a model-operating technique was evolved that permits investigation of various bank-stabilization features. The primary findings of the soils studies Indicated that the massive failures occurring in the banks of the Lower Mississippi River are liquefaction fallures. Hydraulic studies indicated that the interstices in the articulated concrete mat of conventional design permit a flow of sand sufficient to produce extensive underlying pockets and sinking of the revetment.

(h) Final report on hydrographic and hydraulic field investigations completed.

(230) MOIEL STUDY OF FLOOD CONTROL, CUMBERLAND, MARYLAND.

(b) The District Engineer, Washington District, Corps of Engineers, Washington, D. C.

(f) Testing completed.

(h) Final report in preparation.

(236) KISSISSIPPI BASTN KODEL.

(b) Office of the Chief of Engineers, Department of the Army, Washington, D. C.

(d) Experimental; for design.

(e) The project provides for construction and operation of a model of the Mississippi River Besin including the Kississippi, Ohio, Missouri, White, Arkansas, and Red Pivers, and their principal tributarles. All existing and proposed flood-control reservoirs, dikes, floodwalls, and other pertinent works will be reproduced. The model area comprises 200 acres, and measures 4,500 feet east and west, and 3,900 feet north and south. Completed construction consists of the Upper Mississippi River from Hannibal, Missouri, to Tiptonville, Tennessee; the Kissouri River from sioux City, Iowa, to the mouth; the Arkansas Piver from Blackburn Dam site, Oklahoma, to Pine Bluff, Arkansas; the Ohio River from Golconda, Illinois, to the mouth; and the Cumberland River from Old Hickory Dam, Tennessee, to the mouth. The topography of the streams and floodplains are being reproduced to a horizontal scale of $1: 2,000$ and vertical scale of $1: 100$. Water-surface elevations are measured by electrically operated stage devices with the recorders located in central control buildings. Stream flow is introduced and controlled by automatic instruments called inflow controllers. The model was designed to aid in the development of coordinated basin-wide plans for flood control and operation of flood control structures. The extent of operation of the model is determined each year by the testing programs requested by the Districts and Divisions that have operable sections on the model. Tests to check present flood-routing methods to aid in perfecting flood predictions and reservoir operations, and tests to check the grades and to determine the effect of project levees to aid in planning flood protection and other levee studies were conducted during the current year for the Missouri River, Opper Mississippi Valley, and Southwestern Divisions. 
(419) SLIDE GATE TESTS, NORFORK DAM, ARKANSAS.

(b) The District Engineer, Little Rock District, Corps of Engineers, Little Rock, Arkansas.

(d) Experimental; for design.

(f) Testing completed.

(g) Results of full-scale tests of the two types of slide gates, selected on the basis of model tests, indicated that the performance of a gate with a 45-degree upstream bevel at the lower edge was superior to that of the Norfork-type gate which had a flat bottom with a slight slope to fit the sealing surface. High negative pressures on the gate bottom, considerable gate vibration, and crackling sounds characteristic of cavitation were noted for most gate openings of the Norfork gate. By contrast, high positive pressures occurred over the sloping bottom of the 45-degree gate, resulting in elimination of cavitation sounds and in a marked reduction in gate vibration. The high positive pressures also resulted in less air demand at partial gate openings. iests of long duration at partial gate openings with both test gates revealed some cavitation damages to the outer edge of the bronze seals on both sides of the gate frame and to the cast steel immediately downstream and just under the gate.

(h) "Slide Gate Tests, Norfork Dam, North Fork River, Arkansas", Waterways Experiment Station Technical Memorandum No. 2-389, July 1954. (Available on loan).

(425) COMPREHENSIVE MODEL STUDY, DELAWARE RIVER, PENNSYLVANIA.

(b) The District Engineer, Philadelphia District, Corps of Engineers, Philadelphia, Pa.

(d) Experimental; for design.

(e) To develop and test plans for reduction of shoaling in several ranges of the navigation channel, the entire Delaware River estuary from the Atlantic Ocean to Trenton is reproduced in the model which is of the fixed-bed, silt-injection type, with scale ratios of $1: 1,000$ horizontally and $1: 100$ vertically. Tides and tidal currents are reproduced by automatic tide-control machines. Observed prototype salinities are reproduced in the Delaware Bzy portion of the model, and provisions made for the injection of silt, and for measuring silt deposits.

(g) Tests to determine effects of tide range, fresh-water discharge, mean tide level, disposal of industrial and municipal wastes, and regulation of fresh-water discharge on the salinity regimen of the Delaware Estuary were completed.

(h) "Delaware River Model Study", Waterways Experiment Station Technical Memorandum No. 2-337, Report No. 2, "Salinity tests of existing channel", June 1954. (Available on loan).

(673) GERAL SPILLWAY MODEL TESTS.

(b) Office of the Chief of Engineers, Department of the Army, Washington, D. C.

(d) Experimental; applied research.

(e) Tests on a l:40 model are used to study hydraulic characteristics of the standard spillway shape with heads up to $1-1 / 3$ times the design head of the crest, including the effect of crest piers and gates, elevation of downstream floor of spillway, and downstream slope of spillway. Tests are also being made to establish general rules for design of rollertype energy dissipators. The drop from spillway crest to bucket is varied to study the effect of nappe thickness. Tests to study pressures on a flat apron-type energy dissipator were undertaken. Tests to determine the effect of tainter gate location on spillway pressures and discharge characteristics were completed. Tests concerning the effect on discharge coefficients of the location of the toe curve on a low ogee spillway were accomplished.

(g) Tests to obtain discharge and pressure data for various approach elevation conditions indicated that with height of weir equal to or greater than the head, coefficient and pressure data were in the same range for the same crest shape. The spillway discharge per net foot of width is not materially affected by the use of crest piers or by variation in the shape of these piers. Thickening of the spillway nappe permitted established roller action to continue at lower tailwater depths than noted with the thin spillway jet. Pressures on a flat apron-type energy dissipator approximated the water-surface elevation above the apron. Discharge and pressure values were not materially affected by locating the gate seat on the spillway crest or 5.0 feet downstream from the crest. Location of the gate seat on the spillway crest permitted more positive control of flows at low heads. Toe curve location had little effect on discharge coefficients after it falls a $0.849 \mathrm{H}_{\mathrm{d}}$ distance below the spillway crest. The radius of the toe curve had little effect on discharge coefficients. 
(h) Advance Report No. 1, General Spillway Investigation, CW 801, "Spillway Crest Data with and without Piers", dated August 1949.

Advance Report No. 2, General Spillway Investigation, CW 801, "Spillway Crest Data with Varied Depths of Approach", dated June 1950. A consolidated report of the above advance reports, together with results obtained by varying the spillway slope and exit area elevation below the spillway, is in preparation.

(674) MODEL STUDIES OF FORT RANDALL DAM, MISSOURI RIVER, SOUTH DAKOTA.

(b) The District Engineer, Omaha District, Corps of Engineers, Omaha, Nebraska.

(f) Testing completed.

(h) Final report in preparation.

(678) CHARLESTON HARBOR MODEL STUDY.

(b) The District Engineer, Charleston District, Corps of Engineers, Charleston, South Carolina.

(f) Testing completed.

(h) Final report in preparation.

(682) HYDRAULIC CAPACITY OF MEANDERING CHANMELS IN STRAIGHT FLCODWAYS.

(b) Office of the Chief of Engineers, Department of the Army, Washington, D. C.

(f) Testing completed.

(h) Final report in preparation.

(683) MOLEL STUDIES OF FLOW CONDITIONS IN PUMPING PLANT SUMP AND SURGES IN SEWERS.

(b) The District Engineer, Louisville District, Corps of Engineers, Louisville, Kentucky.

(f) Testing completed.

(h) "surges in Southern outfall sewer and Flow Conditions in State Fairgrounds (Western Parkway) Pumping Plant, Louisville, Kentucky", Waterways Experiment Station Technical Memorandum No. 2-367, June 1954. (Available on loan).

(986) YODEL TESTS OF SPILLWAY TAINTER GATE, GHEATHAM DAM, COMBERLAND RIVER, TENNESSEE.

(b) The District Engineer, Nashville District, Corps of Engineers, Nashville, Tennessee.

(d) Experimental; for design.

(e) A 1.36 model of a portion of spillway crest and bucket was used to determine the most adventageous shape for the submergible tainter gate; the forces acting on the gate; and flow conditions for various tailwater elevations. In addition, the submergible tainter gate developed in the 1:36 model was tested in a 1:10 model to determine its operating characteristics at the larger scale. Tests to determire the location and height of end sill for use with a partially submergible tainter gate also were conducted.

(f) Testing completed.

(g) The tests showed that the gate as originally designed was unsatisfactory because of its instability, and the uplift forces and high downpull forces exerted on it. As the test gate was raised, pressure conditions over the gate were such as to cause it to oscillate. Downpull forces were as high as $650 \mathrm{kips}$ or about twice those considered allowable. Revisions to the crest and over-all shape of the gate together with proper venting eliminated all uplift forces tending to float the gate, and recuced downpull forces to within allowable limits. The tendency of the gate to oscillate also was eliminated by the design developed from the model tests. Results of tests on the 1:36-scale model were confirmed by later tests on a $1: 10-s c a l e$ model. The actual design of gate adopted for construction in the prototype was a semisubmergible type; flow is to be passed over this gate up to a head of 7 feet, after which the gate will be raised and all flow will pass under it. This type gate was not tested in the model except for stilling basin tests that were conducted using a schematic reproduction of the final-type gate. These tests indicated that a horizontal apron, 64 feet in length at elevation 345, and a 9-foot-high end sill would be most effective in stilling flow passing either over or under the gate.

(h) "submerglble-Type Tainter Gate for Spillway, Cheatham Lock and Dam, Cumberland River, Tennesseen", Waterways Experiment Station Technic al Memorandum No. 2-381, Aptil 1954. (Ax ailable on loan). 
(992) MODEL STUDIES OF. PINE FLAT DAM, KINGS RIVER, CALIFORIIA.

(b) The District Engineer, Sacramento District, Corps of Engineers, Sacramento, California.

(d) Experimental; for design.

(e) Four models were involved in the study of the Pine Flat spillway: (1) a 1:60 comprehensive model; (2) a 1:40 section model of the spillway crest; (3) a 1:18 model of a conduit outlet portal in the lower tier of conduits; and (4) a 1:18 model of one of the conduits in the upper tier. Special attention was given in the tests to the hydraulic characteristics of the crest, flow from the conduits, and to the effectiveness of the flip bucket in deflecting the water away from the toe of the dam. Pressures on the crest and discharge coefficients were thoroughly investigated because the crest was designed to fit the lower nappe for a head only 75 per cent as great as the maximum head expected. A deflector block was used in the downstream end of each conduit in the lower tier to spread the discharge onto the surface of the tailwater.

(f) Testing completed.

(g) Results of tests on the spillway crest were of particular interest in that the ogee crest was shaped to fit the underside of the nappe for a head of 39 feet whereas the maximum pool for which the dam was designed will create a head of 53.1 feet on the spillway crest. Although negative pressures were measured on the spillway crest at the maximum head, tests in a vacuum apparatus indicated that the spillway nappe will not spring free fram the ogee crest nor will cavitation occur on the crest. Capacity of the crest at the maximum head was slightly greater than that computed. A flip bucket with a radius of 50 feet, terminated at a slope. of 20 degrees abore the horizontal, was deemed adequate for protection of the toe of the dam against harmful erosion. Initial tests indicated the necessity for rerision of the outlets of the conduits in both tiers. Undesirable flow conditions in the flip bucket and exit area, produced by flow from the upper tier of conduits, were corrected by turning the outlet portions of the conduits downward on a parabolic curve which terminated tangent to the spillway face. Negative pressures in the cavitation range were eliminated in the outlet portals of the lower-tier conduits by recessing the face of the spillway around the tetrahedral floor deflectors used to disperse the jets emerging from the conduits.

(h) "Spillway and Conduits for Pine Flat Dem, Kings River, Calif ornia", Waterways Experiment station Technical Memorandum No. 2-375, Dec. 1953. (Ávailable on loan).

\section{(993) CAVITRTION PESEARCH.}

(b) Office of the Chief of Engineers Department of the Army, Washington, D. C,

(d) Experimental; applied research.

(e) Cavitation characteristics of such elements as baffle piers, steps in stilling basins, gate slots, and offset joints are being studied on models installed in a vacuum tank and in a variable pressure water tunnel. Models tested to date have been generally of four types: (1) vertical offsets, into and away from flow; (2) V-notch construction joints; (3) gate slots; and (4) baffle piers. A review of existing literature is under way to evaluate the many $v$ arlables that affect cavitation results. An investigation toward developing a material that would, pit under model cavitation, yet would not erode under tunnel velocities, was initiated. Preliminary experiments were devoted to a lean mixture consisting of sand, cement, and water. If a suitable material $c$ an be developed, it may be possible to determine comparatively the vulnerabilities of $v$ arious boundaries to cavitation damage.

(g) Results of tests indicate that the point of incipient cavitation varies with the scale of the model when caritation results from vortex- or eddy-type flow. When cavitation exists at a zone of separation, the variation in the point of incipient cavitation as a function of model scale is reduced.

(h) "Cavitation of V-Notch Construction Joints for Concrete Spillways", Niscellaneous Paper No. 2-76, Feb. 1954 .

\section{(994) EFFECTS OF MOLEL DISTORTION.}

(b) Office of the Chief of Engineers, Department of the Army, Washington, D. C.

(d) Experimental; applied research. 
(e) A general study is being made to determine the effects of model scale distortion on velocity distribution and other hydraulic conditions. A series of tests has been completed in a triangular flume having an adjustable central angle and adjustable slope. Additional studies are being made in a rectangular flume having a 90-degree bend.

(g) The initial results are being analyzed for incorporation in a report.

(998) STUDY OF WAVE FORCE ON BRE AKWATERS.

(b) Office of the Chief of Engineers, Department of the Army, Washington, D. C.

(d) Experimental; applied research.

(e) A general investigation of wave phenomena and resulting forces is being conducted in a wave tank to develop formulas, supported by experimental data, from which wave pressures on impervious surfaces, vertical and inclined, can be determined.

(g) Development of pressure measuring and recording apparatus and a wave-tank assembly is in progress.

(999) STABILITY OF RUBBLE-MOUND BREAKWATERS.

(b) Office of the Chief of Engineers, Department of the Army, Washington, D. C.

(d) Experimental; applied research.

(e) Rubble-mound structures are studied in a wave tank to determine size of cap rock and slope of mound necessary to withstand action of waves and to develop formulas, supported by experimental data, from which the action of waves on rubble structures can be determined. Test data will be presented in dimensionless form, therefore no model scale, as such, is being utilized.

(g) The Iribarren formula for design of rubble breakwaters is being used as a basis for correlating the results of these tests. Coefficients ( $\left.K^{\prime}\right)$ have been determined for use with Iribarren formula for rubble breakwaters with no overtopping for seaside slopes from $I$ on $1-1 / 4$ to $I$ on 5 and $d / L$ ratios from 0.10 to 0.50 . It was found that $K^{\prime} v a r i e d$ considerably with slope $(\propto)$ but very little with the $d / L$ ratio. Average values of $K^{\prime}$ for different slopes are as follows:

$\begin{array}{lc}\text { Side Slope } & \frac{K^{\prime}}{0.003} \\ 1 \text { on } 1-1 / 4 & 0.008 \\ 1 \text { on } 1-1 / 2 & 0.017 \\ 1 \text { on } 2 & 0.028 \\ 1 \text { on } 2-1 / 2 & 0.036 \\ 1 \text { on } 3 & 0.033 \\ 1 \text { on } 4 & 0.032 \\ 1 \text { on } 5 & \end{array}$

A few tests have been conducted in which tetrapods vere used instead of rubble. Results of these tests indicate that tetrapods are considerably more efficient on a weight basis than rubble.

(1000) ROUGHNESS STANDARDS FOR HYDRAULIC MODELS.

(b) Office of the Chief of Engineers, Department of the Army, Washington, D. C.

(d) Experimental; applied research.

(e) A general study is being conducted to evaluate resistance of definite types of roughness in terms of Manning's "n" and other parameters, so that much of the trial-and-error process of adjusting the surface roughness of river models can be eliminated. Tests have been performed in three rectangular flumes and a triangular flume.

(1001) SCALE EFFECTS ON SPILLWAY DISCHARCE COEFFICIENTS.

(b) Office of the Chief of Engineers, Department of the Army, Washington, D. C.

(d) Experimental; applied research.

(e) Tests were conducted on ojee and sharp-crested weirs to permit comparison of spillway discharge coefficients obtained from models of different scales. Tests to determine effect of variation of viscosity from a high of 220 centipoises to about 3 centipoises also were completed. 
(f) Discontinued.

(g) Tests to determine effect of surface tension on discharge coefficients of spillways revealed no appreciable effect in small-scale spillway models. Analysis of viscosity data indicated that viscous forces did modify discharge coefficients, although no relationship was found between discharge coefficients and viscosity that was valid for the entire viscosity range investigated.

(h) A combined report of tests results to determine the effect of model scale on discharge coefficients of an ogee weir, with particular emphasis on the effect of surface tension and viscosity, is in preparation.

\section{(1002) SCALE EFFECTS IN HARBOR MOLELS.}

(b) Office of the Chief of Engineers, Department of the Army, Washington, D. C.

(d) Experimental; applied research.

(e) Tests will be conducted to determine effects of various model scales and distortion on wave characteristics in a harbor. The effects on test results of various model-testing techniques will also be investigated.

(f) Intermittently active as personnel and testing equipment are available.

(1004) INSTRUMENTATION.

(b) Office of the Ghief of Engineers, Department of the Army, Washington, D. C.

(d) Experimental; development.

(e) Various types of instruments for use in hydraulic models are being developed to make such measurements as those of wave heights, dynamic fluid pressures, and gate vibration and downpull. Development of an improved tidal reproducing apparatus is in progress.

(1207) MODEL SIUDY OF PENSTOCK INTAKE AND SLUICE COASTER GATES.

(b) Office of the Chief of Engineers, Department of the Army, Washington, D. C.

(d) Experimental; applied research.

(e) A general study of relative merits of various penstock intake and sluice coaster gate lip shapes, seals, and recesses is being conducted. The investigation includes determination of downpuli effects of changes in gate-lip shape, length and shape of seals, size and shape of the recess in the face of the dam, and need for an air vent in the entrance. The 1:20 model of the sluice coaster gate is being tested in combination with a typical sluice which includes a slide gate, standard entrance curves conforming to the elliptical equation $\left(\mathrm{x}^{2} / \mathrm{D}^{2}\right)+\left(\mathrm{y}^{2} /(\mathrm{D} / 3)^{2}\right)=1$, and a removable constriction at downstrean end of sluice.

(g) Tests of the sluice coaster gate with various slide gate openings and sluice exit conditions revealed greatest dowmpull forces at coaster gate openings of 2 to 4 feet. Downpull forces tended to increase as the operating speed of the coaster gate was increased. The slide gate and air vent were then moved upstream 15 feet and tested to determine the effect, if any, of location on the over-all performance of the coaster gate. Moving the slide gate 15 feet closer to the intake was found to have little or no effect on the over-all performance of the, sluice gate.

(1210) MOLEL STUDY OF GRAYS HARBOR, WASHINGTON.

(b) The District Engineer, Seattle District, Corps of Engineers, Seattle, Washington.

(d) Experimental; for design.

(e) The fixed-bed model, scales $1: 800$ horizontally and 1:80 vertically, reproduced the Pacific Ocean area adjacent to the harbor entrance and the tidal portion of the harbor and Chehalis River. This model was used to develop a comprehensive plan to protect the existing south jetty fram the undermining effects of tidal currents, and to protect Point Chehalis from erosion by current and wave action. Upon completion of this part of the investigation a portion of the model was converted to a movable-bed type to determine scour and shoal tendencies of the selected plan. Plans for reduction of shoaling in the 30-foot-deep navigation channel were also studied.

(f) Testing completed.

(g) A satisfactory plan for protection of Point Chehalis from further erosion by wave and current action was developed.

(h) Final report in preparation. 
(1211) MODEL STUDIES OF HOOSIC RIVER, ADAMS AND NORTH ADAMS, MASSACHUSETTS.

(b) The District Engineer, New York District, Corps of Engineers, New York, New York.

(d) Experimental; for design.

(e) Two models were used to verify the hydraulic design for improvement of certain sections of the North and South Branches of Hoosic River in North Adams, Massachusetts, and of the main channel in sdams, Massachusetts, and to determine whether changes should be made for safety, increased efficiency, or economy. The flow in the major portion of these channels will be below critical depth. In Phase 1 of the study a 1:30 model reproduced the lower sections of the North and South Branches and about 1,300 feet of the main stream below the confluence of the North and South Branches. In Phase 2 North Branch was extended to include the control weir at the upstream limit of the improvement works for North Adams. A 1:20 model reproduced a section of the main channel beginning in Adams approximately 8 miles above that reproduced in the 1:30 model. About 1,200 feet of Tophet Brook, which joins the Hoosic River, was also reproduced.

(f) Tests on Phase 1 of the 1:20 model of the main channel in Adams, Massachusetts, and of Phase 1 and Phase 2 on the 1:30 model of the North and South Branches of Hoosic River in North Adams, Massachusetts, have been completed. Tests on the initial plan of Phase 2 on the 1:20 model also have been completed. Additional tests are contemplated for Phase 2 of the Adams model.

(g) The stilling basin as designed for the North Adams section was found unsatisfactory and a basin was developed that produced the desired flow conditions. Design of the curves and superelevation for the bends in Phase 2 of the North Adams model were demonstrated to be satisfactory. The design and location of the stilling basin in the main channel at Adams were verified. Flow conditions at the junction of Tophet Brook and the culvert flume feeding into the brook were greatly improved and the turbulence existing in the Hoosic River below the mouth of Tophet Brook was eliminated. The results of tests completed on the Phase 2 Adams model indicate that one drop structure can be eliminated and that channel revisions will be required above the weir at station 113 and at the confluence of the Hoosic River and Fiske Brook.

(1212) MOLEL STUDIES OF OUTLET WORKS, OAHE DAM, MISSOURI RIVER, SOUTH DAKOTA.

(b) The District Engineer, Omaha District, Corps of Engineers, Omaha, Nebraska.

(d) Experimental; for design.

(e) Two models are being used for complete investigation of the outlet works proposed for 0ahe Dam. A 1:60 model, reproducing the downstream portion of six 18.5-foot-diameter outlet tunnels, the stilling basin, and 2,300 feet of the discharge and pilot channels, is being used to investigate the performance of the outlet works and to effect revisions demonstrated to be desirable. A 1:25 model of the upstream portion of one of the tunnels, the control structure located in the center of the embankment, and a short length of the tunnel downstream is being used to: (1) check piezometric pressures at various points in the intake structure and transition, particularly pressure variations in the bulkhead slot area; (2) determine the effect of curvature on flow conditions in the upstream tunnel and critical areas downstream therefrom; (3) check piezonetric pressures at various points in the gate chamber of the control shaft and the upstream and downstream transitions, with particular attention to pressures near the gate slots; (4) study the forces acting on the service gate and effects of such forces on gate operation; and (5) measure air demand characteristics.

(g) A single stage stilling basin was developed on the 1:60 model which performed satisfactorily. However, foundation problems encountered in the field made it desirable to consider use of a double stage stilling base located at a higher elevation. The model tests indicated the length of the primary basin and the secondary basin could be reduced from the lengths proposed. The height and length of the dividing piers separating each conduit also could be reduced.

(1467) ANALTSTS OF HYDRAULIC EXPERTMENTAL DATA (MODEL AND PROTOTYPE) AND DEVELOPMENT OF DESIGN CRITERIA.

(b) Office of the Chief of Engineers, Department of the Army, Washington, D. C. (d) Analytical (model and prototype) and field investigations; for design. 
(e) A general study to develop, analyze, and disseminate to Corps of Engineers establishments, hydraulic design criteria to insure adequate capacity, econony of construction, and safe and satisfactory operation. Criteria are developed from model and prototype tests relating to the design of spillways, outlet works, gates and valves, channels and navigation structures. Program also includes prototype tests in cooperation with other Corps of Engineers establishemnts.

(g) "Hydraulic design criteria" charts have been prepared on: spillway shapes and discharge coefficients, pier coefficients and pressures on the crest face, and design aids of stilling basins and chute spillways; concrete conduit friction factors and design aids for concuit flow; discharge coefficients for vertical gates on a level floor and for Howell-Bunger valves. Design aids have been prepared for trapezoidal channels. Prototype tests have been conducted on sluice pressures at Denison Dam, Pine Flat Dam, and at other field installations. Stilling basin pressures were measured at Bull Shoals Dam. Vibration and other types of tests were made on gates at Ft. Randall Dam and Ft. Peck Dam.

(h) "Hydraulic Design Criteria" Issues Nos. 1, 2, and 3. (Avallable for purchase in limited quantities.)

"Correlation of Model and Prototype Data, Marked Tree Siphon", Waterways Experiment Station Viscellaneous Paper No. 2-1, Revised March 1952. (Available on loan.) "Pressure and Air Demand Tests in Flood-Control Conduit, Denison Dam", Waterways Experiment Station Miscellaneous Paper No. 2-31, April 1953. (Available on loan). vibration, Pressure, and Air Demand Tests in Flood-Control Slutce, Pine Flat Damm, Waterways Experiment Station Kiscellanoous Paper No. 2-75, Feb. 1954. (Available on loan.)

"pressure Cell Tests, Bull Shoals Dam Stilling Basin", Waterways Experiment Station Yiscellaneous Paper No. 2-77, Feb. 1954. (Available on loan.)

(1468) VALIIVIA RIVER MODEL STUDY, CORRAL BAY, GHILE.

(b) Govermment of Chile, South America.

(d) Experimental; for design.

(e) Whether training works or other remedial measures will make possible the maintenance of a channel at least 6 meters deep over the entrance bar from the port of corral to the Valdivia River Mouth, and the effect such structures might have on present depths and widths of Corral Harbor were studied in a mor able-bed model, with scale ratios of 1:400 horizontally and 1:80 vertically. Corral Bay upstream from Point San Carlos and the lower 3 miles of both the Valdivia and Tornagaleones Rivers were reproduced in the model.

(f) Testing completed.

(g) A plan was developed that would provide a satisfactory solution of all existing navigation problems in Corral Bay. The plan would not increase the width and depth of the deepwater portion of the port of Corral, but would prevent subsequent loss of any additional width or depth that might be obtained by dredging. The plan would provide a channel of adequate width and depth for navigation from deep water in Corral Bay to the existing Valdivia River entrance, and would have no detrimental effects on the Valdivia River channel upstream from the existing entrance. The plan should also afford adequate protection to the port of Corral from storm waves. from the north. Of interest was the fact that construction of this plan in the prototype would require less revision of existing structures and installation of new structures than any other plan tested.

(h) uplans for Improvement of Navigation Conditions in Corral Bay and the Valdivia River, Chile", Waterways Experiment station Technical Memorandum No. 2-382, April 1954. (Available on loan.)

(1469) MODEL STUDY OF FLOOD-CONTROL PROJECT, ALLENTOWN, PENNSYLVANIA.

(b) The District Engineer, Philadelphia District, Corps of Engineers, Philadelphia, Pa.

(d) Experimental; for design.

(e) The proposed local improvement plan for Allentown was studied to discover and correct any undesirable features of the plan. The fixed-bed model, scales of $1: 150$ horizontally and 1:50 vertically, reproduced 3 miles of Lehigh River and 1 mile each of Little Lehigh Creek and Jordan Creek.

(f) Testing completed. 
(g) Test results indicated that Bear Creek Roservoir upstream of Allentown would reduce the peak of a flood similar to that of 1942 (worst in 50 years) by 2.6 feet in the area adjacent to the Little Lehigh and Jordan Creeks near their junction; an additional reduction of 4.6 feet would result from 100 al improvements embodied in the original plan (Survey Report Plan). Tests of modifications of this plan, developed during the model study, indicated that flood stages oould be lowered another 0.7 foot by improving the aligment of the $\operatorname{tr}$ aining dike and extending the dike 60 feet. The model study also indicated that: the intensity of the current attack on the closure dike could be materially reduced by realigning the lower end of the dike; the amount of dredging opposite the training dike could be reduced about 55,000 cubic $y$ ards without affecting flood stages in the problem area; and a considerable mount of sediment could deposit in the dredged channel before flood stages in the problem area would be affected.

(h) "Tlood-Control Project for Allentown, Penngylvania; Hydraulic Model Investigation", Waterways Experiment Station Technic al Memor anchum No. 2-376, Dec. 1953. (Available on loan.)

(1470) MOLEL SIUDY OF NIAGARA RIVER AND FALLS.

(b) The District Engineer, Buffalo District, Corps of Engineers, Buffalo, New York.

(f) Testing completed.

(h) Final report in preparation.

(1471) WOLEL STUDY OF SPILLWAY, SAVACF RTVER DAK, MARYLAKD.

(b) The District Engineer, Washington District, Corps of Engineers, Washington, D. C.

(d) Experimental; for design.

(e) Model tests of the side-channel spillway wore conducted on a 1:36 model to determine the discharge rating curve and other hydralic characteristics of the spillway at heads greater than that for which the spillway was originally designed because the spillway design flood for this dam has been increased.

(f) Testing completed.

(g) Tests revealed that maximum efficiency of the spillway was attained at a head of 14.15 feet, at which head the coefficient of discharge, based on the usual weir formula, was 3.80 and a discharge of 62,000 cfs was passed. The capacity of the spillway with the pool at the top of the dam (head 29 feet) was found to be 109,200 cfs but at this head the coefficient of discharge for the weir was only 2.20 as the control had shifted to the chute. The maximum probable flood of 100,000 cfs was passed at a pool elevation of 1,494; at this discharge flow or ertopped the right spillway abutment wall. However, the area in the vicinity of the wall is paved and no damage should result. At discharges of $75,000 \mathrm{cfs}$ and greater, large standing waves formed in the upper portion of the chute.

(h) "Spiliway for Savage River Dam, Savage River, Maryland", Waterways Experiment Station Technical Memorandum No. 2-378, Jan. 1954. (Available on loan.)

(1472) MOLEL STUDY OF WAVE ACTION, INDLANA HABBOR, INDIANA.

(b) Youngstown Sheet and Tube Company, and Inland steel Company, Indi ana Harbor Works, East Chicago, Indiana.

(d) Experimental; for design.

(e) A I:I50 fixed-bed model of Indiana Harbor and sufficient area of Lake Hichigan to permit reproduction of waves from north-northwest to southeast is being used. Effects of proposed harbor structures on wave action conditions in the entrance channel and in the harbor are being studied.

(1474) OPERATING FORCES OF MITER-TYPE LOGK GATES.

(b) Office of the Chief of Engineers, Department of the Ariuy, Washington, D. C.

(d) Experimental; applied research. 
(e) A general study to collect basic data on operating forces of miter-type lock gates and to determine the effect of various elements upon these forces is being conducted in a 1:20 model. A lock chamber 110 feet wide is reproduced with provisions for varying the length up to 600 feet on each side of the gate. Forces required for operation of miter gates will be measured for variations of the following elements: gate leaves, speeds and accelerations of operation, submerged depths, recess shapes, bottom clearances, chamber lengths, and nonsynchronous operation of gate leaves. Variations in the type linkage driving the gate also will be investigated.

(g) Tests indicate that with the Ohio Biver type linkage the peak torque occurs as the gates enter or leave the mitered position. Nonsynchronous operation of the gates resulted in a slight decrease in torque on the leading leaf and a lesser effect on the lagging leaf, as compared with synchronous operation. An increase in the speed of operation or depth of submergence increases the peak torque. Bottom clearances had little effect on torque values. With the modified Ohio River type linkage the peak torque occurs ne ar the mitered position as was noted with the standard Ohio River linkage. The peak torque of the modified type linkage is somewhat less than that of the Ohio type linkage but the average torque is higher and better distributed. Addition of skin plates on the downstream face of the lock gates with the modified type linkage resulted in a slight decrease in torque. Tests with the Panama type linkage indicated that the high initial torque at the recess position was greatly reduced and distributed more evenly throughout the operating cycle.

\section{(IL75) SIPHON ACTION AT PUMPTNG PLANTS.}

(b) Office of the Chief of Engineers, Department of the Army, Washington, D. C.

(d) Experimental; applied research.

(e) This study is being conducted to aid in developing design criteria for pumping plants which depend upon dexelopment of siphonic action on the discharge side of the pumps in order to yield the required discharge. The investigation is to determine the minimum initial priming velocity and length of time required to expel air from (prime) the siphon. Variables to be investigated during the tests are: rates of flow, water levels on the discharge side of the pumps, slope and length of the riverward leg, and venting conditions at the crown. A full size model of a 6-inch plastic discharge line with a lift of 39 feet was assembled for the investigation.

(g) Model test data were correlated with prototype data collected by the Ohio River Division and a generalized equation developed which defines the time required to prime the siphon under a limited range of conditions. It is expected that additional model tests will permit refinement of this equation to cover a wide $r$ ange of conditions.

(1735) KODEL SIUDY OF WAVE RUN-UP ON SHORE STRUCTURES.

(b) The Resident Member, Beach Erosion Board, Corps of Engineers, Washington, D. C.

(d) Experimental; for design.

(e) Tests are being concucted in a wave flume, using a scale of $1: 17$, to investigate the relationship between water level, wave height, wave period, and beach slope and wave run-up on selected types of shore structures used to prevent erosion caused by wave action.

(g) Tests have shown that the volume of overtopping water and height of wave run-up vary with both wave height and length. The variation is discontinuous. The volume of overtopping water and height of wave run-up vary in cycles from minimum to maximum and increase as wave height and wave length increase.

\section{(1736) MODEL STUDY OF EFFECTS OF INLETS ON ADJACENT BEACHES.}

(b) The Resident Member, Beach Erosion Board, Corps of Engineers, Washington, D. C.

(d) Experimental; applied research.

(e) To determine the effects of natural or artificial inlets on adjacent beaches for various conditions of waves, tides, rate of littoral drift, and other factors, tests are being made in a basin simulating an ocean and a lagoon separated by a barrier beach of sand that $c$ an be breached to reproduce the desired inlet. 
(1737) MOLEL SIUDY OF CHAIN OF ROCKS PROJECT, MISSISSIPPI FIVER.

(b) The District Engineer, St. Louis District, Corps of Engineers, St. Louis, Missouri.

(d) Experimental; for design.

(e) The Chain of Rocks reach, a 7-mile-long series of rock ledges, is the principal cause of navigational difficulties in the 15 miles between the mouth of the Missouri River and the city of St. Louis. An improvement plan, involving a long canal from the vicinity of the mouth of the Missouri with a navigation lock at its downstream end, was studied in a combination morable-bed, fixed-bed type model with scales of $1: 400$ horizontally and $1: 100$ vertically. Means were investigated of reducing the silting in the lower approach channel to the canal and of removing and preventing the rebuilding of a bar across the downstream canal entrance.

(f) Testing completed.

(g) Fixed-bed tests were concerned primarily with elimination of shoaling of fine material in the downstream end of the canal, and afforded data from which the following principal conclusions were drawn: (a) considerable deposition will occur in the downstream end of the Chain of Rocks Canal if the adjacent overbank on the lower end of Cabaret Island is not raised; (b) none of the three proposed spoil area aligmments would eliminate entirely the amount of silting in the lower portion of the canal, but they would reduce it considerably; (c) installation of a system of dikes along the Missouri shore upstream from the canal entrance would tend to increase the amount of sedimentation in the lower canal entrance; and (d) operation of the vertical-lift gates of the locks near the downstream canal entrance during the 10- and 20-foot stages would not flush any appreciable amount of sediment from the lower canal entrance. Mov able-bed tests were used to determine the effectiveness of various plans in eliminating or reducing shoaling of relatively coarse material at the dowmstream entrance to the canal. The plans investigated were of two general types: Cne assumed that the dike system would be so designed that the velocity of flow in the problem area would be increased sufficiently to prevent deposition of sediment in the area; the other assumed that the problem area would be protected by a dike system of sufficient height and so located as to prevent the troublesome material from entering that area. Of these two types of plans, the latter was found to be the more effective in eliminating shoaling in the downstream canal entrance.

(h) Final report in preparation.

(1738) MODEL STUDY OF GREENUP LOCKS AND DAM, OHIO RIVER.

(b) The District Engineer, Huntington District, Corps of Engineers, Huntington, West Virginia.

(f) Testing completed.

(h) Final report in preparation.

(1739) MODEL STUDIES OF MARKLAND LOCKS AND DAM, OHIO RIVER.

(b) The District Engineer, Louisville District, Corps of Engineers, Louisville, Kentucky.

(f) Testing completed.

(h) Final report in preparation.

(1740) MODEL SIUDY OF OUTLET STILLING BASIN, TUTTLE CREEK DAM, BIG BLUE RIVER, KANSAS.

(b) The District Engineer, Kans as City District, Corps of Engineers, Kansas City, Missouri.

(f) Testing completed.

(h) Final report in preparation.

(17LI) MODEL SIUDY OF SPILLWAY, GAVTNS POINT DAM, MISSOURI RIVER, SOOTH DAKOTA.

(b) The District Engineer, Omaha District, Corps of Engineers, Omaha, Nebraska.

(f) Testing completed.

(h) Final report in preparation. 
(b) The District Engineer, Pittsburgh District, Corps of Engineers, Pittsburgh, Pennsylvania. (f) Testing completed.

(h) "Spillway for New Cumberland Dam, Ohio River, West Virginia", Waterways Experiment Station Technical Memorancum No. 2-386, July 1954. (Available on loan.)

(1979) KODEL STUDY OF STILLING BASIN, BULL SHONLS DAM, WHTTE RTVER, ARKANSAS.

(b) The District Engineer, Little Rock District, Corps of Engineers, Little Rock, Arkansas.

(d) Experimental; for design.

(e) The spillway was constructed with a stepped-type stilling basin designed to spread the jets issuing from the conduits. After a period of operation the steps were damaged by cavitation. A $1: 12$ model was used to develop a satisfactory method of repairing the basin for conduit discharges; a 1:50 section model was used to check the performance of the modified basin with spilliway discharges.

(f) Testing completed.

(g) Negative pressures and resulting cavitation tendencies in the stilling basin have been eliminated by filling in the steps of the original basin to form a long sloping floor. Tests have demonstrated that spreading of the conduit jets can be accomplished by increasing the end sill height from 4 feet to 10 feet and installing a single row of 8foot-high baffle blocks about 50 feet upstream fron the ond sill.

(h) Final report in preparation.

(1980) MOLEL STUDIES OF TABLE ROCK DAM, WHITE RIVER, MI SSOURI.

(b) The District Engineer, Little Rock District, Corps of Engineers, Little Rock, Arkansas.

(d) Experimental; for design.

(e) A 1:50 section model of the stilling basin was used to determine the adequacy of the basin for spillway flow, and a $1: 12$ model of the stilling basin was used for tests of the basin under conduit flow. Current patterns and velocities around the training walls and in the powerhouse area will be studied in a $1: 100$ general model.

(g) The action of the stilling basin was improved by installing higher baffles. The spacing between baffles was increased and the second row of baffles and the end sill were moved 11 feet upstream without decreasing the efficiency of the basin.

(1981) MODEL STUDIES OT SPILLWAY FLIP BUCKET AND CONDUIT OUTLET PORTAL, HARTWELI DAM, SAVANNAH RIVER, CEORGIA.

(b) The District Engineer, Savannah District, Corps of Engineers, Savannah, Georgia.

(d) Experimental; for design.

(e) A 1:45-section model was used to develop a feasible and economical design for the spillway flip bucket and the training wall between the flip bucket and powerhouse. A 1:20 model of the conduit outlet portal was investigated to assure satisfactory spreading of the jet, pressures, and discharge.

(f) Testing completed.

(g) Tests revealed that although each of four alternate sluice outlet portals tested was adequate as far as safety was, concerned, a portal having a horizontal roof, flared side walls, and upward curved floor appeared to provide the most satisfactory flow conditions. A 30-foot-radius spillway flip bucket with 30-degree bucket lip was the most effective bucket tested. A 5-degree deflector wall constructed on the right wall of the spillway will divert high-velocity flow away from the powerhouse when the gate bay adjacent to the powerhouse is in operation. Tests revealed that the training wall extending 80 feet below the powerhouse into the tailrace can be shortened appreciably with little effect on flow conditions at the draft tube outlets.

(h) "Sluice outlet portal and spillway flip bucket, Hartwell Dam, Savannah River, Georgia", Waterways Experiment Station Technical Memorandum No. 2-393, Aug. 1954. (Available on loan.) 
(1982) MODEL STUDIES OF CONTROL STRUCTURE AT MOUTH OF OLD RIVER, LOUI SIANA.

(b) The President, Mississippi River Commission, Corps of Engineers, Vicksburg, Mississippi.

(d) Experimental; for design.

(e) The Old River control structure will control flow into Old River, which links the Mississippi and Atchafalaya Rivers, so that Mississippi River Flows will be divided between the lower reaches of the Mississippi and Atchaf alaya. Tests are being made on 1:36 models to investigate the over-all performance of the proposed structure with special attention to discharge coefficients, flow conditions at the abutments, and the effectiveness of the stilling basin.

(g) Tests to date indicate that improved flow conditions can be obtained by realigrment of the upstream and downstream training walls. Also it was demonstrated that the horizontal stilling basin could be raised from elevation $-12.0 \mathrm{msl}$ to elevation $-5.0 \mathrm{msl}$. Discharge curves, obtained in preliminary calibration of the structure, agree very closely with the computed curves.

(1983) MOLEL STUDY OF SEDIMENT DIVERSION THROUGH PROPOSED OLD RIVER, LOUISIANA, CONTROL STRUCTURES.

(b) The President, Mississippi River Conmission, Corps of Engineers, Vicksburg, Mississippi.

(d) Experimental; for design.

(e) A 10-mile reach of the Mississippi River upstream of the mouth of old River is reproduced in a fixed-bed model to scale ratios of $1: 400$ horizontally and 1:100 vertically. Tests are being made to determine a suitable location and design for control structures (consisting of an overbank and a low-sill structure) that will permit the same percentage of sediment to enter the Atchaf alaya River as now enters that stream through Old River, should Old River be closed with a lock and dam. Additionel tests have been undertaken to determine effects of changes in design and location of structures, changes in shape and alignment of approach channel, and effect of diversion on Mississippi River channel.

(g) Tests were made of currents and sediment movement with the structures in operation without and with permeable dikes, and with recession of the bankline in the bend upstream. Test results indicated the general location selected for the structures to be satisfactory insofar as sediment diversion is concerned, provided that the relative positions of the overbank and low-sill structures are reversed so as to place the overbank structure upstream of the low-sill structure. The model study also indicated that velocities on the structures side of the Mississippi River channel will increase and velocities on the opposite side will decrease, which will result in some adjustment in the Mississippi River channel in the vicinity. The extent of changes in the Mississippi River channel resulting from installation of the structures and the effects of such chenges on the water-sediment ratio of the diverted flow could not be determined from the fixed-bed model, therefore the fixed-bed study is to be followed by a movable-bed study.

(h) Initial results were presented in nold River Control Structure, Sediment Diversion; Hydraulic Model Investigation", Waterways Experiment Station Technical Memorandum No. 2-388, June 1954. (Available on loan.)

(1984) MOIEL STUDY OF CONTROL GATE FOR TUNNEL NO. L, FORT PECK DAM, MISSOURI RIVER, MONThNA.

(b) The District Engineer, Fort Peck District, Fort Peck, Montana, and the District Engineer, Garrison District, Corps of Engineers, Bismarck, South Dakota.

(d) Experimental; for design.

(e) Tests to study methods of eliminating cavitation on the port liner end vibration of the cylinder gate in the main control shaft of tunnel. No. 4 will be conducted on $a 1: 25$ model. Discharge capacities, pressures, air demand, and gate vibration will be determined for the existing cylinder gate installation.

(g) The use of an offset lip in the inner tower below the discharge ports afforded sufficient back pressure in the discharge ports to eliminate cavitation tendencies in these areas. Air vents are installed below the lip to satisfy air demand in this area. Installation of guide vanes at the entrance to the discharge ports reduced turbulent conditions in the outer water passage and cylinder gate vibrations. 
(1985) TEVELOPMENT OF TURBULENCE METER.

(b) Office of the Chief of Engineers, Department of the Army, Washington, D. C.

(d) Experimental; development.

(e) The investigation is being conducted to develop instruments that will: (a) indicate the speed and direction of fluid currents at great depths and moder ate velocities; (b) indicate the speed and direction of currents at shallow depths and high velocities; (c) receive signals from (a) or (b) and separate them into (1) instantaneous velocity and direction, (2) mean velocity and direction, and (3) the root-mean-square deviations from the mean.

(f) Suspended pending a review of the status of the developmental work on each phase.

(1986) SALT WATER WEDGE PHENOMENA.

(b) Conmittee on Tidal Hydraulics, Corps of Engineers.

(c) Mr. C. F. Wicker, Chairman, Committee on Tidal Hydraulics, Philadelphia District, Corps of Engineers, Philadelphia, Pennsylvania.

(d) Experimental; applied research.

(e) To determine the effects of salinity and related phenomena on the vertical distribution of currents and shoaling characteristics in estuaries, tests are being made in a lucite flume 327 feet long, 1.5 feet deep, and 0.75 foot wide. One end of the flume is connected to a 25-foot-square tidal basin in which any desired tide may be produced and in which the salinity may be controlled. The opposite end is connected to a fresh-water source.

(g) Performance tests to determine limitations of apparatus over range of desired testing conditions have been completed.

(h) Preparation of an interim report on results of performance tests is in progress.

(1987) MOLEL REPRODUCTION OF PROTOTYPE EROSTON BELOW STILLING BASINS.

(b) Office of the Chief of Engineers, Department of the Army, Washington, D. C.

(d) Experimental; applied research.

(e) Initially, the investigation will be conducted on a model of a selected dam with provisions for studying sands of different sizes in the channel below the stilling basin. Later, models with two or more different linear scales will be constructed to verify findings using suitable bed materials.

(f) Preliminary design and layout in preparation.

(1988) WATER TEMPERATURE EFFECTS ON BED FORMS AND ROUGHNESS.

(b) Office of the Chief of Engineers, Department of the Army, Washington, D. C.

(d) Experimental; applied research.

(e) Existing laboratory flumes, in which water temperatures can be varied to simulate normally experienced sumner and winter temperatures, will be used for investigating the effects of water temperature on bed forms and bed roughness of various types of bed materials.

(f) Preliminary design and layout in preparation.

(2200) MODEL STUDY OF FLOOD CONTROL, ANACOSTIA RIVER, MARYLAND AND DISTRICT OF COLUMBIA.

(b) The District Engineer, Washingten District, Corps of Engineers, Washington, D. C.

(d) Experimental; for design.

(e) A fixed-bed model, scale 1:30, reproducing 2,100 feet of the Northwest Branch channel of the Anacostia River is being used: (a) to verify conclusions, based upon theoretical computations, that the paved channel as designed will induce the supercritical velocities necessary to lower water-surface elevations to provide clearance under existing and proposed bridges, and that the hydaulic jump will be formed and retained on the paved section for the expected range of tailwater elevations; and (b) to test modifications of the original design.

(g) Results to date indicate that with the channel as originally designed the hydraulic jump would not be retained on the paved channel for the entire range of tailwater elevations. 
(2201) MODEL STUDY OF LAKE REGULATION, LAKE ERIE.

(b) The District Engineer, Buffalo District, Corps of Engineers, Buffalo, New York.

(d) Experimental; applied research.

(e) The existing Niagara River and Falls Model (1470) was used to determine the nature and extent of the excavation required to increase the outlet capacity of the Niagara River to pernit regulation of levels of Lake Erie.

(f) Testing completed.

(g) Excavated channels of sufficient capacity to meet the design criteria were developed for a deep, narrow-type channel and for a shallow, wide-type channel.

(h) Final report in preparation.

(2202) MODEL STUDY OF WAVE ACTION, TACONITE HARBOR, TWO ISLANDS (LAKE SUPERIOR), MINNESOTA.

(b) Erie Mining Company, Cleveland, Ohio.

(d) Experimental; for design.

(e) A 1:150, fixed-bed model of the Taconite Harbor area was used to determine the optimum breakwater plan for the harbor.

(f) Testing completed.

(g) Preparation of report in progress.

(2203) MOIEL STUDY OF WAVE RUN-UP AND OVERTOPPING, LAKE OKEECHOBEE IEVEE SECTIONS, FLORIDA.

(b) The District Engineer, Jacksonville District, Corps of Engineers, Jacksonville, Florida.

(d) Experimental; applied research and design.

(e) Tests are being conducted in a wave flume using a model scale of 1:30 to determine the optimum levee section for Lake Okeechobee, Florida, with respect to overtopping due to wave and wind setup.

(2204) STILLING BASINS FOR OUTLET WORKS.

(b) Office of the Chief of Engineers, Department of the Army, Washington, D. C.

(d) Experimental; for design.

(e) Scale models are being used for a general study of the hydraulic characteristics of stilling basins below outlet works and will involve study of such items as radii and flare of side walls as affected by the length of the curved portion of the basin immediately downstream from the conduit; shape of conduit exit portal to improve entrance conditions into stilling basin; advantages of the use of diverging side walls as compared to parallel walls. Emphasis will be placed on the development of a satisfactory stilling basin for a simple circular outlet tunnel without any transition inside the tunnel.

(g) Analysis of stilling basin data below a 0.8 -foot-diameter outlet tunnel has been undertaken. In these tests the elevation of the stilling basin was varied from the invert of the conduit to a depth below the invert equal to 1.08 times the conduit diameter. Side walls flared 1 on 4,1 on 5 , and 1 on 6 were investigated for each apron elevation. The effect of parallel side walls inserted in the downstream portion of each stilling basin alternation was also studied.

U. S. DEPARTMENT OF COMMERCE, BUREAU OF PUBLIC ROADS.

(578) SCOUR AT BRIDGE PIERS AND ABUTMENTS.

Cooperative with Iowa Institute of Hydraulic Research. See page 42.

(1095) SCALE MODEL STUDIES OF INLET BOXES.

Cooperative with University of Illinois. See page 39. 
(1096) FULL SCALE GUTTERS TESTS.

Cooperative with University of Illinois. See page 39.

(1101) MOVEMENT OF SEDTMENT IN HICHWAY DRADNACE SISTEMS.

Cooperative with Iowa Institute of Hydraulic Research. See page 43.

(1597) A STUDY OF THE EFFICIENCY OF SAND TRAPS.

Cooperative with Iowa.Institute of Hydraulic Research. See page 45.

(19L5) ESTIMATTNG RAINFALU INTENSTTY FROM TOPOGRAPHIC PARAMETERS.

Cooperative with Stanford University. See page 84 .

(2066) STUDY OF OPEN CHANNEL CONSTRICTIONS IN A SLOPING FLUME.

Cooperative with Color ado A and M College. See page 24.

(2089) STUDIES OF DESIITING STRUCTURES FOR HIGHWAY DRAINAGE SISTEMS.

Cooperative with University of Illinois. See page 40.

(2134) HEAD LOSSES IN STORM DRAIN JUNCTIONS.

Cooperative with the University of Missouri. See page 67.

U. S. DEPARTMENT OF COMMERCE, NATIONAL BUREAU OF STANDARDS, Fluid Mechanics Section.

Inquiries concerning Projects Nos. 159, 160, 1477 to 1480 , incl., 1482, 1742, 1989, 1990 and 2205 , should be addressed to the Chief, Fluid Mechanics Section, National Bureau of Standards, Washington $25, \mathrm{D}$. C.

(159) MODEL LAWS FOR DENSITY CURRENTS.

(b) Waterways Experiment Station, Corps of Engineers, Department of the Army.

(d) Theoretical and experimental; basic and applied research.

(e) To determine model laws for models involving the motion of stratified liquids. The two major problems are (1) the motion of a heavy liquid initially confined in a "lock" when released into a long channel containing a stationary lighter liquid, and (2) the motion of a heavy liquid from a "sea" into a long channel with either still or flowing lighter liquid.

(h) "Laws of Salt-Water Flow in Fresh Water", by G. H. Keulegan, presented before the Annual Meeting of the A.S.C.E., New York City, Oct. 19-21, 1954.

(160) EFFECT OF STORM WINDS ON LAKE LEVELS.

(b) Laboratory project.

(d) Theoretical and experimental; basic research.

(e) To determine frictional forces of wind on lake surfaces and the resulting set-up.

(1477) TURBULENT EXPANSTON OF JETS IN WATER.

(b) Office of $\mathrm{Naval}$ Research, Department of the Navy.

(d) Experimental and theoretical; basic research.

(e) To determine experimentally the nature of turbulent expansion of jets in water with relation to Reynolds number, using jets of hot water, salt water, etc. 


\section{(1478) WIND WAVES.}

(b) Office of Naval Research, Department of the Navy.

(d) Experimental and theoretical; basic research.

(e) Includes mathematical and experimental studies of (1) wind tides (set-up), (2) growth of wind waves, and (3) surface traction of wind on wavy surfaces.

(h) Paper in preparation.

\section{(1479) ENERGY DISSIPATION IN STANDING WAVES.}

(b) Office of Naval Research, Department of the Navy.

(d) Experimental and theoretical; basic research.

(e) To determine significance of viscous boundary layer effects in wave phenomena.

(1480) POSITIVE WAVES IN DRY CHANNELS.

(b) Office of Naval Research, Department of the Navy.

(d) Experimental and theoretical; basic research.

(e) To determine mathematically velocity and form of waves taking friction into account. To analyze the tip of the wave mathematically, and to determine form of wave experimen$t a l l y$ as function of time and roughness.

(h) "Comparison of Theories and Experiments for the Hydraulic Dam-Break Wave", by R. F . Dressler, presented at meeting of Intl. Union of Geodesy and Geophysics, kome, Italy, September 1954.

(1482) INITIAL VELOCITY DISTRIBUTIONS IN SALT WATER WEDGE.

(b) Laboratory project.

(d) Experimental; basic research.

(e) To determine velocities and particle trajectories during initial motion when a gate separating two bodies of liquids of different densities is suddenly opened.

(1742) MECHANISM OF TURBULENCE.

(b) Office of Scientific Research, Air Research and Development Board.

(d) Experimental.

(e) To determine whether reproducible fundamental flow pattern occuring at initiation of turbulence can be demonstrated.

(1989) STABILITY OF THE INTERFACE BETWEEN TWO PARALLEL STREAMS OF IMMISCIBLE FLUID OF DIFFERENT DENSITIES.

(b) Office of Naval Research, Department of Navy.

(d) Theoretical.

(e) To determine the stability criterion of the free laminar boundary layer between two parallel streams of difierent densities.

(h) "Hydrodynamical Stability of Interfacial Oscillations in Two Streams", by C.-lí. Tchen, presented Intl. Cong. for Math., Amsterdam, Aug. 1954.

(1990) INTERNAL PROGRESSIVE WAVES.

(b) Office of Naval Research, Department of the Navy.

(d) Theoretical and experimental.

(e) To determine laws of propagation and dissipation of internal progressive waves.

(2205) WAVE FORCES ON IMMERSED OBJECTS.

(b) Office of Naval Research, Department of the Navy.

(d) Theoretical and experimental.

(e) Forces on submerged cylinders subjected to waves of various characteristics will be determined. 
U. S. DEPARTMENT OF COMMERCE, WEATHER BUREAU .

- Inquiries concerning Projects Nos. 1010 to 1015, incl., 1744, 1745, 1748 to 1751, incl., 1753, 1992, 1993, 1994, and 2206 to 2209, incl., should be addressed to Mr. William E. Hiatt, Chief, Hydrologic Services Division, U. S. Weather Bureau, Washington 25, D. C.

(1010) ELECTRONIC FLOOD ROUTING ANALOGUE.

(b) Laboratory project.

(d) Field investigation; applied research.

(e) A basic circuit for an electronic analogue computer to solve flood wave problems by the Muskingum method has been developed and its application to the solution of local streamflow problems is being studied at the following River Forecast Centers: Cincinnati, Ohio; Knoxville, Tenn.; St. Louis, Mo.; Kansas City, Mo.; Tulsa, Okla.; Portland, Oregon;

Harrisburg, and Pittsburgh, $\mathrm{Pa}$. A circuit for more complex routing, developed at Stanford University, is being added to the analogue at Washington, D. C.

(10I1) SHORT RANGE SNOW-IELT FORECASTTNG.

(b) Laboratory project.

(d) Field investigation; applied research.

(e) To develop relations between streamflow resulting from melting snow and appropriate meteorological parameters using a statistical approach.

(g) A reasonably adequate procedure has been established and is being refined and tested.

(h) "Insolation as an Empirical Function of Daily Sunshine Duration", Russell W. Hamon, Leonard L. Weiss, and Walter T. Wilson, Monthly Weather Review, Vol. 52, No. 6, June 1954.

(1012) AUTOMATIC RADIO REPORTING RAIN GAGE.

(b) Laboratory project.

(d) Field investigation; applied research.

(e) A simple telemetering device has been constructed for use with a standard recording rain gage. Limited field tests indicate satisfactory performance. Other telemetering units are also being tested.

(1013) PRESSURE-ACTUATED RIVER GAGE.

(b) Labor atory project.

(d) Field investigation; development.

(e) To develop a more economical remote, recording gage.

(g) Satisfactorily tested for accur acy in labor atory. Experimental field installation at Willi amsport, Md.

(1014) UTILIZATION OF SOIL MOT STURE DATA IN FORECASTING STREAMFLOW.

(b) Laboratory project.

(d) Field investigation; applied research.

(e) Standard electrical resistance soil moisture and temperature equipment has been installed in selected areas. After sufficient data has been obtained, statistical tests will be made to determine whether such data can be used to improve forecasts of runoff from rainfall.

(1015) MEASUREMENT OF EVAPORATION.

(b) Laboratory project.

(d) Theoretical and field investigation; applied research.

(e) Studies are directed toward the derivations of reliable procedures for estimating evaporation from reservoirs (existing and proposed) and land surfaces, utilizing readily available meteorological data and pan evaporation observations. 
(g) Test of methods and techniques at Lake Hefner, Okla., completed; and similar project being conducted at Lake Mead. Both are cooperative projects involving Bureau of Reclamation, Navy, Geological Survey as well as Weather Bureau. Another such study has been started at Felt Lake, on contract with Stanford University. Evaporation pan comparative studies also being made at Silver Hill, Md.

(h) "Water-Loss Investigations: - Lake Hefner Studies, Basic Data Report", Geol. Survey Prof. Paper 270, 1954 .

"Evaporation from Pans and Lakes", a Weather Bureau Research Paper, is to be published in 1955.

(1744) DEVELOPMENT OF RIVER FORECASTING METHODS.

(b) River Forecast Centers for Ohio River Basin, Cincinnati; susquehanna and Delaware River Basins, Harrisburg, Pa.; Lower Missouri River Basin, Kansas City, Mo.; Tennessee River Basin, Knoxville, Tenn.; Columbia River Basin, Portland, Ore.; Middle and Upper Miss. River Basin, St. Louis, Mo.; and Arkansas River Basin, Tulsa, Okla.

(d) Experimental; applied research.

(e) To develop modern river forecast procedures for all $\mathrm{r}$ anges of flow for $\mathrm{v}$ arious streams of each basin. Procedures include (a) rainfall-runoff relations involving consideration of the physics of soil moisture, vegetative reception, transpiration, evaporation and geological features of the basins; (b) snow melt forecasting relation involving consideration of the physics of snow and heat transfer; (c) unit hydrographs; (d) streamflow routing procedures; based upon adaptations of basic hydraulic principles.

(g) Forecasting procedures have been developed for key points; refinement of these procedures and development for other basins are underway.

(h) "The Influence of the Great Miami River on Ohio River stages at Cincinnatin, Frank E. Caldwell. Presented at Amer. Met. Soc. meeting, Columbus, Ohio, Sept. 1954.

(17L5) WATER SUPPLY FORECASTS FOR WESTERN UNITED STATES.

(b) Work being conducted in field offices for River Forecast Center, Portland, Oreg., Water Supply Forecast Unit, SaIt Lake City, Utah, and River Forecast Center, Kansas City, Mo.

(d) Experimental; applied research.

(e) The purpose of these investigations is the development of precipitation-runoff relations for water supply forecasting utilizing statistical methods to correlate precipitation during the winter with runoff during the melting season.

(g) Water Supply Forecasts are prepared for over 300 points in the Western United States. These forecasts of water year flow are released in Monthly Water Supply Forecast Bulletins January through May. This research program is of a continuing nature designed to improve and extend the present forecasting service.

(h) "Low Winter Flows as Index to Short and Long Term Effects in Water supply Forecasting", E. I. Peck, Western Snow Conference, Salt Lake City, April 1954.

(1748) CENTRAL VALLEY PROJECT.

(b) Bureau of Reclamation.

(d) Applied research.

(e) Irvolves the development of a generalized procedure for quickly estimating the probable maximum precipitation over areas from 10 to $1,000 \mathrm{sq}$. mi. on the west slopes of the Sierra Nevada from the Feather River Basin to the San Joaquin.

(f) Completed.

(g) Relation established for Western Sierra slopes above 1,000-ft. elevation; work continuing on relation for $v$ alley floor.

(h) "Probable Maximu Precipitation on Sierra Slopes of the Central Valley of Calif ornia", Coop. Studies Report No. 12, U. S. Weather Bureau 1954.

(1749) WEST COAST RATNFALL INTENSTTY-FREQUENCY PROJECT.

(b) Corps of Engineers, Department of the Army .

(d) Applied research.

(e) Involves determination of 1-hour rainfall amounts expected to be equalled or exceeded once in 2, 5, and 10 years. Also includes derivation of relationships between the 1-hour intensities and those for 5, 10, 15, 30, 120, and 240 minutes. 
(f) Completed.

(g) Project extends eastward to 105th meridian.

(h) "Rainfall Intensities for Local Drainage Design in the United States for Durations of 5 to 240 minutes and 2, 5, and 10-year return periods - Part II: Between 105th and 115th meridian", Weather Bureau Tech. Paper No. 24, 1954.

(1750) CRITICAL METEOROLOGICAL ANALYSIS OF MAJOR STORMS.

(b) Corps of Engineers, Department of the Army.

(d) Basic research.

(e) Detailed hour-by-hour analysis of all meteorological data available during major rainstorms.

(h) "The Great-Volume Rainstorm at Elba, Alabama", George A. Lott, Monthly Weather Review, Vol. 82, No. 6, June 1954.

(1751) MAXIMUM STATION PFECIPITATION.

(b) Corps of Engineers, Department of the Army.

(d) Analysis of data.

(e) Tabulations of maximum recorded 1-, 2-, 3-, 6-, 12- and 24-hour precipitation, for automatic recording rain gage stations, by states.

(g) Project contimuing for additional states.

(h) Weather Bureau Technical Paper No. 15, Part VIII: Virginia, Part IX: Georgia, Part X: New York (in process of publication).

\section{(1753) SURVEY OF HURRICANES.}

(b) Corps of Engineers, Department of the Army.

(d) Applied research.

(e) Climatological analysis of 50 years of hurricanes affecting United States to establish frequencies of winds and pressures required as engineering design data.

(h) "Analysis and Synthesis of Hurricane Wind Patterns over Lake Okeechobee, Florida", Hydrometeorologic al Report No. 31, U. S. We ather Bureau, 1954.

"Characteristics of United States Hurricanes Pertinent to Levee Design for Lake Okeechobee, Florida", Hydrometeorological Report No. 32, U. S. Weather Bureau, 1954.

(1992) CONTTNUOUS RAIN GAGE CHART.

(b) Laboratory project.

(d) Experimental; operation.

(e) To substitute recording chart between rollers instead of on drum to avoid superposition of traces.

(1993) PRESSURE JUMP LINES.

(b) Laboratory project supported in part by U.S.A.F. Geophysical Research Directorate.

(c) Dr. Morris Tepper, Scientific Services Division, U. S. Weather Bureau, Washington, D.C.

(d) Theoretical and field investigation; basic and applied research.

(e) Investigate the properties of and the mechanisms producing pressure jump lines in the atmosphere. These lines, indentified by means of discontinuities in microbarograms, have been found to be correlated very strongly with severe local storms. The study is based on (1) observational data collected from a special field program and (2) theoretical models in which the pressure jump line is interpreted as a gravity wave propagating on an inversion surface between stratified atmospheric layers.

(h) "Pressure Jump Lines in Mid-Western United States, Jan. - Aug. 1951", Morris Tepper and staff, U. S. Weather Bureau Research Paper No. 37, 1954.

"The Washington, D. C. Storm of June 26, 1954", J. B. Holleyman, Mo. Wea. Review, July 1954 .

"Successive Pressure Jump Lines of August 16, 1954", J. B. Holleyman and J. M. Hand, Mo. Wea. Review, August 1954 .

"Tornado-Pressure Jump Line Situation of March 18, 1954", H. Newstein, Mo. Wea. Review, August 1954 .

"On the Generation of Pressure Jump Lines by the Impulsive Addition of Momentum to Simple systems", M. Tepper, Jour. of Met., submitted for publication. 


\section{(1994) SHORT PERIOD FLUCTUATIONS IN GREAT LAKE WATER IEVELS.}

(b) Laboratory project.

(c) Mr. De Harris, Scientific Services Division, 0. S. Weather Bureau, Washington 25, D.C.

(d) Theoretical and field investigation; basic and applied research.

(e) The contimuous records of lake level gages belonging to the U. S. Lake survey and several other organizations for the year 1950 and a few other periods have been examined to learn the properties of the seich-like phenomena observed on the Great Lakes. A theoretical model which appears to explain the observations has been derived. This work was undertaken to investigate the possibility of forecasting the floods which are due to the oscillations of the lakes.

(f) Suspended.

(g) It appears that the east-west oscillation of Lake Erie may be forecastable. It does not appear that useful forecasts can be prepared for the other lakes at this time. However, the analysis of the problem may be of some value in harbor engineering.

(2206) HYDROMETEOROLOGICAL ASPECTS OF MISSISSIPPI LEVEE DESIGN.

(b) Corps of Engineers, Department of the Army.

(d) Applied research for design purposes.

(e) An investigation of the meterological storm potential associated with past floods and the likelihood of various meteorological combinations of possible future flood-producing storms.

(2207) SEASONAL VARIATION OF THE PROBABLE MAXIMUM STORM.

(b) Corps of Engineers, Department of the Army.

(d) Applied research for design purposes.

(e) An attempt to break down the probable maximum precipitation developed in Hydrometeorologic al Report No. 23 to seasonal values.

(2208) EXTENSTON OF FLOOD FREQUENCY RECORDS.

(b) Laboratory project in cooperation with Bureau of Public Roads.

(d) Experimental; applied research.

(e) Extension of the record of peak annual discharge values through use of precipitation data and river forecasting procedures, in order to increase the reliability of frequency analyses of relatively short discharge records.

(g) Pilot project showed differences between frequency curves based on observed and estimated flood peaks to be small and far less than between frequency curves developed from segments of observed records.

(h) "Use of Flood Forecasting Procedures in the Derivation of Flood Frequencies", Ralph F. Kresge and Tor J. Nordenson. Presented at ASCE meeting, Austin, Texas, Sept. 1954.

(2209) SINTHESIS OF SHORT-DURATION INTENSITY-FREQUENCY RATNFALI DATA.

(b) Laboratory project.

(d) Field investigation; applied research.

(e) Derivation of objective method for estimating short-duration rainfall intensity-frequency values from usually available climatic data, to provide data for coast drainage design in areas without recording rain-gage data.

(f) Completed.

(g) Objective method derived, based on U. S. and foreign data. Tests with independent foreign data indicate average error of about 20\% in estimates of 2-year 1-hour rainfall.

(h) "Synthesis of Rainfall Intensity-Frequency Regimes", David M. Hershfield, Leonard L. Weiss, and Walter T. Wilson. Presented at ASCE meeting, Austin, Texas, Sept. 1954 . 
U. S. DEPARTMENT OF THE INTERTOR, GEOLOGICAL, SURVEY.

(194) A STUDY OF METHODS USED IN THE MEASUREMENT AND ANALYSIS OF SEDIMENT LOADS IN STHEAMS.

(b) Cooperative. See Project 194, page 122.

(439) EFFECT OF REFORESTATION ON STREAM FLOW.

(b) Cooperative with state of New York.

(c) Mr. A. W. Harrington, U. S. Geological Survey, Albany, N. Y.

(d) Field investigation; basic research.

(e) To study effect on stream flow of growing trees on abandoned farm land. Observations of stream flow, precipitation, ground-water levels, and evaporation at three small reforested drainage basins and adjacent controls were begun in 1935 .

(445) SMALL RESERVOIRS IN ARID REGIONS.

(b) Laboratory project.

(c) Mr. H. V. Peterson, U. S. Geological Survey, Salt Lake City, Utah.

(d) Field investigation; applied research.

(e) To determine munoff, evaporation, seepage, and sedimentation in arid regions. Readings are being obtained on staff gages installed on a number of representative stock-watering reservoirs in western states.

(h) Progress reports on file.

(690) DI SCHARGE THROUGH MULTIPLE OPENINGS.

(b) Laboratory project.

(c) Prof. C. E. Kindsvater, D. S. Geological Survey, Atlanta, Ga.

(d) Field investigation; applied research.

(e) Crest-stage gates are installed on upstream and downstream sides of all openings of selected bridge and valley crossings, so that study can be made of the drop through each opening and of the transverse water-surface profiles. Current-meter meesurements made during the floods will be used to study relationships of discharge through each opening to the total discharge, the drop, and the conveyance.

(691) COMPUTTNG PEAK DISCHARCES.BY INDIRECT METHODS.

(b) Labor atory project.

(c) Mr. Tate Dalrymple, U. S. Geological survey, Washington 25, D. C.

(d) Field investigation; applied research.

(e) Establishment of maximum stage gages on slope-reaches or suitable contracted openings, computing flood discharges and comparing with measured discharge; to test slope-area method of computing flood discharge and to verify roughness coefficients.

(1219) ELECTRICAL LOGGING INSTRUMENTS FOR GROUND-WATER WELLS.

(b) Cooperative with State of Maryland.

(c) Mr. R. R. Bennett, U. S. Geological Survey, Baltimore, Md.

(d) Development.

(e) Development of geophysical unit for obtaining resistivity curves of electrical log, fluid velocity, conductivity, caliper, and temperature for deep well surveying - all combined in a single unit and mounted in station wagons.

(f) Completed.

(1221) STEADY STATE ELECTRIC FLOW NET MODELS.

(b) Cooperative with State of Maryland.

(c) Mr. R. R. Bennett, U. S. Geological, Survey, Washington 25, D. C.

(d) Experimental.

(e) Preparation of electrical flow net models using coloidal carbon. Boundary conditions simulate those commonly found in nature. Object is to catalogue various types of nets for future reference. 
(1222) INFTITRATION AND EVAPO-TRANSPIRATION STUDY.

(b) Cooperative with State of Maryland.

(c) Mr. W. C. Rasmussen, U. S. Geological survey, Washington 25, D. C.

(d) Field investigation.

(e) Weekly measurement of wells, rain gages, soil moisture, runoff and pond storage in two drainage basins near Salisbury, Md., to measure all factors in hydrologic cycle to determine infiltration, evapo-transpiration and specific yield.

(f) Field work completed.

(h) Report in preparation.

(1223) EVALUATION OF HYDROLOGIC CYCLE.

(b) Cooperative with State of Virginia.

(c) Mr. D. S. Wallace, U. S. Geological Survey, Charlottesville, Va.

(d) Field investigation.

(e) Establishment of gaging station and network of observation wells on headwaters of Hudson Creek, Louisa Co., Va., for correlation of water levels and stream flow.

(1225) STORM WATER INFILTRATION IN GROUND-WATER FECHARGE BASINS.

(b) Cooperative with Nassau County, N. Y.

(c) Mr. A. W. Harrington, U. S. Geological Surrey, Mineola, L. I.

(d) Field investigation.

(e) Observations are made of precipitation, evaporation, ground-water levels and storm water inflow into artificial recharge basins, to determine rate of infiltration and amount of storm water available for ground-water recharge when collected in recharge basins, and to evaluate effectiveness of these basins.

(1227) STOCK-WATER RESERVOIR STUDIES.

(b) Cooperative with Bureau of Reclamation.

(c) Mr. R. C. Culler, U. S. Geological Survey, Salt Lake City, Utah.

(d) Field investigation.

(e) Development of techniques for determination of effects of stock-water reservoirs on water supply. Detailed surveys made of number, capacity and performance of reservoirs in the Cheyenne River Basin in Wyoming, will be analyzed to determine evaporation, transpiration, and seepage losses and their effect on flow of Cheyenne River.

(1229) GLACIER RUNOFF.

(b) Laboratory project.

(c) Mr. C. S. Heidel, U. S. Geological Survey, Helena, Mont.

(d) Field investigation.

(e) Study of recession and accretion of Grinnel Glacier, Mont. Glacier mapped anmually for some years, storage rain gage and stream gaging station installed in 1949.

(h) Annual reports of surveys av ailable.

(1230) EFFECT OF LOGGING ON STREAM FLOW.

(b) Cities of Tacoma and Seattle.

(c) Mr. F. M. Veatch, U. S. Geological Survey, Tacoma, Wash.

(d) Field investigation.

(e) Operation of seven gaging stations on small streams in areas where logging operations are scheduled in several years. There are control basins where no timber will be cut.

(1231) CATHODIC PROTECTION OF BURIED PIPE AGAINST CORROSION.

(b) Cooperative with State of Pennsylvania and State of Louisiana.

(c) Mr. Max Noecker, U. S. Geological survey, Pittsburgh, Pa., and Mr. R. P. Smith, U. S. Geological Survey, Jonesboro, La.

(d) Field investigation. 
(e) Magnesium anodes are to be installed at several gaging stations where corrosion of pipe. wells or intake pipes has required frequent replacement. Anodes and pipes are to be inspected annually to determine rate of loss of magnesium and to observe extent of corrosion.

(1233) MAGNTUDE AND FREQUENCY OF FLOODS.

(b) Cooperative with several state agencies.

(c) Mr. Tate Dalrymple, U. S. Geological survey, Washington 25, D. C.

(d) Applied research.

(e) Analyses of flood records to determine magnitude and frequency of flood discharge at gaging stations, and at supplementary network of crest-stage gages on small streams, to determine techniques for establishing flood discharges on ungaged streams.

(h) Reports published for Georgia, Iowa, Minnesota, Western Weshington, Ohi ^, Western Pennsylvania, Alabama, Louisiana, and Illinois.

(1235) SEDIMENT CARRIED AS BED LOAD.

(b) Laboratory project.

(c) Mr. P. C. Benedict, U. S. Geological Survey, Lincoln, Neb.

(d) Field investigations; theoretical studies.

(e) Determination of the amount of sediment moving as bed load at three stations, evaluation of the several bed-load formulas, and basic studies of bed-load movement.

(14,85) EROSION AND DEPOSITION OF SEDIMENT.

(b) Laboratory project.

(c) Mr. P. C. Benedict, Lincoln, Neb.

(d) Field surveys; applied research.

(e) Studies of the effects of climate, soil types, geology, topography, and land use in rates of erosion.

\section{(1L87) FLON THROUGH CONTRACTED OPENINGS.}

(b) Laboratory project.

(c) Prof. C. E. Kindsvater, U. S. Geological Survey, Atlanta, Ga.

(d) Experimental; applıed research.

(e) To obtain data on model and prototype on flow through contracted openings.

(h) Results published as Geological. Survey Circular 284.

(1L88) ROUGHNSSS COEFFICIENTS OF SAND BED STREAMS.

(b) Laboratory project.

(c) Mr. C. E. Ellsworth, U. S. Geological Survey, Austin, Texas, and Mr. D. D. Lewis, U. S. Geological survey, Lincoln, Neb.

(d) Field survey; applied rese erch.

(e) To determine channel coefficients for use in computing peak discharges by indirect methods in sand bed streams, extent of scour and fill.

(1755) CHARACTERISTICS OF SAND CHANNEL STREAMS.

(b) Laboratory project.

(c) Mr. Tate Dalrymple, U. S. Geological Survey, Washington, D. C.

(d) Field investigation; applied research.

(e) The research is conducted at a 1,900 feet reach. The following factors are being investigated; variation of value of " $n$ " with stage; accuracy and rellability of highwater marks recovered after a rise; accuracy of slope of water surface determined by present. procedures; extent of scour and fill; reliability with which scoured depths can be determined by subsequent prodding; definition of the pattern of scour and fill during floods; shapes of vertical velocity curves; and quantity of suspended sediment in transport. 
(1756) WATER LOSS FROM LAKE MEAD.

(b) Cooperative with Bureau of Reclamation.

(c) Mr. G. E. Harbeck, U. S. Geological Survey, Denver, Colo.

(d) Field investigation.

(e) Evaporation from Lake Mead is being determined using mass-transfer and energy budget techniques. The cumnings radiation integrator is being used to determine the areal variability in solar and atmospheric radiation.

(f) Field work completed.

(h) Final report in preparation.

(1757) EVAPOTRANSPIRATION INVESTIGATION.

(b) Cooperative with Bureau of Reclamation, Division of Hydrology.

(c) Mr. G. E. Harbeck, U. S. Geological Survey, Denver, Colo.

(d) Field investigation at site near Bruning, Nebr.

(e) Tests are to be made by mass-transfer and energy budget techniques of evapotranspiration from grass land, with comparis on with water-budgei control.

(1758) RELATION OF GROUND WATER TO STRE AMFLOW.

(b) Laboratory project.

(d) Field investigation; applied research.

(e) Study of hydrologic cycle in small drainage basins, in Massachusetts, Virginia, New Jersey, Connecticut, North Carolina, Louisiana, OkIahoma, New York and Tennessee to determine the relationships between ground-water. levels, runoff, evapotranspiration, and the geology.

\section{(1759) TNFILTRATION STUDIES.}

(b) Laboratory project.

(c) Mr. Irwin Remson, Seabrook, N. J.

(d) Field investigation; applied research.

(e) Study of the movement of percolating waters between the land surface and the water table, and water-budget studies in connection with the waste disposal project at Seabrook Farms.

(f) In progress.

(h) Provisional reports on file.

(1764) COMBINED PHYSTOGRAPHIC AND HYDRAULIC STUDTES.

(b) Laboratory project.

(c) Mr. Luna B. Leopold, U. S. Geological survey, Washington 25, D. C.

(d) Field and office research.

(e) Longitudinal profiles of natural channels, relation to bed material, geologic history, and hydraulic characteristics. Problems in meanders and flood plain construction.

(1765) SONAR INVESTIGATIONS (EQUTPMENT DEVELOPMENT).

(b) Laboratory project.

(c) Dr. A. N. Sayre, U. S. Geological Survey, Washington, D. C.

(d) Development; theoretical laboratory.

(e) To adopt the sonar principle of the fathometer as method of delineating under-water sediments of moderate thickness (several hundred feet) and depth to underlying bedrock. Development work is presently in progress to modify and simplify the procedures of interpretation and use of the sonar technique for geophysical investigations on land.

(1995) COMPARATIVE STUDY OF SOIL MOT STURE EQUIPMENT.

(b) Laboratory project.

(c) Mr. Irwin Remson, U. S. Geological Survey, Trenton, N. J.

(d) Field investigation; applied research.

(e) A comparative study of all commercially available instruments for measuring soil moisture; possible design of new instruments.

(g) Laboratory and field calibrations in progress. 
(1996) TNFILTRATION AND EVAPOTRANSPIRATION STUDY.

(b) Laboratory project.

(c) Mr. Irwin Remson, U. S. Geological survey, Trenton, N. J.

(d) Field investigation; applied research.

(e) To determine interrelation of the various factors involved in the hydrologic cycle with special emphasis on the magnitude of evapotranspiration.

(g) Observation networks established, periodic measurements begun.

(1997) EFFECT OF FOREST MANAGEMENT ON WATER YIELD.

(b) Cooperative with State of New Jersey.

(c) Mr. H. C. Barksdale, U. S. Geological Survey, Trenton, N. J.

(d) Field investigation.

(e) Study of effects caused by forest management practices on interception, infiltration capacity, evapotranspiration, and yield of water-bearing sands in New Jersey Pine Barrens area.

(g) Instrumentation in process of installation.

(1998) DEVELOPMENT OF INSTRUMENTS AND TECHNIQUES FOR SUBSURFACE EXPLORATION OF GROUND WATER.

(b) Cooperative with State of Arizona.

(c) Mr.H. E. Skibitzke, U. S. Geological Survey, Tucson, Arizona.

(d) Applied research.

(e) To adapt instruments and techniques for solving problems of the occurrence of water in alluvial fill; including electrical resistivity methods, electric logging and deep well current meters.

(1999) PERFORMANCE OF RECHARGE POND.

(b) Cooperative with Bureau of Reclamation.

(c) Mr. H. A. Waite, U. S. Geological Survey, Salt Lake City, Utah.

(d) Field investigation.

(e) Studies of factors controlling rates of infiltration in an abandoned gravel pit used as a recharge pond.

(2000) GHYBEN-HERZBERG LENS.

(b) Laboratory project.

(c) Mr. Dan A. Davis, U. S. Geological survey, Honolulu, T. H.

(d) Field investigation.

(e) Study of ground-water body in marine islands, to determine the relationship of fresh water storage to the geology of the island, rainfall, head, tidal fluctuations, leakage, and draft.

(2001) HYDROLOGIC INVESTIGATION, LITILE MIAMI RIVER.

(b) Cooperative with State of Ohio.

(c) Mr. William C. Walton, U. S. Geological Survey, Columbus, Ohio.

(d) Field investigation.

(e) Detailed studies of ground-water levels in various types of glacial deposits to determine effects on ground-water storage of various land use and stream improvement practices.

(g) Instruments and observation wells installed.

(2210) THERMAL STRUCTURE OF COOLING POND.

(b) Cooperative with Texas Board of Water Engineers.

(c) Mr. Trigg Twichell, U. S. Geological Survey, Austin, Texas.

(d) Field investigation at Lake Color ado City, Texas.

(e) Observations of effect of advected heat upon thermal structure, evaporation, and radiation from cooling pond at power plant. 
U. S. DEPARTMENT OF THE INTERIOR, BUREAU OF FECLAMATION.

Inquiries concerning Projects Nos. 707, 1236, 1243, 1244, 1255, 1262, 1495, 1498, 1499, 1501, 1502, 1766 to 1769, incl., 1773 to 1777, inc1., 2002 to 2007, inc1., 2009 to 2011, incl., 2013 to 2017, incl., and 2211 to 2227, incl., should be addressed to the Chief Engineer, Bureau of Reclamation, Denver Federal Center, Denver, Colo.

(707) WYOMING CANAL DROPS.

(b) Laboratory project.

(d) Experimental; for design.

(e) 1:6 model was used in developing canal drops, trapezoidal in cross section, thereby reducing cost of the structures from that of conventional rectangular cross section.

(f) Completed.

(h) "Hydraulic Model Studies of the Concrete Drop at Station 997+00, Wasteway at Station $1188+56$, and Intercepting Ditch Chute at Station 1+31, Wyoming Canal--Riverton Project, Wyoming", Hyd-376, by W. E. Wagner.

"Hydraulic Model Studies of Trapezoidal Drop Structures for Wyoming Canal--Riverton Project, Wyoming", Hyd-371, by W. E. Wagner.

(1236) WILLOW CREEK DAM EMERGENCY SPILIWAY.

(f) Completed.

(h) "Hydraulic Model Studies of Willow Creek Dam Auxiliary Spillway", G. I. Beichley, Report No. Hyd-356.

(1243) RECTANGULAR SEMIBELLMOUTH ENTRANCE STUDIES.

(f) Completed.

(h) Report in preparation.

(12L4) WILLOW CREEK DAM SPILLWAY AND OUTLET WORKS.

(f) Completed.

(h) Report in preparation.

(1255) PALISADES DAM RECTANGULAR REGULATING GATES.

(f) Completed.

(h) "Hydraulic Model Studies of the 7-foot 6-inch by 9-foot Palisades Regulating Slide Gate-Palisades Project, Idaho", Hyd-387, by W. P. Simnons, Jr.

(1262) SHEEP CREEK DIVERSION SEDTMENTATION BASIN.

(b) Laboratory project.

(d) Experimental; for design.

(e) Tests on a 1:9 model of a sedimentation basin were conducted to determine the modifications required to improve the efficiency of the basin. Tests will also be made on prototype structure to determine additional data on model prototype relationships for movable bed models.

(f) Suspended.

(1495) YELLOWTAIL DAM SPILLWAY AND OUTLET WORKS.

(b) Laboratory project.

(d) Experimental; for design.

(e) A 1:54 scale model of all discharge facilities and surrounding area was used to determine feasibility of entire layout, develop a low-cost tunnel spillway and energy-dissipating device, check the proposed powerhouse outlet works layout, and determine all inter-related discharge effects in river. A $1: 28$ scale model of the outlet works was used to develop a low-cost efficient stilling basin.

(f) Completed.

(h) Report suspended. 
(1498) WEIR STANDS--IRRIGATION WATER DISTRIBUTION SYSTEM.

(f) Completed.

(h) Report in preparation.

(1499) CANAL TURNOUT--METER LOCATION.

(f) Completed.

(h) Report in preparation.

(1501) STABLE CHANNEL STUDIES--SCOUR ON CURVES.

(e) A program of general testing is being made to obtain information which will correlate extent of scour with degree of curvature in canals. Tests to be conducted in same facility as Item (1502) at end of tests using straight flume.

(f) Suspended.

(1502) STABLE CHANNEL STUDIES--TRACTIVE FORCES REQUIRED TO MOVE NON-COHESTVE MATERIALS.

(b) Laboratory project.

(d) Experimental; for design.

(e) Tests are being started in a trapezoidal channel using a pit-run gravel to determine critical tractive forces required to scour given sizes of materials in the normal mixture. Tests using curves will be made after tests on straight sections are completed. Information obtained will be used in design of canals in cohesive materials and choosing gravel blankets for protective cover for canals.

(g) Model studies started.

(I7ó6) HYDRAULIC AND SOIL TESTS ON PROPOSED CANAL LINING MATERIAL FOR MADERA DISTRIBUTION SYSTEMS.

(b) Laboratory project.

(d) Experimental; for design.

(e) A model study of the action of a proposed earth lining material, under the action of flowing water, was made. Various velocities were used in the testing program. To study the possibilities of creating a more stable channel, several types of sand-gravel blankets were tested.

(f) Completed.

(g) The material was found suitable for canal embankment but unsuitable for canal lining. The use of a sand-gravel blanket over the soil increased the stability of the section.

(h) "Results of Soil and Hydraulic Tests on Proposed Canal Lining Material from Borrow Area 13 for Madera Irrigation District, Madera Distribution Systems--Central Valley Project (Progress Report No. 2)", Hyd-358, by P. F. Enger.

(1767) MILBURN DIVERSION DAM, HEADWORKS AND SLUICEWAY STRUCTURES.

(b) Laboratory project.

(d) Experimental; for design.

(e) Tests on a 1:16 scale model of the headworks and sluiceway structures were made to improve the sediment-excluding characteristics of the stmucture. A short tunnel separating the low sediment laden top water and the heavy sediment laden bottom water was developed and recormended.

(f) Model studies and report completed.

(g) Short tunnel entrance to headworks and sluiceway was developed which gave very good sediment control characteristics.

(h) "Milburn Diversion Dam Model Study, Missouri River Basin Project, Nebraska, Progress Report No. 4, General Studies of Headworks and Sluiceway Structures", R. A. Dodge, Jr., Report No. Hyd-385. 
(1768) BARTIEY DIVERSION DAM, HEADWORKS AND SLUICEWAY STRUCTURES.

(b) Laboratory project.

(d) ExperimenteI; for design.

(e) Tests on a 1:7 scale model of the headwork and sluiceway structures were made to improve the sediment-excluding characteristics of the sluiceway.

(f) Completed.

(g) Guided flow immediately upstream from the headworks and sluiceway obtained by installing curved parallel guide walls proved most effective for reducing bed-load sediment passing the he adworks.

(h) "Hydraulic Mociel Studies of Bartley Diversion Dam--Progress Report No. 3--General Studies of Headworks and Sluiceway Structures--Missouri River Basin Project", Hyd-38L, by P. F. Enger.

(1769) WEIR TURNOUT.

(b) Laboratory project.

(d) Experimental; for design.

(e) To develop a weir turnout, with enphasis on minimun structure dimensions, that will give a smooth head-on-weir water surface when the turnout is discharging (1) 5 cfs at 6-foot head and (2) 2 cfs at l-foot head.

(f) Completed.

(h) Report being prepared.

(1773) WEBSTER DAM SPIILTAY.

(f) Completed.

(h) "Hydraulic Model Studies of the Webster Dan Spillway--Missouri River Basin Project", Hyd -390 , by G. L. Beichley.

(1774) KIRITN DAM SPIIIWY AND STIIIING BASIN.

(b) Laboratory project.

(d) Experimental; for design.

(e) f I:L8 moiel used to test the approach conditions, coefficient of discharge, flow distribution on concrete apron and the efficiency of the stilling basin.

(f) Conpletec.

(g) Approzch conditions improved. Training walls realigned to secure better flow distribution in the stilling basin. Spur-type wing vells were added below the stilling basin to prevent erosion.

(h) Report in preperation.

(1775) HIGH-HE SARNOUT WITH REGULATED VALVE AND TMPEIJER-TYPE FLOMIETER.

(f) Completed.

(h) Report in preparation.

(1776) ADAITNABI TUNEL JONCTION SHAFT AND CYIINDER GATE.

(b) Snowy Mountains Hydro-Electric Authority, fustralia.

(d) Experimental; for design.

(e) Hydraulic model studies ere being made of an 18-foot-diameter vertical shaft approximately 300 feet deep which supplies excess water from a river to a 14-mile-long, 2l-foot-diameter tunnel. The 2l-foot tunnel connects a storage and power reservoir. Water from the river flowing through the vertical shaft is controlled by a proposed 2i-foot-diemeter cylinder gate at the junction of the shaft and tunnel. Two models are used ( 1 ) a $1: 21.6$ model of the inlet and a section of the vertical shaft and (2) a 1:18 model of the cylinder gate.

(f) Completed.

(g) Controlling the shaft pressure with the cylinder gate will prevent air entrainment.

(h) "Hydrauiic Model Studies of the Eucumbene-Tumut Tunnel Junction Shaft for the Australian snowy Mounteins Authority", Hyd-392, by J.C. Schuster. 


\section{(1777) SIPHON SPILLWAY STUDIES.}

(b) Combined field and laboratory investigation; development of design data.

(e) Purpose of the study is to determine the operating characteristics of siphon spillways as currently designed with a viev to lessening the priming time and lowering the head necesscry to prime. Also, attempts will be made to design a partialization device to regulate the degree of prime through the automatic control of air intake, thereby enabling the siphon to operate more or less continually at reduced flow rather than intermittently at full capecity.

(g) The shortcomings of present design practice have been defined, and design changes for model testing have been set for trial in the laboratory. A new model is in the construction stage.

(h) No reports issued. A silent film on the first phase of model studies is being prepared.

(2002) INVESTIGATION OF HYDRAULIC CHARACTERISTICS OF VERTICAL STILLING VELLS.

(b) Laboratory project.

(d) Experimental; applied research.

(e) Unwatering certain structures which contain weter under high pressure and supplying irrigstion water from high pressure conduits to earth ditches present problems of energy dissipation. Investigations of several particuler structures and operation of a completed field structure have established the feasibility of the stilling well. Area, depth, and shape of well for various discharges and entrance velocities will be obtained in a generalized form.

(g) Data now available have been anelyzed, indicating that design criteria can be established for the circular well.

(2003) STUDY OF HYDRAULIC JUMP AND BUCKET ENERGY DISSIPATORS.

(b) Laboratory project.

(d) Experimental; applied research.

(e) Many stilling devices are used in dems and irrigation works. Four general types are considered in this program (1) stilling basins with horizontal floors (with or without baffle piers and sills), (2) basins with sloping floors (no baffle piers), (3) short stilling basins for canal chutes, drops, river crossings, and wasteways, and (4) bucket dissipators .

(g) Data available indicates that extensive generalization for design application may be possible.

(h) "Progress Report--Research study on Stilling Basins and Bucket Dissipators", Hyd-380, by J. N. Bradley.

(2004) STANDARDIZATION OF DESIGN OF SMALL CANAL STRUCTURES.

(b) Laboratory project.

(d) Experimental; applied reseerch.

(e) Canal systems contain numerous and many kinds of small structures such as drops, turnouts, overchutes, wasteways, culverts, and bifurcation works. Many of these incorpor ate dissipating devices which are quite different from the conventional types. The velocity of flow is low compared to lerger structures. This research will standardize designs to a large extent.

(2005) CAVITATION EROSION OF ROUGHENED SURFACES.

(b) Laboratory project.

(d) Experimental; applied research.

(e) Irregularities in surface of concrete water passages can be a source of cavitation. The purpose of this project is to explore into a method of determining the cavitation potential of $v$ arious types and degrees of roughened surfaces.

(f) Suspended.

(g) A successful test apparatus has been designed and built, and an interpretation method evolved, from which any specific surface can be evaluated. 
(2006) CAMINO CONDUIT TURNOUT AND METERING STRUCTURES.

(b) Leboratory project.

(d) Experimental; for design.

(e) A 1:4 scale model was used to determine the head loss through the proposed turnout structures for Stations $105+85$ and $263+50$, and to develop suitable baffles and basins to hancle and measure the flow which may be diverted through a gate or over an elevated skiming weir.

(g) The losses through the structures were low enough to permit passage of the desired flows wi.th the heads available. Economical baffles and basins were developed which produced relatively tranquil flow at the measuring weirs.

(h) "Hydraulic Model Studies of the Turnout and Measuring Structure at Stations $105+85$ and 263+50 in the Camino Conduit--Sly Park Unit--American River Division--Central Valley Project, California", Hyd-382, by W. P. Simnons, Jr.

(2007) SLY PARK DAM OUTLET WORKS.

(f) Completed.

(h) "Hydreulic Model Studies of the Outlet Works Stilling Basin--Sly Park Dam--American River Division--Central Valley Project, California", Hyd-383, by W. C. Case and W. P. Simmons, Jr.

(2009) NIMBUS DAM SPILLWAY.

(f) Completed.

(h) Report suspended.

(2010) BOULDER SUPPLY CANAL.

(f) Completed.

(h) Report suspended.

(2011) PILOT FISH SCREEN STRUCTURE--DELTA-PENDOTA CANAL.

(b) Labor atory project.

(d) Combined field and laboratory investigation; applied research.

(e) Purpose of the project is to devise an efficient and economical means of preventing small game fish from entering the intake canal to the Tracy Pumping Plant, Central Valley Project, California. Present scheme under test is to use sets of louvers installed at such an angle to the direction of flow that the fish are guided along them, without passing through, to a small bypass channel feeding a holding basin. The fish are then transported by truck to safer areas. Project is an extension of original study under same project number in 1954.

(g) Laboratory model tests and field studies have yielded basic information on louver angles, $v$ ane spacing, velocity effects, and characteristics of different species of fish.

(h) Progress reports will be written and published by the Hydraulic Laboratory, Bureau of Reclamation, and the Fish and Wildife service.

(2013) MAIN UNLINED CANAL, KENNEWICK DIVISION, YAKIMA PROJECT--PROTECTIVE COVER MATERIAL.

(f) Completed.

(h) "Hydraulic Model Studies to Determine the Required Cover Blanket to Prevent Fine Base Material from Leaching Due to Wave Action--Kennewick Main Canal, Yakima Project, Washington", Hyd-381, by P. F. Enger.

(2014) CODING DEVICE FOR RADIO-REPORTING RAIN GACE.

(b) Region 2, Bureau of Reclamation, Sacramento, California.

(d) Field investigation; development. 
(e) A consistently accurate, dependable, low power DC coding device for radio telemetering from remote rain gage stations was needed for control of releases from Shasta Reservoir. A coding system which transmits intelligence by patterned pulse signals from a photoelectric cell to the screen of a cathode-ray tube has been developed. Measurement is read directly from the cathode-r ay screen. Development was extended to cover the housing of the apparatus, wind shields to insure an accurate precipitation catch, and heating equipment to melt snow and ice on the collector.

(f) Completed.

(g) Some refinements in the circuitry of the device and the cathode-ray tube receiver have been made. Six installations have been made. Results to be analyzed after the 19541955 season.

(h) "A Coding Device for Telemetering Hydrologic Data", by C. R. Daum. Paper No. 54-50 presented at the First International Instrument Congress and Exposition, September 1954, Philadelphia, Pennsylvania; the paper will be published in the Proceedings of the Instrument Society of America. An evaluation of the installations is contained in "Precipitation Measurement Study, Final Report, 15 February 1954", issued by the Meteorologic Laboratory, IIlinois State Water Survey, University of Illinois, Urbana, Illinois.

\section{(2015) DEVELOPMENT OF A LOW VELOCITY CURRENT METER.}

(b) Laboratory project; field performance tests.

(d) Experimental; for development and field studies.

(e) To develop a recording current meter capable of operating unattended for periods up to 14 days; to operate under tidal influence and the attendant reversing direction of flow without physical rotation of the meter; to develop electronic circuits capable of converting impulses received from the meter to a direct recording of velocity versus time; to evaluate various bearings in attempts to measure velocities down to 0.1 foot per second or lower, and up to 5.0 feet per second.

(g) Two meters have been built and given field tests. Bearing designs and materials have become standardized with the use of carboloy for the pivots running in miniature pivot ball bearings. Calibration tests show the meter will. operate satisfactorily from 0.12 foot per second to over 5 feet per second.

(2016) STUDIES OF AIR DEMAND OF GATES AND VALVES IN CONDUITS.

(b) Laboratory project.

(d) Experimental; applied research.

(e) This project is being made to determine the size of air vents to prevent adverse effects of vibration and cavitation erosion from "in line" gates and valves. Small amount of model testing is contemplated to provide data for comparison with results of field tests.

(f) Inactive.

(2017) INVESIIGATION OF METHODS FOR MEASURING DISCHARGE IN LARGE CONDUITS.

(f) Inactive.

(2211) CLE VELAND DAM SKI JMPP SPILLWAY.

(b) Greater Vancouver Water District, British Columbia, Canada.

(d) Experimental; for design.

(e) Study of a 1:60 model to investigate the overall hydraulic characteristics of the spillwəy from the entrance to the river channel downstream.

(f) Completed.

(g) Determination was made of the water surface at the piers for bridge girder clearance, and on the spillway training walls to determine proper walls to prevent overtopping. size, shape, and placement of the ski jump bucket flow splitters were determined.

(h) "Hydraulic Studies of the Ski Jump Spillway for Cleveland Dam, Greater Vancouver Water District, Vancouver, British Columbia, Canada", by L. V. Wilson, Report No. Hyd-369. 
(2212) AINSWORTH CANAL DUNE SAND.

(b) Laboratory project.

(d) Experimental; for design.

(e) Tests were made in trapezoldal flume to determine tractive force distribution and ellowable tractive forces for dune sand through which Ainsworth Canal will be constructed. Tests were also made on dune sand stabilized with asphalt emulsion.

(f) Model study completed, report completed.

(g) Allowable tractive force for dune sand is very low. Asphalt emulsion stabilizes dune sand when properly applied but breaks down when subjected to freezing and thawing penetrated macadam cover consisting of fine $\mathrm{gr}$ avel and rapid setting emulsion gives a stable cover and does not break down when subjected to freezing and thewing.

(h) "Hydraulic and Bituminous Studies of Ainsworth Canal Dune Sand, Missouri River Basin Project, Nebraska", General Report No. 18, by P. F. Enger and L. M. Ellsperman.

(2213) SEEPACE LOSS STUDIES--CENERAL.

(b) Laboratory project.

(d) Combined field and laboratory investigation; applied research.

(e) Coordinating and analyzing the efforts of our own laboratory and various state colleges engaged in cooperative studies with the Bureau. Part of a long range study toward development of good lower-cost canal linings.

(g) In the present year tests on seepage meters and the effects of soil density, moisture content, ground-water levels, temperature, humidity, and barometric pressure on seepage rates were completed by Colorado $\mathrm{A}$ and $\mathrm{M}$.

(h) Report on the studies in $(\mathrm{g})$ being reviewed.

(2214) LOWER-COST CANAL IINING STUDIES--USING BENTONITIC CLAYS TO CONTROL SEEPAGE.

(b) Laboratory project.

(d) Experimental; for design.

(e) Tests in a l-ioot recirculating flume will be made to determine effect bentonitic cleys in water have on reducing seepage using various soil types in which seepage rate will be controlled.

(f) Flume constructed.

(2215) GORGE HIGH DAM SPILLWAY AND OUTLET WORKS.

(b) City of Seattle, Washington.

(d) Experimental; for design.

(e) A 1:24 scale model of the spillway was used to study the spillway approach conditions and to develop a satisfactory means of dissipating the high velocity flow while directing the flow into the downstream river channel. Tests were conducted on a $1: 16.47$ scale model of the outlet works to develop a cavitation-free bellmouth entrance and to determine discharge capacity curves.

(g) Spillway end pier contractions were reduced by redesigning the spillway piers. A highly superelevated "flip" bucket was developed to direct the flow away from the adjacent unstable river bank. A satisfactory bellmouth entrance for outlet works was developed. Discharge capacity curves for the structure were obtained.

(h) Report in preparation.

(2216) ROSS DAM SPILLWAY.

(b) City of Seattle, Washington.

(d) Experimental; for operation of completed structure.

(e) A 1:24 scale model of three bays, or half of one of the two spillways, was constructed for the purpose of determining spillway head-discharge curves and pressures on the crest and spillway hood.

(f) Completed.

(g) Head-discharge curves for free flow and l-foot increments of gate opening were determined for one bay with and without adjacent bays operating, from which total flow over spillway was computed. Pressures on crest and hood were obtained for later correlation with field data. 
(h) MHydraulic Model Studies to Determine Spillway Discharge Curves for Ross Dam-- City of Seattle, Washington ", by W. E. Wagner, Report No. Hyd-375.

(2217) PALO VERDE DIVERSION DAM.

(b) Laboratory project.

(d) Experimental; for design.

(e) A 1:28.3 scale sectional model of one spillway bay was used to develop the design of the bucket-type energy dissipator. A $1: 50$ scale model of the diversion dan including the spillway, canal headworks, and the surrounding area in the reservoir and the downstream river area is to be used to study the hydraulic characteristics of the flow approaching the spillway and canal headworks and of the flow leaving the spillway.

(g) A bucket-type energy dissipator has been developed. Construction of 1:50 scale model is in progress.

(2218) GATEWAY CANAL, INVERTED SIPHON SAFETY DEVICE.

(b) Laboratory project.

(d) Experimental; design.

(e) The studies were performed to develop a safety device to be constructed as an integral part of the entrance to inverted siphons. The device is intended to carry to safety floating or partially submerged humans and animals that have fallen into the canal upstream from the siphon.

(f) Completed.

(g) A safety device was developed that consisted of a partially submerged ramp composed of five steps having part of the riser of each step left open to allow passage of the surface flow. A specially designed transition was used upstream from the $r$ amp to converge the flow approaching the siphon without producing objectionable vortices and eddies, since early tests had shown that such yortices would pull a floating object beneath the surface and into the siphon.

(h) "Safety Device for the Inverted Siphons on Gateway Canal, Weber Basin Project, Utah", by T. J. Rhone, Report Hyd-391.

(2219) CARTER LAKE DAM NO. I OUTLET WORKS.

(b) Laboratory project.

(d) Experimental; design.

(e) Studies made on a $1: 16$ scale model of the outlet works and associated measuring flume and canal to increase the capacity of the stilling basin and to reduce the wave heights and surges in the measuring flume and canal.

(f) Completed.

(g) Specially shaped baffle piers added to the stilling basin increased the capacity and improved the performance of the stilling basin, and a short-tube underpass-type wave suppressor reduced wave heights so that accurate staff gage readings could be obtained in the measuring flume.

(h) Report in preparation.

(2220) FRIANT-KERN CANAL HEADWORKS, WAVE SUPPRESSOR DEVICE.

(b) Laboratory project.

(d) Experimental; design.

(e) Studies were made using a 1:32 scale model of the stilling basin and canal to develop a wave suppressor. It was desired to reduce the wave action in the canal so that the canal could discharge about 25 percent more water without overtopping the concrete lining.

(f) Completed.

(g) A wave suppressor was developed in the form of a culvert or short-tube underpass placed across the channel so that it intercepted the upper 40 percent of the flow depth at maximum discharge. Waves and surges were reduced as they passed through the culvert, the necessary length of culvert being dependent on the required amount of wave suppression. For the Friant-Kern Canal headworks, a culvert length approximating the flow depth at maximum discharge resulted in a 75 percent reduction in the wave heights.

(h) "Hydraulic Model Studies on a Wave suppressor Device at the Friant-Kern Canal Headworks", by T. J. Rhone, Report Hyd-395. 
(2221) FRIANT DAM RIVER OUTLETS.

(b) Laboratory project.

(d) Combined field and laboratory investigation; applied research.

(e) Purpose of the study was to define the operating characteristics of the 96-inch hollowjet valves at Friant Dam, and to compare model data with that of the prototype as a means of evaluating model calibrations for use in the prototype.

(f) Field and laboratory studies completed.

(g) Results show the model calibration was as accurate as that made on the prototype. The action in the stilling basin in regard to the relative position of the hydraulic jump also agreed well with the model.

(h) Hydraulic Laboratory Report Hyd-388 to be published in the near future.

(2222) DRAIN TESTS, COACHELLA VALLEY, CALIFORNIA.

(b) Coachella Valley County Water District, Coachella, California, laboratory project.

(d) Field investigation; development of design data.

(e) Purpose of the study was to determine the friction coefficients in a 16-inch concrete pipe drain at full and partial flows.

(f) Field work completed.

(g) Apparent friction coefficient in Manning's equation for partial flow condition was found to be 0.0142 , average for six tests at varying discharge; for a full pipe the friction coefficient computed to be 0.0115 .

(h) No formal report to be issued.

(2223) LOVEWELL OUTLET WORKS AND WASTEWAY.

(b) Laboratory project.

(d) Experimental; for design.

(e) A $1: 18$ model is being used to study the proposed design of the radial control gate, stilling basin, bifurcation, wasteway and waste gate, and the channel leading to the irrigation canal. Smooth flow is required at the bifurcation for proper operation of the automatically controlled waste gate, and at the entrance to the irrigation canal to permit accurate measurement of the flow rate.

(f) Model studies nearly completed.

(g) Satisfactory flow conditions can be obtained by means of a culvert-type wave suppressor in the downstream end of the stilling basin.

(h) Report to be prepared.

(2224) SHERBURNE LAKES OUTLET WORKS.

(b) Laboratory project.

(d) Experimental; for rehabilitation.

(e) A 1:15 model of the outlet works control tower with control gates; the downstream tunnel and stilling pool are being used to determine the feasibility of altering the gate structure and utilizing the tower as a combination spillway and outlet works.

(2225) ALAMOGORDO DAM, SPILLWAY.

(b) Laboratory project.

(d) Experimental; for rehabilitation.

(e) Study of a 1:36 model to determine the shape of the redesigned spillway crest and approach, and the positioning of the upstream control so that the reservoir water surface may be raised 21 feet while the control gate remains in its present location.

(f) Model being constructed.

(2226) FALCON DAM OUTLET WORKS.

(b) Laboratory project.

(d) Experimental; for operation.

(e) $1: 15$ and $1: 12$ scale models were used to calibrate the hollow-jet valvas as installed at Falcon Dam. 
(f) Completed.

(g) The pressure distribution around the periphery of the conduits 1 diameter upstream fram the hollow-jet valves is not uniform because of bends, branches, and valves farther upstream. This study concerned the proper piezometer location and the valve calibration for each of the four outlets.

(h) Report being prepared.

(2227) ADAMTNABY OUTLET WORKS.

(b) Snowy Mountains Hydroelectric Authority, Australia.

(d) Experimental; for design.

(e) Hydraulic model studies were made of the outlet works which are to be used in routing floods through the reservoir above Adaminaby Dam and for diversion of the river during construction of the dam. The outlet, including the gate section which has two 9- by 20foot slide gates to be used for regulating releases during construction and used for emergency closure of the ultimate structure, two 6- by 7.5-foot slide gates for regulating releases through the final structure, a 25-foot horseshoe tunnel, and a stilling basin, was constructed on a scale of $1: 30$.

(f) Completed.

(g) Flow conditions in the gate section, in the downstream tunnel, and in the stilling basin were improved by minor but important changes. The entrances to the passages leading to the 6- by 7.5-foot gates were changed to eliminate cavitation pressures and baffles, and stabilizing walls were placed in the stilling basin to aid in the dissipation of the energy in the outlet flow.

(h) "Hydraulic Model Studies of the Outlet Works of Adaminaby Dam for the Australian Snowy Mountains Authority", by J. C. Schuster, Report No. Hyd-397.

U. S. DEPARTMENT OF THE NAVY, NAVAL BOILER AND TURBINE LABORATORY.

Inquiries concerning Projects Nos. 1523 and 1524 should be addressed to Mr. James W. Murdock, Instrument Division, U. S. Naval Boiler and Turbine Labor atory, Philadelphia $\mathrm{Nav}$ al Base, Philadelphia 12, $\mathrm{Pa}$.

\section{(1523) HIGH PHECISION POWER INSTRUMENTS.}

(b) Bureau of Ships and Office of Naval Research, Department of the Navy.

(d) Experimental; applied research.

(e) For improvement of fluid flow measurement. (1) Tests underway to determine influence of approach conditions on orifice meters. Various fittings placed 6 to 60 pipe diameters before orifices. (2) Determination of expansion effects of steam, particularly in low superheat regions; involves introduction of low superhe at steam through proper approaches to orifices having beta ratios of 0.30 to 0.87 . (3) Work is currently being undertaken to determine the effect of two phase flow. Data to date have been obtained for moisture contents in the order of 20 percent.

(g) Results indicate that (I) length of straight pipe required before orifice meter is reducible to less than 50 percent of that presently stipulated without appreciably affecting accuracy of measurement; (2) expansion factors for steam are in general agreement with those now specified except at low superheats where empirical equations must be modified; (3) preliminary results indicate that additional correction for wet steam is essential over and above compensation for density.

(h) "Interference Effects of Approach Piping on Orifice Meter Accuracy", NBTL Test I-67, March 16, 1954.

"Effect of a Globe Valve in Approach Piping on Orifice Metering Accuracy", by J. W. Murdock, C. J. Foltz, C. Gregory, Jr. ASME preprint 54-A-122, presented at Annual Meeting Nov. 29, 1954 . 


\section{(1524) DET}

(b) Bureau of Ships, Department of the Navy.

(d) Field investigation; design.

(e) Study of design arrangement for accurate prediction of pressures in copper-nickel piping systems. (1) Runs conducted to determine friction factors of $1-1 / 2^{\prime \prime}, 2-1 / 2^{\prime \prime}, 4 "$, 5" IPS CuNi tubing. (2) $\mathrm{K}$ factors for $125 \mathrm{psi} \mathrm{Navy}$ and cormercial valves, tees, and ells.

(f) Completed.

(g) (1) Friction factors agree with ASME (Moody's factors). (2) K values with special Navy fittings are lower than with standard equipment.

(h) Final report being prepared for issue about 1 Jamary 1955.

U. S. DEPARTIENT OF THE NAVY, NAVAL ORDNANCE TEST STATION.

Inquiries concerning Projects Nos. 1531, 2021, and 2228, should be addressed to the Commander, U. S. Naval Ordnance Test Station, Pasadena Annex, 3202 E. Foothill Blvd., Pasadena 8, Calif., Attn: Code P807.

(I531) LECHANISM OF CAVITATION.

(b) Laboratory project.

(d) Experimental and theoretical; basic research.

(e) The rates of growth of $v$ apor bubbles in water near equilibrium size are being obtained in order to understand the initial behavior of cavitation bubbles in terms of liquid properties and air content.

(g) High-speed photographs have been obtained of bubbles in slightly superheated water which seem to indicate rough agreement with theory. Attempts will be made to obtain data for higher superheat temperatures in order to obtain a more detailed check with theory.

(h) A report describing previous work on the growth of vapor bubbles in various superheated liquids and the present work is in preparation.

(2021) EXPLORATORY, ANALYTICAL INVESTIGATION OF ROTATIONAL NONVISCOUS FLON.

(b) Laboratory project.

(d) Theoretical; basic research.

(e) The character of rotational nonviscous incompressible flow over bodies situated near or on a bounding wall of the flow region are being investigated. Plan or axial symmetry and simple vorticity distributjons are assumed. Object is to obtain information about boundary layer flow over shrouds, ducts and protuberances from the surface of a large bocty.

(g) Explicit solutions have been found for several models of plane flow with constant vorticity.

(h) A partial report appeared in Decemher $195 \%$.

(2228) BOUNDARY LAYER STUDIES.

(b) Laboratory project.

(d) Theoretical; basic research.

(e) The character of the boundery layer flow over a body of revolution which is yawing or revolving about some axis in space is being investigated. For small angles of yaw, the problem is considered in terms of small perturbations from the axially symmetric problem. Object is to evolve a technioue for solving the incompressible three-dimensional laminar and turbulent boundary layer equations on bodies of revolution when deviations from axially symetric conditions are smell.

(g) A method has been devised for computing incompressible, steady, non-meridional boundary layer flow on bodies of revolution. The method is applicable to laminar and turbulent boundary layer computations over slightly yawed bodies of revolution, which may or may not rotate about some axis in space.

(h) "Incompressible Non-lferidional Boundary Layer Flow on Bodies of Revolution", Artur Mager, NAVORD Report 3366. 
J. S. DEPARTYENT OF THE NAVY, OFFICE OF NAVAL RESEARCH.

For sponsored projects see the following:

Project

$\underline{\text { Page }}$

(15) Studies of cavitation phenomena

(16) Hydrodynamic forces on submerged bodies

(279) Flow in rotating channels

(803) Dynamics of cavitation and cavitation damage

(804) The effect of physical characteristics of liquid on the inception of cavitation

(1300) Basic water entry study

(1301) Hydrodynamics of free-boundary flows

(1548) Special problems in hydrodynamics

(1817) Scale effects in cavitating flow

(2052) Experiments on small scale planing surface

(47) Grevity waves and related phenomenon

(1307) Determination of pressure fluctuations in turbulence in liquid flow

(822) Diffusion of heat, vapor, and momentum

(1838) Behavior of model ship hulls in an oblique sea

(1335) Mathematical theory of waves and ship wave resistance

(69) Relation of sediment characteristics of bed erosion

(72) Electrical analogy of three-dimensional flow

(73) Measurement of turbulence in flowing water

(79) Cavitation

(81) Mathematical analysis of pressure distribution

(851) A constant-iemperature hot-wire anemometer for the measurement of turbulence on air Boundary-layer development on smooth and rough surfaces

Transportation of sediment as suspended and total load

Research on ship theory

Characteristics of solitary waves

$(1355)$

Turbulence measurements in free surface flow

Inrestigation of flow characteristics in unsteady motion

Cavitation inception for steady motion

Recovery factors and heat-transfer coefficients for supersonic flow of air in a tube Three-dimensional flows in compressors

Study of atomization of liquids injected into high velocity gas streans

Development of instrumentetion to measure properties of high-velocity gas streams cont eining liquid droplets in suspension.

The characteristics of a series of controllable pitch propellers

The effect of hydrofoils on the wavemaking and seakeeping characteristics of ships

Forces on oscillating hydrofoils

(1387) Study of tip vortex cavitation

(1388) Turbulent boundery layers

(100) fir entrainment research

(924) Free-jet water tunnel studies

(2143) Experimental and analytical studies of the mechanics of selected methods of surface wave absorption

(2144) Experimental and analytical studies of hydrofoils

(895) The compilation of resistance and propulsion data

(3L0) Planing suriaces

(1L10) Self-propelled testing

(1680) Computation of wave resistance of ships

(1948) Systematic investigation of the turning characteristics of a ship model fitted with various combinations of appendages

(2153) Eveluation of wave fraction and thrust deduction of a ship propeller

(2154) Investigation of ship motions

(2155) Investigation of the seakeeping qualities of ships with particular reference to motions in irregular head seas 
(2156) Motion and stability of hydrofoil systems 88

(2157) Wake and downwash of hydrofoils 89

(2158) Conparison of streamlined bodies and prolate spheroids 8 ,

(1477) Turioulent expsnsion of jets in water $1 / 0^{\circ}$

(1478) Wind waves 141

(1479) Energy dissipation in standing waves

(1480) Positive waves in dry channels

(1989) Stability of the inierface between two parallel streams of imiscible fluid of
different densities lil

(1990) Internal progressive waves

(2205) Wave forces on immersed objects

(1523) High precision power instruments (I-II)

U. S. DEPARTIENT OF THE NAVI, DAVID TAYLOR YODEL BASIN.

Inquiries concerning Projects Nos. 1,67, 470, 709 to 711, incl., 1258, 1503, 1505, 1506, $1511,1512,1514,1515$, 1517, 1521, 1522, 1778 to 1786, incl., 1738 to 1791, incl., 2018 to 2020, incl., and 2229 to 22 t/0, incl., should be addressed to The Commending of ficer and Director, David Taylor Model Basin, Washington 7, D. C.

(467) DEVELOPMENT OF A HOT-IIRE INSTRUEENT FOR TURBULENCE ME

(b) Bureau of Ships, David Taylor Model Basin.

(d) Flow instrumentation.

(e) Development of the hot-rire technique for measuring turoulent velocity components in water.

(g) Manj of the wire instabilities have been eliminated by the use of alternating heating current, isolation transformers, and by the elimination of corrosive action between dissimilar metals by insul ating from the water all parts of the probe holder except the wire. Accunulation of dirt on the wire is still a problem. Progress report in preparation. A theoretical study of the time response of a coated wire has been made.

(470) ELECTROLYTIC TANK STUDIES.

(b) Bureau of Orcinance; David Taylor Kodel Basin.

(d) Potential flow research.

(e) Investigations using the method of electricel analogy to obtein pressure measurements on and about $v$ arious bodies in a fluid.

(g) in electrolytic tank has been developed for obtaining the pressure distribution about cylinaricel bodies. A single probe method is used to obtain potential differences on the body and a double probe method is used for obtaining the potential differences in the surrounding field.

Refinement of instrumentation and techniques has made possible the determination of pressure coefficients at a body surface with an accuracy of better than 0.4 percent of the stagnation pressure.

Plans are underwy for adapting the present tank to other problems in potential flow.

(h) wall corrections for two and three dimensional bodies in a rectangular electrolytic tank", is. Borden, TMB Report 864, Dec. 1954.

(709) THEORY OF WAVE RESISTANCE.

(b) Bureau of Ships; Devid Taylor Hodel Basin.

(d) Hydrodynaric research.

(c) A mathemetical study of the theory of wave resistance for the purpose of establishing methocis for extending the theory to the analysis of ship resistance. Studies will include the general theory of waves in liquids and will encompass a review of existing theory and comperisons with existing experimental data.

(g) A synopsis has been written on the application of theory to the calculations of weve resistince. Calculations were made to obtain general information about wave resistance of subnerged bodies of revolution. The forms considered are ellipsoids, Rankine oroids, and a simple $\mathrm{i}$ amily of streamlined bodies. A report of this work is to be published.

(h) "ih Systematic Evaluation of Michell's Integral", G. P. Weinblum, TMB Report 886, Dec. 1954. 
(710) RESEARCH ON MAIN INJECTION SCOOPS AND OVERBOARD DISCHARGES.

(b) Cooperative with Bureau of Ships.

(d) Applied research; for design.

(e) Investigations to determine the characteristics of a broad series of injection scoops and discharges to provide design data for use in design of future high-speed ships.

(g) An analysis has been made to determine the important paremeters and develop a means of mathematically describing the geometry of several series of injection scoops. A contract hes been awarded to the Newport News Shipbuilaing and Dry Dock Cornpany for the conduct of an extensive experimental study to determine the effect of changes in scoop geometry on efficiency. Three different families of scoop shapes are to be tested.

\section{(7II) CAVITATTON RESEARCH.}

(b) Bureau of Ships; David Teylor Model Basin.

(d) Hy arodynamic research.

(e) Research on the mechanism and effects of cavitation phenomena including the physics and anciytical description of steedy-state cavities in real and ideel fluids and investigations of the inception of cevitation, the growth and collepse processes of transient cavities, and the effects of cavitation on the forces on uncierwater bodies.

(g) A linearized theory has been derived for steady, two-dimersional cavity flows about hydrofoil sections at zero cavitation number. The results are being applied to flcws about low-drag hydrofoil sections.

\section{(1268) STUDIES OF THE INTERLCTION OF APPENDEGES AND BODIES.}

(b) Bureau of Ships; David Taylor Model Basin.

(d) Hydrodynamics of submerged bodies.

(e) hn investigation of potential flow and boundary layer phenomene associated with appendage-body combinations in order to determire the nature of interference effects. The generetion of lif't and moments by fins in non-uniform flows is being studied. A theoretical and experimental investigation is being made in crder to determine the mutual interference effects of appendages and bodies. In addition an experimentel investigation is being carried out in order to determine the effects of non-uniform flows on the lift' and moments of a low aspect ratio fin.

(f) Suspended.

(g) A theoretical investigation is being made.

\section{(1503) BOUNDARY LAYER TRANSITION STULY.}

(b) Cooperative with Bureau of Ships.

(d) Bâsic research.

(e) A study of methods for stimulating predictable turbulent boundary layers to improve the reliability of model tests for resistance prediction. Tests are to be made with flat plates, ship models and bodies of revolution and will include investigations of the effects of size arrangement of stimulators and the effect of pressure gradient.

(g) Theoretical studies have directed attention toward internal roughness stimulators. Design criteria are being developed by means of qualitative boundary layer measurements on flat pletes using pin type stimulators.

\section{(1505) EFFECT OF TRANSVERSE CURVATURE ON FRICTTONAL RESTSTANCE.}

(b) Bureau of Ships; David Taylor Model Basin.

(d) Frictional resistance research.

(e) Studies to determine the effect of transverse curvature on the frictional resistance to motion of a body through a liquid. Shear stress messurements and velocity profiles will be obtained at 10-foot intervals along a 150-foot length of towed cylinder. Results will be extended to determine flat plate resistance without surface and edge effects normally present.

(g) A theoretical analysis of the laminar flow case for slender cylinders has been made to determine significant parameters and the expected magnitude of the curvature effect. Equipment for the experimental phase has been designed and is under construction. 
(1506) STTMULATION OF TURBULENCE ON SHIP MODELS.

(b) Bureau of Ships; David Taylor Model Basin.

(d) Frictional resistance research.

(e) Development of a turbulence stimulating device which will insure adequate turbulence in the boundary layer over the entire length of any ship model. Empirical and theoretical studies will be conducted to evaluate the relstive effectiveness of turbulence rods, trip wires, sand roughness, isolated studs, noise makers and vibrators. Their relative effectiveness will be calculated by studying the model resistance and the character of the boundary layer flow around ship models as determined by the dye-method, the chemical compound, and the hot-wire survey method.

(g) The work of the previous year was devoted to the study of the stimulating effect of studs and the development of the technique of the chemical compound. The evaluation of the stimulators used is still continuing.

(h) The following reports are in review: "Turbulence Stimulation Tests on BSRA Model and an Evaluation of the Effectiveness of the Various Stimulators."

"Technique and Application of Chemical Compounds to Detect Laminar and Turbulent Flow on surfaces of Catamaran Planes and Ship Models and their Correlation with other Detecting Methods."

"Qualitative Measurements of Effectiveness of Noise Makers for Production of Turbulent Flow."

"Qualitative Analysis of Effectiveness of Vibration for Production of Turbulent Flow Around Ship Models."

\section{(1511) SERIES SO SEAWORTHINESS.}

(b) Bureau of Ships; David Taylor Model Basin.

(d) Experimental and theoretical.

(e) Experimental and theoretical investigation of the effect of changes in certain features of hull shape on the seaworthiness characteristics of a series of ship models. Three single screw ship forms of $0.60,0.70$ and 0.80 block coefficient have been adopted for this purpose. Tests to determine the motion end speed reduction characteristics of the 0.60 block model were completed.

(g) Continuation of the experimental work with the 0.70 and 0.80 block models. Correlation between existing motion prediction theories and experimental results in order to find the limitations of the theory.

(h) "Seaworthiness Tests of Series 60 Model, Block Coefficient 0.60." Seventh International Conference on Ship Hydrodynamics, 1954.

\section{(1512) EFFECTIVENESS OF BILCE KEELS.}

(b) Bureau of Ships; Devid Taylor Model Basin.

(d) Experimental testing.

(e) Measurements of the amplitudes of roll versus rolling moment and frequency at or near resonance for a ship model with and without bilge keels; the increase in resistance of a model due to rolling and roll-induced yawing; and the lift, drag, and torque developed by fins. Data will be used in arriving at criteria for the design of fin stabilizers.

(g) Roll tests have been made in the basin on a ship model with and without bilge keels. Also, wind tunnel measurements have been made to determine the effect of variation in fin

- stabilizers on lift, drag, and torque characteristics.

(h) "Model Tests of the Effect of Sweep Hydrofoils on Ships Bilge Keels", by C. G. Moody, Report 888, Jan. 1954.

"Roll Damping and Resistance Due to Rolling for Model 3878-2 Representing DD692 Class (Long Hul工) Destroyers", by George P. Stefun, Report 889, Feb. 1954 .

\section{(1514) MANEUVERING CHARACTERISTICS OF STNGLE-SCREW VESSELS.}

(b) Bureau of Ships, David Taylor Model Basin.

(d) Experimental testing.

(e) Measurements of side forces on propeller, rudder, and hull of a single-screw ship model during successive phases of starting, stopping, and backing maneuvers.

(f) Inactive.

(g) A test program has been formulated. A side-force dynamometer has been designed and completed. 
(1516) STUDIES OF RESISTANCE PREDICTION METHODS.

(b) Cooperative with Bureau of Ships.

(d) Theoretical research.

(e) The theoretical possibility of separating the viscous and wave $\mathrm{drag}$ for surface flows by meens of wake surveys, has been demonstrated. Experiments are to be performed on ship models to verify the practical possibility of using this method to improve resistance predictions.

(g) Instrumentation for the wake survey, including pitot rakes and traversing mechanisms with associate manometric system, is under construction.

(1517) MINIATURE MODEL BASIN.

(b) Bureau of Ships; David Taylor Model Basin.

(d) Facility development.

(e) In order to obtain date on the drag, side force, and vortex configurations of vibrating cylinders a special model basin facility was required. This facility consists of a miniature model basin with small towing carriage whereby cylinders may be tovjed over a range of speeds while oscillating with controllable amplitude and frequency. Measurements of the attendent forces are made by means of strain gege apperatus and vortex configurations may be studied by means of special photographic technioues.

(g) Preliminary tests have been conducted on a 2-inch diameter circular cylinder to determine the magnitude of vortex-induced forces. Results suggested the existence of three-dimensionality of the wake. This was subsequently verified by flow visualization of the wake on the seme cylinder. A new cylinder is being constructed which will permit measuring the forces on a small segment over which the flows should be two-dimensional. Concurrent tests are being conducted in a low-turbulence wind tunnel to determine criteria for twodimensional flow over a cylinder. Hot-wire enemometer techniques are being used to determine span-wise correlation of vortex shedding as a function of Reynolds number.

(1521) 36-INCH VARIABLE PRESSURE WATER TUNNEI.

(b) Bureau of Ships; David Taylor Model Basin.

(d) New facility.

(e) Design and construction of a 36-inch variable pressure water-tunnel for investigation of propulsion, cavitation, and noise characteristics of propellers as well as tests on subsurface bodies. Interchangeable test sections of open and closed jet type will be provided. The maximum design speed is $85 \mathrm{fps}$.

(g) Architectural and engineering work has been completed. Construction is expected to start this year.

(1522) WAVEMAKER STUDIES.

(b) Bureau of Ships; David Taylor Model Basin.

(d) Hydrodynamic research and facility development.

(e) Theoretical and experimental studies of surface wave generators to develop criteria for the design and construction of a large-scale wevemaker installation. A program of research on wave absorbers is also underway. Prerequisite to this latter investigation is the development of practical means for evaluating the ef fectiveness of a given absorber.

(g) A small pilot model of a pneumatic wevemaker has been developed and successfully operated. Improvement has been made in the means of controlling amplitude and frequency of generated waves. A much larger pneumatic wavemaker has been installed in the 140-foot model basin, and has been in regular operation generating waves for ship model tests. A 51-foot wide pneumatic wevemaker has been installed in the deep water basin. A method of making measurements and determining weve absorption characteristics therefrom has been developed analytically. The accuracy with which weve height $c$ an be determined has been improved by the development of an electronic wave-height recorder which operates on a change of capacitance principle. 
(1778) HYDRODYNAMIC NOISE.

(b) Bureau of Ships; David Taylor Model Basin.

(d) Hydrodynamic research.

(e) Investigations of the characteristics of underwater noise associated with various hydrodynamic phenomena such as cavitation, bubble oscillation, turbulence and splashing.

(g) Measurements of the noise radiated by a turbulent jet have been made and compared to existing theory. Studies have been made of noise produced by cavitation, splashing, and oscillating air bubbles.

(1779) TURBULENT BOUNDARY LAYERS.

(b) Bureau ô Ships; David Taylor Model Basin.

(d) Frictional resistance research.

(e) A theoretical and experimental investigation of the velocity profiles and surface shearing stresses in turbulent boundery layers. An instrument for measuring local shearing stresses utilizing the inner velocity law for shear flow.

(1780) BUBBLE FLON STUDIES.

(b) Bureau of Ships; David Taylor Model Basin.

(d) Hydrodynamic research.

(e) Studies of bubble drag and virtual mass, and the kinematic behavior of bubbles as a function of size, pressure gradient, density, viscosity and surface tension of the media.

(g) Experiments were made to determine the shape and drag of individual air bubbles rising freely in various liquids. Theoretical analyses are being made to determine the effect of varying pressure gradients on the motion of bubbles in a fluid.

(1781) ROTATING-APII AND MANEUVERING BASIN.

(b) Cooperative with Bureau of Ships.

(d) New facility.

(e) Design and construction of a circular basin oi 260-foot diameter with a rotating arm whose radius can be varied from 18 to 120 feet. To be used for towing tests of surface and sub-surface models. Also, design and construction of a maneurering basin 350 feet long and 230 feet wide, equipped with traveling bridge and towing carriages, and wavemakers for the purpose of making maneurering tests on ship models.

(g) Functional specifications for the facility have been prepared and a Phase I Advance Planning Engineering Report completed.

(1782) SHIP MOTIONS.

(b) Bureau of Ships; David Taylor Model Basin.

(d) Basic research.

(e) Determination of ship motions in a regular seaway when coupling exists between heave and pitch. The work is to be based on the linear theory and is a contimuation of work on uncoupled motion. It is intended to extend the epplicability of the linear theory to a larger number of vessels of various type.

(1783) MATHEMATICAL SHIP IINES.

(b) Bureau of Ships; David Taylor Model Basin.

(d) Theoretical research.

(e) Development of a suitable method for the mathematical determination of ship lines which can be applied to a wide $v$ ariety of ship forms especially to those of modern design.

(g) A preliminary study has been made which indicates that a solution should be sought through mathematical fairing by waterlines (Benson) instead of by sections (Taylor). First application will be made to the design of an oceanographic research vessel.

(1784) RESEARCH ON UNSTEADY FIOW PROBLEMS - UNSTERDY EFFECTS ON STABIIITY DERIVATIVES.

(b) Bureau of Ships; David Taylor Model Basin.

(d) Theoretical and experimental.

(e) Studies of the effect of oscillation frequency and amplitude, speed of advance and geometry on the stability derivatives of an oscillating body in a fluid. 
(g) The ef fect of the various parameters has been studied with a spheroid of 7 to $I$ fineness ratio. It was shown that unsteady effects may be of importance especially when combined with non-linearity.

(1785) RESEARCH ON UNSTEADY FLOW PROBLEMS - GENERAL THEORY.

(b) Bureau of Ships; David Taylor Model Basin.

(d) Theoretical research.

(e) A general theoretical study of the field of time-dependent hydrodynamic phenomena.

(g) Flows with d'Alembert type unsteadiness, unsteady jet problems, decay of vorticity, d'Alembert flows, Gerstner's waves, potential waves, have been studied. It was shown that the dimensionless parameter which describes the unsteadiness of general fluid motion reduces to the conventional strouhal muber (or dimensionless frequency ratio) for oscillatory flows under certain conditions.

\section{(1786) SIUDIES OF THE SLAMMING OF SHIPS.}

(b) Bureau of Ships; David Taylor Model Basin.

(d) Experimental and theoretical.

(e) Computations and measurements of the maximum pressure and impact forces on the bottoms of slaming ships for the purpose of developing design criteria to effect their reduction.

(g) Studies with ship models were made to determine hydrodynamic impact forces on ships. Regular and confused seas were studied to determine conditions favorable for slamming.

(h) "Ship Slamming in Head Seas", by V. G. Szebehely and M. A. Todd, TMB Report 913. "Model Experiments of Slamming of a Liberty Ship in Head Seas", by V. G. Szebehely and S. M. Y. Lum, TMB Report 914.

"Progress in Theoretical and Experimental Studies of Ship Slamming", by V. G. Szebehely. Conference on Ships and Waves, Council on Wave Research, 1954.

"On Slamming", by V. G. Szebehely, M. A. Todd, S. M. Y. Lum. Seventh International Conference on Ship Hydrodynamics, 1954.

\section{(1788) WAX DEVELOPMENT.}

(b) David Taylor Model Basin.

(d) Experimental testing.

(e) Development of a wax composition and manufacturing techniques for the manufacture of ship models up to 30 feet on water-line length.

(f) Completed.

(g) The blend developed is entirely suited to the climatic conditions existing in Washington, D. C. The strength of this material is such that all types of models, including submarines, may be constructed and handled with no greater care than is given to corresponding wood models. Ninety-one (91) models, varying in length between 19 and $2 \mathrm{~L} \mathrm{ft.} \mathrm{and} \mathrm{in}$ weight between 1,000 and $4,500 \mathrm{lbs.}$, and four $30 \mathrm{ft}$. models have been successfully manufactured and tested since the development of this new wax blend. The introduction of wax model construction technique has resulted in a substantial saving in time and cost of ship model manuf acturing at TMB.

(h) The following reports are being reviewed prior to publication:

"Wax Model Construction at the David Taylor Model Basin", by J. Hadler and W. Hinterthan. "The Development of a N-Butyl Methacrylate Wax Blend for Manufacturing Wax Models at TMB", by W. Hinterthan.

"Development and Application of a Wax Composition for the Manufacture of Experimental Ship Models", by W. Hinterthan. Memorandum: "Methods to be Followed in the Blending of Wax for TMB Wax Model Production", by W. Hinterthan.

\section{(1789) PRESSURE DISTRIBUTTON ON SHIP MODELS.}

(b) Bureau of Ships; David Taylor Model Basin.

(d) Frictional resistance research.

(e) Measurements of pressure distribution and resistance with photographs of wave profiles and flow lines for a series of ship models. Data are to be used for the design of turbulent boundary layer stimulators and the improvement of resistance prediction technique. 
(g) Piezometer orifices have been installed over the surface of a wax model of a merchant ship. A special multiple-tube, circular manometer has been designed and built for use in obtaining a large number of simultaneous pressure measurements. Preliminary experiments have been conducted on the above wax model. Consistent data were obtained for the piezometers mounted in the side of the model, but the lack of consistency for those on the bottom indicate the need for improving the measuring technique.

(1790) PROPELLER THEORY, ARBITRARY DISTRIBUTION OF CIRCULATION.

(b) Cooperative with Bureau of Ships.

(d) Theoretical; applied research.

(e) Studies of moderately loaded propellers with a finite number of blades and an arbitrary distribution of circulation. The theory is based on the velocity potential of helical vortices with numerical representation of the velocity field by means of "induction factors." Application of basic theory to contra-rotating propellers.

(f) Completed.

(g) Problens have been solved both for a free-running and for a wake-adapted contra-rotation propeller.

(h) "Moderately Loaded Propellers with a Finite Number of Blades and an Arbitrary Distribution of Circulation." H. W. Lerbs, Soc. of Nav. Architects and Marine Engineers, 60, 73 to $123,1952$.

(1791) PROPELLER THEORY, OPTIMUM DISTRIBUTION OF CIRCULATION.

(b) Cooperative with Bureau of Ships.

(d) Theoretical; applied research.

(e) Study to determine the optimum distribution of circulation for a moderately loaded propeller which operates in a radially varying wake. Studies have been carried out to determine whether or not the assumption of an axi-symmetrical inflow is sufficiently realistic.

(f) Completed.

(g) The loss of energy which arises from a peripheral non-uniformity of the inflow is small and may be neglected.

(2018) SERIES 60-RESISTANCE OF VARIOUS RELATED HULL FORMS.

(b) Bureau of Shios; Maritime Commission; Devid Taylor Model Basin.

(d) Experimental testing.

(e) The dependance of resistance upon the coefficients of hull form for a practical range of single-screw ship forms is to be determined. The history of the project, the scope of the proposed series is given in $(h)$ for series 57. The resistance results of the original Series 57 models were somewhat disappointing and therefore careful thought was given to the problem of improving the original parents. As a result, new parent forms have been drawn out, together with necessmry contours and models run for resistance. The new family was designated number Series 60 .

(g) It is believed that the new Series 60 contours now are such as to justify their use as a starting point for future research in a number of fields. Suggestions as to such systematic research were made in the exrlier paper, and include the evaluation of the effect of LCB position, $L / B$ and $B / H$ ratios etc.

(2019) PROPELIER EXCITED VIBRATION.

(b) David Taylor Model Basin and Suciety of Naval Architects and Marine Engineers.

(d) Experimental; basic research.

(e) Investigation, measurement and prediction of propeller excited vibratory forces on ship models.

(g) Development of the instrumentation and testing technique for single screw vessels has been completed. An investigation of the principal main hull, propeller and rudder parameters is being conducted in order to determine the effect of such parameters on the vibratory force.

(h) "Propeller Forces Exciting Hull Vibration", Prof. F. M. Lewis and A. L. Tachindji, Nov. 1954, Paper for Society of Naval Architects and Marine Engineers. 


\section{(2020) SHIP MOTIONS.}

(b) Bureau of Ships; David Taylor Model Basin.

(f) Completed.

(h) "On the Motions of Ships in Confused Seas", M. St. Denis and W. Pierson, Transactions by S.N.A.M.E. 1953.

\section{(2229) NEAR SURFACE EFFECTS.}

(b) Bureau of ships; David Taylor Model Basin.

(d) Hydrodynamic research.

(e) A mathematical study of the forces and moments acting on bodies due to the proximity of a free surface. The studies will include both the case in which the surface is initially undisturbed and the case in which there are disturbances originating at a distance.

(g) Methods have been developed for computing the forces and moments acting on bodies of revolution, both due to waves generated by the body itself and to regular trains of waves.

(h) "The Moment Acting on a Rankine Ovoid Moving Under a Free Surface", by H. I. Pond TMB Report 795, Nov. 1951.

"The Pitching Moment Acting on a Body of Revolution Moving Under a Free Surface", by $\mathrm{H}$. I. Pond, TMB Report 819, May 1952.

"The Forces and Moments Acting on a Body Moving in an Arbitrary Potential stream", by W. E. Cumnins, TMB Report 780, June 1953.

"Hydrodynamic Forces and Moments Acting on a Slender Body of Revolution Moving Under a Regular Train of Waves", by W. E. Cummins, TMB Report 910, Dec. 1954.

\section{(2230) THEORY OF SEAWORTHINESS.}

(b) Bureau of Ships; David Taylor Model Basin.

(d) Hydrodynamic research.

(e) A theoretical and experimental study of factors affecting the seaworthiness of ships, for the purpose of developing procedures for predicting their motion.

(g) Tests have been completed on two geometrically similar ship models of different lengths. The analysis of these tests will aid in estimating the validity of model tests for predicting full-scale behavior.

\section{(2231) HYDRAULIC ROUGHENSS STUDIES.}

(b) Bureau of Ships; David Taylor Model Basin.

(d) Frictional resistance research.

(e) Theoretical and experimental research on methods for analyzing and predicting the frictional resistance of arbitrary rough surfaces, especially the painted surfaces of ship hulls. The geometrical characteristics of arbitrary rough surfaces are to be analyzed by amplitudefrequency spectra while the hydrodynamic characteristics are to be analyzed by similarity laws.

(g) The low frequency characteristics of the roughness records necessitate the development of a low frequency spectrum analyzer. The analytical procedures for predicting the frictional resistance of arbitrary rough surfaces from similarity laws have been completed for issuance in a TMB report.

(2232) PRESSURE AND VELOCITY DISTRIBUTIONS ON TWO-DIMENSTONAL AND AXI-STMMETRIC THREE-DIMENSIONAL FORMS.

(b) Bureau of Ships; David Taylor Model Basin.

(d) Potential flow research.

(e) Investigate analytic techniques for determining the pressure and velocity distribution on two-dimensional and axi-symmetric three-dimensional forms. The solution is to be amenable to coding for UNIVAC computation.

(g) An iterative solution has been developed and coded for the UNIVAC. The pressure distribution for a number of bodies whose pressure distribution is known have been completed and verified. Some difficulty is experienced however, with convergence in certain portions of the calculations.

(h) "The Axially Symmetric Potential Flow About Elongated Bodies of Revolution", by L. Landweber, TMB Report 761, Aug. 1951. 
(2233) THE STRUCTURE GF TURBULENCE IN BOUNDARY LAYERS AND WAKES.

(b) Bureau of Ships; David Teylor Model Basin.

(d) Turbulence research.

(e) A study to investigate the behavior of the basic turbulence quantities in boundary layer and wake flows.

(g) Experimental results indicate that the intensity decay and width increase of the turbulent wake in its downstream course behind three-dimensional bluff bodies (discs and plates) are in agreement with theoretically predicted $-2 / 3$ and $1 / 3$ power laws, respectively.

(h) Report in preparation.

(2234) SURFACE WAKES BEHLND TONED STRUTS.

(b) Bureau of Ships; David Taylor Model Basin.

(d) Hydrodynamic Research.

(e) Research on the mechanism of plume and wake formation of surface piercing struts, incluoing the deternination of wave drag, spray drzg, and induced drag for geometrically varied series.

(2235) INVESTIGATION OF LIBERTY SHIP - SEAWORTHINESS.

(b) Bureau of Ships; David Taylor Model Basin.

(d) Experimental and theoretical.

(e) Computations and measurements of motion of Liberty ships in regular and irregular seas. Wetness and acceleration studies at two draft conditions, speed reduction characteristics, etc. are also included.

(g) Some 200 experiments were performed with a 5-foot model. Acceleration, motion and speed records were obtained and in part analyzed.

(2236) OSCILLATING PRESSURES IN THE VICINITY OF PROPEILERS.

(b) David Taylor Model Basin.

(d) Experimental and theoretical; applied research.

(e) Studies of the oscillating pressures on boundaries and in the free space produced by propeller operation. The purpose of the work is to determine the magnitude of the hydrodynamic propeller excited vibratory forces acting on ship's hulls and the effect of operating parameters.

(g) Experimental results are being obtained.

(2237) LIFTING SURFACE THEORY OF PROPELLERS.

(b) Cooperative with Bureau of Ships.

(d) Theoretical; applied research.

(e) Studies of the corrections on lifting line theory which arise from the finite extent of the blades.

(f) Application of an approximate lifting surface theory is completed. Development of a rigorous theory in preparation.

(g) The available results are being applied to propeller design methods.

(h) "Propeller Pitch Correction Arising from Lifting Surface Effect", by H. W'. Lerbs, Preliminary Report, David Taylor Model Basin, June 1954.

(2238) THE EVALUATION OF THE EFFECT OF LCB POSITION UPON RESISTANCE OF VARTOUS RELATED HULI FORMS SERTES 60.

(b) Bureau of Ships; Maritime Commission; David Taylor Model Basin.

(d) Experimental testing.

(e) For each block, four models are built from the contours of Series 60, and tested. The plot of resistance against LCB positions will show the effect of the latter upon the former.

(g) Only part of this work has been completed.

(h) When this project has been completed, a paper will be given to the society of Naval Architects and Marine Engineers. 
(2239) PROPULSIVE CHARACTERISTICS UF VARIOUS RELHTED HULL FORMS SERIES 60.

(b) Bureau of Ships; Maritime Commission; David Taylor Model Basin.

(c) Commanding Officer and Director, David Taylor Model Besin.

(d) Experiment-il testing.

(e) The dependance of propulsion characteristics upon the coefficients of hull form and propeller diameter for a practical range of single-screw ship forms are to be determined. Series 60 parent models are used for this project.

(g) The dependance of wake, thrust deduction, propulsive coefficient, etc. upon the block coefficient, propeller di mmeter, trim etc. has been obtained.

(h) "Propulsion Experiments on Single-Screw Merchant Ship Forms - Series 60", by J. B. Hadler, G. R. Stuntz and P. C. Pien of Nov. 1954. Paper for Society of Naval Architects and Marine Engineers.

(22LO) ROLL DAMPING - GENERAL SEAWORTHINESS.

(b) Bureau of Ships; David Taylor Model Basin.

(d) Experimental and theoretical.

(e) The purpose of this work is to establish a method for predicting the damping characteristic of a ship in rolling motion. Ursell's theoretical results are compared with experimentally obtained values.

(g) Preliminary experimental investigation showed that using properly selected frictional resistence coefficients the experimental results were in agreement with the theoretically predicted values as far as orders of magnitude were concerned.

\section{TENNESSEE V:LLEY AUTHORITY, Hydraulic Data Branch.}

Inquiries concerning all TVA Projects should be addressed to Mr. Albert S. Fry, Hydraulic Data Branch, Tennessee Valley Authority, Knoxville, Tennessee.

Unless otherwise noted, work is being done for Tennessee Valley Authority, Hydraulic

Laboratory Section.

(728) SOUTH HOLSTON AND WATAUGA DAMS, SPILLWAY MODEL STUDIES.

(d) Experimental; for design.

(e) Tests on 1:100 and 1:51 models were made to develop a morning-glory spillway to handle flood overflows.

(f) Model studies completed.

(g) Proper location of piers on crest were determined, and a deflector in the vertical shaft to deflect flow to outside of bend at bottom was developed.

(h) Final report published.

(730) SOUTH HOLSTON DAM, SPILLWAY OUTLET MOLEL STUDIES.

(d) Experimental; for design.

(e) Tests on a 1:51 model were made to develop an outlet structure to dissipate the energy from the morning-glory spillway and the Howell-Bunger valve sluiceway without damage to the tunnel or outlet structures.

(f) Model studies completed.

(h) Final report published.

(731) SOUTH HOLSTON DAM, SURGE TANK MODEL STUDY.

(d) Experimental; for design.

(e) A 1:50 model of the penstock and surge chamber was used to determine (1) the orifice size and characteristic shape to produce favorable pressure and water surface elevation changes for the best governor operation; (2) the maximum and minimum water surface elevations to be expected in the surge chamber; and (3) the operational characteristics or the selected design. 
(f) Model studies completed.

(g) With the proper orifice between the riser and the surge chamber as satisfactory results can be obtained as with the differential riser type of surge tank.

(h) Report in preparation.

(732) WATAUGA DAM, BED LOAD STUDY.

(d) Experimental; for design.

(e) A fixed-bed 1:70 model of the river near the powerhouse was tested to determine whether bed load moved by the spillway discharge would be deposited in the powerhouse tailrace, and, if so, how it could be prevented.

(f) Model studies completed.

(g) A small wall located along the upstream edge of the tailrace channel was found sufficient to keep the bed load from depositing in the draft tubes and the tailrace.

(h) Report in preparation.

(736) APALACHIA DAM, SPILLWAY RATING.

(d) Experimental; operation.

(e) Model tests, checked by field measurements, are to be used in determining the discharge ratings for all anticipated operating conditions. Discharge tables for operating purposes will be prepared.

(f) Model studies completed.

(738) CHEROKEE DAM, SPIILWAY RATTNG.

(d) Experimental; operation.

(e) Model tests, checked by field measurements, are to be used in determining the spillway discherge ratings for all anticipated operating conditions. Discharge tables for operating purposes will be prepared.

(f) Model studies completed.

(739) CHEROKEE DAM, SLUICE RATING.

(d) Field investigation; operation.

(e) Measurement of discharges and differential pressures in the sluices, supplemented by model test data, will be used to establish the discharge retings for the eight sluices. Tables of discharge for any gate opening at any headwater elevation within the operating range are to be prepared.

(741) DOUGLAS DAM, SPILLWAY RATING.

(d) Experimental; operation.

(e) Model tests, checked by field measurements, are to be used in determining the spillway discharge ratings for all anticipated operating conditions. Discharge tables for operating purposes will be prepared.

(f) Model studies completed.

(7L2) DOUGLAS DAM, SLUICE RATING.

(d) Field investigation; operating.

(e) Correlation of the measured differential pressures in the sluice with discharges obtained at a downstream river discharge gage will be used to establish the discharge ratings for the eight sluices. Tables of discharge for one half and full gage openings at any headwater elevation within the operating range are to be prepared.

(f) Completed.

(h) Sluice tables in preparation. 
(7L5) FONTANA DAM, SLUICE RATING.

(d) Field investigation; operation.

(e) Model tests, checked by field measurements, are to be used in determining the discharge ratings for all anticipated operating conditions. Discharge tables for operating purposes will be prepared.

(f) Model studies completed.

(7L6) FORT LOUDOUN DAM, SPILLWAY RATING.

(d) Experimental and field investigation; operation.

(e) Model tests, checked by field mesurements, are to be used in determining the discharge ratings for all anticipated operating conditions. Discharge tables for operating purposes will be prepared.

(f) Model studies completed.

(758) CHEROKEE DAM, PROTOTYPE CHECK TESTS.

(d) Field investigation; applied research.

(e) Periodic checks and observations will be made on the various hydraulic appurtenances to determine the operating characteristics of the structures and the effect of operation on the structures.

(g) Measurement of pressures in the sluice barrel have been obtained and will be compared with pressures obtained in model tests. The apron and sluice barrels were inspected in 1953 to determine the effect of intermittent operation during the past 11 years.

(759) DOUGLAS DAM, PROTOTYPE CHECK TESTS.

(d) Field investigation; applied research.

(e) Periodic checks and observations will be made on the various hydraulic appurtenances to determine the operating characteristics of the structures and the effect of operation on the structures.

(g) Measurement of pressures in the sluice barrel have been obtained and will be compared with pressures obtained in model tests. The apron and sluice barrels were inspected in 1953 to determine the effect of intermittent operation during the past 10 years.

(760) FONTANA DAM, PROTOTYPE CHECK TESTS.

(d) Field investigation; applied research.

(e) Plaster surface impressions of carefully located sections are taken after each extended period of tunnel operation to obtain evidence of damage. Entire tunnel is examined for erosion, cavitation damage, or structural failure.

(g) Inspections made in Sept. 1946, 0ct. 1949, and May 1950.

(7б1) KENTUCKY DAM, PROTOTYPE CHECK TESTS.

(d) Field investigation; applied research.

(e) Measurements are made of lateral pressures on the face of the spillway piers and on the submerged baffle piers on the spillway apron to be compared with the results of the model tests.

(g) Field measurements of crest and baffle block pressures were made in 1946 and 1950.

(762) SOUTH HOLSTON DAM, SURGE TANK PROTOTYPE CHECK TESTS.

(d) Field investigation; applied research.

(e) The prototype installation was equipped to allow testing in a manner similar to that used in the model studies which established the design. A check on the model accuracy can thus be obtained.

(g) Initial tests made in Feb. 1950. 
(763) HIWASSEE DAM, PROTOTYPE CHECK TESTS.

(d) Field investigation; applied research.

(e) Measurements of pressure in sluices are being obtained for comparison with pressures measured in model tests.

(g) Field measurements of sluice pressures were made in 1943 and 1954 . The sluice barrels and apron were inspected in 1954.

(1038) HALES BAR DAM, SPILLWAY APPROACH STUDIES.

(d) Experimental; for design.

(e) Tests are made on a 1:65 model to determine effect of the remains of cofferdam structures upstream of the spillway on the spillway discharge and to determine amount of the obstructions which should be removed.

(f) Model tests completed.

(h) Report in preparation.

(1273) HALES BAR DAM, MISCELLANEOUS STRUCTURES STUDIES.

(d) Experimental; for design.

(e) Tests were made on a 1:65 model to determine location of trash boom and head-water gage intake for a new powerhouse.

(h) Final report issued.

(1274) BOONE DAM, SPILLWAY MODEL STUDIES.

(d) Experimental; for design.

(e) Tests are made on a 1:50 model to determine proper dimensions for bucket-type spillway and associated training walls.

(f) Model studies completed.

(g) The tests proved that for certain anticipated operating comditions for the bucket-type spillway can be adventageously used.

(h) "Boone Project Hydr rulic Model Studies", Tech. Memo. 74, 1954. TVA, Treasurers Office, Knoxville, $(\$ 2.25)$.

(1277) WATAUGA DAM, PROTOTYPE CHECK TESTS.

(d) Field investigation; applied research.

(e) Outlet tunnel surfaces are inspected after completion and after extended pariods of operation to determine erosion, cavitation damage, or structural failure.

(g) Initial inspection in Dec. 1949.

(1283) STEAM PLANT AIR POLLUTION STUDIES.

(d) Field investigation; design and operation.

(e) To obtain information for use in studies of air pollution and its control. Measurements of air temperatures, wind velocities and directions, and atmospheric sulpur dioxide are being obtained at Johnsonville, Shawnee, Widows Creek, and Kingston steam Plant areas. Air temperature, wind velocities, and wind directions are being measured at colbert, Gallatin, and John Sevier Steam Plant areas.

(1534) FORT PATRICK HENRY DAM, SPIILWAY MODEL STUDIES.

(d) Experimental; for design.

(e) Tests are being conducted on a $1: 50 \mathrm{sc} e l e$ and $1: 112.5$ scale model to determine the apron design, training wall dimensions, and other related data.

(f) Model studies completed.

(g) An apron using a single row of rectangular baffle blocks was developed on the 1:50 scale model. This apron was then used in the 1:112.5 scale model and the necessary appurtenant structures developed. Of main interest in the developed design was the lack of training walls. Studies to determine the effect of vegetative growth on the island areas below the spillway showed which areas must be kept free of growth and which may be allowed to grow up.

(h) Report in preparation. 
(1535) DEVELOPMENT OF ERODIBLE BED MATERIAL FOR USE IN MOIEL TESITNG.

(d) Experimental; devel opmental.

(e) An erodible material that will start to move at model velocities comparable to the anticipated velocity at which the prototype material will erode is needed when erosion tests are to be made for areas in which steep banks or cliffs exist. Experiments are under way to develop such a material.

(g) Limited success has been achieved. Experiments are continuing.

(1536) VHF RADIO GAGES FOR REPORTING RAINFALI AND RIVER STAGES.

(d) Experimental; development.

(e) Standard FM tone modulated $169-172$ Mc. radio equipment has been modified to transmit pulsed signals produced in a specially designed electro-mechanical converter unit (keyer). This keyer can be directly operated for river stage measurement by the conventional float system. By use of an electrical servo system, rainfall caught in a standard weighing type gage can be transmitted to the keyer unit. Standard VHF radio station transmitterreceiver units have been modified for use as automatic repeater units. A printing type recorder operated by a standard VHF, FM receiver suitably modified, records and prints all transmitted signals on a 5 inch tape. All transmitting units are supplied with at least 3 days emergency power in case of AC power failure. suitable signals indicate when any gage is on emergency power.

(g) Seven receiving systems which include 14 stream gages, 14 rainfall gages, 9 repeater stations, and 7 receivers have been installed and operated up to two years very satisfactorily. Installation is continuing. Keyer unit has been patented.

(1794) WATTS BAR LOCK PROTOTYPE TESTS.

(d) Field investigation; applied research.

(e) The prototype installation was equipped with piezometers to allow checking of culvert and port pressures and discharges. The culverts and ports were designed from model. studies. Thus, measurement on the prototype would provide model-prototype verification data.

(f) Complete field tests were conducted in May 1952.

(h) Reduction of data is being completed.

(1795) HALES BAR DAM, PROPOSED LOCK LOCATION SIUDIES.

(d) Experimental; for design.

(e) To determine the most expeditious location for the proposed 110 by 600 foot lock, tests are being made on a 1:65 scale model. Effect of changes is determined by measurement of bow and stern forces on model tows and by measurement of wave heights in the navigation channel.

(f) Model studies completed.

(g) The study showed that any of the proposed locations were satisfactory and that only the minimum length of lower guide wall was required. An upstream guide wall set on spaced cell without connecting diaphragms provided satisfactory approach flow conditions.

(h) Report in preparation.

(1796) KINGSTON STEAM PLANT, CONDENSER WATER INTAKE TEMPERATURE SIUDIES.

(d) Theoretical and field investigation; design.

(e) The condenser water intakes and outlets draw water from and discharge into Watts Bar Reservoir (Tennessee River). During the warmer portions of the year this reservoir becomes stratified and the inflowing waters pass through the reservoir as density currents. By means of theoretical considerations and field observations, the proper location and shapes for the intakes and outlets are to be determined and the probable intake temperature calculated.

(g) Six-point recording temper ature gages were installed on the Tennessee, Clinch, and Emory Rivers and data obtained during the period of stratification in 1953 and 1954 . Velocity and temperature profile measurements were made at eight sections in the Clinch and Emory 
Rivers for periods of steady flow to define thermal density underflow. Theoretical analyses were made to show the benefits that could be derived by the installation of a submerged dam in the Clinch River below the mouth of the Emory River to divert the density underflow up the Emory River.

(1797) GAJLATIN STEAM PLANT, CONLENSER WATER INTAKE TEMPERATURE STUDY.

(d) Theoretical and field investigation; design.

(e) The condenser water intakes and outlets are to draw water fron and discharge into the proposed 0ld Hickory Reservoir (Cumberland River). The entire setup is to be analyzed to determine the type of flow conditions to be expected in the reservoir; the temperatures to be expected at the inlets; and the best design for the inlets and outlet structures.

(g) Single-point temperature recorders were installed at six stations which, in combination with turbine intake temperature recorders at three upstrean dams, will be used to determine temperature increases between points on the cumberland River for various conditions. Data are being collected and ev aluated.

(2028) JOHN SEVIER SIEAM PLANT, INTAKE DAM.

(d) Experimental; design.

(e) A 1:50 scale model was used to study the energy dissipating characteristics and the erosion tendencies of the cascade-type water diversion dam.

(f) Completed.

(g) The model studies showed that an end sill 4 feet high, instead of 2 feet, provided excellent operation. These studies also showed that this simple apron was effective in front of the gates, which eliminated a more elaborate and expensive apron.

(h) Final report issued.

(2029) APALACHIA POWER TUNNEL, PROTOTYPE CHECK TESTS.

(d) Field investigation; operation.

(e) Periodic inspections of the power tunnel will be made to determine change in subsurface roughness. Field test measurements will be made to determine the change in friction and roughness coefficients.

(g) The tunnel was inspected in 1953 after 10 years of contimuous operation. Fleld pressure measurements were made in March 1954 to determine change in friction coefficients as compared to those obtained as reported in Project 757 in Hydraulic Research in the United states, Vol. 14, 1950. These tests are now being analyzed.

(2030) BOONE DAM, SPILLWAY RATING.

(d) Experimental; operation.

(e) Model tests, checked by field measurements, are to be used in determining the spillway discharge ratings for all anticipated operating conditions. Discharge tables for operating purposes will be prepared.

(f) Model studies completed.

(2031) FORT PATRICK HENRY DAM, SPIILWAY RATING.

(d) Experimental; operation.

(e) Model tests, checked by field measurements, are to be used in determining discharge ratings for all anticipated operating conditions. A $1: 15$ scale model of one bay and its associated Taintor gate was used to determine discharges for gate openings below crest level and up to five feet above crest level. Discharge tables for operating purposes will be issued.

(f) Model studies completed. 
(22LI) KINGSTON STEAM PLANT - CONDENSER COOLING WATER CONDUIT LOSS.

(d) Experimental; for design.

(e) Longitudinal interior support was required for 96-inch concrete pipe conduit. A study was made of the relative loss for a six-inch thick vertical concrete wall, I beams separated by $4-I / 2$ inch pipe columns and $I$ beams separated by streamlined $4-I / 2$ inch pipe columns.

(f) Laboratory studies completed; field tests planned.

(2242) NORRIS DAM, TAILRACE HEAD-LOSS STUDIES.

(d) Field investigation; applied research.

(e) Measurements were made to determine the effect of obstructions in the tailrace channel on head at turbines.

(2243) OCOEE 3, PROTOTYPE CHECK TESTS.

(d) Field investigation; applied research.

(e) Periodic checks and observations will be made on the various hydraulic appurtenances to determine the operating characteristics on the structures and the effect of operation on the structures.

(g) The power tunnel to the powerhouse was inspected and found to be in good condition. A partial inspection was made of the spillway apron and sluice channel.

(2244) WAYNESVILIE WATERSHED, RATTNG OF SAN DIMAS FLUME.

(d) Experimental; applied research.

(e) A steel 1.5 foot wide San Dimas Flume was rated in the laboratory for heads up to 2.16 feet.

(f) Completed.

(g) Rating issued.

(2245) SOUTH HOLSTON DAM, TAILRACE HEAD-LOSS STUDY.

(d) Experimental; applied research.

(e) The study was conducted to determine the increase in head at the turbine that could be produced by removel of certain flow obstructions.

(f) Completed.

(g) It was estimated that removal of about 300 cubic yards of debris would reduce the tailwater about 1 foot. Subsequent investigations after removal of material showed that a gain of 1.5 feet was realized due to the careful removal job.

(22L6) DISCHARGE COEFFICIENTS FOR RADIAL GATE ON STANDARD CREST.

(d) Experimental; master's thesis in cooperation with University of Tennessee.

(e) Tests were made on a $1: 15$ scale model of a single bay to determine the effect of trunnion and gate seat location on the 'spillway discharge coefficient using the Creager-Justin standard crest.

(f) Model tests completed.

(22L7) DOUGLAS DAM, SLUICE OPERATING ORDER STUDY.

(d) Field investigation; operation.

(e) Prototype flow conditions were studied to determine the best sluice gate operation sequence to minimize the type of apron damage that had occurred during the first ten years of operation.

(f) Completed.

(g) A gate sequence utilizing gates set at half discharge and full discharge was developed which minimized eddy formation on the apron and practically eliminated backflow onto the apron.

(h) Data on file; no report contemplated. 
Hydraulic Investigations Section.

(764) DETERMTINATION OF SEDTMENT CARRTED IN SUSPENSION BY TENNESSEE RIVER AND TRIBUTARIES.

(d) Field investigation; basic research.

(e) To provide data for estimating effective life of storage reservoirs, and loss of soil from the land. Samples of water were collected periodically at stream gaging stations in the watershed, analyzed to determine the sediment content, and correlated with river discharge to determine the suspended sediment load at each station.

(h) Report in preparation.

(765) EVAPORATION IN THE TENNESSEE BASTN.

(d) Fielf investigation; applied research.

(e) To provide data for estimating reservoir losses and derive a general rule, applicable to the Basin, permitting computation of evaporation from pans at six locations in Basin together with standard meteorological readings.

(h) "Precipitation in Tennessee River Basin", published in monthly and annual bulletins.

(768) PEECIPITATION IN TENNESSEE RIVER BASTN.

(d) Field investigation; basic research.

(e) A comprehensive study of rainfall and other weather phenomena for purposes of water dispatching and improvements in water control; storm studies as related to maximum precipitation, rainfall-runoff, spillway design and operation, etc.

(h) Monthly bulletin, "Precipitation in Tennessee River Basin." Also annual surmary.

(769) RESERVOIR AND STREAM TEMPERATURES.

(d) Field investigation; basic research.

(e) Study of water utilization and water movement as concerns industrial plant locations and stream pollution. Variations in temperature from surface to botton in reservoirs throughout the year are determined by soundings, and by contimuous recording gages in natural streams.

(77) GALLERY DRATNAGE IN LARGE DAMS.

(d) Field investigation; design.

(e) Weirs are placed in main galleries and drainage measured as check on tightness and stability.

(783) WHITE AND RICHLAND CREEKS--DETERMINATTON OF ROUGHESS COEFEICIENT.

(d) Field investigation; basic research.

(e) Determinations being made in several river reaches of known discharge to extend knowledge of relation between roughness coefficient and physical characteristics of rivers.

(f) Completed.

\section{(785) SEDIMENTATION OF EXISTMNG BE SERVOTRS.}

(d) Field investigation; basic research.

(e) Selected ranges in reservoirs are probed and sounded, yolumetric samples are collected and analyzed, quantity and distribution of sediment are computed to determine deposition by stream, probable life of reservoir, effect of sediment storage on navigation channels and sedimentation of downstream reservoirs, and probable sedimentation in future reservoirs.

(786) WATER TRAVEL IN NATURAL STREAMS.

(d) Field investigations; applied research.

(e) Sanitary and chemical changes in water during passage downstream are determined. A given mass of water is identified by electrical conductivity or chemical titration.

(f) No work done in recent years. 
(787) MOVEMENT OF WATER THROUGH LARCE RESERVOIRS.

(d) Field investigation; applied research.

(e) Because of slow water travel, samples are collected by traverse through lake.

(f) No work done in recent years.

(g) Water entering a reservoir does not intermix with the rest of the reservoir, but remains as a density current as a result of the difference in temperature between the inflowing Water and that in the reservoir. During certain seasons of the year, in Watts Bar Reservoir the cold water released from Norris Reservoir passes upstream along the bottom of the Emory River arm of the former reservoir.

(1284) RESERVOIR SEDTMENT DENSTTY SAMPLER.

(b) Cooperative with Federal Inter-Agency Committee on Water Resources.

(d) Experimental; applied research, design, operation, development.

(e) Preliminary laboratory testing of the device for making in-place density measurements of deposited reservoir sediment showed the need for simpler and better instruments and a more satisfactory source material.

Hydrology section.

(777) RUNOFF-EROSION INVESTIGATIONS ON SMALC WATERSHEDS.

(d) Field investigation; basic and applied research.

(e) To evaluate hydrologically existing or changed land-use practices or management. Data are obtained on rainfall, runoff, and soil loss, and in some instances include groundwater levels and soil moisture.

(778) EFFECT OF ALTITUDE UPON RAINFALL.

(f) Completed.

(h) Final report on a precipitation-altitude study in the snowbird Mountains is in preparation.

(779) MAXIMUM POSSIBLE PRECIPITATION IN TENNESSEE VALLEY.

(b) Cooperative with U. S. Weather Bureau.

(d) Theoretical; applied research.

(e) Hydrometeorological analysis of large storms with upward adjustments of controlling factors to maximum limits as applied to the Tennessee Valley and subdivisions.

(g) Results to be published as one of current series of hydrometeorological reports by the U. S. Weather Bureau and cooperating agencies.

(780) MONTHLY EVALUATION OF GROUND-WATER STORAGE.

(d) Theoretical; operation.

(e) By analysis of current records of stream discharge, the volumes of runoff in groundwater and channel storage are determined for use in operation of multi-purpose reservoirs.

(g) Results reported monthly within the organization.

Procedures Development Section.

(1801) RATN GAGE LOCATION STUDIES--SOUTH CHICKAMAUGA CREEK WATERSHED.

(d) Field investigation; applied research.

(e) A study to learn the most applicable location and necessary density of rain gages to obtain an accurate record, particularly for river forecasting purposes, in a basin having numerous parallel ridges, and to compare several methods of computing average rainfall and of estimating runoff. Three recording and 11 nonrecording rain gages, in addition to 4 existing nonrecording gages, were established in the South Chickamauga Creek watershed, which has a drainage area of 428 square miles.

(f) completed. 
(g) Daily observations began December 1, 1952. Two recording and 8 nonrecording gages are being discontinued December 1, 1953 .

(h) Report in preparation for internal use. Condensed paper in preparation for publication in Trans. Amer. Geophys. Union.

(2032) DEVELOPMENT OF RIVER FORECASTTNG METHODS.

(d) Experimental; applied research.

(e) Studies to develop improvements to river forecast procedures with particular application to streams and local inflows into reservoirs operated by the TVA. Procedures include

(1) rainfall-munoff relations involving the effect of soil moisture, evapo-transpiration and interception losses, geological features of the watersheds, and seasons; (2) unit surface-water and ground-water hydrographs; (3) streamflow routing procedures; (4) coordinated studies with an established unit of the U. S. Weather Bure au for determination of natural flows at pertinent river points.

(22L8) RAIN GAGE LOCATION STUDIES--FLINT RIVER WATERSHED.

(d) Field investigation; applied research.

(e) A study, similar to that on the South Chickamauga Creek watershed (1801), to determine the most advantageous location and necessary density of rain gages to obtain the desired accuracy in storm rainfall for river forecasting purposes, on a watershed having in general a gently rolling topography. In addition to one existing nonrecording rain gage and two existing recording rain gages in or adjacent to the area, eight nonrecording gages were established on the watershed, which has a drainage area of 342 square miles. These gages were located to provide approximately uniform distribution throughout the watershed.

(f) Daily observations beginning November 1, 1954.

Field Investigations Section.

(2249) EXPERIMENTAL RAIN GACE.

(d) Experimental; applied research.

(e) An inner concentric ring was installed in the collector of a standard nonrecording rain gage so that the gage would collect only half of the catch of a standard gage. This would double the measuring capacity of gages and would be particularly useful in remote areas where heavy seasonal $r$ ainfall is experienced.

(f) Initial tests completed. Tests continuing on several alternate designs.

(g) A 12-month record, compared with the record for an adjacent standord gage, showed an accuracy within 0.5 percent. 
UNI VERSITY OF BRITISH COLUMBIA, Hydraulics Leboratory.

Inquiries concerning Projects Nos. 1044 and 2033, should be addressed to Prof. Edwerd S. Pretious, Department of Civil Engineering, University of British Columbia, Vancouver, Canada.

\section{(1044) FRASER RIVER MODEL.}

(b) Cooperative with the Department of Public Works of Canada.

(d) Experimental; to assist in problems of river regulation and control.

(e) An outdoor erodible-bed tidal rivver model to study methods for improving and maintaining the navigable channels of the lower Fraser River estuary. Horizontal scale 1:600, vertical scale 1:70. The model occupies approximately 4 acres and represents the tide water area of the lower Fraser River from the Strait of Georgia to Sumas, and includes Pitt River and Pitt Lake. Natural tides and river discharges can be simulated in the model. Sand injection is automatically controlled and is a function of river discharge. Instantaneous water surface slopes can be obtained by automatic electrically recording point gauges.

(h) Progress and technical reports submitted periodically.

\section{(2033) VANCOUVER HARBOUR MODEL.}

(b) Cooperative with the National Research Council of Canada.

(d) Experimental; to determine the hydraulic effects of dredging the First Narrows in Burrard Inlet.

(e) An outdoor fixed-bed model to investigate the effect on tides and current patterns in Vancouver Harbour and current velocities in Second Nerrows due to dredging the First Narrows. Pilot model of First Narrows being constructed initially, with horizontal scale 1:L00, vertical scale $1: 100$, to determine required roughness for this distortion.

(h) Progress and technical reports submitted periodically.

MCGILL UNI VERSITY, Department of Civil Engineering.

(2039) LOSSES IN BENDS IN STEEL PIPING CARRYING WATER-BORNE SUSPENSION OF WOUD-PULP.

(b) Laboratory project.

(c) Prof. V.W.G. Wilson, Department of Civil Engineering, McGill University, Montreal 2, P.Q. Canada.

(d) Experimentel.

(e) Measurements made of head losses in mitre bends, long radius and standard bends in 4 inch pipe line carrying wood pulp suspensions of 2 to 2.55 percent.

(f) Completed.

(h) Paper delivered at Annual Meeting of Technical Section of Canadian Pulp and Paper Association, Montreal, Jan. 1954.

(20LO) SUPERCRITICAL FLOW IN CURVED CHANNELS.

(b) Laboratory project, for master's thesis.

(c) Prof. Carleton Craig, Department of Civil Engineering, Mcgill University, Montreal 2, P.Q. Canada.

(d) Experimental.

(e) Experiments done on model of curved steep rectangulap channel with six different sill arrangements and with three different flow rates.

(f) Completed.

(h) Thesis published, McGill University, May 1954. 
ECOLE POLYTECHNIQUE DE MONTREAL, Hydraulics Laboratory.

Inquiries concerning Projects Nos. 266, 268 and 1803, should be addressed to Prof. Raymond Boucher, École Polytechnique, Montreal 18, Canada.

(266) HYDRAULIC MODEL STUDIES OF DIFFERENT SPILLWAY PROFILES.

(b) Laboratory project.

(d) Experimental; applied research.

(e) To establish a comparison between the discharge capacities of different spillway designs. Studies are made on concrete models of existing and recommended spillway profiles. Pressure distribution on spillway faces and coefficients of discharge are determined for $v$ arious heads up to the designed head. The effect of gate piers of $v$ arious design is also investigated. Eight different profiles have been studied, including two modifications of the Creager profile upstream of crest line.

(268) CALIBRATION TESTS OF A SHARP-CRESTED PARABOLIC WEIR.

(b) Laboratory project.

(d) Experimental; applied research.

(e) To obtain the head-discharge curves and head-discharge coefficient curves for a sharpcrested parabolic weir (2l-inch maximum width by 18-inch maximum height) having a capacity of $3 \mathrm{cfs}$. The influence of viscosity is also being investigated. This weir is to be used in a flume for model testing and open channel s.tudies.

(f) Completed.

(g) Report in preparation.

(1803) MODEL STUDY OF LAC BETSY LOGWAY.

(f) completed.

(g) Report in preperation.

NATIONAL RESEARCH COUNCIL, Division of Mechanical Engineering.

Inquiries concerning Projects Nos. 1806, 2041 to 2043, incl., 2250 and 2251, should be addressed to Mr. J. H. Parkin, Director, Division of Mechanical Engineering, National Research Council, Montreal Road, Ottawa, Ontario, Canada.

(1806) ST. LAWRENCE RIVER MODEL - PPESCOTT-CARDINAL REACH.

(b) Department of Transinrt.

(d) Experimental; for design and development.

(e) A 1:240 × 1:48 scale model of the St. Lawrence River between the towns of Prescott and Cardinal is being constructed to study the effect of engineering works on the water level relationships throughout the reach. The model is being made of 2 foot $\times 4$ foot concrete blocks which are cast from patterns made.by projecting directly from the contour map of the area. This procedure enables the model to be built by mass production methods and provides for modifications to any area. Note: This model covers the same area as the model reported previously under No. 1806, but is being made to approximately twice the horizontal scale.

(20LI) ST. LANRENCE RIVER MODEL - CORNWALL ISLAND REACH.

(b) St. Lawrence Seaway Authority.

(d) Experimental; for design and operation.

(e) A $1: 480 \times 1: 96$ scale model of about five miles of the St. Lawrence River in the vicinity of cornwall has been constructed to study the design of proposed engineering works in connection with the seaway. The model has been constructed of 2-foot square concrete blocks cast from patterns made by projecting directly from contour maps of the area. 
The model has been verified with respect to gauge heights vs. discharge relationship and current distribution and the first of several modifications is ready for testing.

(g) Verification was successfully achieved with added roughness in the form of $1 / 2$ inch $x$ 18 gauge aluminum strips cemented to the bed of the channels. The strips are entirely submerged and do not af fect surface currents.

(20L2) LOCK MODEL.

(b) St. Lawrence Seaway Authority.

(d) Experimental; for design.

(e) A I/30 scale model of an 800 foot by 80 foot navigation lock, having a lift of 40 feet, has been constructed to study the design of side port filling systems upon filling time and turbulence in the lock chamber.

(g) The tests on the arrangement of the filling ports and supply conduits have been completed and tests are in progress on the design of the conduit discharge ports so that there will be a minimum of disturbance in the lower pool as the lock is emptied. Consideration is being given to rebuilding the model to represent a flight lock.

\section{(20L3) FILITNG PORTS FOR IOCK.}

(b) St. Lawrence Se away Authority.

(d) Experimental; for design.

(e) A $1 / 15$ scale model of a section of supply culvert including three filling ports and a section of the canal lock were constructed to determine the coefficient of discharge of the ports and pressure distributions for various heads over a range of velocities in the supply conduit. A limited number of tests were made with reverse flow to represent the emptying condition.

(f) Completed.

(h) Report submitted to sponsor.

(2250) LOCK CULVERT JUNCTION.

(b) St. Lawrence Se away Authority.

(e) A l/30 scale model of a lock supply culvert was constructed consisting of two parallel conduits connected by a short tube. Object was to design tube such that flow in one conduit was divided equally to each half of other conduit. Combining flow from second culvert to first one was also studied. A range of discharges was studied for which flow division, secondary flow and pressure distribution were measured.

(g) Several practical designs have been evolved.

(h) Report in preparation.

\section{(2251) SPILWWAY MODEL.}

(b) Shawinigan Engineering Company Limited, Montreal.

(d) Experimental; for design.

(e) A $1 / 64$ scale model of a proposed spillway was tested to determine the pressure at the sill, discharge coefficient and scouring action below the apron.

(f) Completed.

(g) Tests made with the apron at the same height as the end of the spillway showed that scouring of the river bed occurred a considerable distance downstream. With the apron lowered 18 feet scouring was excessive and was reduced to acceptable proportions by a protecting wall 13 feet high at the end of the apron.

(h) Report submitted to sponsor. 
QUEEN'S UNIVERSITY, Hydr aulics Labor atory.

Inquiries concerning Projects Nos. 1807 and 2044 should be addressed to Prof. R. J. Kennedy, Dept. of Civil Engineering, Queen's University, Kingston, Ontario, Canada.

(1807) SIUDY OF CUBE-TIPPED PITOT TUBE.

(b) Laboratory project.

(d) Experimental; basic research.

(e) To develop methods of measuring flow in pipes by means of a cube-tipped pitot tube.

(f) Completed.

(h) Report in preparation.

(2044) ECONOMLCAL CONSTRUCTION OF SAFE PULPWOOD HOLDING GROUNDS.

(b) Pulp and Paper Research Institute of Canada Limited, 3420 University St., Montreal, Quebec, Canada.

(d) Applied research; experimental field and labor atory investigation.

(e) Field and laboratory model investigation of forces acting on various types of pulpwood holding grounds.

UNIVERSITY OF TORONTO, Department of Mechanical Engineering.

(2252) HYDRAULIC FLOW IN OPEN CHANNELS OF VARIABIE SLOPE.

(b) Laboratory project.

(c) Prof. I. E. Jones, University of Toronto, Toronto 5, Canada.

(d) Experimental; applied research for master's thesis.

(e) An experimental investigation making use of a tilting flume now in process of design.

(2253) A CRITICAL STUDY OF THE SI ANDARD STEP METHOD FOR COMPUTING BACKWATER CURVE IN OPEN CHANNELS.

(b) Laboratory project.

(c) Prof. I. E. Jones, University of Toronto, Toronto 5, Canada.

(d) Computational research for master's thesis.

(e) This research is for the purpose of investigating the various procedures used in the standard step method of backwater computation with a view to selection of the best procedure.

(2254) MODEL STUDY OF MOTRA RIVER DAM.

(b) Moira River Conservation Authority.

(c) Prof. G. Ross Lord, University of Toronto, Toronto 5, Canada.

(d) Experimental; design.

(e) A scale model of a proposed dam to prevent flooding in a city due largely to ice flows.

(f) Completed.

(h) Report submitted to sponsor. 
Accelerated motion spheres (1923).

Air entrairment

flumes (100)

pipes $(1303) \ldots \ldots \ldots \ldots \ldots \ldots \ldots \ldots \ldots \ldots . \ldots \ldots$

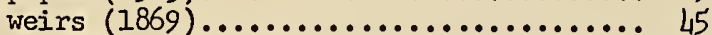

Air pollution (1283) ................. 175

Airfoils, cascades (1118)............. 55

Air-water flow (1834)............... 17

Air-water mixtures

closed channels $(2148) \ldots \ldots \ldots \ldots \ldots \ldots . \ldots 8$

Apparatus

channels, rotating (279) .............. ${ }^{3}$

coast model basin $(973) \ldots \ldots \ldots \ldots \ldots \ldots \ldots 114$
flood forecasting $(1010) \ldots \ldots \ldots \ldots \ldots 142$

photo-electric, sediment (1331)........ 29

polariscope, design (1546)............ I

precipitation gage $(547) \ldots \ldots \ldots \ldots \ldots \ldots$....... 31

" " (2080)............ 33

" " , radio (1012)....... I 142

rotating arm $(1781) \ldots \ldots \ldots \ldots \ldots \ldots \ldots \ldots 167$

sand separator $(52) \ldots \ldots \ldots \ldots \ldots \ldots \ldots, 18$

sediment sampler (194)............... 122

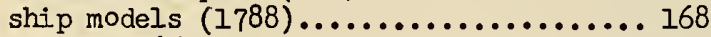

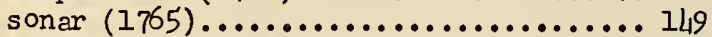

stream gage (1013)................. 142

tank, electrolytic $(470) \ldots \ldots \ldots \ldots \ldots \ldots 163$

tilting design (1336)............... 35

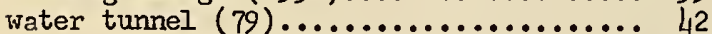

" " (924)................... 78

" " (1150)(1151)............. 74

" $"$ (1521)..................... 166

" $\quad$ " (1547).................... 2

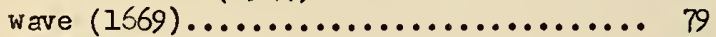

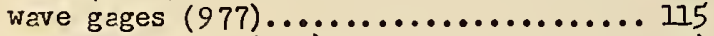

wave generator $(973) \ldots \ldots \ldots \ldots \ldots \ldots . \ldots 114$

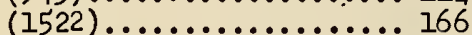

wave tank (399) ..................... 113

wind tunnel (1152)................ 75

Backwater

constricted channels (1487).......... 148

Baffle piers

cavitation (993) .................. 128

Barges

resistance $(585) \ldots \ldots \ldots \ldots \ldots \ldots \ldots \ldots \ldots$

Beaches

by-passing sand, inlets (975)......... 115 effect, inlets (1736)............... 134 equilibrium profile (181)............. 113 model laws $(184) \ldots \ldots \ldots \ldots \ldots \ldots \ldots \ldots . \ldots 113$ structures, design (972)............ 114 tidal effects (1725)................. 115 wave action (47).................. 10

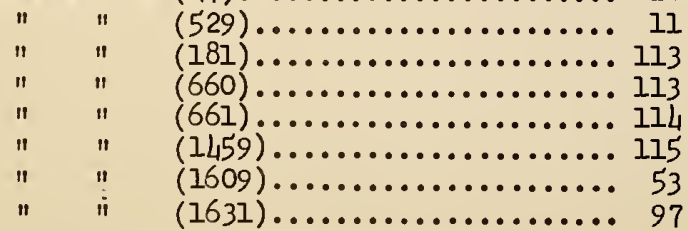

Beach fills (2195)................... 117 Bends (see Pipes, bends)

Bibliographies ships (895) ............. 83

Boundary flow (1301)................. 4

Boundary layer

body of revolution (2228) .............161

conduits $(290) \ldots \ldots \ldots \ldots \ldots \ldots \ldots \ldots \ldots . \ldots . \ldots 26$

diffuser, pipe entrance (2123)......... 64

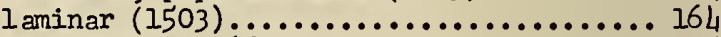

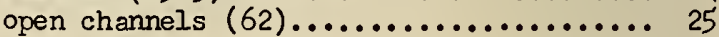

pipe entrance $(2122) \ldots \ldots \ldots \ldots \ldots \ldots \ldots .64$

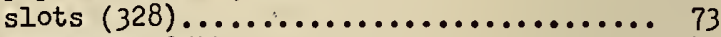

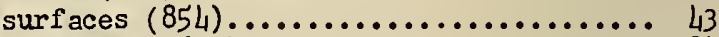

turbulent $(627) \ldots \ldots \ldots \ldots \ldots \ldots \ldots \ldots \ldots . . . . .14$

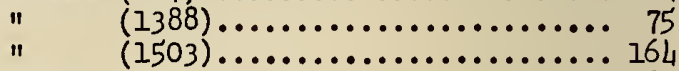

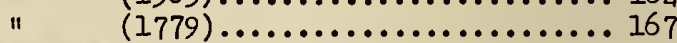

Breakwaters

pervious and impervious (998).......... 129

rubble-mound (999).................... 129

wave diffraction $(47) \ldots \ldots \ldots \ldots \ldots \ldots \ldots . . . .10$

Bridge piers

scour $(568) \ldots \ldots \ldots \ldots \ldots \ldots \ldots \ldots \ldots \ldots, 42$

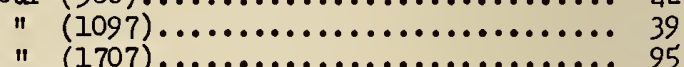

Bubbles

air nuclei....................... 3

diffusion $(1060) \ldots \ldots \ldots \ldots \ldots \ldots \ldots \ldots . \ldots \ldots \ldots$

drag and shape $(1780) \ldots \ldots \ldots \ldots \ldots \ldots \ldots . . \ldots 167$

ice sheets $(1156) \ldots \ldots \ldots \ldots \ldots \ldots \ldots \ldots . \ldots 76$

oxygen transfer $(580) \ldots \ldots \ldots \ldots \ldots \ldots \ldots . \ldots \ldots$

resorption $(803) \ldots \ldots \ldots \ldots \ldots \ldots \ldots \ldots \ldots . \ldots \ldots \ldots$

vapor $(1548) \ldots \ldots \ldots \ldots \ldots \ldots \ldots \ldots \ldots \ldots \ldots \ldots \ldots$ L

Bulk modulus, oils $(904) \ldots \ldots \ldots \ldots \ldots \ldots$. 7

Canal drop, Wyoming canal (707)...........151

Canals

density currents (1482)............ I 141 irrigation

linings $(1766) \ldots \ldots \ldots \ldots \ldots \ldots \ldots \ldots \ldots \ldots$

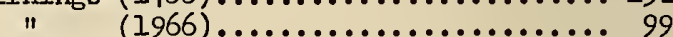

seepage $(820) \ldots \ldots \ldots \ldots \ldots \ldots \ldots \ldots \ldots . \ldots . \ldots . \ldots 19$

" (2213)..................... 157

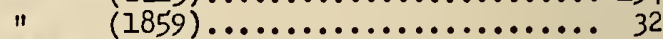

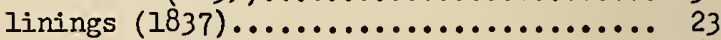

", lower-cost (2214)............. 157

model study (2010).................... 155

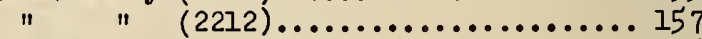

navigation, silting (1737)........... 135

scour on curves (1501)................ 152

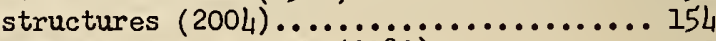

Cascades, flow through (2082)........... 33

Cavitation

baffle piers (993)................. 128

basic research $(993) \ldots \ldots \ldots \ldots \ldots \ldots \ldots \ldots 128$

Calif. Inst. of Tech. (15) ........... 2

" " " " (1548)......... 4

David Taylor Model Basin (711)......... 164

Iowa State University $(79) \ldots \ldots \ldots \ldots \ldots, 42$

" " " (81)........... 42

Mass. Inst. of Tech. (579).......... 51 
Cavitation

Northwestern Univ. (326)........... 71

Penna. State College (1386)......... 75

Waterways Experiment Station (993).... 128

boundary misalignment $(90) \ldots . \ldots \ldots \ldots$..... 49

bubbles

air nuclei $(804) \ldots \ldots \ldots \ldots \ldots \ldots \ldots . . \ldots$

cavity flow (1301)................ L

conduit contractions $(72) \ldots \ldots \ldots \ldots \ldots \ldots, 42$

damage from $(1815) \ldots \ldots \ldots \ldots \ldots \ldots \ldots \ldots . . . \ldots$

dynamics of $(803) \ldots \ldots \ldots \ldots \ldots \ldots \ldots \ldots \ldots$

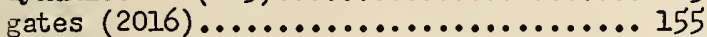

gate slots $(993) \ldots \ldots \ldots \ldots \ldots \ldots \ldots \ldots . \ldots . \ldots . \ldots 128$

inception $(1355) \ldots \ldots \ldots \ldots \ldots \ldots \ldots \ldots . \ldots \ldots \ldots$

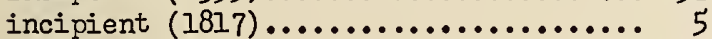

intake $(674) \ldots \ldots \ldots \ldots \ldots \ldots \ldots \ldots \ldots . \ldots \ldots . \ldots \ldots$

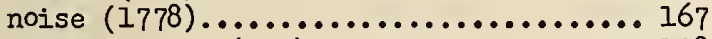

offset joints $(993) \ldots \ldots \ldots \ldots \ldots \ldots \ldots \ldots . \ldots 128$

pipe bends $(993) \ldots \ldots \ldots \ldots \ldots \ldots \ldots \ldots \ldots . \ldots 128$

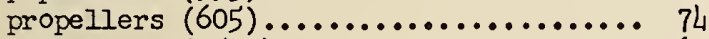

(1531).................. 161

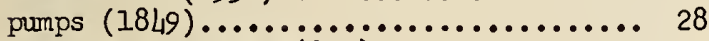

rotating channels (279).............. 3

rough surfaces $(2005) \ldots \ldots \ldots \ldots \ldots \ldots \ldots . . .154$

scale effects $(1817) \ldots \ldots \ldots \ldots \ldots \ldots \ldots . .5$

sluice gates $(79) \ldots \ldots \ldots \ldots \ldots \ldots \ldots \ldots . \ldots . \ldots 2$

stilling basin steps $(993) \ldots \ldots \ldots \ldots \ldots . . \ldots 128$

tip vortex (1387)................ 75

turbines

models $(1133) \ldots \ldots \ldots \ldots \ldots \ldots \ldots \ldots \ldots .68$

propeller $(271) \ldots \ldots \ldots \ldots \ldots \ldots \ldots \ldots$ I

unsteady motion (579).............. 51

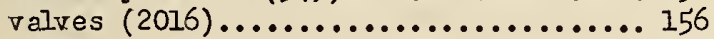

water tunnel (79)................. 42

Cavities

shape (1386)..................... 75

Channel improvement

flood control

Allentown, $\mathrm{Pa} .(1469) \ldots \ldots \ldots \ldots \ldots . \ldots 132$

Cumberland, Md. (230).............. 125

Hoosic River, Mass. (1271).......... 131

Los Angeles River (1203)............. 121

Middle Miss. River (236)........... 125

nevigation

Charleston Harbor, S. C. (678)........ 127

Delaware River, Pa. (425) .............. 126

Fraser River (1044)............... 182

Valdivia River, Chile (1468)......... 132

power development (1470) .............. 133

Channels (see open channels)

alluvial (1313)................... 21

boundary roughness $(1854) \ldots \ldots \ldots \ldots \ldots . . . .30$

conservative linings (1723)........... 101

constricted flow (1855).............. 30

converging, diverging (1558)......... 17

hydraulic jump $(1857) \ldots \ldots \ldots \ldots \ldots \ldots . . . .6$

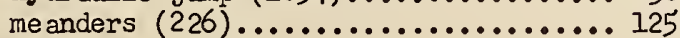

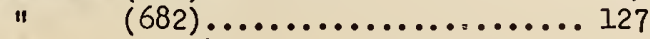

" $\quad(1313) \ldots \ldots \ldots \ldots \ldots \ldots \ldots . \ldots 21$ regime theory of (1839)................ 23

rotating flow (279)................. 3

side flow $(2073) \ldots \ldots \ldots \ldots \ldots . . . \ldots \ldots . . . .26$

super-critical flow $(2040) \ldots \ldots \ldots \ldots \ldots \ldots 182$

transition (1321)................... 25

trapezoidal (682)................... 127

(1568)................... 22

velocity distribution (1343)........... 38

unsteady flow (1565)................. 22

Circulation, condenser water

Schuylkill River $(1712) \ldots \ldots \ldots \ldots \ldots \ldots . .96$

Cofferdams

Dalles Dam, Ore. (1L62)..............118

compressible fluids $(2110) \ldots \ldots \ldots \ldots \ldots \ldots .60$

conduits

boundary layer (290)................. 26 condenser cooling water loss (2241)..... 178 discharge measurements (2017) .......... 156 inlets $(72) \ldots \ldots \ldots \ldots \ldots \ldots \ldots \ldots \ldots \ldots, 42$

corrosion

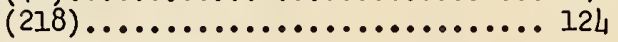

basic research (1341)................ 35

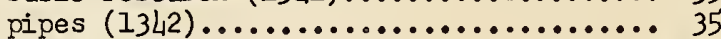

plumbing $(49) \ldots \ldots \ldots \ldots \ldots \ldots \ldots \ldots \ldots \ldots . \ldots \ldots$

Culverts

discharge characteristics (1856)........ 30

drop inlet $(111) \ldots \ldots \ldots \ldots \ldots \ldots \ldots \ldots . \ldots . \ldots$

cylinders

lift coefficients (1905)..............6 63

vibrations $(1517) \ldots \ldots \ldots \ldots \ldots \ldots \ldots \ldots \ldots \ldots$

Dams

gallery drainage (771) .............. 179

ice holding $(2254) \ldots \ldots \ldots \ldots \ldots \ldots \ldots . . . \ldots 185$

Density currents

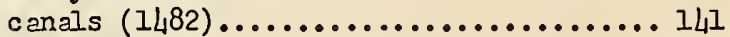

model laws (159).....................140

reservoir

cold water $(1796) \ldots \ldots \ldots \ldots \ldots \ldots \ldots \ldots$

" " (1797).................. 177

sedimentation (307) ............... 51

suspended sediment $(805) \ldots \ldots \ldots \ldots \ldots . . . .3$

salt water intrusion

Delaware River $(425) \ldots . \ldots \ldots \ldots \ldots \ldots . \ldots 126$ stability of interface (1989)........... 141 tidal estuaries (1986) ................. 138 Diffusers

vaned (1901).................... 58

survey of literature (2079)............ 31

Diffusion

gases (1566) ..................... 22

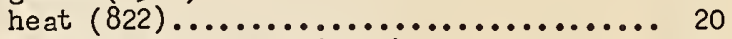

particles in fluid (1331)............. 29

Distillation, sea water (1554).......... 13

Diversion channels, model studies (1975)... 120

Draft tubes

efficiency (1851)................... 29

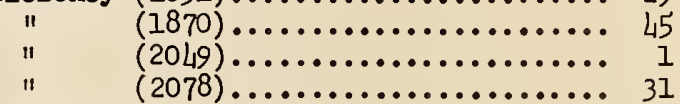

Drag, accelerated spheres (1923)........ 80 
Drain, storm, head loss (2134).......... 67 Drain interceptor (2067).............. 24 Drainage

Central Valley, Calif. (2183)......... 104 Coachella valley, Calif. (26)......... 8 Florida (1966).................... 99 galleries, dams (771)................. 179 irrigated lands (359)................. 91

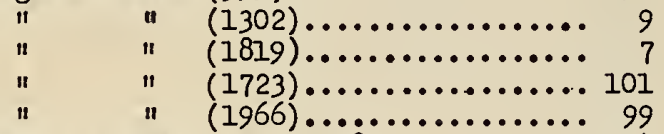
Payette Valley, Idaho (2182)................ 104 surface, subsurface (2126)........... 65 Upper Color ado River Basin (2184)...... 105 Drain tile, junction losses (1929)....... 81 Drains, durability (2127)............. 65 " , stability $(2127) \ldots \ldots \ldots \ldots \ldots \ldots \ldots . . .65$ Dust separators, cyclone $(1884) \ldots \ldots \ldots \ldots . . \ldots 56$ Eddies, effect of boundary geometry (1875) 46 Electric analogy

three-dimensional (72).............. 42

Embankments (291).................. 29

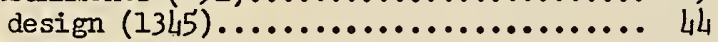

Erosion research canal, ditch linings (1966)........... 99 " " " (2013)............. 155 conservation farming $(150) \ldots \ldots \ldots \ldots \ldots . .100$ (2187)............. 108 effect sediment characteristics (69).... 41 effect vegetation (261)............... 105 " " (376)................ 109

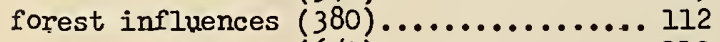
" $\quad$ " $(657) \ldots \ldots \ldots \ldots \ldots \ldots . \ldots 110$

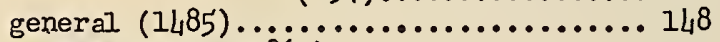
Lake Michigan (1863)............... 37 mountain watersheds $(261) \ldots \ldots \ldots \ldots \ldots . \ldots 105$ " " (376).............. 109 range management $(27) \ldots \ldots \ldots \ldots \ldots \ldots \ldots$........ 8 semi-desert vegetation $(657) \ldots \ldots \ldots \ldots \ldots .110$ stream-bed (69).................... 41 Evaporation

arid regions (445)................. 146 effect of reforestation ( 439$) \ldots \ldots \ldots \ldots .146$ ev apo-transpiration (1222) ........... 147 " " " (2188)............ 112 grassland (1757)...................... 149 he at diffusion $(822) \ldots \ldots \ldots \ldots \ldots \ldots \ldots, 20$

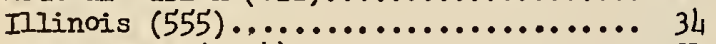
lake models (13I 4$) \ldots \ldots \ldots \ldots \ldots \ldots \ldots . . .21$

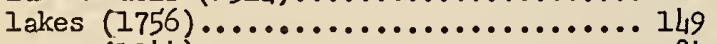

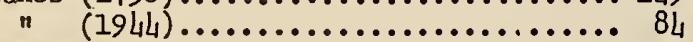
measurement $(1015) \ldots \ldots \ldots \ldots \ldots \ldots \ldots . \ldots 142$ " (2179).................. 103 reservoirs $(765) \ldots \ldots \ldots \ldots \ldots \ldots \ldots \ldots . \ldots 179$

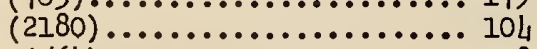
urban areas (564)................... 38 watersheds, Tennessee Basin (765)....... 179 Filters (1577).................... 27 Fisheries engineering research (2197).... 121
Fish ladders dams

Dalles Dam, Ore. $(1462) \ldots \ldots \ldots \ldots \ldots \ldots 118$
$\|$

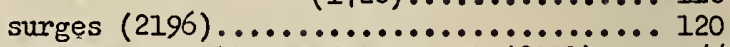
Fish screen, Delta-Mendota Canal (2017).... 155 Fishway model study $(1974) \ldots \ldots \ldots \ldots \ldots \ldots . . \ldots 120$ " " " (2086)................ 40

Flood control

basin, Whittier Narrows (980).......... 121 crop rotation (1966)................. 99 Hogback Dam (1961).................... 96

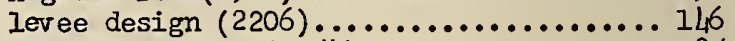
Moira River Dam (2254) ............... 185 policy $(2097) \ldots \ldots \ldots \ldots \ldots \ldots \ldots \ldots \ldots . \ldots . \ldots 47$ rivers

Anacostia, Md. (2200)............... 138

Cumberland, Md. (230)................ 125

Mississippi Basin (236).............. 126

Flood discharge

frequency-magnitude (1233)............ 148 me asurement $(691) \ldots \ldots \ldots \ldots \ldots \ldots \ldots \ldots . \ldots 146$

Flow controller

coefficient of discharge (2076)........ 28

Flow between flat plates $(1890) \ldots \ldots \ldots \ldots . . .56$

Flow regulator, three-way (2160).......... 90

Flow routing $(1943) \ldots \ldots \ldots \ldots \ldots \ldots \ldots . \ldots . \ldots . \ldots$

Flow, rotational nonviscous (2021)........ 161

Flow, steady viscous

effect cylindrical boundary (2135)...... 70

Flow, stratified, stability of (2092)..... 47

", transitional phenomenon (2114)....... 61

" three-dimensional, compressors (2104) 59

Fluidization (1138)................. 69

Fluidized solids, flow of $(1882) \ldots \ldots \ldots . . . .55$

Flumes

air entrainment (100)................ 78

standing waves $(2139) \ldots \ldots \ldots \ldots \ldots \ldots \ldots \ldots \ldots \ldots$

tilting design $(1336) \ldots \ldots \ldots \ldots \ldots \ldots \ldots \ldots, 35$

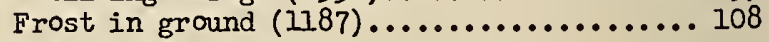

Gas-liquid

distribution, porous media (1830)....... 15

flow (1829)........................ 15

Gates

cavitation (993)................... 128

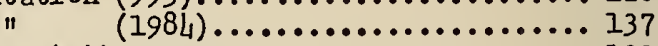

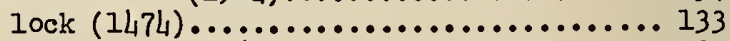

operation $(1206) \ldots \ldots \ldots \ldots \ldots \ldots \ldots \ldots \ldots . \ldots 123$

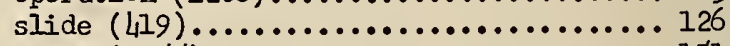

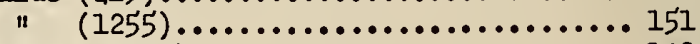

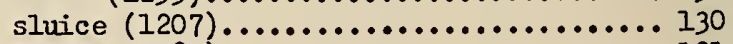

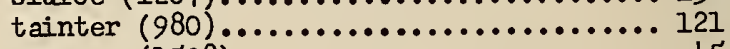

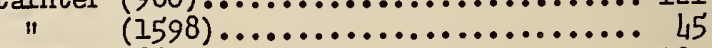

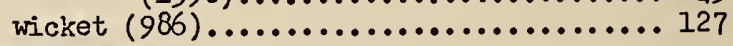

Ground water

artesian aquifer $(2124) \ldots \ldots \ldots \ldots \ldots \ldots 64$

artificial recharge $(559) \ldots \ldots \ldots \ldots \ldots \ldots . . . \ldots 36$

" " (1966).............. 99

Carroll county, Ill. $(843) \ldots \ldots \ldots \ldots \ldots$......... 34 Central valley, Calif. (2183)............ 104 Chicago area $(1335) \ldots \ldots \ldots \ldots \ldots \ldots \ldots . . . . . .67$ 
Ground water

Coachella valley, Calff. (26).......... 8 compilation of theories, formulas (1866) 37 East st. Louis area (56i)............. 34 effect forests $(656) \ldots \ldots \ldots \ldots \ldots \ldots . \ldots . \ldots 108$ " $\quad$ (1997)................. 150 electric flow net $(1221) \ldots \ldots \ldots \ldots \ldots \ldots$ IL 6

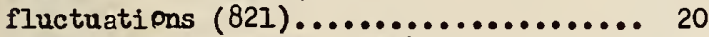
fresh water storage (2000)............ 150 frost $(1574) \ldots \ldots \ldots \ldots \ldots \ldots \ldots \ldots \ldots \ldots . \ldots \ldots$ $(1575) \ldots \ldots \ldots \ldots \ldots \ldots \ldots \ldots \ldots \ldots \ldots \ldots$ hydrologic cycle $(1092) \ldots \ldots \ldots \ldots \ldots \ldots . \ldots . \ldots$ hydrologlc investigation (2001)........ 150 instruments, adaptation (1998)......... 150 irrigation (1966).................. 99 Jo Daviess County, II1. $(843) \ldots \ldots \ldots \ldots . . . .34$

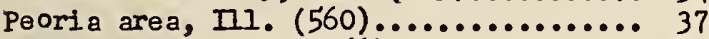
Ralston Creek, Iowa (66)............. 41 Rapid Creek, Iowa (68).............. LI reforestation $(430) \ldots \ldots \ldots \ldots \ldots \ldots \ldots . \ldots \ldots$ root $z$ one $(2172) \ldots \ldots \ldots \ldots \ldots \ldots \ldots . \ldots \ldots$ Stephenson County, IIl. (843)........ 34 stream flow (1223).................. 147

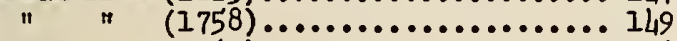

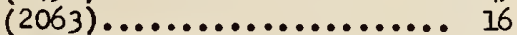
Tennessee Valley $(777)(780) \ldots \ldots \ldots \ldots . . .180$

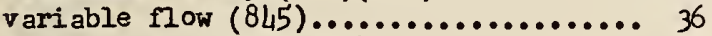
Gutters, side flow (2073).............. 26 Harbor improvement

Charleston, S. C. $(678) \ldots \ldots \ldots \ldots \ldots \ldots . . . .127$ Grays Harbor, Wash. (1210) ........... 130 Indi ana Harbor, Ind. (1472)......... 133 Harbor models

Black River (2130)................. 65 scale effects $(1002) \ldots \ldots \ldots \ldots \ldots \ldots \ldots . . \ldots 130$ Vancouver (2033)................... 182

Heat transfer

cooling pond $(2210) \ldots . . . . . . . . . .150$

cooling towers (1059)............... 12

general research $(822) \ldots \ldots \ldots \ldots \ldots . . \ldots 20$

supersonic flow $(880) \ldots . . . \ldots \ldots . . . . .54$

unsteady phenomena (1594)............. 44

Highway drainage

culverts (111)

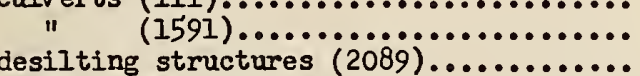

embankments (29l) ...................

flow gage, sewers (1111) .............

gutters $(1096) \ldots \ldots \ldots \ldots \ldots \ldots \ldots \ldots \ldots \ldots . . \ldots \ldots$ sediment in sewers $(1101) \ldots \ldots \ldots \ldots \ldots . . . .$. subway grating design (2087)...........

Hydraulic control system

$v$ alves (2105)

Hy draulic history $(i 102) \ldots \ldots \ldots \ldots \ldots \ldots \ldots . \ldots \ldots$

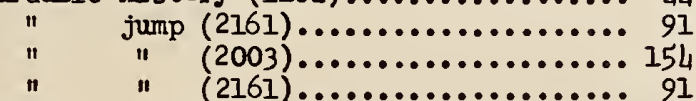

Hydraulic laboratory design (2094)....... 47 Hydrofoil systems, motion, stability (2156) 88
Hydrofoils

cavitating flow (1871).............. 45

hydrodynamic forces $(2138) \ldots \ldots \ldots \ldots \ldots . . \ldots 72$

model tests (2119).................. 63

shock wave formation $(2061) \ldots \ldots \ldots \ldots . \ldots 16$

study of $(1618) \ldots \ldots \ldots \ldots \ldots \ldots \ldots \ldots \ldots \ldots$

$"$ " $\quad(2144) \ldots \ldots \ldots \ldots \ldots \ldots \ldots \ldots \ldots \ldots . \ldots \ldots$

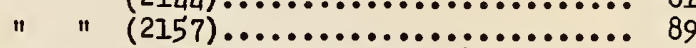

Hydrologic studies, Florida (150)......... 100 Waller creek Watershed (2162).......... 91

Hydrodynamic forces $(2053) \ldots \ldots . . \ldots \ldots . . . .6$

" ", missiles $(2054) \ldots . . . .6$

Ice sheets, fracture $(1156) \ldots \ldots \ldots \ldots \ldots \ldots . . \ldots$

Infiltration

effect vegetation (376).............. 109

" $"$ (1966).............. 99

farms $(1759) \ldots \ldots \ldots \ldots \ldots \ldots \ldots . . \ldots \ldots . . . \ldots 149$ recharge

basins (1225) ..................... 147

ponds $(1999) \ldots \ldots \ldots \ldots \ldots \ldots \ldots \ldots . . \ldots \ldots$

soil (25) ......................... 7

" (1058)........................ 9

" $\quad(1222) \ldots \ldots \ldots \ldots \ldots \ldots \ldots \ldots \ldots \ldots \ldots \ldots . \ldots . \ldots 147$

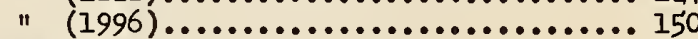

Inlets

conduits $(72) \ldots \ldots \ldots \ldots \ldots \ldots \ldots \ldots \ldots \ldots \ldots . \ldots . \ldots . \ldots$

culverts $(111) \ldots \ldots \ldots \ldots \ldots \ldots \ldots \ldots \ldots \ldots \ldots . \ldots 78$

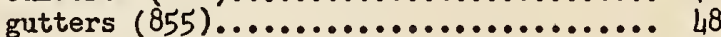

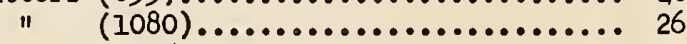

" $(1095) \ldots \ldots \ldots \ldots \ldots \ldots \ldots \ldots \ldots \ldots \ldots . \ldots \ldots \ldots$

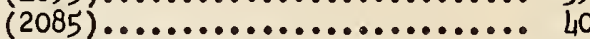

hydraulic characteristics $(2084) \ldots \ldots . . .39$

storm water, design $(2149) \ldots \ldots \ldots \ldots \ldots \ldots . . . . .83$

theory $(2088) \ldots \ldots \ldots \ldots \ldots \ldots \ldots \ldots \ldots . . . . . .40$

Instruments

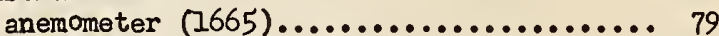

drop-size measuring probe (2110) ........ 60

flow gage, storm sewers (1111)......... 49

high velocity gas $(2113) \ldots \ldots \ldots \ldots \ldots \ldots . . \ldots 6$

hot-wire, anemometer $(851) \ldots \ldots \ldots \ldots . . . . .43$

" $"$, meter $(467) \ldots \ldots \ldots \ldots \ldots \ldots \ldots . \ldots \ldots$

photonetric drop-size (2110).......... 60 power (1523) ......................... 160 precipitation gage $(547) \ldots \ldots \ldots \ldots \ldots . \ldots . \ldots . \ldots . \ldots$

" (2080) .............. 33

pressure cells (1004)................ 130 pressure fluctuation (1307) ............ 12 radio rain gage $(1012) \ldots \ldots \ldots \ldots \ldots \ldots \ldots . \ldots 142$

" $"$ " (1536)............... 176

rain gage, continuous (1992)........... 144

" ", coding device (2014).......... 155

river gage (1013).................... 142

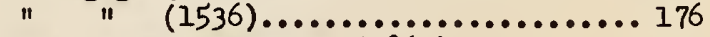

river, stage-me asuring (1861)......... 32 soil moisture $(1995) \ldots . . . . . . . . . . . .149$ temperature measuring probe (2116)..... 62 turbulence meter $\left(1985^{\prime}\right) \ldots \ldots \ldots \ldots \ldots \ldots \ldots 138$ velocity meter (1004)................ 130 
Instruments

wave gage (660)..................... 113

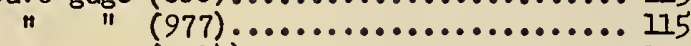

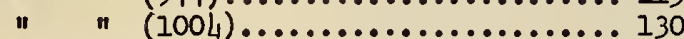

wel1 testing (1219)................ 146

\section{Intakes}

(1337)................ 35

condenser water (1796)(1797)........... 176 conduit, design $(218) \ldots \ldots \ldots \ldots \ldots \ldots 124$

dams $(674) \ldots \ldots \ldots \ldots \ldots \ldots \ldots \ldots \ldots \ldots . \ldots \ldots$

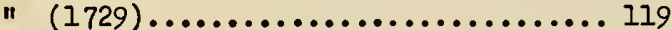

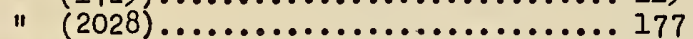

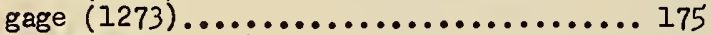

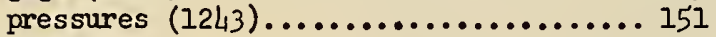

Irrigation

canals

design study (2069)................ 24

linings (1966).................... 99

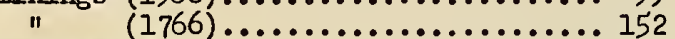

seepage $(820) \ldots \ldots \ldots \ldots \ldots \ldots \ldots \ldots \ldots . \ldots . \ldots . \ldots 19$

" (1966)................... 99

concrete pipe $(24) \ldots \ldots \ldots \ldots \ldots \ldots \ldots \ldots . \ldots \ldots$

control of water $(1966) \ldots \ldots \ldots \ldots \ldots . . .99$

drainage studies (1302) .............. 9

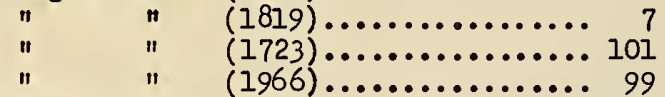

equipment (1955)................... 92

" , design (2186)............. 105

farm structures $(2 L) \ldots \ldots \ldots \ldots \ldots \ldots \ldots \ldots . \ldots 7$

" " $(2065) \ldots \ldots \ldots \ldots \ldots \ldots . . .24$

infiltration (1966)................ 99

meters (1499)..................... 152

percolation (1966).................. 99

pipe, air vents $(1690)(1691) \ldots \ldots \ldots \ldots . .93$

pipe friction $(24) \ldots \ldots \ldots \ldots \ldots \ldots \ldots \ldots . \ldots 7$

Rockdale soils (1766)............... 152

snow surveys $(55) \ldots \ldots \ldots \ldots \ldots \ldots \ldots \ldots \ldots . . \ldots 18$

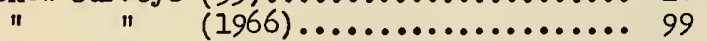

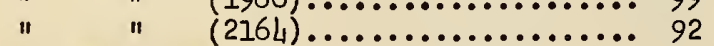

soil moisture $(26) \ldots \ldots \ldots \ldots \ldots \ldots \ldots \ldots .68$

" " (2164)................. 92

soil permeability (1966)............. 99

sprinkling systems (21) $\ldots \ldots \ldots \ldots \ldots \ldots$

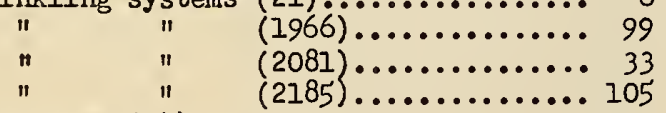

structures $(24) \ldots \ldots \ldots \ldots \ldots \ldots \ldots \ldots \ldots . .7$

temperature control $(2128) \ldots \ldots \ldots \ldots \ldots . .65$

weter application (1966).............. 99

water measurement $(24) \ldots \ldots \ldots \ldots \ldots \ldots \ldots$. 7

water supply $(23) \ldots \ldots \ldots \ldots \ldots \ldots \ldots \ldots$ ? 7

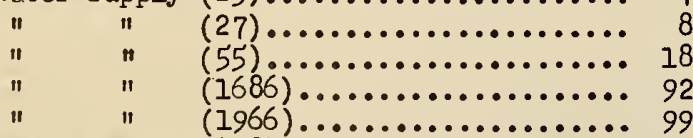

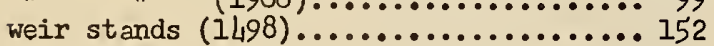

well drilling $(24) \ldots \ldots \ldots \ldots \ldots \ldots \ldots . . \ldots$

Jets

boundary effects (1301)...............

free, water tunnel $(924) \ldots \ldots \ldots \ldots \ldots \ldots, 78$
Jets

high speed (2167)................. 94

pressure distribution $(72) \ldots \ldots \ldots \ldots \ldots .42$

spray formation $(1637) \ldots \ldots \ldots \ldots \ldots \ldots \ldots$. 7

submerged diffusion $(948) \ldots \ldots \ldots \ldots \ldots .90$

turbulent expansion $(1477) \ldots \ldots \ldots \ldots \ldots 140$

Jetties

design, location (38)............... 9

effect littoral drift (2190)........... 117

effect wave action (529).............. 11

Laboratory equipment, design (2100)....... 50

Lake levels, Great Lakes (1994)........... 145

" " , Lake Erie (2201)............... 139

Lake Levels, storm winds (160)............. 140

Laminar flow, stability of (1873)........ 46

Laminar flow tube entry friction (2108).... 59

" " " " (2109)....6 60

Iift, measurement (2052).............. 6

Locks

approaches $(1738) \ldots \ldots \ldots \ldots \ldots \ldots \ldots \ldots . \ldots 135$

(1739) ..................... 135

culvert junction $(2250) \ldots \ldots \ldots \ldots \ldots \ldots . \ldots . \ldots . \ldots 184$

filling, emptying systems

Dalles Dam, Ore. (1L66).............. 119

Greenup, Ohio River (1977)........... 123

Hales Bar (1795)...................... 176

Markland, Ohio River (1977) ........... 123

Miss. River Keokuk, Iowa (196) ........ 123

model $(2042)(2043) \ldots \ldots \ldots \ldots \ldots \ldots \ldots . \ldots 184$

st. Lawrence Seaway $(2198) \ldots \ldots \ldots \ldots . .124$

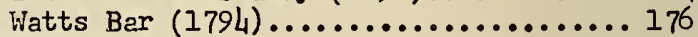

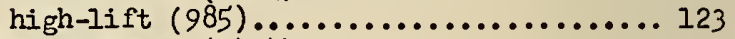

miter gates (1474).................. 133

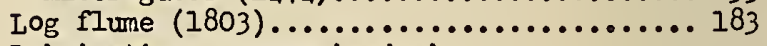

Lubrication, pressurized air

bearings (1890)..................... 56

pressurized liquid bearings (1891)...... 57

Manifolds (1171)...................... 84

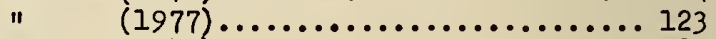

" (2042)........................ 184

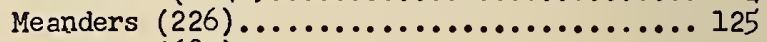

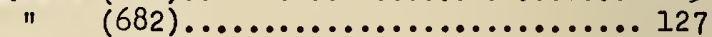

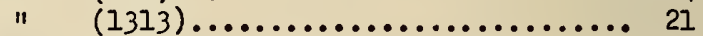

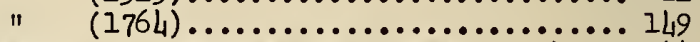

Meteorology, pressure jump lines (1993).... 144

Meters (see Nozzles, Orifice meters, Venturis)

calibration (124)................. 68

current, low velocity (2015)............ 156

elbow $(1602) \ldots . . . \ldots \ldots \ldots \ldots \ldots \ldots \ldots . . . \ldots$

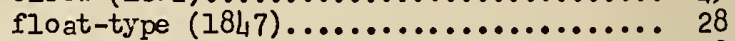

flow, inferential $(2074) \ldots \ldots \ldots \ldots \ldots \ldots 28$

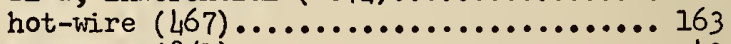

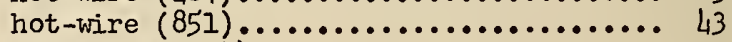

irrigation $(24) \ldots \ldots \ldots \ldots \ldots \ldots \ldots \ldots \ldots$. 7

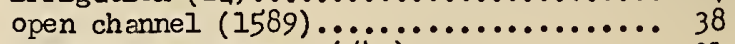

precipitation gages $(547) \ldots \ldots \ldots \ldots \ldots \ldots$........ 31

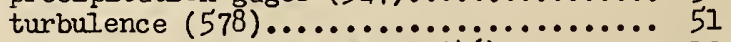

velocity, $\in$ lectro-magnetic $(46) . . . . . . .10$

Model distortion $(994) \ldots \ldots \ldots \ldots \ldots \ldots \ldots . \ldots 128$

Model laws

be aches (184)

113 
Model laws

density currents (159).............. 140 scale effects

harbors (1002) .................... 130

spillways (1001) .................. 129

small models (593)................. 70

streams, me andering (226)........... 125

waves $(184) \ldots \ldots \ldots \ldots \ldots \ldots \ldots . . \ldots \ldots 113$

Model roughness standards $(1000) \ldots . . . \ldots . .129$

Model verific ation

pressure measurement

penstocks, South Holston Dam (762) .... 174

sluices, Cherokee Dam (758)......... 174

", Douglas Dam ( 759$) \ldots \ldots \ldots . . . .174$

", Hiwassee Dam (763)......... 175

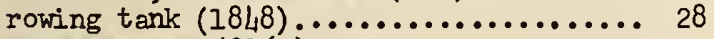

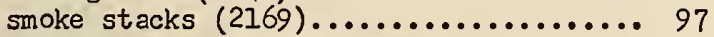

spillway piers and baffles

Kentucky Dam (761)................ 174 prototype confirmation (1L67)........ 131

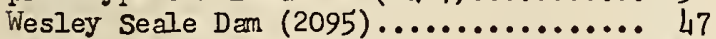

Models, bed material $(1535) \ldots \ldots \ldots \ldots \ldots$

Noise $(1778)$....................... 167

Nozzles

calibration $(1843) \ldots \ldots \ldots \ldots \ldots . \ldots \ldots$

mixing $(40) \ldots \ldots \ldots \ldots \ldots \ldots \ldots \ldots \ldots . \ldots \ldots . \ldots \ldots$

pressure distribution $(72) \ldots \ldots \ldots \ldots . \ldots 42$

Open channels (see Channels)

air entraiment (100).............. 78

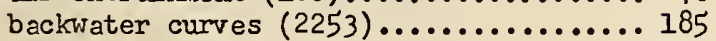

boundary layer $(62) \ldots \ldots \ldots \ldots \ldots . \ldots \ldots$

boundary roughness $(1854) \ldots \ldots \ldots \ldots \ldots . . . . .30$

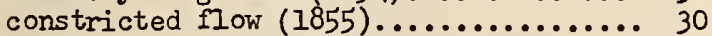

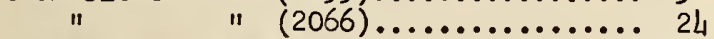

converging, diverging (1558) ......... 17

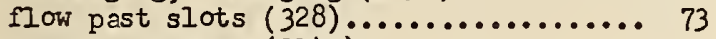

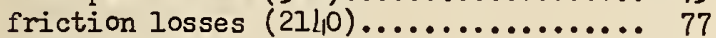

hydraulic jump $(1857) \ldots \ldots \ldots \ldots . . \ldots \ldots 30$

meanders $(1313) \ldots \ldots \ldots \ldots \ldots \ldots \ldots . \ldots \ldots 2_{21}$

orifice flow control (2l29) ........... 65

roughness $(2070) \ldots \ldots \ldots \ldots \ldots \ldots . . \ldots \ldots . . \ldots 25$

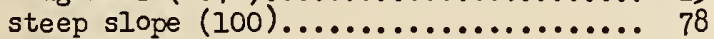

supercritical flow

air entrainment (100) ............. 78

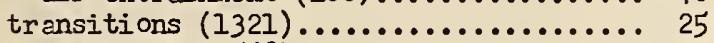

trapezoidal $(1568) \ldots \ldots \ldots \ldots \ldots \ldots \ldots \ldots . \ldots \ldots$

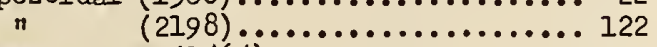

unsteady flow $(1565) \ldots \ldots \ldots \ldots \ldots \ldots \ldots . \ldots . \ldots . . \ldots 22$

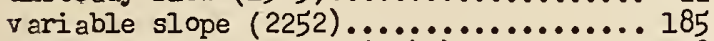

velocity distribution $(1343) \ldots \ldots \ldots . . . . .38$

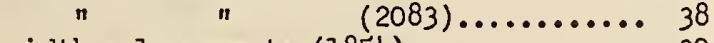

width enlargements $(1854) \ldots \ldots \ldots \ldots \ldots . . .30$

Orifice meters

installation effects (1919).......... 73

rounded entrances $(1887) \ldots \ldots \ldots \ldots \ldots . . \ldots 56$

Orifices

coefficient study (2133)........... 67

vortex flow (1181)................ 95

Outlets

model study, Crawford Station (2090).... L6

Pipe, cantilevered (1168)............ 79

short, in dams $(290) \ldots \ldots \ldots \ldots \ldots \ldots \ldots . . \ldots 26$
Outlet works

dams

Adaminaby (2227) .................. 160

Friant (2221)..................... 159

Garrison, N. D. (2li) ................ 12L

gorge high $(2215) \ldots \ldots \ldots \ldots \ldots \ldots \ldots \ldots \ldots$

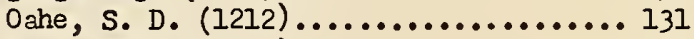

San Antonia (1732)................ 122

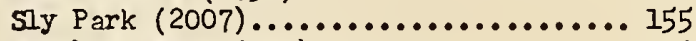

South Holston $(730) \ldots \ldots \ldots \ldots \ldots \ldots . . \ldots 172$

Willow Creek $(1236)(1244) \ldots \ldots \ldots \ldots \ldots . . \ldots 151$

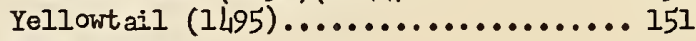
model studies

Sherburne Lakes (2224)............. 159

Lovewell (2223).................... 159

spillway tunnels

Scuth Holston Dam (730)............ 172 stilling basins

hydraulic characteristics (2204)...... 139

Penstocks

South Holston Dam (762)............ 174

Percolation studies, California (2181)..... 104

Pipe fittings

bends, elbows (1602)............... 49

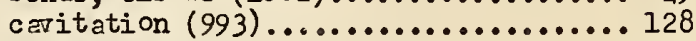

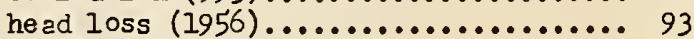

ships $(1524) \ldots \ldots \ldots \ldots \ldots \ldots \ldots \ldots \ldots \ldots \ldots . \ldots 16 \ldots \ldots \ldots$

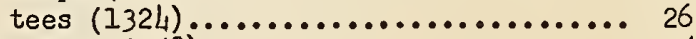

welded $(958) \ldots \ldots \ldots \ldots \ldots \ldots \ldots \ldots . \ldots \ldots$

Pipes

cavitation (993).................. 128

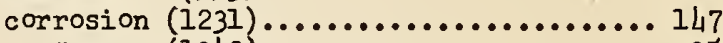

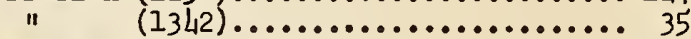

effect air pocket $(2121) \ldots \ldots \ldots \ldots \ldots \ldots . . \ldots 6$

entrance sections (290)............... 26

flow of mixtures

$(627) \ldots \ldots \ldots \ldots \ldots \ldots \ldots . \ldots \ldots$

liquid-gas $(1551) \ldots \ldots \ldots \ldots \ldots \ldots \ldots . \ldots \ldots \ldots$

liquid-solid $(2039) \ldots \ldots \ldots \ldots \ldots \ldots \ldots . \ldots . \ldots 182$

solid-gas $(40) \ldots \ldots \ldots \ldots \ldots \ldots \ldots . . \ldots \ldots . . . \ldots 10$

two-phase, two-component ( $($ il $) \ldots . . . . . .10$

flow patterns (2099) ................ 50

friction

concrete $(24) \ldots \ldots \ldots \ldots \ldots \ldots \ldots \ldots \ldots . . \ldots \ldots$

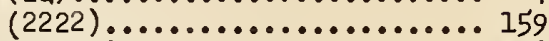

corrugated $(1198) \ldots \ldots \ldots \ldots \ldots \ldots \ldots . \ldots \ldots$

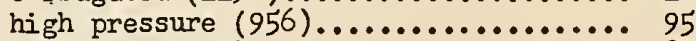

roughness $(944) \ldots \ldots \ldots \ldots \ldots \ldots \ldots \ldots . \ldots \ldots . \ldots \ldots$

he at $\operatorname{transfer}(40) \ldots \ldots \ldots \ldots \ldots \ldots \ldots \ldots \ldots . \ldots \ldots$

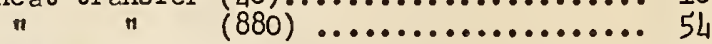

leakage $(2170) \ldots \ldots \ldots \ldots \ldots \ldots \ldots \ldots \ldots . \ldots \ldots$

losses at bends $(2039) \ldots \ldots \ldots \ldots \ldots \ldots \ldots 182$

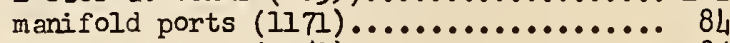

" $"$ " $(2150) \ldots \ldots \ldots \ldots \ldots \ldots \ldots$......... 85

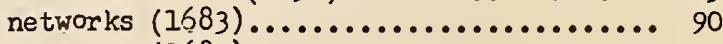

" $\quad(1689) \ldots \ldots \ldots \ldots \ldots \ldots \ldots \ldots . \ldots \ldots . \ldots \ldots$

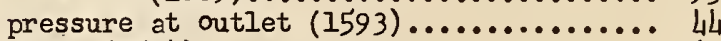

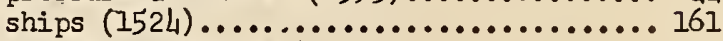

surge suppressors $(1.77) \ldots \ldots \ldots \ldots \ldots \ldots \ldots$ 7

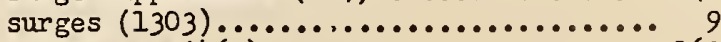

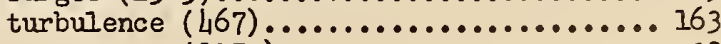

$" \quad(2077) \ldots \ldots \ldots \ldots \ldots \ldots \ldots \ldots \ldots . \ldots 30$ 
Pipes

velocity fluctuations $(46) \ldots \ldots \ldots . . . .10$ waved walls $(1552) \ldots \ldots \ldots \ldots \ldots \ldots \ldots \ldots . \ldots 12$

Pitot tubes

development (1807).................. 185

Plates, rough $(854) \ldots \ldots \ldots \ldots \ldots \ldots \ldots . \ldots 43$

Plumbing

backflow prevention (49) ............. 16

corrosion (49) ..................... 16

cross-connections $(49) \ldots \ldots \ldots \ldots \ldots \ldots$

fixtures (49)...................... 16

Pneumatic control systems

design $(1896) \ldots \ldots \ldots \ldots \ldots \ldots \ldots . . \ldots \ldots$

Pneumatic $\checkmark$ alves

characteristics of (1900)........... 58

porous media, flow

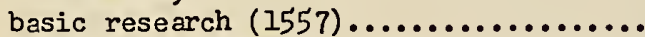

fluidized, systems $(1535) \ldots \ldots \ldots \ldots \ldots . . . .$.

sand $(1318) \ldots \ldots \ldots \ldots \ldots \ldots \ldots \ldots \ldots \ldots \ldots$

spheres $(590) \ldots \ldots \ldots \ldots \ldots \ldots \ldots \ldots \ldots \ldots \ldots . . \ldots \ldots$

turbulence $(557) \ldots \ldots \ldots \ldots \ldots \ldots \ldots \ldots \ldots$

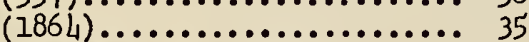

porous media, unsteady flow $(1826) \ldots \ldots \ldots$.....

Pressure distribution

basic research (79)

" $"$ ( 81$) \ldots \ldots \ldots \ldots \ldots \ldots \ldots \ldots 42$

by electric analogy $(72) \ldots \ldots \ldots \ldots \ldots \ldots L_{1}$

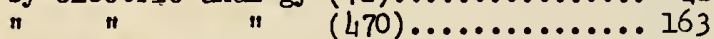

entrances $(1243) \ldots \ldots \ldots \ldots \ldots \ldots \ldots \ldots \ldots 151$

$(2115) \ldots \ldots \ldots \ldots \ldots \ldots \ldots \ldots \ldots \ldots$

slots $(328) \ldots \ldots \ldots \ldots \ldots \ldots \ldots \ldots \ldots \ldots \ldots \ldots . \ldots \ldots$

submerged bodies $(16) \ldots \ldots \ldots \ldots \ldots \ldots 2_{2}$

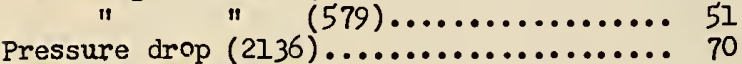

Pressure measurement

electric analogy $(72) \ldots \ldots \ldots \ldots \ldots \ldots$ " $"(470) \ldots \ldots \ldots \ldots \ldots \ldots \ldots 153$

instruments $(1307) \ldots \ldots \ldots \ldots \ldots \ldots \ldots \ldots . \ldots \ldots$ ship models $(1789) \ldots \ldots \ldots \ldots \ldots \ldots \ldots \ldots \ldots 168$ sluices

Cherokee Dam (758) ................ 174

Douglas Dam (759) ................. 174

Hiwassee Dam $(763) \ldots \ldots \ldots \ldots \ldots \ldots . \ldots \ldots$

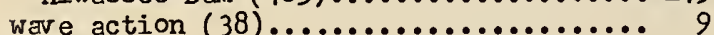

Propellers

action forces (2178) ............... 63

cavitation $(1531) \ldots \ldots \ldots \ldots \ldots \ldots \ldots$

controllable pitch $(1904) \ldots \ldots \ldots \ldots . \ldots 62$

synmetric wakes (921).............. 74

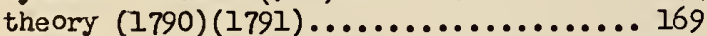

theory, lifting (2237).................

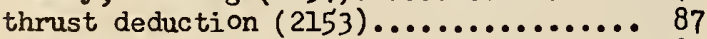

wake fraction (2153).............. 87

Prototype check tests

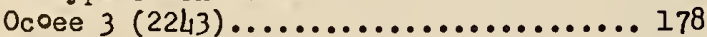

penstocks $(762) \ldots \ldots \ldots \ldots \ldots \ldots \ldots \ldots \ldots \ldots$

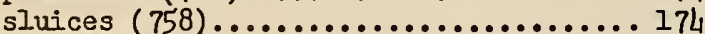

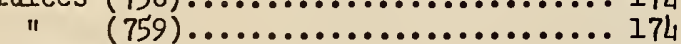

spillways $(761) \ldots \ldots \ldots \ldots \ldots \ldots \ldots \ldots \ldots \ldots$

tunnels $(760) \ldots \ldots \ldots \ldots \ldots \ldots \ldots \ldots . . \ldots 174$

$(1277) \ldots \ldots \ldots \ldots \ldots \ldots \ldots \ldots \ldots \ldots$

(2029) .................... 177
Pulpwood holding grounds (2044).......... 185

Pumping plant, sewers (683)............. 127

Pumps

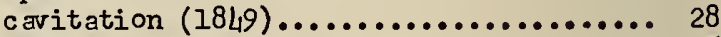

centrifugal (2051) .................. 5

regenerative turbines $(1883) \ldots \ldots \ldots \ldots \ldots$

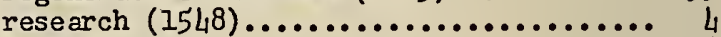

tests $(1132) \ldots \ldots \ldots \ldots \ldots \ldots \ldots \ldots \ldots \ldots \ldots \ldots . \ldots 6$

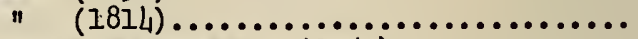

turbine model tests $(2050) \ldots \ldots \ldots \ldots \ldots \ldots$

turbulence $(2057) \ldots \ldots \ldots \ldots \ldots \ldots \ldots \ldots . \ldots \ldots$

Rainfall

altitude effect $(778) \ldots \ldots \ldots \ldots \ldots \ldots$

frequency $(2102) \ldots \ldots \ldots \ldots \ldots \ldots \ldots \ldots . \ldots \ldots$

gages $(547) \ldots \ldots \ldots \ldots \ldots \ldots \ldots \ldots \ldots \ldots \ldots \ldots$

" $(1801) \ldots \ldots \ldots \ldots \ldots \ldots \ldots \ldots \ldots \ldots \ldots$

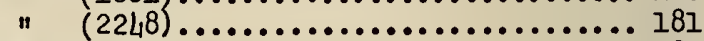

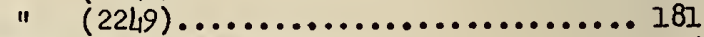

hydrologic cycle $(1092) \ldots \ldots \ldots \ldots \ldots \ldots . \ldots . \ldots$

intensity $(1945) \ldots \ldots \ldots \ldots \ldots \ldots \ldots \ldots . \ldots \ldots$

" $\quad(2209) \ldots \ldots \ldots \ldots \ldots \ldots \ldots \ldots \ldots \ldots \ldots$

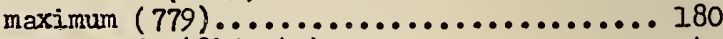

" $\quad(1748)(1749) \ldots \ldots \ldots \ldots \ldots \ldots \ldots \ldots \ldots . \ldots \ldots \ldots$

n $\quad(1750)(1751)(1753) \ldots \ldots \ldots \ldots \ldots . \ldots \ldots . \ldots \ldots$

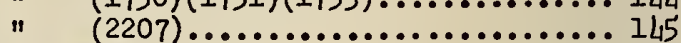

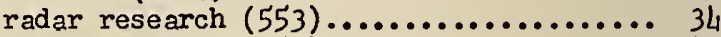

rainfall-munoff $(68) \ldots \ldots \ldots \ldots \ldots \ldots \ldots$. 41

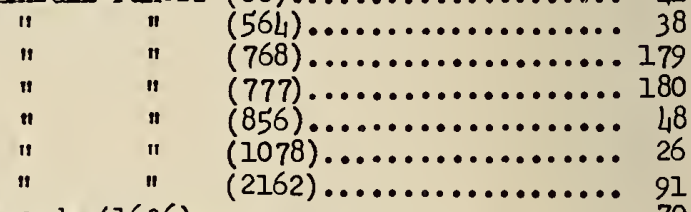

records $(1536) \ldots \ldots \ldots \ldots \ldots \ldots \ldots \ldots \ldots . \ldots . \ldots . \ldots$ research, southern California (261)..... 105 Tennessee River Basin (768) ............ 179

$" n=1 "$ "

Range - management practices $(27) \ldots \ldots \ldots \ldots \ldots . . \ldots$

Reclamation, waste lands

Louisiana (2098) ................... 50

Reservoirs

ev aporation $(765) \ldots \ldots \ldots \ldots \ldots . \ldots . \ldots 179$

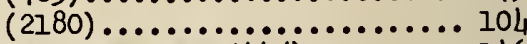

, arid regions $(445) \ldots \ldots \ldots . . .146$

linings $(1837) \ldots \ldots \ldots \ldots \ldots \ldots \ldots \ldots \ldots . \ldots \ldots . \ldots \ldots$

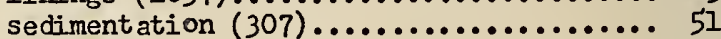

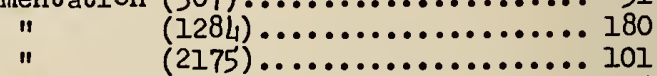

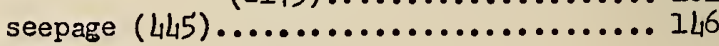
silting

arid regions $(445) \ldots \ldots \ldots \ldots \ldots \ldots . . \ldots 146$

Illinois $(552) \ldots \ldots \ldots \ldots \ldots \ldots \ldots \ldots \ldots \ldots \ldots \ldots$

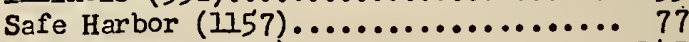

stock water $(1227) \ldots \ldots \ldots \ldots \ldots \ldots \ldots . . \ldots 147$

temperature gaging $(769) \ldots \ldots \ldots \ldots \ldots \ldots 179$

Tennessee River $(764) \ldots \ldots \ldots \ldots \ldots \ldots \ldots . \ldots 179$

" " $"(785) \ldots \ldots \ldots \ldots \ldots \ldots \ldots 178$

Texas (1966)..................... 99

water supply, Illinois (551)......... 33

water travel $(787) \ldots \ldots \ldots \ldots \ldots \ldots \ldots 78$

Revetments, stream control meandering (226) 125 
River control stmuctures

Old River, La. (1982)(1983)......... 137

Rockfill

model tests $(1464) \ldots \ldots \ldots \ldots \ldots \ldots \ldots . . \ldots 118$

Rotary air motor $(2106) \ldots \ldots \ldots \ldots \ldots \ldots . \ldots 59$

Roughness

artificial

open channels (1854)................ 30

standards, models (1000)............. 129

surfaces, drag (854)............. 43 effect of water temperature (1985).... 138 Runoff

arid regions $(445) \ldots \ldots \ldots \ldots \ldots \ldots \ldots 146$

denudation effects $(23) \ldots \ldots \ldots \ldots \ldots \ldots$ ?

" $"$ effect of forest (377) $\ldots \ldots \ldots \ldots \ldots \ldots \ldots, 8$

" " $"(376) \ldots \ldots \ldots \ldots \ldots \ldots . \ldots 109$

" $"$ " (656)............... 108

forecasting

rainfall (1693)................. 94

snow melt $(1692) \ldots \ldots \ldots \ldots \ldots \ldots \ldots . . . . . . . .14$

soi.1 moisture $(1014) \ldots \ldots \ldots \ldots \ldots . . .142$

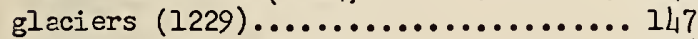

hydrologic cycle (1092)............. 35

rainfall-runoff $(564) \ldots \ldots \ldots \ldots \ldots \ldots \ldots, 38$

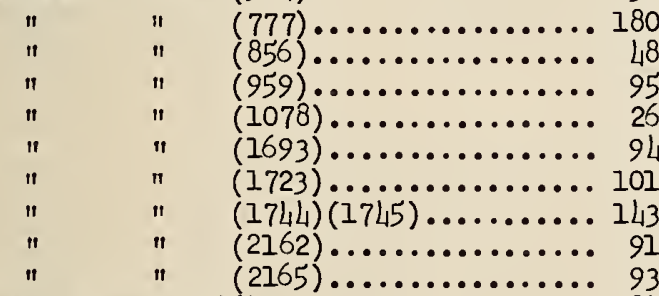

small areas $(19 L 6) \ldots \ldots \ldots \ldots \ldots \ldots \ldots . .6 \%$. 84

soil moisture (1014)............... 142

urban areas $(564) \ldots \ldots \ldots \ldots \ldots \ldots \ldots \ldots, 38$

" " (856)................... 48

watersheds

Illinois (551)................. 33

Laf 2yette, Ind. (1966)............ 99

Ohio and Great Plains (150)......... 100

Pennsylvania (656)............... 108

Ralston Creek, Iowa (66).......... LI

Rapid Creek, Iowa (68)........... L i

Tennessee River Valley (777) (780) .... 180

Idaho (1862)................... 32

Salt water intmusion

control of (1831) .................. 15

Delaware River ( 425$) \ldots \ldots \ldots \ldots \ldots \ldots \ldots . \ldots 126$

Florida (1966).................... 99

irrigated 1 ands $(1302) \ldots \ldots \ldots \ldots \ldots . . .99$

Sand boils (558)................... 36

Sand classification methods (52)........ 18

Sand mixtures, permeability (556)....... 36

" " $"(2145) \ldots \ldots .82$

Sand transport

influence of waves and currents (2191). 117

Sand traps, design (53).............. 18

" $"$, efficiency (1597)........... 45

Sand-water mixtures, shear (2062)........ 16
Scour

bridge piers $(568) \ldots \ldots \ldots \ldots \ldots \ldots \ldots . \ldots 2$

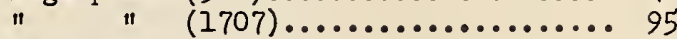

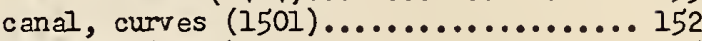

culverts $(1707) \ldots \ldots \ldots \ldots \ldots \ldots \ldots \ldots . . . . . .65$

dams

Ft. Randall, S. D. (674) ........... 127

seaplane hulls (1567)................. 22

" " (1570)................ 22

Seaway, St. Lawrence (1806) (204I)........ 183

Sediment

analysis methods $(2147) \ldots \ldots \ldots \ldots \ldots \ldots . \ldots 2$

bed erosion (69)................... 4

bed load (1235)....................... 148

bed load motion (2059).............. 15

converging, diverging streams (1558).... 17 reservoir sampler $(1284) \ldots \ldots \ldots \ldots \ldots \ldots 180$ suspended

uItrasonic radiation measurement (2144) 81

Sediment transportation

beaches (529)..................... 11

bed load $(1107) \ldots \ldots \ldots \ldots \ldots \ldots \ldots \ldots . . . \ldots 4$

" " (1313).................... 21

" " (1917)..................... 73

Del aware River $(425) \ldots \ldots \ldots \ldots \ldots \ldots 126$

Ni obrara River (1235).............. 148

wave action, effect (1823)........... 14 critical tractive force (1502)........ 152

density currents (307) 51

forces on particles (280)............. Il

me asurement $(194) \ldots \ldots \ldots \ldots \ldots \ldots \ldots \ldots \ldots . \ldots 122$

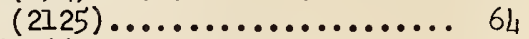

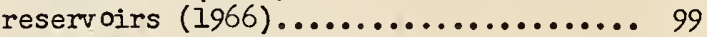

suspended load (1107)................. 44

density currents $(805) \cdots \cdots \cdots \cdots \cdots \cdots$

internal mechanics $(6) \ldots \ldots \ldots \ldots \ldots \ldots . .2$

Sediment transportation

suspended load

measurement (194)................. 122

" $\quad$ (1966).................... 99

" (661)................. 114

temperature changes (1928)........... 80

Tennessee River (764) .............. 179

Weutauga Dam (732)................ 173

Sedimentation

arid regions (445)................. 146

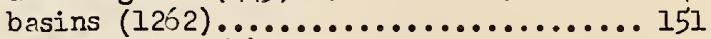

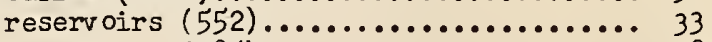

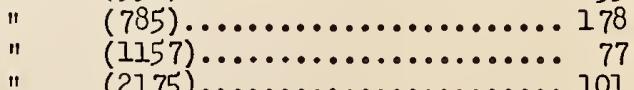

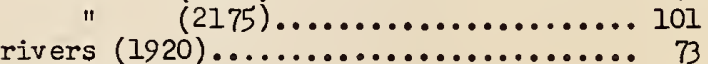

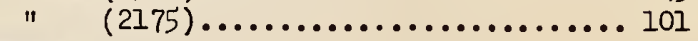

Seepage

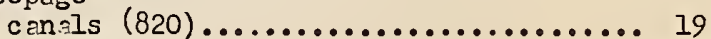

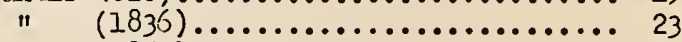

" (1859)....................... 32

" (1966)............................ 99

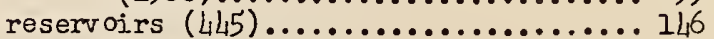
soil sediments $(185 \%) \ldots \ldots \ldots \ldots \ldots \ldots, 32$ 
Servornechanism, closed-loop (1877)...... 48 Settling, fall velocity effect shape $(828) \ldots \ldots \ldots \ldots \ldots \ldots \ldots . .20$

Sewage activated sludge process (580)........ 52 pumping plant (683) ................ 127

Sewers surges (683).................... 127 Ships appendage-body inter action (1268)..... 164 bending moment (1409)............... 86 bilge, keels (1512) ................ 165 commercial, design (i128)............6 66 design $(2120) \ldots \ldots \ldots \ldots \ldots \ldots \ldots \ldots \ldots . \ldots 6$

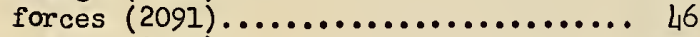
" (2229)...................... 170 injection scoops $(710) \ldots \ldots \ldots \ldots \ldots . .164$ " " (1634)............. 69 Iines $(1783) \ldots \ldots \ldots \ldots \ldots \ldots \ldots \ldots \ldots \ldots . \ldots \ldots \ldots$ maneuvering $(1514) \ldots \ldots \ldots \ldots \ldots \ldots . \ldots 165$ models, turbulence stimulation (1506).. 165 models

towing test maneuvering basin (1781). 167 motion (1782)..................... 167

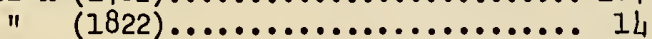

" $\quad(1838) \ldots \ldots \ldots \ldots \ldots \ldots \ldots \ldots \ldots . \ldots . \ldots 23$

" $\quad(2020) \ldots \ldots \ldots \ldots \ldots \ldots \ldots \ldots \ldots \ldots . \ldots 170$

" (2091).................... 46

" $(2154)(2155) \ldots \ldots \ldots \ldots \ldots \ldots . . . .68$ motor-boats, transom immersion (1127).. 66 performance $(2171) \ldots \ldots \ldots \ldots \ldots \ldots \ldots . . .68$ planing surfaces $(340) \ldots \ldots \ldots \ldots \ldots \ldots .65$ " " (2152)............. 87 pressure distribution (1789).......... 168 propellers " (2232).......... 170 oscillating pressures (2236)........ 171 symmetric wakes $(921) \ldots \ldots \ldots \ldots \ldots 74$ propulsive characteristics (2239)...... 172 resistance

compilation data (895)............ 83

frictional (1505).................. 164 " (2231)................ 170 hull forms $(1906) \ldots \ldots \ldots \ldots \ldots \ldots \ldots . .66$

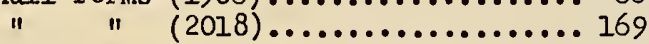

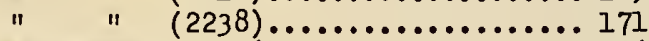
measurement $(1516) \ldots \ldots \ldots \ldots \ldots \ldots \ldots \ldots . \ldots 166$ " (1947)............... 87 models (901)................... 68 prediction (1515) ................. 166

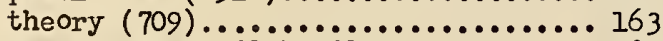
wave making $(1680)(1681) \ldots \ldots \ldots \ldots . .68$ seawor thiness $(1407) \ldots \ldots \ldots \ldots \ldots \ldots \ldots .6 \%$

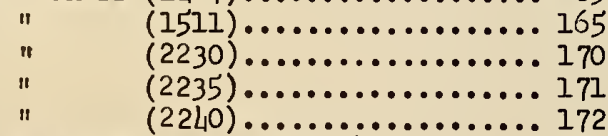

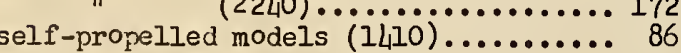
" " (1906)........... 66 skeg design (2132)................ 67 slamming $(1786) \ldots \ldots \ldots \ldots \ldots \ldots \ldots \ldots \ldots . \ldots \ldots$
Ships

turning characteristics (1948) ....... 87 velocity distribution $(2232) \ldots \ldots \ldots \ldots . . .170$ vibration (1378)................... 66

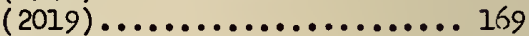
wake formation $(2234) \ldots \ldots \ldots \ldots \ldots \ldots \ldots . \ldots \ldots \ldots$ Shore processes (2192).............. 117 Shore protection methods, techniques (2193)........... 117 structures $(38) \ldots \ldots \ldots \ldots \ldots \ldots \ldots \ldots \ldots$. 9 " (529)................... 11

Silting

reservoirs

arid regions $(445) \ldots \ldots \ldots \ldots \ldots \ldots \ldots . \ldots 146$ Illinois (552)................... 33 Lake Mead $(445) \ldots \ldots \ldots \ldots \ldots \ldots \ldots \ldots . \ldots \ldots \ldots$ Tennessee Valley $(785) \ldots \ldots \ldots \ldots \ldots \ldots . \ldots 178$ Texas (2178)...................... 103 small watersheds $(777) \ldots . . . \ldots \ldots \ldots . . .180$ streams, Texas (2178)................. 103 Siphons

irrigation (24)..................? ? pumping plants $(1475) \ldots \ldots \ldots \ldots \ldots \ldots \ldots \ldots \ldots$

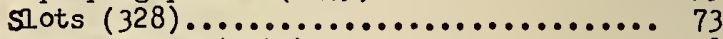

Sluice gates $(2247) \ldots \ldots \ldots \ldots \ldots \ldots \ldots \ldots \ldots \ldots \ldots$ cavitation $(79) \ldots \ldots \ldots \ldots \ldots \ldots \ldots \ldots, 42$ Sluiceways

dams

discharge ratings

Cherokee Dam (739).............. 173

Douglas Dam (742).............. 173

Fontana Dam ( 745$) \ldots \ldots \ldots \ldots \ldots \ldots . \ldots 174$ pressure measurement

Cherokee Dam (758).............. 174 Douglas Dam (759) ............... 174 Hiwassee Dam $(763) \ldots \ldots \ldots \ldots \ldots . . .175$ sand, design (53).................. 18 sediment excluding $(1767) \ldots \ldots \ldots \ldots \ldots 152$

" " (1768)............. 153

snow, forecast, melting (1011)......... 142 snow surveys

Colorado (55)..................... 18

runoff forecasting $(55) \ldots \ldots \ldots \ldots \ldots \ldots, 18$

"

Soil moisture

(2164) $\ldots \ldots \ldots \ldots \ldots . . .92$

effect demudation (23) .............. 7

" timber cutting $(377) \ldots \ldots \ldots \ldots . .110$

evaporation (21 73)................. 100

forecasting stream flow (1014)........ 142

forest influences $(380) \ldots \ldots \ldots \ldots \ldots \ldots 112$

" " $\quad(657) \ldots \ldots \ldots \ldots \ldots \ldots . \ldots \ldots 110$

measurement $(261)(2188) \ldots \ldots \ldots \ldots \ldots \ldots) 112$

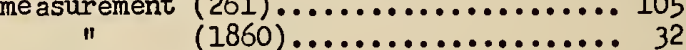

(2164) $\ldots \ldots \ldots \ldots \ldots \ldots \ldots \ldots . . . \ldots 2$

morement $(1058) \ldots \ldots \ldots \ldots \ldots \ldots \ldots \ldots \ldots, q_{9}$

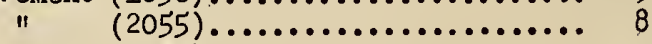

" (2173)....................... 100

permeability $(119 i) \ldots \ldots \ldots \ldots \ldots \ldots \ldots . \ldots 100$ 
Soil molsture

semi-desert vegetation (657)........... 110 small watersheds (777) ............... 180 Southern Califormi (261)............. 105 soll permeability (1194)................ 100 sounding leads $(1973) \ldots \ldots \ldots \ldots \ldots \ldots \ldots . . \ldots \ldots 116$

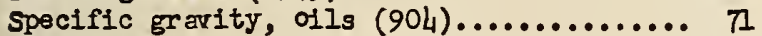
Spillways

aeration, Pine Flat, Calif. (992)....... 128 basic research $(1584) \ldots \ldots \ldots \ldots \ldots . . \ldots . . .29$

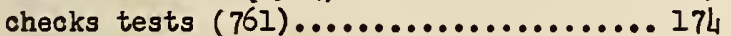
conparlson, profiles (266)............ 183 dams

Alamogordo (2225) .................. 159

Boone $(1274) \ldots \ldots \ldots \ldots \ldots \ldots \ldots \ldots \ldots \ldots$

Cleveland (2211) ................... 156

Chickamauga (709) ................ 163

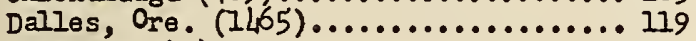

Douglas (7LI) ...................... 173

Fort Patrick Hemry $(1534) \ldots \ldots \ldots . . . .175$

Ft. Randall, S. D. $(674) \ldots \ldots \ldots \ldots \ldots . . . .127$

Garrison Dan (2ll)................. 12L

Gavins Point, S. D. (17LI) ........... 135

Hales Bar (1038)................... 175

Hartwell, Ga. (1981) ................ 136

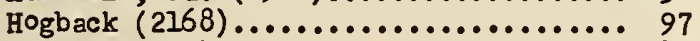

Keokuk (2093) ...................... 47

Kentucky (76I).................... 174

Kerwin $(1774) \ldots \ldots \ldots \ldots \ldots \ldots \ldots \ldots \ldots \ldots \ldots$

Littleton $(1713) \ldots \ldots \ldots \ldots \ldots \ldots . \ldots \ldots$

Markl and, Ohio River (1739)........... 135

Menomonie $(2146) \ldots . . \ldots \ldots \ldots \ldots \ldots . . \ldots . . \ldots 2$

Nimbus (2009) ......................... 155

Hoxon Rapids (2166).................... 94

Peters (2151).................... 85

Pine Flat, Calif. (992)............. 128

Ross (2276) ...................... 157

San Antonio (1732) .................. 122

Sav age River, Md. (IL7L) ............. 133

South Holston $(728)(730) \ldots \ldots \ldots \ldots \ldots 172$

Watauga $(728) \ldots \ldots \ldots \ldots \ldots \ldots \ldots \ldots \ldots \ldots \ldots . . \ldots 172$

$(732) \ldots \ldots \ldots \ldots \ldots \ldots \ldots \ldots \ldots \ldots$

Willow Creek $(1236)(1244) \ldots \ldots \ldots \ldots \ldots 151$

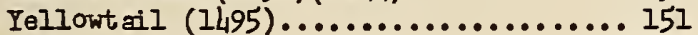

design $(673) \ldots \ldots \ldots \ldots \ldots \ldots \ldots \ldots \ldots \ldots \ldots$

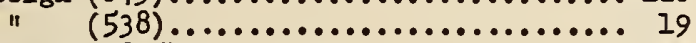

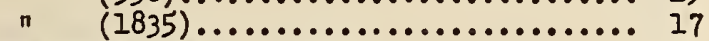

discharge capacity $(2215) \ldots \ldots \ldots \ldots \ldots \ldots . . \ldots 157$

discharge coefficients (2159)........... 90 $\| "$ (22L6)................ 178 $" n \quad(2251) \ldots \ldots \ldots \ldots . . .184$

discharge ratings, dams

Apalachia (736).................... 173

Boone $(2030) \ldots \ldots \ldots \ldots \ldots \ldots \ldots \ldots \ldots \ldots \ldots . \ldots \ldots \ldots$

Cherokee $(738) \ldots \ldots \ldots \ldots \ldots \ldots \ldots \ldots \ldots \ldots 173$

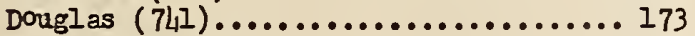

Ft. Loudoun $(746) \ldots \ldots \ldots \ldots \ldots \ldots \ldots \ldots . . . . .174$

Fort Patrick Henry (2031)............ 177

Peligre, Haiti (2l01)............... 54

drop, design (1398)................ 79

$"$ " $"(1865) \ldots \ldots \ldots \ldots \ldots \ldots \ldots \ldots \ldots \ldots$
Spl11uags

effect $t a i$ race $(732) \ldots \ldots \ldots \ldots \ldots \ldots \ldots 173$

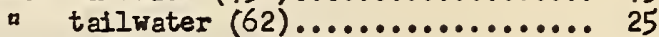

entrance conditions $(1685) \ldots \ldots \ldots \ldots . . . . .91$ morning-glory dams

South Holston (728) ............... 172

Wautauga $(728) \ldots \ldots \ldots \ldots \ldots \ldots \ldots \ldots \ldots \ldots . \ldots \ldots$

profiles (266)..................... 183

roller-type bucket $(673) \ldots \ldots \ldots \ldots \ldots \ldots . \ldots 126$

scale effects $(1001) \ldots \ldots \ldots \ldots \ldots \ldots \ldots \ldots . \ldots . \ldots . \ldots$

siphon $(1777) \ldots \ldots \ldots \ldots \ldots \ldots \ldots \ldots \ldots \ldots \ldots$

Whittier Nar rows (980) ............... 121

Spray, droplet formation (2137)......... 72

Spray, from jets $(1637) \ldots \ldots \ldots \ldots \ldots \ldots \ldots . . \ldots 7$

Sprinkling systems

irrigation (1076)................. 20

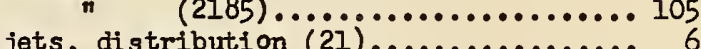

stability

model studies (5).................. 97

wave tests $(1136) \ldots \ldots \ldots \ldots \ldots \ldots \ldots \ldots . . \ldots \ldots$

st all, rotating $(1903) \ldots \ldots \ldots \ldots \ldots \ldots . \ldots . \ldots$

stilling basins

dams

Bonneville (1976)................. 120

Bull Shoals, Ark. (1979)............. 136

Chick an auga (709) ................. 163

Ft. Randall, S. D. (674)........... 127

Garrison, N. D. (2li) ............... 12L

Gavins Point, S. D. (174I).......... 135

Kerwin (1774).................... 153

Karkland, Ohio River (1739).......... 135

New Cumberland, Ohio River (1978)..... 136

Nimbus (2009)...................... 155

Peligre, Haiti (2l01)............. 54

South Holston (730) ................. 172

Table Rock, Ho. (1980).............. 136

Tuttle Creek, Kansas (1740).......... 135

Webster (1773) ................... 153

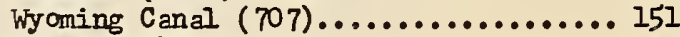

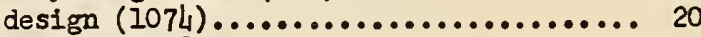

$n \quad(1918) \ldots \ldots \ldots \ldots \ldots \ldots \ldots \ldots \ldots \ldots . \ldots \ldots \ldots$

$n \quad(2003) \ldots \ldots \ldots \ldots \ldots \ldots \ldots \ldots \ldots \ldots \ldots \ldots$

" (2071) ...................... 25

energy dissipation (2103) ............ 54

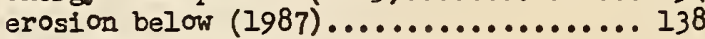
hydraulic characteristics (2204)....... 139 stilling wells

hydraulic characteristics (2002)....... 15L $(2204) \ldots \ldots \ldots 139$

Streanflow forecasts $(1744)(1745) \ldots \ldots . . .143$

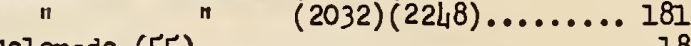

colorado $(55) \ldots \ldots \ldots \ldots \ldots \ldots \ldots \ldots . \ldots \ldots$ salfnity me asurements (2060).......... 16 snow surveys $(55) \ldots \ldots \ldots \ldots \ldots \ldots \ldots \ldots \ldots . \ldots \ldots$

stre an gaging

$(1966) \ldots \ldots \ldots \ldots \ldots \ldots \ldots \ldots$

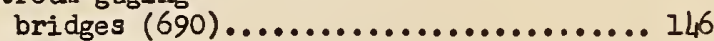

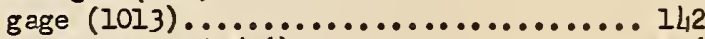
radio gages $(1536) \ldots \ldots \ldots \ldots \ldots \ldots \ldots \ldots \ldots \ldots$ Tennessee $\mathrm{Valley}(769) \ldots \ldots \ldots \ldots \ldots \ldots \ldots . \ldots 179$ 


\section{Stre ems}

channel form (2068)................. 24

discharge $(1642) \ldots \ldots \ldots \ldots \ldots \ldots \ldots \ldots \ldots . . \ldots 72$

(1705)..................... 94

discharge values (2208).............. 145

effect logging (969)................... 108

" n (1230)................ 14.7

erosion control (226)................. 125

" research (69)................ li

flood peaks (2072)................. 25

forest effects (439).................. 116 meandering (226) ................... 125 peak discharge $(691) \ldots \ldots \ldots \ldots \ldots \ldots \ldots 146$ roughness coefficient $(783) \ldots \ldots \ldots \ldots \ldots 178$ " $\quad(1488) \ldots \ldots \ldots \ldots .148$ sand channel (1755)................. 148 st age-discharge

I0wa $(67) \ldots \ldots \ldots \ldots \ldots \ldots \ldots \ldots \ldots . . \ldots 4$ water quality $(786) \ldots \ldots \ldots \ldots \ldots \ldots \ldots \ldots . \ldots 178$ Strut wake $(1389) \ldots \ldots \ldots \ldots \ldots \ldots \ldots \ldots \ldots \ldots . . \ldots 76$

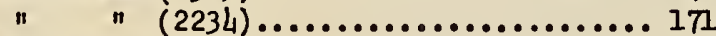

Structures

canal (2004)....................... 154 conservation (1723).................. 101

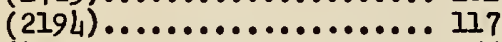

metering (2006) ..................... 155

wave forces on (1881).............. 53

submerged bodies

pressure distribution

basic research (16)................. 2 " " (579)............... 51

electric analogy (72).............. 42

theoretical analyses (81) ........... 42

surges

pipes (1303)....................... 9

sewers $(683) \ldots \ldots \ldots \ldots \ldots \ldots \ldots \ldots \ldots \ldots \ldots . \ldots 127$

surge tanks

mechanical-pneumatic (127)........... 71 South Holston Dam (731) ............... 172

" " $" 762) \ldots \ldots \ldots \ldots \ldots \ldots 174$

Tailn aces

Norris Dam (2242)..................... 178 South Holston Dam $(2245) \ldots \ldots \ldots \ldots \ldots \ldots . \ldots 178$ Waut auga Dam (732) ................. 173

Tidal flow

channels

Charleston Harbor, s. C. (687)....... 127

Del aware River, $\mathrm{Pa} .(425) \ldots \ldots \ldots \ldots \ldots . . .126$

Torque, converter (1660).............. 77 Towing tank rese arch

David Taylor Model Basin............... 163

Michigan University................... 66

Newport News S. and D. D. Co.......... 67

Society of Naval Architects............ 83

Stevens Institute of Technology........ 85

Transitions

tunnels (1206)...................... 123

Tubes, flow

expansion coefficients (2075).......... 28

Tunnels

check tests $(760) \ldots \ldots \ldots \ldots \ldots \ldots \ldots . . .174$
Tunnels

check tests (1277).................. 175

n $n$ (2029)................... 177

dams

Fontana (760)..................... 174 vertical shaft $(1776) \ldots \ldots \ldots \ldots \ldots \ldots \ldots . \ldots 153$

Turbines

buckets (1915)..................... 72

cavitation (1133) ................. 68

impulse

head effects, tests (1146)............ 72

model tests $(123) \ldots \ldots \ldots \ldots \ldots \ldots \ldots \ldots \ldots \ldots . . .67$

n " $(1926) \ldots \ldots \ldots \ldots \ldots \ldots \ldots \ldots \ldots . . .60$

performance $(123) \ldots \ldots \ldots \ldots \ldots \ldots \ldots \ldots \ldots . . \ldots 6$

" (2117).................6 62

propeller

cavitation (271)................... I

performance $(271) \ldots \ldots \ldots \ldots \ldots \ldots \ldots \ldots, 1$

vane moments $(896) \ldots \ldots \ldots \ldots \ldots \ldots \ldots \ldots . \ldots 68 . \ldots 6$

Turbulence

boundary layers (627)................ 84

" $"$ " (2233)............... 17

characteristics $(2058) \ldots \ldots \ldots \ldots \ldots \ldots \ldots \ldots . \ldots \ldots$

gr anul ar media $(557) \ldots \ldots \ldots \ldots \ldots \ldots \ldots . . . \ldots$

measurement

apparatus $(73) \ldots \ldots \ldots \ldots \ldots \ldots \ldots \ldots . \ldots, 42$

" $\quad(578) \ldots \ldots \ldots \ldots \ldots \ldots \ldots \ldots . \ldots \ldots$

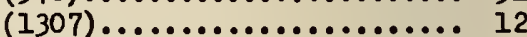

electro-magnetic (46)............... 10

hot-wire, water $(467) \ldots \ldots \ldots \ldots \ldots . . .163$

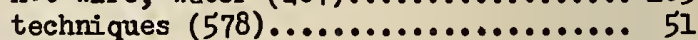

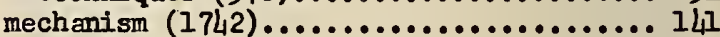

pipes $(627) \ldots \ldots \ldots \ldots \ldots \ldots \ldots \ldots \ldots \ldots . \ldots 84$

" $\quad(944) \ldots \ldots \ldots \ldots \ldots \ldots \ldots \ldots \ldots . \ldots . \ldots 9 . \ldots$

basic research $(46) \ldots \ldots \ldots \ldots \ldots \ldots \ldots . .10$

" " (467)................... 163

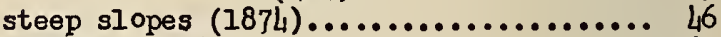

stimulation (1506)................... 165

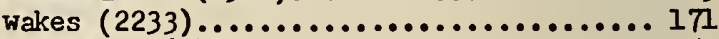

Turnouts $(1769) \ldots \ldots \ldots \ldots \ldots \ldots \ldots \ldots \ldots \ldots \ldots \ldots \ldots$

" (1775)...................... 153

" (2006)......................... 155

Unsteady flow $(1784) \ldots \ldots \ldots \ldots \ldots \ldots \ldots \ldots . . . \ldots 167$

" " $(1785)(1786) \ldots \ldots \ldots \ldots \ldots \ldots . . . \ldots 168$

Valves

butterfly (1603)...................... 50

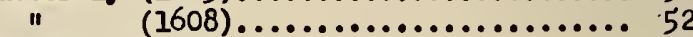

check (1846)........................ 28

control, jet pipe (2107)............... 59

dynamic flow forces on (1895)........... 57

head loss, check ( 961$) \ldots . . . . . . . . . . . .996$

hollow-jet (2226)...................... 159

transfer $(1876) \ldots \ldots \ldots \ldots \ldots \ldots \ldots \ldots . . \ldots$

Velocity distribution

air, over ocean waves $(1824) \ldots \ldots \ldots \ldots .14$

Velocity measurement

electro-magnetic (46).................. 10

$"$ " $\quad$ " $\quad(73) \ldots \ldots \ldots \ldots \ldots \ldots \ldots \ldots . \ldots \ldots 42$

hot-wire (73)...................... 42

" $n \quad(467) \ldots \ldots \ldots \ldots \ldots \ldots \ldots \ldots \ldots \ldots . \ldots 163$ 
Velocity measurement

ultrasonics $(1154) \ldots \ldots \ldots \ldots \ldots \ldots \ldots \ldots . \ldots \ldots$

Ventilation (1684).................. 91

Venturi.

calibration (1843) ................ 27

characteristics $(1841) \ldots \ldots \ldots \ldots \ldots \ldots \ldots . \ldots 27$

Virtual mass (2064) ................... 17
" $"$
(2158)

Viscosity

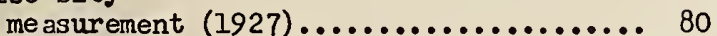

oils $(904) \ldots \ldots \ldots \ldots \ldots \ldots \ldots \ldots \ldots \ldots . . \ldots \ldots$

Viscous flow

through assemblages of spheres (1911)... 69

Water channel rotating (279)............ 3

Water, consumptive use (1966)........... 99

irrigated crops (2l77) ............. 103

San Francisco Bay Area (2179) .......... 103

Santa Margarita River Basin (2176)...... 102

Water control facilities, design (1723)... 101

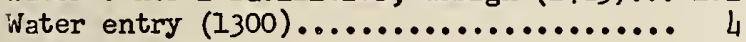

Water hammer

surge suppressors (127) ............ 71

Water measurement

irrigation $(23)(24) \ldots \ldots \ldots \ldots \ldots \ldots \ldots \ldots \ldots . \ldots \ldots$.

stream flow $(67) \ldots \ldots \ldots \ldots \ldots \ldots \ldots \ldots . . \ldots . . \ldots$

Water resources, southwestern Utah (2163). 92

Watershed management

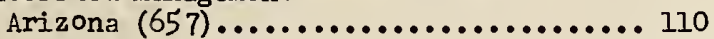

colorado (1971) ................... 111

Continental Divide (377) ............. 110

New Mexico (1967)(1968) .............. 110

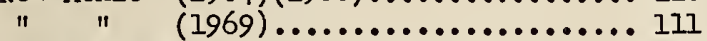

Pennsylv ani a $(656) \ldots \ldots \ldots \ldots . . \ldots \ldots . . \ldots 108$

Rocky Mount ain Front Range (376) ....... 109

Southeastern United States $(380) \ldots \ldots . . .112$

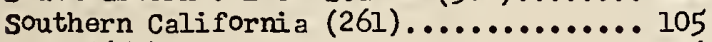

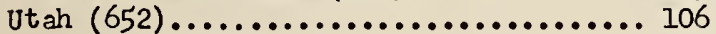

" $(653)(654) \ldots \ldots \ldots \ldots \ldots \ldots \ldots \ldots \ldots \ldots$

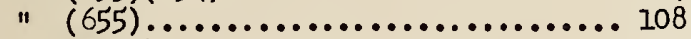

" $(1971) \ldots \ldots \ldots \ldots \ldots \ldots \ldots \ldots \ldots \ldots \ldots$

Wayne county, $\mathrm{Pa} .(966) \ldots \ldots \ldots \ldots \ldots \ldots . \ldots 108$

wyoming (1971) ................... 117

Watershed studies

Blackl ands, Texas (150) .............. 100

Color ado (1970)(1971)............... 117

effects logging (969) ................ 108

forest influences $(376) \ldots \ldots \ldots \ldots \ldots . . \ldots 109$

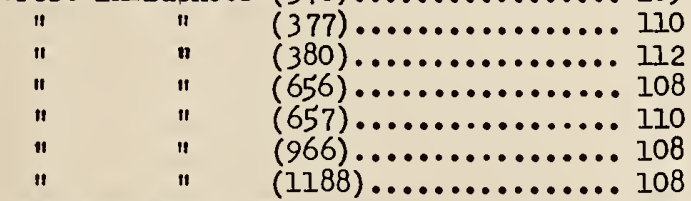

frost studies $(1187) \ldots \ldots \ldots \ldots \ldots \ldots \ldots . \ldots . \ldots 108$ hydrologic cycle $(1758)(1764) \ldots \ldots \ldots . . . . .149$ " $"$ " (2162) .............. 91

Illinois $(551)(552) \ldots \ldots \ldots \ldots \ldots \ldots \ldots . . \ldots \ldots$

Laf ayette, Ind. (1966) .............. 99

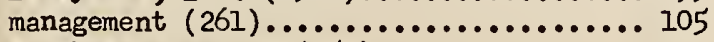

North Appal achian $(150) \ldots \ldots \ldots \ldots \ldots . . . \ldots 100$
Watershed studies

Ohio and Great PI ains (150)........... 100

Pine Region, N. J. (1662) ............. 77

Ralston Creek, Iowa $(66) \ldots \ldots \ldots \ldots \ldots \ldots \ldots$ LI

Rapid Creek, Iowa (68) ............... LI

Tennessee River Valley (768).......... 179

" " " $(777)(780) \ldots \ldots \ldots 180$

Waynesville $(2244) \ldots \ldots \ldots \ldots \ldots \ldots \ldots \ldots . . \ldots 178$

Water tunnel

cavitation (1671).................. 80

design

Calif. Inst. of Tech. (15)(16) ....... 2

closed jet (1672).................. 80

Penn. State University (1151)........ 74

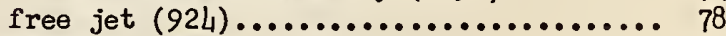

Water utilization (769) ................ 179 Wave action

barges, anchored and towed (2131).......66 66

beaches $(47) \ldots \ldots \ldots \ldots \ldots \ldots \ldots \ldots \ldots \ldots \ldots \ldots . . \ldots 10$

"

" $\quad(181) \ldots \ldots \ldots \ldots \ldots \ldots \ldots \ldots \ldots \ldots \ldots \ldots \ldots$

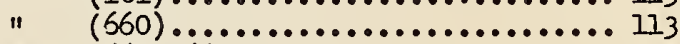

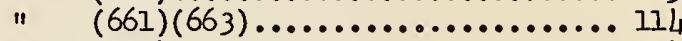

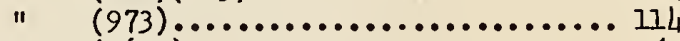

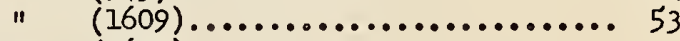

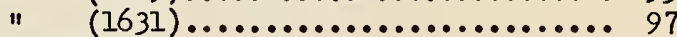

breakwaters

harbors

Indiana Harbor, Ind. (1472)........ 133

Taconite Harbor (2ll1) ............ 81

(2202) ............ 139

pervious, impervious (998)............ 129

rubble-mound (999)................... 129

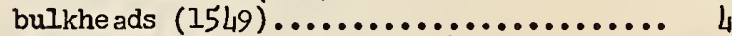

shore protection, tank (399).......... 113

" " " $"$ " works $(38) \ldots \ldots \ldots \ldots \ldots . . . .9$

spillways $(674) \ldots \ldots \ldots \ldots \ldots \ldots \ldots \ldots \ldots \ldots \ldots \ldots 127$

structures $(972) \ldots \ldots \ldots \ldots \ldots \ldots \ldots \ldots \ldots . \ldots \ldots$

Waves

forces, immersed objects (2205)........ ILI

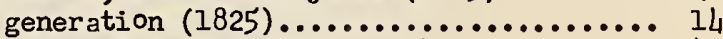
internal progressive $(1990) \ldots \ldots \ldots \ldots$. . . 1 . measurement

data for coasts (1727)............ 115

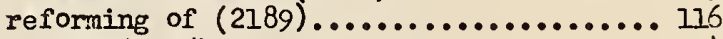

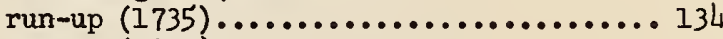

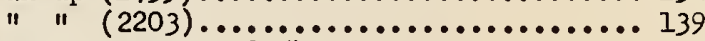

shallow water $(1825) \ldots \ldots \ldots \ldots \ldots \ldots \ldots . \ldots \ldots$

shock $(1610) \ldots \ldots \ldots \ldots \ldots \ldots \ldots \ldots \ldots \ldots \ldots \ldots . \ldots \ldots$

n $(1827) \ldots \ldots \ldots \ldots \ldots \ldots \ldots \ldots \ldots \ldots \ldots \ldots$

theory $(1335) \ldots \ldots \ldots \ldots \ldots \ldots \ldots \ldots \ldots \ldots . . \ldots \ldots$

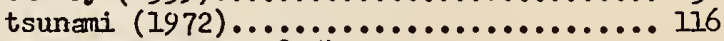

wind generated $(1825) \ldots \ldots \ldots \ldots \ldots \ldots \ldots \ldots$

Waves, surface

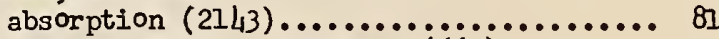

characteristics, observed (660)........ 173

contours $(340) \ldots \ldots \ldots \ldots \ldots \ldots . \ldots \ldots . . \ldots \ldots$

diffraction $(47) \ldots \ldots \ldots \ldots \ldots \ldots \ldots \ldots \ldots . . . \ldots \ldots$

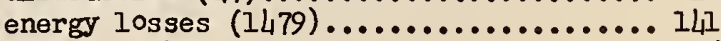

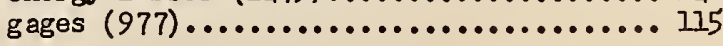


Waves, surface

general research $(47) \ldots \ldots \ldots \ldots \ldots \ldots . .10$

generation $(4) \ldots \ldots \ldots \ldots \ldots \ldots \ldots \ldots \ldots . \ldots 9$

" (35)...................... 9

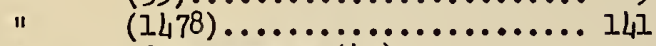

" , forec asting (47)........... 10

model laws $(184) \ldots \ldots \ldots \ldots \ldots \ldots \ldots \ldots \ldots \ldots \ldots$

oscillatory $(35) \ldots \ldots \ldots \ldots \ldots \ldots \ldots . . . . . .9$

" , theory $(47) \ldots \ldots \ldots \ldots . . . . . .10$

positive, dry channels $(1480) \ldots \ldots \ldots \ldots . . . \ldots 141$

resistance $(709)$........................ 163

shallow water $(35) \ldots \ldots \ldots \ldots \ldots \ldots \ldots . . . \ldots 9$

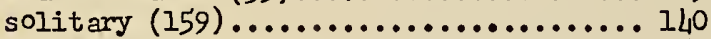

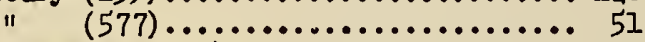

wind-generated $(4) \ldots \ldots \ldots \ldots \ldots \ldots \ldots \ldots 97$

Wave tank, design (399) ................ 173

Weirs

aeration demand (1869).............. 45

basic research (1584)................ 29

rectangular $(1852) \ldots \ldots \ldots \ldots \ldots \ldots \ldots . \ldots 29$
Weirs

sharp-crested

circular (1113)................. L9

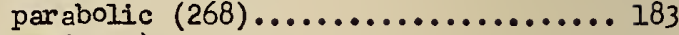

side $(1912) \ldots \ldots \ldots \ldots \ldots \ldots \ldots \ldots \ldots \ldots . . \ldots 70$

v-notch $(1709) \ldots \ldots \ldots \ldots \ldots \ldots \ldots \ldots . \ldots 96$

Wells

casing perforations (2055)........... 8

drilling (24).................... 7

testing instruments $(1337) \ldots \ldots \ldots \ldots \ldots . .35$

" $"$ (1219) ........... IL6

Well screens

design $(287) \ldots \ldots \ldots \ldots \ldots \ldots \ldots \ldots \ldots \ldots, 18$

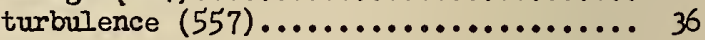

Wind

building forms (1079)................ 26

design, tunnel (1152)............... 75

lake levels (160)..................... 140

velocity $(1665) \ldots \ldots \ldots \ldots \ldots \ldots \ldots \ldots \ldots . \ldots . \ldots 79$

wind tides, research (1478)............. 141

\$O. S. GOVERNMENT PRINTING OFFTCE; 1955 O - 342060 
answering a number of questions regarding the adequacy of stack venting of plumbing fixtures for one- and two-story dwellings. Diagrams, tables, and graphs show the various components of a stack-vented system and provide pressure and trap-seal data.

Order NBS Building Materials and Structures Report 118, Stack Venting of Plumbing Fixtures, 21 pages. Price: 25 cents.

\section{Hydraulic Research in the United States}

Guides to projects conducted by various hydraulic and hydrologic laboratories in the United States and Canada during 1951, 1952, 1953, and 1954 . Project reports cover work done at 66 private or State laboratories in the United States, 34 Federal laboratories, and 5 Canadian laboratories. These publications outline individual projects on nearly 200 subjects in the field.

Order:

NBS Miscellaneous Publication 201, Hydraulic Research in the United States, 1951, 190 pages. Price: $\$ 1.25$.

NBS Miscellaneous Publication 205, Hydraulic Research in the United States, 1952, 200 pages. Price: $\$ 1.00$.

NBS Miscellaneous Publication 208, Hydraulic Research in the United States, 1953, 215 pages. Price: \$1.25.

NBS Miscellaneous Publication 210, Hydraulic Research in the United States, 1954, 207 pages. Price: \$1.25.

\section{Correcting for Density and Viscosity of Incompressible Fluids in Float-Type Flowmeters}

Information on the theory of the flow of incompressible fluids through floattype flowmeters developed by the methods of dimensional analysis and experimental verification of the relations thus derived. Procedures are described whereby, after calibration of a metering tube with a few fluids of known physical properties, accurate corrections may be calculated for any fluid whose properties lie within the range embraced by the calibration fluids.

Order NBS Research Paper 2247, Correcting for Density and Viscosity of Incompressible Fluids in Float-Type Flowmeters, 12 pages, Price: 10 cents.

\section{Hydrodynamic Effects of Gales on Lake Erie}

The coefficients of wind stress and sea roughness are derived from research of water levels and wind intensities relating to gales passing ovor Lake Erie during the past 50 years. Both of these coefficients are found to decrease with increasing wind velocities. A theoretical determination of the wind tides is made and agrees well with the observations.

Order NBS Research Paper 2396, Hydrodynamic Effects of Gales on Lake Erie, 11 pages. Price: 15 cents. 


\section{PERIODIGALS OF THE NATIONAL BUREAU OF STANDARDS}

\section{(Published monthly)}

The National Bureau of Standards is engaged in fundamental and applied research in physics, chemistry, mathematics, and engineering. Projects are conducted in fifteen fields: electricity and electronics, optics and metrology, heat and power, atomic and radiation physics, chemistry, mechanics, organic and fibrous materials, metallurgy, mineral products, building technology, applied mathematics, data processing systems, cryogenic engineering, radio propagation, and radio standards. The Bureau has custody of the national standards of measurement and conducts research leading to the improvement of scientific and engineering standards and of techniques and methods of measurement. Testing methods and instruments are developed; physical constants and properties of materials are determined; and technical processes are investigated.

\section{Journal of Research}

The Journal presents research papers by authorities in the specialized fields of physics, mathematics, chemistry, and engineering. Complete details of the work are presented, including laboratory data, experimental procedures, and theoretical and mathematical analyses. Annual subscription: domestic, $\$ 4.00$; foreign, $\$ 5.25$.

\section{Technical News Bulletin}

Summaries of current research at the National Bureau of Standards are published each month in the Technical News Bulletin. The articles are brief, with emphasis on the results of research, chosen on the basis of their scientific or technologic importance. Lists of all Bureau publications during the preceding month are given, including Research Papers, Handbooks, Applied Mathematics Series, Building Materials and Structures Reports, Miscellaneous Publications, and Circulars. Each issue contains 12 or more two-column pages; illustrated. Annual subscription: domestic, $\$ 1.00$; foreign, $\$ 1.35$.

\section{Basic Radio Propagation Predictions}

The Predictions provide the information necessary for calculating the best frequencies for communication between any two points in the world at any time during the given month. The data are important to all users of long-range radio communications and návigation, including broadcasting, airline, steamship, and wireless services, as well as to investigators of radio propagation and ionosphere. Each issue, covering a period of one month, is released three months in advance and contains 16 large pages, including pertinent charts, drawings, and tables. Annual subscription: domestic, $\$ 1.00$; foreign, $\$ 1.25$.

\section{GATALOG OF NBS PUBLIGATIONS}

National Bureau of Standards Circular 460 and its Supplement list all Bureau publications from 1901 through June 1952, including Applied Mathematics Series, Building Materials and Structures Reports, Circulars, Handbooks, Research Papers, and Miscellaneous Publications. Brief abstracts for the publications issued after January 1, 1942, are also included.

National Bureau of Standards Circular 460, 375 pages, \$1.25. Supplement to Circular 460, 223 pages, 75 cents. (A free mimeographed list of publications issued since June 1952 is available on request to the National Bureau of Standards.) 